Carlos do Carmo Pagani Júnior

\title{
Mapeamento de Fontes Aeroacústicas de um Eslate em Túnel de Vento de Seção Fechada Utilizando Beam-forming com Deconvolução DAMAS.
}

Tese apresentada à Escola de Engenharia de São Carlos da Universidade de São Paulo para obtenção do título de doutor em Engenharia Mecânica.

Área de concentração: Aeronaves.

Orientador: Prof. Dr. Marcello A. Faraco de Medeiros

ESTE EXEMPLAR TRATA-SE DA

VERSÃO CORRIGIDA.

A VERSÃO ORIGINAL ENCONTRA-

SE DISPONIVVEL JUNTO AO

DEPARTAMENTO DE

ENGENHARIA MECANICA DA EESC-USP.

São Carlos 
AUTORIZO A REPRODUÇÃO TOTAL OU PARCIAL DESTE TRABALHO, POR QUALQUER MEIO CONVENCIONAL OU ELETRÔNICO, PARA FINS DE ESTUDO E PESQUISA, DESDE QUE CITADA A FONTE.

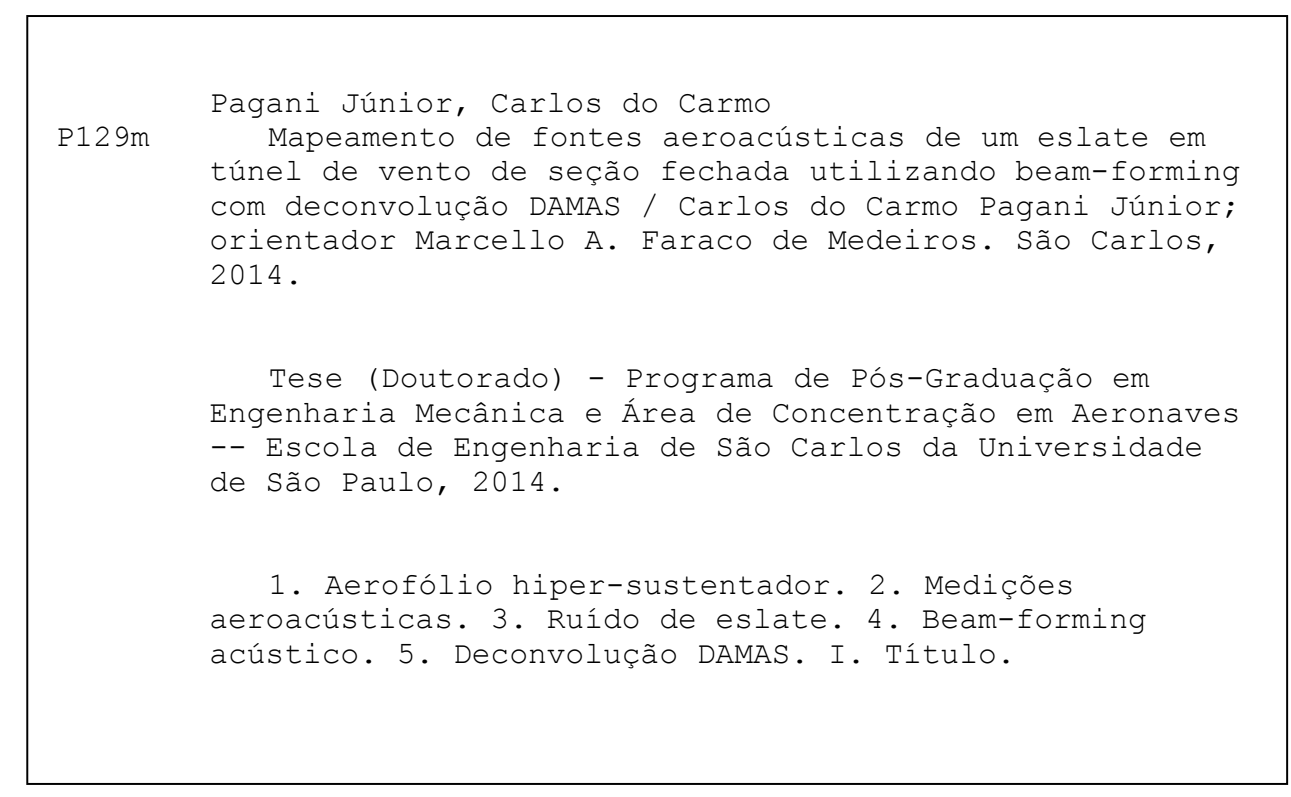




\section{FOLHA DE JULGAMENTO}

Candidato: Bacharel e Licenciado CARLOS DO CARMO PAGANI JUNIOR.

Título da tese: "Mapeamento de fontes aeroacusticas de um eslate em túnel de vento de seção fechada utilizando beam-forming com deconvolução DAMAS".

Data da defesa: 18/08/2014

Comissão Julgadora:

Prof. Associado Marcello Augusto Faraco de Medeiros (Orientador)

(Escola de Engenharia de São Carlos/EESC)

Prof. Dr. Leopoldo Pisanelli Rodrigues de Oliveira

(Escola de Engenharia de São Carlos/EESC)

Prof. Dr. José Roberto de França Arruda

(Universidade Estadual de Campinas/UNICAMP)

Prof. Dr. William Roberto Wolf

(Universidade Estadual de Campinas/UNICAMP)

Prof. Titular Julio Romano Meneghini

(Escola Politécnica/EP-USP)
Resultado:

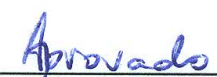

APROUADO

ARROVADO

APROUAD。

Aprevado

Coordenador do Programa de Pós-Graduação em Engenheira Mecânica:

Prof. Associado Marcelo Areias Trindade

Presidente da Comissão de Pós-Graduação:

Prof. Associado Paulo César Lima Segantine 



\section{Agradecimentos}

É importante ressaltar que este trabalho foi desenvolvido no contexto do projeto Aeronave Silenciosa, que se pauta pela colaboração entre a Embraer e universidades. Desta forma, embora tenham havido grandes desafios de cunho pessoal, o desenvolvimento deste trabalho decorre de uma dinâmica de cooperação com os integrantes do projeto. Embora não seja possível registrar aqui, de maneira formal, o meu agradecimento a todos aqueles que de alguma forma colaboraram para a realização deste trabalho, procuro destacar e agradecer àqueles que o fizeram de forma mais contundente.

Ao orientador Marcello Augusto Faraco de Medeiros, pela oportunidade de realização deste trabalho e colaboração efetiva prestada em todas as etapas do seu desenvolvimento.

Ao Departamento de Engenharia Aeronáutica, representado pelo corpo docente, secretariado e técnicos, pelo suporte prestado, sem o qual certamente a realização deste trabalho não seria possível. Bem como ao Programa de Pós-Graduação em Engenharia Mecânica, pelo suporte administrativo.

Aos engenheiros e técnicos da Embraer envolvidos no projeto Aeronave Silenciosa, cujo apoio para a realização dos experimentos e difusão de conhecimento na parte inicial do projeto foi de suma importância para as realizações alcançadas.

Aos então alunos de pós-graduação Filipe Ramos do Amaral, Daniel Sampaio e Elmer Genaro, que contribuíram de forma inestimável para a realização deste trabalho, bem como aos demais alunos do Programa de Pós-Graduação, pelo apoio e companheirismo.

Ao $\mathrm{CNPq}$, pela apoio financeiro em tempo parcial, na forma de bolsa de fomento para a pesquisa. À CAPES e à FAPESP, pelo suporte financeiro que viabilizou a compra dos equipamentos utilizados na realização dos experimentos aeroacústicos. 
Ao Prof. Fernando Martini Catalano e aos técnicos responsáveis pelo Túnel de Vento da Escola de Engenharia de São Carlos (LAE-1).

Ao Departamento de Engenharia de Transportes da EESC, particularmente ao técnico Paulo Sérgio Batista e aos professores Paulo Cesar Lima Segantine e Ricardo Schaal. À Leica Geosystems do Brasil e sua equipe técnica de São Carlos.

Aos membros da banca que se dispuseram a avaliar este trabalho e contribuíram de forma construtiva para a melhoria do mesmo.

Agradeço à minha esposa Elisângela, por cada instante de nossa convivência que abdicou para que a realização deste trabalho fosse possível. Por fim, aos meus pais, por toda uma vida de apoio incondicional. 


\section{Lista de Figuras}

2.1 a) distribuição de fontes sobre componentes do perfil hiper-sustentador DC11 mapeadas por algoritmo de beam-forming convencional na frequência de $10 \mathrm{kHz}, \mathrm{b}$ ) espectros de ruído mostrando a importância do ruído de eslate em relação aos demais componentes. . . . . . . . . . . . . . . . . . . . 34

2.2 Espectro de ruído do eslate indicando a ocorrência dos componentes MTP, BB e HT. As medições foram feitas por um microfone em campo distante nas condições $U=50 \mathrm{~m} / \mathrm{s}$ e $\alpha=14^{\circ} \ldots \ldots \ldots$. . . . . . . . 36

2.3 Representação da geometria do eslate e potenciais mecanismos de geração de ruído aerodinâmico. . . . . . . . . . . . . . . . . . . 37

2.4 Comparação entre espectros de ruído do eslate antes e após a transição forçada da camada limite a montante da cúspide do eslate e representação de espectros de pressão estimados a partir de medições por sensores posicionados na cova do eslate.

2.5 (Instalação do dispositivo SCF (Slat Cove Filter), projetado para eliminar efeitos da separação da camada limite na cúspide do eslate sobre o escoamento na cova. O filtro acoplado (linha verde) se adapta à região da cova do eslate, formando uma superfície aerodinamicamente contínua em relação à configuração baseline da cova (linha vermelha). Também está representado o efeito do dispositivo SCF sobre o ruído do eslate, com a notória supressão das componentes MTP e BB. . . . . . . . . . . . . . .

2.6 (a) perfil hiper-sustentador enflexado em $30^{\circ}$ e posicionado para medições aeroacústicas no túnel DWN e (b) espectros de ruído de eslate obtidos sob vários regimes de Reynolds. . . . . . . . . . . . . . . . . .

2.7 Espectro do ruído do eslate para vários ângulos de incidência do aerofólio, com velocidade de escoamento livre de 58 m/s. . . . . . . . . . . . . . . . . 42

2.8 Espectros de ruído em campo distante para a) vários ângulos de ataque do aerofólio e b) várias velocidades de escoamento livre. . . . . . . . . . . 
2.9 Representação de fontes acústicas associadas ao pico tonal de máxima amplitude para ângulos de incidência do aerofólio de $10^{\circ}$ e $18^{\circ},\left(U_{\infty}=50 \mathrm{~m} / \mathrm{s}\right)$.

2.10 Mapas de beam-forming convencional nas frequências de $880 \mathrm{~Hz}$ e 1008 $\mathrm{Hz}$, representando distribuições de fontes associadas a pontos de máxima e mínima amplitude de ruído na região de ocorrência de picos tonais $\left(\alpha=14^{\circ}\right.$ e $\left.U_{\infty}=50 m / s\right) \ldots \ldots \ldots \ldots \ldots \ldots$

2.11 Representação de fontes de ruído sobre o eslate em frequências intermediária $(2300 \mathrm{~Hz})$ e de ocorrência de pico tonal $(2500 \mathrm{~Hz})$, para velocidade de escoamento base de $U=50 \mathrm{~m} / \mathrm{s}$. Os mapas de beam-forming foram obtidos pelo método de deconvolução DAMAS. . . . . . . . . . . . . . . . .

2.12 Vórtices gerados na camada de mistura a partir da cúspide do eslate (A) são amplificados e atingem o eslate um ponto próximo ao seu bordo de fuga (c). Ondas acústicas geradas no ponto (c) propagam-se à montante, atingindo o ponto (A). A incidência de ondas acústicas no ponto (A) excita instabilidade hidrodinâmica e o processo se torna auto-sustentável. . . . . .

2.13 Espectros de ruído para vários ângulos de incidência do aerofólio, estimados a partir de medidas com um microfone em campo distante. Velocidade de escoamento livre de $50 \mathrm{~m} / \mathrm{s} . \ldots \ldots \ldots$

2.14 Representação detalhada de um possível mecanismo de geração de ruído tonal e definição dos parâmetros envolvidos na formulação. . . . . . . . . . . 4

2.15 Comparação dos resultados para predição de frequências de ruído tonal com velocidades de escoamento livre variando entre $30 \mathrm{~m} / \mathrm{s}$ e $50 \mathrm{~m} / \mathrm{s}$. . . . .

2.16 Comparação entre espectros de ruído de banda larga obtidos a partir de metodologias numérica e experimental. A linha contínua representa o resultado experimental. A linha tracejada representa o resultado numérico obtido sem a influência da asa e a curva com o símbolo (o) representa o resultado numérico com a influência da asa. . . . . . . . . . . . . . . . .

2.17 Geometria do modelo de testes 2D em configuração de eslate e flape denominada L1T2. As regiões mapeadas pela técnica de PIV encontram-se hachuradas.

2.18 (a) representação do campo de vorticidade instantâneo na cova do eslate com escoamento turbulento para $\alpha=8^{\circ}$. (b) campo de vorticidade instantâneo na cova do eslate com escoamento quasi-laminar para $\alpha=8^{\circ} \mathrm{e}$ (c) campo de vorticidade instantâneo na cova do eslate com escoamento quasi-laminar para $\alpha=6^{\circ} \ldots \ldots \ldots \ldots \ldots$

2.19 Afastamento do ponto médio de recolamento da camada de mistura e achatamento da região de recirculação com o aumento do ângulo de ataque do aerofólio. $\operatorname{Em} \alpha=4^{\circ}$ e $\alpha=8^{\circ}$ os pontos de recolamento são estimados a $6.77 \mathrm{~mm}$ e $10.93 \mathrm{~mm}$ da ponta do bordo de fuga do eslate. . . . . . . . . . 
2.20 (a) mapa de beam-forming representando a ruído de eslate em $48.697 \mathrm{~Hz}$ e detalhes da geometria do modelo hiper-sustentador EET, (b) espectros de ruído mostrando ruído de banda larga em baixas e médias frequências e um ruído tonal de grande amplitude com pico em $48.697 \mathrm{~Hz}$ para a configuração

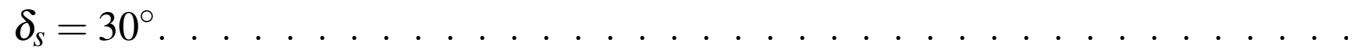

2.21 (a) flutuação instantânea do campo de pressão e (b) vorticidade no bordo de fuga do eslate mostrando o fenômeno de desprendimento de vórtices. . .

3.1 Desenho esquemático do túnel de vento LAE-1 com alguns detalhes de projeto. As letras de $\mathrm{A}$ até $\mathrm{E}$ indicam os locais onde foram realizados tratamento acústico. . . . . . . . . . . . . . . . . .

3.2 Representação do aerofólio em configuração de referência (acima) e recolhida (abaixo). Na parte dianteira, à esquerda do elemento principal, encontra-se o eslate. Na parte traseira, encontra-se o flape.

3.3 Representação esquemática dos parâmetros gap, overlap e deflexão do elemento eslate, com o aerofólio hiper-sustentador em sua configuração geométrica de referência. . . . . . . . . . . . . . . . . . .

3.4 Detalhes do intradorso do aerofólio 30P30N. Na vista em perspectiva, à esquerda, estão representadas as peças de prototipagem (em alaranjado) na parte central e os suportes de fixação (em amarelo) do eslate (à esquerda) e do flape (à direita). Na vista do intradorso do aerofólio, à direita, estão representadas a posição e as distâncias entre os suportes, bem como a corda do aerofólio estendido; 611. Dimensões em mm. . . . . . . . . . . . . . .

3.5 Vista interior do modelo 30P30P durante a instalação de pequenos tubos para medida de pressão: (a) ao longo da envergadura e (b) ao longo da corda do aerofólio.

3.6 Posicionamento do perfil hiper-sustentador 30P30N na câmara de ensaios do túnel de vento LAE-1: (a) vista parcial do extradorso do perfil a partir de uma posição à montante do aerofólio e (b) vista parcial do intradorso a partir de uma posição à jusante. . . . . . . . . . . . . . . . . . . . .

3.7 Imagem gerada pelo instrumento de medição Leica Nova MS50 MultiStation. O feixe de linhas representado na figura liga pontos de observação (posicionamento do aparelho de medição) às posições de alguns microfones na antena. As posições dos microfones são consideradas como pontos de referência, ou controle, cujas coordenadas são previamente conhecidas em relação ao sistema de referência da antena.

3.8 Posição do aerofólio em relação ao sistema de referência da antena e dimensões típicas. A antena está projetada ao fundo para representar a sua dimensão em relação ao aerofólio e à distância relativa entre ambos. A figura representa o ponto de vista de um observador que verifica o escoamento da esquerda para a direita. . . . . . . . . . . . . . .

3.9 Modelo de dipolo representando o padrão de diretividade do ruído aerodinâmico de eslate. 
3.10 Representação polar da diretividade do ruído de eslate em bandas de $1 / 3$ de oitava sob várias condições operacionais e bandas de frequência. A linha contínua em $26^{\circ}$ (figura à esquerda) representa a linha pela corda do eslate, usada como referência para a representação polar da diretividade do ruído de eslate. . . . . . . . . . . . . . . . . . . .

3.11 Representação da geometria de antena com 62 microfones utilizada nos experimentos aeroacústicos para medição do ruído de eslate. . . . . . . . 75

3.12 Representação gráfica do critério utilizado para a determinação da largura do lóbulo do array. A curva representa um corte transversal no lóbulo principal, na direção x, do padrão de resposta (pfs) do array de 62 microfones descrito na seção anterior, e dois pontos indicando a altura do lóbulo determinada para o cálculo da largura. O padrão de resposta do array é representado em escala de $\mathrm{dB}$.

3.13 Estimativa de beamwidth e faixa dinâmica da antena de microfones (Fig. 3.11) na banda de frequência entre $500 \mathrm{~Hz}$ e $18 \mathrm{kHz}$, com resolução em frequência dada pela tabela 5.1.

3.14 Antena de microfones em processo de montagem no túnel de vento LAE1: (a) parte frontal com superfície em contato com o escoamento e (b) instalação/cabeamento dos microfones 46BD.

3.15 (a) espectros de ruído representando a média dos sinais correlacionados para uma antena de 96 microfones, (b) diferença entre espectros de ruído e (c) diferenças entre integrais de nível de pressão sonora do ruído de fundo estimadas a partir de mapas de beam-forming convencional. Os sinais em cada microfone foram medidos durante $\mathrm{T}=60 \mathrm{~s}$ e particionados em sinais com duração $\mathrm{T} / 2, \mathrm{~T} / 4, \mathrm{~T} / 8, \mathrm{~T} / 16, \mathrm{~T} / 32$ para posterior processamento. Os sinais foram amostrados em $40960 \mathrm{~Hz}$ e processados com resolução em frequência de $10 \mathrm{~Hz}$. . . . . . . . . . . . . . . . . . .

3.16 Representação do conjunto microfone/amplificador 46BD. . . . . . . . . .

3.17 Na planilha de controle, o microfone de número 1 , com posição $\mathrm{x}=0,015$ $\mathrm{m}$ e y $=-0.029 \mathrm{~m}$, identificado pelo número de série 107230, e com sensibilidade de calibração 1.7881913 é associado ao canal de leitura de dados com índice 0. Esta identificação permite uma associação entre a posição física do microfone no sistema de referência da antena e um índice de posição do sinal medido no arquivo de saída do sistema de aquisição de dados, bem como a leitura correta de sua sensibilidade.

4.1 Representação geométrica das quantidades vetoriais usadas na formulação de beam-forming acústico adotada neste trabalho. O ponto designado pela letra $s$ é um ponto focal, que se define para cada ponto de uma malha, a partir da qual é determinado o mapa de beam-forming. Na ilustração, a identificação da fonte $q_{k}$ ocorre para a condição $s=k . \ldots$. . . . . .

4.2 Imagens acústicas de uma fonte puntual de amplitude unitária nas frequências e $1 \mathrm{kHz}, 2 \mathrm{kHz}, 4 \mathrm{kHz}$ e $8 \mathrm{kHz}$, obtidas pela aplicação da metodologia de beam-forming representada na Eq. 4.25. 
4.3 Cortes transversais no lóbulo principal da fonte, pelo seu ponto de máximo, ao longo das direções x e y. . . . . . . . . . . . . . . . . . . . . . . 101

4.4 A onda sonora emitida sob o ângulo $\theta_{e}$ é detectada sob o ângulo $\theta_{p}$, em uma posição aparente deslocada de $U_{\infty} \Delta t$ à jusante de sua posição real, devido ao efeito convectivo do escoamento uniforme. . . . . . . . . . . . . . 102

4.5 Representação em diagrama de blocos do código utilizado para o processamento da matriz de espectros cruzados.

4.6 Imagens acústicas representando distribuições de fontes em linha nas frequências de $2 \mathrm{kHz}, 4 \mathrm{kHz}$ e $8 \mathrm{kHz}$. Os resultados foram obtidos pela aplicação dos códigos de beam-forming convencional e deconvolução DAMAS. . . . . 123

4.7 Comparação entre o espectro de ruído obtido por integração dos níveis de pressão sonora sobre o domínio da fonte com o código DAMAS e a média dos auto-espectros dos 62 microfones.

4.8 Correspondência entre $\left(\varphi_{1,29}\right)_{\text {mes }}$ e $\left(\varphi_{1,29}\right)_{\text {cal }}$ para os microfones de índices 1 e 29, antes (a) e depois (b) da aplicação da calibração de fase, conforme definida na Eq. 4.81. A linha contínua representa a variação de $\left(\varphi_{m, n}\right)_{c a l}$ com a frequência, enquanto que a nuvem de pontos representa estimativas

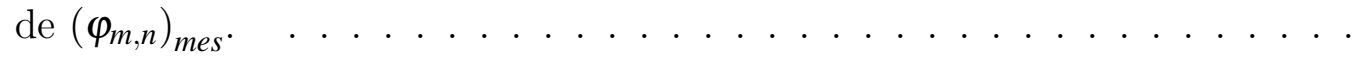

4.9 Razão entre auto-valores dominantes nas matrizes de espectros cruzados obtidas a partir de medições do ruído branco de um teweeter com e sem espumas para o isolamento acústico da fonte.

4.10 Comparação entre a fase teórica simulada, $(\varphi)_{\text {cal }}$, e a fase experimental $(\varphi)_{\text {exp }}$, calculada a partir da correlação espectral entre pares microfones distintos.

5.1 Representação esquemática das etapas de processamento definidas no código (1).

5.2 Representação esquemática das etapas de processamento definidas no código (2). O fluxograma à esquerda é utilizado para resultados obtidos com deconvolução DAMAS, equanto que o fluxograma à direita aplica-se ao caso de processamento com beam-forming convencional. . . . . . . . . . . 135

5.3 Representação de um malha cartesiana com número total de pontos $N$, extensão $L_{x}$, extensão vertical $L_{x}$ e espaçamentos regulares nas direções $x$, $(\Delta x)$, e $y,(\Delta y)$. O beamwidth do padrão de resposta da antena, $B$, acha-se projetado sobre a superfície da malha.

5.4 Distribuição de valores $\triangle x / B$ entre $500 \mathrm{~Hz}$ e $18 \mathrm{kHz}$, em escala logarítmica de frequência.

5.5 Representação do comportamento típico dos parâmetros chave para o projeto de malha; $\triangle x(\triangle y), N_{x}, N_{y}$, e $N$, em função da frequência. . . . . . . 140

5.6 Resultados para avaliação de desempenho computacional do algoritmo DAMAS em termos dos parâmetros adotadas na construção da malha. . . . 142 
5.7 Comparação de desempenho computacional para o código DAMAS a partir do uso das malhas (1) e (2): (a) comparação entre o número de iterações necessário para a convergência dos resultados, (b) comparação entre o espaçamento entre os pontos na malha e comparação entre o tempo total de processamento, estando o tempo referente à malha (2) multiplicado por 10. 144

5.8 Representação das curvas de convergência dos espectros de ruído, considerando um número máximo de 500 iterações. Para cada figura está indicada a frequência de processamento. A linha vertical indica o número de iterações, indicado ao lado da frequência, e o respectivo nível de ruído determinados pelo critério de parada do processo iterativo. . . . . . . . . . 147

5.9 Comparação entre curvas de convergência para malhas uniformes com diferentes espaçamentos entre pontos. . . . . . . . . . . . . . . . . 148

5.10 Representacão do perfil hiper-sustentador 30P30N com eslate (elemento hachurado à esquerda) e elemento principal, com destaque para a partição da envergadura do eslate em vários domínios de integração enumerados de 1 até 6 .

5.11 Espectros de ruído do eslate decorrentes da integração de fontes sobre as regiões enumeradas de 1 até 6 , conforme a Fig. 5.10. Uma faixa dinâmica de $12 \mathrm{~dB}$ foi adotada para integração.

6.1 Representação do escoamento ao redor de um perfil aerodinâmico com formação de estruturas vorticais 3D. . . . . . . . . . . . . . . . . . . 155

6.2 (a) sopro tangencial e (b) representação de superfície porosa utilizada para a sucção da camada limite. A região efetiva para aplicação da sucção pode ser otimizada pela utilização parcial da superfície porosa total. . . . . . . . 156

6.3 Distribuições do coeficiente de pressão ( $\mathrm{Cp}$ ) ao longo da envergadura do elemento principal; próximo ao bordo de ataque (linhas azuis superiores) e ao bordo de fuga (linhas vermelhas inferiores), com sucção (linhas com símbolos hachurados) e sem sucção para o controle da camada limite da parede.

6.4 Distribuições de pressão ( $\mathrm{Cp}$ ) ao longo do ponto médio da envergadura do perfil hiper-sustentador 30P30N, obtidas por simulação computacional e medições experimentais (com e sem sucção da camada limite da parede). Os resultados correspondem ao aerofólio em ângulo de ataque de $4^{\circ}$ e velocidade de escoamento livre de $34 \mathrm{~m} / \mathrm{s}$

6.5 Distribuições de pressão (Cp) ao longo do ponto médio da envergadura do perfil hiper-sustentador 30P30N, obtidas por simulação computacional e medições experimentais (com e sem sucção da camada limite da parede). Os resultados correspondem ao aerofólio em ângulo de ataque de $8^{\circ}$ e velocidade de escoamento livre de $34 \mathrm{~m} / \mathrm{s}$.

6.6 Espectros de ruído do eslate obtidos via simulação computacional e processamento de dados experimentais (com e sem o controle da camada limite da parede), para $\alpha=4^{\circ}$ e $U_{\infty}=34 m / s$. 
6.7 Espectros de ruído do eslate obtidos via simulação computacional e processamento de dados experimentais (com e sem o controle da camada limite

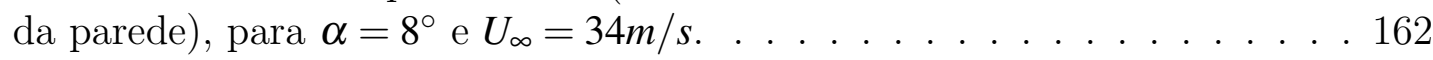

7.1 Espectro de ruído típico do elemento eslate do aerofólio 30P30N, apresentando componentes de ruído bem definidos em baixa, média e alta frequência.

7.2 Espectros de ruído do eslate para $\alpha=0^{\circ}$ e $U_{\infty}=24,27,31$ e $34 \mathrm{~m} / \mathrm{s}$. . . 169

7.3 Espectros de ruído do eslate para $\alpha=2^{\circ}$ e $U_{\infty}=24,27,31$ e $34 \mathrm{~m} / \mathrm{s}$. . . 169

7.4 Espectros de ruído do eslate para $\alpha=4^{\circ}$ e $U_{\infty}=24,27,31$ e $34 \mathrm{~m} / \mathrm{s}$. . . 170

7.5 Espectros de ruído do eslate para $\alpha=6^{\circ}$ e $U_{\infty}=24,27,31$ e $34 \mathrm{~m} / \mathrm{s}$. . . 170

7.6 Espectros de ruído do eslate para $\alpha=8^{\circ}$ e $U_{\infty}=24,27,31$ e $34 \mathrm{~m} / \mathrm{s} . \quad$. . 171

7.7 Espectros de ruído do eslate para $\alpha=10^{\circ}$ e $U_{\infty}=24,27,31$ e $34 \mathrm{~m} / \mathrm{s} . \quad$. . 171

7.8 Espectros de ruído do eslate para $\alpha=2^{\circ}, \alpha=4^{\circ}, \alpha=6^{\circ}, \alpha=8^{\circ}$, e $\alpha=10^{\circ}$

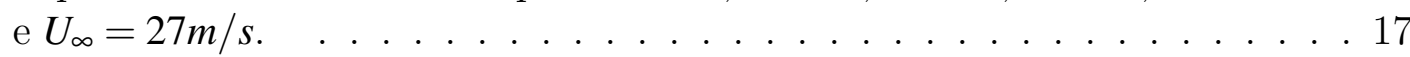

7.9 Espectros de ruído do eslate para $\alpha=2^{\circ}, \alpha=4^{\circ}, \alpha=6^{\circ}, \alpha=8^{\circ}$, e $\alpha=10^{\circ}$ e $U_{\infty}=34 m / s . \ldots \ldots \ldots \ldots \ldots$. . . . . . . . . . . . . . . . . . . . . . .

7.10 Representação da posição do aerofólio, com elemento principal, flape e eslate, em relação à antena de microfones para ângulos de ataque de $2^{\circ} \mathrm{e}$ $10^{\circ}$.

7.11 Representação da câmara de ensaios após a instalação de placas de espuma no entorno do perfil hiper-sustentador 30P30N. Da esquerda para a direita, as paredes horizontais inferior e superior, a região exposta para a sucção da camada limite e a parede oposta ao plano da antena de microfones.

7.12 Representação do efeito da instalação de espumas para absorção acústica na câmara de ensaios do túnel de vento LAE-1, sobre a caracterização da distribuição de fontes e espectros de ruído do eslate.

7.13 Mapas acústicos representando distribuições de fontes sobre o eslate com o aerofólio em ângulo de ataque de $2^{\circ}$ e velocidade de escoamento de $34 \mathrm{~m} / \mathrm{s} .178$

7.14 Mapas acústicos representando distribuições de fontes sobre o eslate com o aerofólio em ângulo de ataque de $6^{\circ}$ e velocidade de escoamento de $34 \mathrm{~m} / \mathrm{s} .179$

8.1 Superfícies de contorno representando tendências de variação do ruído global do eslate em relação ao gap e ao overlap, com o eslate defletido em $30^{\circ}$. O ruído global é dado pela soma dos componentes de ruído, em unidades de $\mathrm{Pa}^{2} / \mathrm{Hz}$, para cada frequência na banda entre $500 \mathrm{~Hz}$ e $22 \mathrm{kHz}$. Os resultados são apresentados em escala $d B / H z \ldots$. . . . . . . . . . . 186

8.2 Comparação entre espectros de ruído do eslate para as configurações geométricas obtidas com 1) gap fixo em $2,95 \%$ e 2) overlap fixo $-1,60 \%$. Os resultados são apresentados para $\alpha=2^{\circ}$, e $6^{\circ}$, com $U_{\infty}=34 \mathrm{~m} / \mathrm{s} . \quad$. . . . 190 
8.3 Configuração com $o_{s}=-2,95 \%$ e $g_{s}=2,95 \%$ : comparação dos espectros de ruído para diferentes velocidades de escoamento e avaliação do colapso das curvas em amplitude e Strouhal para $2^{\circ}$ e $8^{\circ}$. . . . . . . . . . . . . . . 192

8.4 Configuração com $o_{s}=1 \%$ e $g_{s}=2,95 \%$ : comparação dos espectros de ruído para diferentes velocidades de escoamento e avaliação do colapso das curvas em amplitude e Strouhal para $2^{\circ}$ e $8^{\circ}$. . . . . . . . . . . . . . . 193

8.5 Representação das posições do eslate em relação ao elemento principal do aerofólio, correspondentes aos ângulos de deflexão de $20^{\circ}, 25^{\circ}, 30^{\circ}$ e $35^{\circ}$. . 194

8.6 Comparação entre espectros acústicos do eslate para vários ângulos de deflexão do eslate, na configuração $g_{s}=2,95 \%$ e $o_{s}=-1,60 \%$. . . . . . 195

8.7 Espectros de ruído do eslate em diferentes velocidades de escoamento e o colapso das curvas normalizadas pelo Mach do escoamento livre com expoente 4.5 e adimensionalizadas pelo número de Strouhal. . . . . . . . . 196

A.1 Resultados indicando as frequências de ocorrência dos picos tonais de baixa frequência do ruído do eslate para o aerofólio 30P30N, obtidas a partir de medições experimentais, resultados numéricos ( LBM Simulation) e previsão com o modelo proposto por Terracol, Manoha e Lemoine (2011), que se baseia nos modos de Rossiter para o ruído de cavidade, adaptado para a geometria e condições do escoamento na cova do eslate. . . . . . . . . . . 204

A.2 Perfil de velocidades na esteira do bordo de fuga do eslate do aerofólio 30P30N, para ângulos de ataque do $4^{\circ}$ e $8^{\circ}$, e velocidade de escoamento livre de $34 \mathrm{~m} / \mathrm{s}$. 
3.1 Configuração geométrica do aerofólio 30P30N . . . . . . . . . . . . . . 64

3.2 Parâmetros de configuração experimental e geométrica do aerofólio . . . . 84

3.3 Parâmetros de controle do experimento . . . . . . . . . . . . . . . . 84

3.4 Grandezas medidas indiretamente a partir de $p_{\infty}$ e $T \ldots \ldots$. . . . . . 87

3.5 Grandezas derivadas da velocidade de escoamento livre . . . . . . . . . 87

3.6 Valores típicos dos números de Mach e Reynolds . . . . . . . . . . . . . 87

4.1 Erro para diferentes frequências . . . . . . . . . . . . . . . . 124

5.1 Bandas e respectivas resoluções em frequência, em $\mathrm{Hz}$. . . . . . . . . . 138

5.2 Parâmetros adotados no estudo de convergência na malha . . . . . . . . . 146

6.1 Dimensões dos modelos experimental e numérico . . . . . . . . . . . 158

6.2 Parâmetros utilizados nos processamentos numérico e experimental. Nas duas últimas linhas encontram-se representados os números de blocos de dados usados nos processamentos experimental e numérico. . . . . . . . . 160

7.1 Parâmetros de configuração do aerofólio . . . . . . . . . . . . 165

8.1 Representação das configurações experimentais consideradas neste estudo, com variações dos parâmetros de configuração geométrica do eslate; gap, $\left(g_{s}\right)$, overlap, $\left(o_{s}\right)$ e deflexão, $\left(\boldsymbol{\delta}_{S}\right)$, mantendo-se o flape em configuração de referência. . . . . . . . . . . . . . . . . . . 184

8.2 Representação da posição física do eslate para cada configuração dos parâmetros de gap e overlap avaliada, com o eslate defletido em $30^{\circ}$. . . . . . 185

8.3 Espectros de ruído de eslate para $\alpha=2^{\circ}$ e $\alpha=8^{\circ}$, com $U_{\infty}=27 \mathrm{~m} / \mathrm{s}$. . . 188

8.4 Espectros de ruído de eslate para $\alpha=2^{\circ}$ e $\alpha=8^{\circ}$, com $U_{\infty}=34 m / s$. . . 189 

1 Introdução $\quad 25$

1.1 Considerações Gerais . . . . . . . . . . . . . . . . . . . . 25

1.2 Proposta e Objetivos do Trabalho . . . . . . . . . . . . . . . . . . . 29

1.3 Organização do Trabalho . . . . . . . . . . . . . . . . . . . 30

2 Revisão Bibliográfica: Ruído de Eslate 33

2.1 Uma Visão Geral Sobre o Ruído de Eslate . . . . . . . . . . . . . . . . . . 33

2.2 Ruído Tonal de Baixa Frequência . . . . . . . . . . . . . . . . 38

2.2.1 Mapas de Beam-forming para o Ruído Tonal de Baixa Frequência . 43

2.3 Mecanismos de Geração de Ruído Tonal . . . . . . . . . . . . . . . . . . . 45

2.4 Ruído de Banda Larga de Eslate . . . . . . . . . . . . . . . . . . . . . . . . 49

2.5 Noções Básicas Sobre o Escoamento 2D na Cova do Eslate . . . . . . . . . 51

2.6 Ruído Tonal de Alta Frequência . . . . . . . . . . . . . . . . . . 55

2.7 Configurações Geométricas e o Ruído de Eslate . . . . . . . . . . . . . . 57

2.8 Considerações Gerais . . . . . . . . . . . . . . . . . . . . 59

3 Aparato e Procedimentos Experimentais $\quad 61$

3.1 Descrição do Túnel de Vento Utilizado . . . . . . . . . . . . . . . . . . 61

3.1.1 Tratamento Acústico do Túnel de Vento LAE-1 . . . . . . . . . . . 62

3.2 Descrição do Perfil Hiper-Sustentador . . . . . . . . . . . . . . . . . . . . . 63

3.2.1 Fabricação e Instrumentação do Aerofólio 30P30N ........ 65

3.3 Posicionamento do Aerofólio na Câmara de Ensaios . . . . . . . . . . . . . 67 
3.4 Referenciamento de Posição do Aerofólio em Relação à Antena de Microfones 69 3.4.1 Diretividade do Ruído de Eslate . . . . . . . . . . . . . . . . . 71

3.5 Projeto e Geometria da Antena de Microfones . . . . . . . . . . . . . . . . 72

3.5.1 Avaliação do Projeto da Antena: Beam-width e Faixa Dinâmica . . 75

3.5.2 Construção, Instalação e Aplicações da Antena da Microfones . . . 78

3.6 Sistema de Aquisição de Dados . . . . . . . . . . . . . . . . . . . . 82

3.6.1 Microfones . . . . . . . . . . . . . . . . . 83

3.7 Procedimentos Para Medições Experimentais . . . . . . . . . . . . . . . . 84

3.7 .1 Medições Acústicas . . . . . . . . . . . . . . . . . 85

3.7.2 Medições Aerodinâmicas . . . . . . . . . . . . . . . . 86

4 Fundamentos de Beam-forming Acústico $\quad 89$

4.1 Introdução . . . . . . . . . . . . . . . . . . . . . . . 89

4.2 Considerações Gerais . . . . . . . . . . . . . . . . . . . . . . . 90

4.3 Beam-forming Convencional: Formulação Teórica . . . . . . . . . . . . . . 90

4.3.1 Integração de Fontes na Formulação de Beam-forming Convencional 94

4.3.2 Faixa Dinâmica para Integração de Fontes . . . . . . . . . . . . . . 95

4.4 Implementação do Algoritmo de Beam-forming Convencional . . . . . . . . 96

4.5 Mapeamento de uma Fonte Monopolo com o Algoritmo de Beam-forming Convencional . . . . . . . . . . . . . . . . . . . . . . . . . . . . 98

4.6 Correção do Efeito Convectivo de Escoamento Livre . . . . . . . . . . . . . 101

4.7 Implementação Numérica do Algoritmo de Beam-forming Convencional . . 105

4.8 Métodos de Deconvolução em Aeroacústica . . . . . . . . . . . . . . . 105

4.8.1 CLEAN-SC - CLEAN Based on Spatial Source Coherence . . . . 106

4.8.2 DAMAS - Denconvolution Approach for the Mapping of Acoustic Sources . . . . . . . . . . . . . . . . . . 108

4.8.3 Variações do Método DAMAS . . . . . . . . . . . . . . . . . 110

4.9 Formulação Matemática do Método DAMAS . . . . . . . . . . . . . . . . . 111

4.9.1 Implementação Numérica do Algoritmo DAMAS . . . . . . . . . . . 113

4.10 Cálculo da Matriz de Espectros Cruzados . . . . . . . . . . . . . . . 115

4.10.1 Cálculo do Fator de Correção de Energia para a Aplicação da Função de Janelamento Hanning . . . . . . . . . . . . . . . . . . . . . . 119

4.11 Avaliação dos Códigos de Beam-forming Convencional e DAMAS . . . . . 120

4.11 .1 Fonte Sintética: Monopolos em Linha . . . . . . . . . . . . . . . . 121 
4.11.2 Estudos para a Calibração de Fase dos Microfones . . . . . . . . . . . 124

5 Metodologias de Pós-Processamento Aplicadas ao Ruído do Eslate

5.1 Introdução . . . . . . . . . . . . . . . . . . . . . . . . 131

5.2 Metodologias de Processamento para a Base de Dados Acústicos . . . . . . 132

5.2 .1 Descrição do Código (1) . . . . . . . . . . . . . . . 132

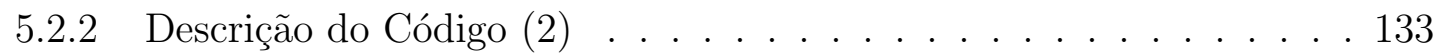

5.3 Definição de uma Malha de Pontos para o Mapeamento de Fontes Acústicas 133

5.3.1 Descrição da Malha Adotada para o Mapeamento de Fontes com o Método DAMAS . . . . . . . . . . . . . . . . 137

5.3.2 Desempenho Computacional do Algoritmo DAMAS . . . . . . . . . 141

5.4 Independência dos Resultados em Relação à Malha e ao Critério de Parada 145

5.5 Definição de uma Região para a Integração . . . . . . . . . . . . . . . . . . 148

6 Validação das Metodologias Experimental e de Pós-processamento: Comparação entre Resultados Numéricos e Experimentais 153

6.1 Introdução . . . . . . . . . . . . . . . . . . . . . . . 153

6.2 Sucção da Camada Limite da Parede do Túnel de Vento . . . . . . . . . . 154

6.3 Breve Descrição da Metodologia Numérica . . . . . . . . . . . . . . . . . 157

6.4 Comparação entre Resultados Numéricos e Experimentais . . . . . . . . . . 158

6.4.1 Distribuição de Pressão ao Longo da Corda do Aerofólio ..... 158

6.4.2 Espectros de Ruído do Eslate . . . . . . . . . . . . . . . . . . . . . 160

7 Ruído Aerodinâmico do Eslate $\quad 165$

7.1 Introdução . . . . . . . . . . . . . . . . . . . . . . 165

7.2 Espectros de Ruído do Eslate e Dependência Com o Mach do Escoamento 168

7.3 Variação do Ruído de Eslate Com o Ângulo de Ataque do Aerofólio . . . . 172

7.4 Imagem Acústica das Fontes de Ruído do Eslate - Mapas de Beam-forming 174

7.5 Considerações Gerais sobre o Ruído Aerodinâmico do Eslate do Aerofólio 30P30N . . . . . . . . . . . . . . . . . . 179

8 Efeitos de Configuração Geométrica Sobre o Ruído do Eslate 183

8.1 Introdução . . . . . . . . . . . . . . . . . . . . . . 183

8.2 Dependência do Ruído do Eslate em Relação ao Gap e ao Overlap . . . . . 185

8.2.1 Dependência em Relação ao Mach do Escoamento . . . . . . . . . . . 191 
8.3 Dependência do Ruído do Eslate em Relação ao Parâmetro de Deflexão $\left(\boldsymbol{\delta}_{\boldsymbol{s}}\right) 194$ 8.3.1 Dependência em Relação ao Mach do Escoamento . . . . . . . . . . 196

\section{Conclusões}

9.1 Descrição do Ruído do Eslate . . . . . . . . . . . . . . . . . . . . 197

9.2 Dependência do Ruído do Eslate em Relação aos Parâmetros do Experimento197

9.3 Representação de Fontes Acústicas: Mapas de Beam-forming . . . . . . . . . . . . . . . . 198

9.4 Resultados Experimentais e Numéricos para o Ruído do Eslate . . . . . . . 198

9.5 Efeitos da Geometria Sobre o Ruído do Eslate . . . . . . . . . . . . . . . . 199

9.6 Avaliação das Metodologias Adotadas . . . . . . . . . . . . . . . . . 199

9.6.1 Metodologia Experimental . . . . . . . . . . . . . . 199

9.6.2 Metodologia de Processamento de Dados . . . . . . . . . . . . . . 200

9.7 Considerações Finais ． . . . . . . . . . . . . . . . . . . . . . . 201

Apêndice A Investigação Sobre Mecanismos de Geração do Ruído Tonal do Eslate

A.0.1 Múltiplos Picos Tonais . . . . . . . . . . . . . . . . 203

A.0.2 Tonal de Alta Frequência . . . . . . . . . . . . . . . . . . . . 204

Apêndice B Descrição da Metodologia Lattice-Boltzmann 207

$\begin{array}{ll}\text { Referências Bibliográficas } & 209\end{array}$ 
PAGANI JR, C. C. Mapeamento de fontes aeroacústicas de um eslate em túnel de vento de seção fechada utilizando beam-forming com deconvolução $D A$ $\boldsymbol{M A S}$. 2014. Tese (Doutorado) - Escola de Engenharia de São Carlos, Universidade de São Paulo, São Carlos, 2014.

A redução do ruído externo gerado por aeronaves operando nas proximidades de grandes centros urbanos é apontada como uma questão vital para a manutenção e expansão sustentável das atividades da aviação civil. Nas últimas décadas, reduções significativas no ruído gerado pelos sistemas de propulsão da aeronave tornaram relevantes as contribuições do trem de pouso e dos dispositivos de hiper-sustentação (flapes e eslates) para o ruído global da aeronave. A caracterização do espectro acústico de cada componente hiper-sustentador é necessária para o desenvolvimento de métodos preditivos de ruído e projetos aerodinâmicos que viabilizem a redução de ruído sem penalizações severas para o desempenho e a segurança da aeronave. Experimentos com modelos em escalas mostram que a contribuição de cada elemento hiper-sustentador para o ruído global é determinada pelo tamanho e modelo da aeronave. Tal fato dificulta a generalização dos resultados experimentais e determina a caracterização do espectro acústico de cada componente de um aerofólio em termos de sua geometria e configuração operacional. Este trabalho tem como objetivo principal a caracterização do ruído do eslate a partir de medições experimentais com um aerofólio hiper-sustentador McDonnell Douglas (30P30N), composto por flape, eslate e elemento principal. Os experimentos foram realizados em túnel de vento de seção fechada, e as medições acústicas contaram com o uso de uma antena composta por 62 microfones. Os dados acústicos foram processados com algoritmos de beam-forming convencional e deconvolução DAMAS (Deconvolution Approach for the Mapping of Acoustic Sources). A aplicação de técnicas de beam-forming permite representar uma distribuição 
espacial de fontes na forma de um mapa acústico e determinar o nível de ruído gerado por fontes que concorrem de forma independente para o ruído global. A base de dados experimentais permite o estudo do ruído do eslate sob diferentes configurações operacionais e geométricas do aerofólio. A análise do espectro acústico do eslate revela a ocorrência de ruído tonal em baixa e alta frequências, e ruído de banda larga em média frequência. Os mapas de beam-forming obtidos associam o ruído de banda larga com uma distribuição bidimensional de fontes ao longo da envergadura do eslate. O ruído do eslate aumenta com a velocidade de escoamento livre, enquanto que os picos tonais de baixa frequência e o ruído de banda larga decrescem com o aumento do ângulo de ataque do aerofólio de $2^{\circ}$ para $10^{\circ}$. Os espectros de ruído do eslate colapsam quando reescalados pelo número de Mach do escoamento livre elevado a uma potência entre 4 e 5, e o ruído tonal colapsa em Strouhal dado pela corda do eslate e pela velocidade do escoamento base. Os resultados mostram que o ruído do eslate é fortemente dependente da geometria do aerofólio, particularmente para variações de overlap. Uma boa correspondência quantitativa foi obtida comparando-se espectros experimentais de ruído do eslate com espectros numéricos, obtidos a partir de um modelo com a mesma geometria e em condições de teste idênticas, o que indica a viabilidade do uso de túneis de vento de secção fechada para a realização de experimentos aeroacústicos.

Palavras-chave: Aerofólio hiper-sustentador. Medições aeroacústicas. Ruído de eslate. Beam-forming acústico. Deconvolução DAMAS. 
PAGANI JR, C. C. Aeroacoustic source mapping of a slat in a closed-section wind tunnel using beam-forming with DAMAS deconvolution. 2014. Tese (Doutorado) - Escola de Engenharia de São Carlos, Universidade de São Paulo, São Carlos, 2014.

The reduction in the noise produced by aircraft operating in the vicinity of large urban centers is an important issue for a sustainable growth in the civil aviation activities. Over the last decades, from a significant reduction achieved in the noise generated by aircraft propulsion systems, the contribution of both landing gears and high-lift devices (flaps and slats) has become important to the aircraft overall noise. The identification of the noise signature of each high-lift component is required for the development of both noise prediction methods and new aerodynamic design concepts toward achieving a noise reduction without severe penalty over the aircraft performance and safety. Scaled model experiments have shown that the importance of each airframe component to the overall noise is determined by particularities in both aircraft geometry and size. Such noise model dependence hampers the generalization of experimental results from a reference testing model and leads to the necessity of assessing noise generation according to the testing model geometry and operational condition. This study focuses mainly on the characterization of slat noise from experimental measurements on a high-lift Mcdonnell Douglas (30P30N) airfoil, composed of a slat, a flap and a main element. Measurements were performed in a closed-section wind tunnel by a 62-microphone array and the acoustic data were processed with in-house codes based on conventional beam-forming and DAMAS (Deconvolution Approach for the Mapping of Acoustic Sources) algorithms. Beam-forming techniques potentially enable the representation of a spatial source distribution as an acoustic map, from which the contribution of independent sources to the overall noise 
can be estimated. The experimental database enables the study of the slat noise from different airfoil operational conditions and geometrical settings. The slat noise spectral signature reveals the occurrence of tonal noise over both low- and high-frequency bands and also broadband noise over a mid-frequency range. Beam-forming maps indicate the slat broad-band noise originates from a source spatially distributed along the slat span. The slat noise increases in function of the flow speed, whereas low-frequency tonal peaks and the broadband noise decrease as the airfoil angle of attack increases from $2^{\circ}$ to $10^{\circ}$. The slat noise spectra scalle when the Mach number is raised to a power between 4 and 5, and the tonal noise collapses with Strouhal based on the slat chord and the flow speed. Results show the slat noise is strongly influenced by the airfoil geometry, particularly for variations in the overlap. A good quantitative agreement was achieved through the comparison between the experimental and numerical slat noise spectra for the same model geometry and test conditions, which indicates the viability of performing aeroacoustic experiments in closed-section wind tunnels.

Keywords: High-lift airfoil. Aeroacoustic measurements. Slat noise. Acoustic beamforming. Deconvolution DAMAS. 


\section{CAPÍTULO 1}

\section{Introdução}

\subsection{Considerações Gerais}

Este trabalho tem como tema de estudo o ruído aerodinâmico do elemento eslate de um aerofólio hiper-sustentador MDA (McDonnell Douglas) com geometria 30P30N. A motivação para o desenvolvimento desta pesquisa decorre da demanda por redução do ruído externo em aeronaves de transporte civil, como forma de melhorar a qualidade de vida em comunidades alocadas nas imediações de grandes aeroportos. Do ponto de vista da indústria aeronáutica, o ruído externo é um aspecto de projeto que representa restrições para a certificação de uma aeronave, e cuja redução representa um diferencial que agrega valor ao projeto da aeronave.

As fontes de ruído externo em uma aeronave são de natureza aerodinâmica, e têm sua origem nos sistemas de propulsão e na interação entre o escoamento e os dispositivos de airframe; um termo técnico que designa a estrutura física não-propulsiva de uma aeronave, notadamente flapes, eslates e trem de pouso. O conceito de fonte aerodinâmica é de significado geral, e pode representar a geração de ruído por meio de escoamento turbulento ou forças aerodinâmicas interagindo com superfícies (DOWLING; WILLIAMS, 1983).

A contribuição relativa entre fontes propulsivas e de airframe para o nível de ruído total de uma aeronave depende, sobretudo, de sua condição operacional. Durante a decolagem, o trem de pouso e os sistemas hiper-sustentadores encontram-se acionados, porém, as turbinas operam em potência máxima e configuram-se como fontes dominantes de 
ruído. Durante voo de cruzeiro, os dispositivos de airframe estão recolhidos e a aeronave encontra-se, em geral, em grandes altitudes e distante dos centros urbanos. Na aterrissagem, os dispositivos de hiper-sustentação e o trem de pouso estão acionados e a aeronave opera sob propulsão reduzida, maximizando os níveis de emissão acústica de airframe em relação ao sistema de propulsão.

Melhorias constantes no desempenho acústico de motores turbo-jato resultaram em uma redução significativa do nível de emissão de ruído e tornaram os dispositivos de airframe um concorrente direto para a composição do nível de ruído total da aeronave. Portanto, o ruído de airframe constitui-se em uma barreira em potencial para reduções adicionais no nível de ruído externo em aeronaves comerciais (DOBRZYNSKI, 2010).

Flapes e eslates são projetados para elevar a sustentação aerodinâmica de uma aeronave (SMITH, 1975; DAM, 2002). O flape aumenta a curvatura da asa, ou camber, o que representa um aumento na sustentação da aeronave. O eslate atua aerodinâmicamente no sentido de elevar o ângulo de ataque do aerofólio no qual ocorreria a perda de sustentação (stall) em um aerofólio simples. Flapes e eslates, quando acionados, atuam como extensões móveis da asa, estando o eslate localizado na parte dianteira e o flape na parte traseira da asa. Quando recolhido, o eslate se encaixa ao elemento principal do aerofólio, formando uma superfície praticamente contínua do ponto de vista aerodinâmico. Uma vez acionado, o eslate é projeto frontalmente e separa-se do elemento principal do aerofólio. Surge, então, regiões de escoamento separado na cova do eslate e acelerado através da folga, ou gap, entre o bordo de fuga do eslate e o bordo de ataque do elemento principal. Estes escoamentos são fortemente influenciados pela geometria do aerofólio e determinam o surgimento de complexos mecanismos de geração e emissão de ruído (CHOUDHARI; KHORRAMI, 2006). O ruído aerodinâmico gerado pelo escoamento é objeto de estudo da aeroacústica. No contexto da aeronáutica, medições experimentais e modelos simulados computacionalmente por métodos numéricos são abordagens usadas como meio de investigação do ruído aerodinâmico gerado pelo escoamento no entorno de uma geometria de interesse.

Experimentos para a investigação do ruído aerodinâmico em aeronaves podem ser realizados em condição de voo livre (flyover), na qual uma aeronave em configuração operacional pré-estabelecida sobrevoa uma antena de microfones para a coleta de dados, bem como utilizando modelos reais ou em escala em túneis de vento. A realização de experimentos em túneis de vento representa menores custos operacionais e a possibilidade de alterações in situ no modelo de testes, isto associado a melhores condições de repetibilidade das medições e controle das condições aerodinâmicas durante o experimento.

Experimentos em túneis de vento, em geral, são realizados em regimes de baixo Reynolds, devido à dificuldade de se obter em condições experimentais a relação entre a 
corda do aerofólio e a velocidade de escoamento livre que se verifica em voo (POTTPOLLENSKE; DELFS; REICHENBERGER, 2013). Variações no número de Reynolds estão associadas com alterações no escoamento e, potencialmente, nos mecanismos de geração do ruído aerodinâmico (HAYES et al., 1999).

Efeitos sobre o ruído também estão relacionados à imperfeições no projeto base do modelo de testes. Como exemplo, os modelos em escala, em geral, apresentam bordos de fuga mais espessos que seus similares em tamanho real. O motivo desta disparidade é a dificuldade técnica para a fabricação de contornos suficientemente delgados para representar a proporção entre a dimensão da corda e a espessura do bordo de fuga que se verifica em modelos reais. Idealmente, efeitos associados o regime de Reynolds e ao uso de modelos em escala devem ser compreendidos e corrigidos, de forma a permitir que os resultados obtidos a partir de experimentos possam ser extrapolados para representar o ruído da aeronave real em condições operacionais.

Túneis de vento de uso comum em medições aeroacústicas e aerodinâmicas são de secção aberta ou fechada. Estes túneis de vento distinguem-se essencialmente pelas condições de contorno impostas ao escoamento e à propagação de ondas acústicas, que em grande medida determinam as correções adotadas na fase de processamento dos dados medidos (KROBER; STEFAN, 2013).

Túneis de vento de seção aberta são facilmente adaptados para a condição de câmaras anecoicas, o que permite a medição do ruído a partir de sensores posicionados externamente ao escoamento. Nestas condições, a mobilidade dos sensores acústicos em relação ao modelo de teste permite medições polares das fontes de ruído para a determinação do padrão de diretividade de emissão acústica. A condição anecoica também permite o uso de microfones em campo livre para a determinação do nível absoluto de ruído. Em contrapartida, túneis de vento de secção aberta não possuem condições de fronteira bem definidas para o escoamento, o que dificulta a aplicação de correções para a determinação do ângulo de ataque efetivo de um aerofólio.

Do ponto de vista acústico, as ondas de pressão que se propagam a partir de um modelo de teste deparam-se com uma camada de mistura turbulenta que separa o escoamento do meio em repouso onde se encontram os instrumentos de medição. A passagem da onda acústica através da camada de mistura turbulenta está associada a fenômenos de refração Amiet (1975), e perda de coerência entre os sinais medidos pelos microfones, o que requer a apliação de correções para compensar perdas de resolução e amplitude para as fontes de interesse (SIJTSMA, 2008).

Túneis de vento de secção fechada, por sua vez, apresentam condições de fronteira bem definidas para o escoamento e a propagação de ondas acústicas, sendo facilmente modeladas a partir da geometria, dimensões e propriedades acústicas da câmara de ensaios. 
No entanto, conforme Jaeger, Horne e Allen (2000), medições acústicas em túneis de vento de seção fechada são potencialmente afetadas pelas flutuações locais de pressão na camada limite turbulenta sobre a antena, bem como por altos níveis reverberação que ocorrem por conta das paredes rígidas (SIJTSMA; HOLTHUSEN, 2003). Os altos níveis de ruído de fundo praticamente inviabilizam medições com um microfone de referência para a estimativa do nível absoluto de ruído e diretividade das fontes acústicas. Restrições severas também são impostas ao posicionamento da antena de microfones em relação ao modelo de teste, que em geral permanece fixa durante a realização dos experimentos. Desta forma, a viabilidade da realização de experimentos aeroacústicos em túneis de vento de seção fechada ainda é um tema controverso, especialmente no que diz respeito à capacidade dos métodos de processamento de dados disponíveis em estimar corretamente o nível de pressão sonora das fontes.

Apesar das restrições salientadas, experimentos aeroacústicos em túneis de vento de secção fechada têm se mostrado promissores mediante a aplicação de técnicas de tratamento acústico e aperfeiçoamentos no projeto de antenas, com o uso de sistemas de hardware e software desenvolvidos para a medição de dados acústicos. Em particular, o desenvolvimento de técnicas de processamento de dados dedicadas à medições com antenas de microfones proporcionou um avanço notável no campo das pesquisas em aeroacústica experimental (MICHEL, 2006; MUELLER, 2002). A técnica de beam-forming acústico permite o mapeamento seletivo de fontes e a obtenção de uma estimativa de nível de pressão sonora para cada distribuição de fontes concorrentes. Desta forma, é teoricamente possível decompor o nível de ruído absoluto em componentes independentes e determinar a importância relativa entre elas, bem como identificar distribuições de fontes sobre regiões específicas de um modelo de testes (GUO; YAMAMOTO; STOKER, 2003).

A técnica de beam-forming convencional pode ser aplicada à identificação de fontes de ruído aerodinâmico em aeronaves (OERLEMANS, 2009). Entretanto, os resultados obtidos pela aplicação da técnica de beam-forming convencional são dependentes da geometria da antena de microfones e, em geral, apresentam baixa resolução de fontes e forte influência de lóbulos laterais (DOUGHERTY, 2005b). Todavia, os resultados obtidos pelo método de beam-forming convencional podem ser pós-processados por métodos de deconvolução, que potencialmente oferecem um ganho significativo em termos resolução de fontes e maior confiabilidade na identificação de fontes aerodinâmicas concorrentes. Os métodos de deconvolução DAMAS (Deconvolution Aprroach for The Mapping of Acoustic Sources), Brooks e Humphreys (2006), e CLEAN-SC (Clean Based on Spatial Source Coherence), Sijtsma (2007), apresentam bons resultados para o mapeamento de fontes de ruído em modelos aeronáuticos. Por outro lado, métodos de deconvolução iterativos, em geral, agregam complexidade aos códigos de beam-forming e representam um aumento na demanda por recursos computacionais (EHRENFRIED; KOOP, 2007). 
Simulações computacionais representam uma outra vertente de estudos em aeroacústica (BONATTO, 2013; SIMOES, 2011). Esta abordagem utiliza técnicas numéricas para a modelagem de um campo de escoamento supostamente associado aos mecanismos de geração do ruído aerodinâmico de interesse. A propagação do ruído em campo distante é geralmente feita pelo uso da analogia de Ffowcs-Willians e Hawking (WILLIAMS; HAWKINGS, 1969). A comparação entre resultados numéricos e experimentais representa um ponto de convergência das pesquisas em aeroacústica. Do ponto de vista numérico, a validação de resultados com base em dados experimentais valida os modelos utilizados: escoamento, turbulência, camada limite e propagação do som. Do ponto de vista experimental, a validação dos resultados representa a viabilidade de uma série de hipóteses assumidas durante a realização dos experimentos, tal como a hipótese de escoamento 2D ao longo da envergadura do aerofólio.

\subsection{Proposta e Objetivos do Trabalho}

Este trabalho tem por objetivo uma abordagem descritiva das principais características do ruído do eslate medido sob várias condições experimentais e configurações geométricas do perfil hiper-sustentador 30P30N, porém não investiga a origem dos mecanismos de geração do ruído aerodinâmico. Os resultados são baseados em dados experimentais obtidos pela medição do ruído de eslate com uma antena de 62 microfones, no túnel de vento LAE-1 (Túnel de Vento do Laboratório de Aerodinâmica da Escola de Engenharia de São Carlos). A base de dados experimentais é bastante ampla, contemplando medições acústicas e aerodinâmicas em diferentes velocidades de escoamento, ângulos de incidência e configurações geométricas do aerofólio.

A realização deste trabalho se deu no contexto do projeto Aeronave Silenciosa - Uma investigação em aeroacústica, que tem por objetivo investigar a origem de mecanismos de geração de ruído aerodinâmico e desenvolver tecnologias para redução do ruído de aeronaves.

A realização de medições aeroacústicas em um túnel de vento de seção fechada representou um desafio do ponto de vista experimental, mas permitiu avaliar as metodologias adotadas para a identificação das fontes de ruído aerodinâmico do eslate e a obtenção de estimativas coerentes do nível de pressão sonora das fontes. Não obstante, as condições de fronteira bem definidas na câmara de ensaios de seção fechada permitem uma boa modelagem dos experimentos a partir de simulações computacionais.

Do ponto de vista experimental, ações foram adotadas para reduzir os efeitos de escoamento tridimensional nas extremidades do aerofólio em contato com as paredes do túnel de vento. A ação do escoamento tridimensional altera a distribuição típica de pressão so- 
bre a superfície do aerofólio Paschal et al. (1991), Rumsey, Lee-Rausch e Watson (2003), o que potencialmente impacta os mecanismos de geração do ruído aerodinâmico, conforme sugerem os resultados apresentados neste trabalho. O controle adequado do efeito de escoamento tridimensional permite uma comparação mais realista entre resultados experimentais e resultados obtidos com modelos numéricos, que assumem a uniformidade do escoamento ao longo da envergadura da asa.

Do ponto de vista do processamento da base de dados acústicos, a necessidade de reduzir incertezas na identificação das fontes de interesse determinou o uso da técnica de deconvolução DAMAS (Deconvolution Aprroach for the Mapping of Acoustic Sources). Face à complexidade e alta demanda computacional imposta pelo método DAMAS, houve a necessidade de otimização de parâmetros computacionais e implementação de códigos capazes de viabilizar o processamento sistemático de uma base de dados extensa.

As principais metas que nortearam o desenvolvimento deste trabalho de pesquisa são resumidas nos seguintes itens:

(1) Estabelecer a viabilidade de realizar medições acústicas com um aerofólio hipersustentador em túnel de vento de seção fechada, com ênfase na determinação do nível de pressão sonora associado com fontes no eslate.

(2) Avaliar as metodologias experimentais e de processamento adotadas a partir da comparação entre resultados obtidos no contexto do trabalho e resultados de referência apresentados na literatura, bem como comparar os resultados experimentais com resultados obtidos por simulações computacionais realizadas no grupo de pesquisa.

(3) Apresentar um estudo descritivo do ruído do eslate do aerofólio 30P30N, identificando componentes de ruído no espectro acústico e padrões nas distribuições de fontes mapeadas com técnicas de beam-forming.

(4) Investigar a dependência do ruído do eslate em relação ao número de Mach do escoamento livre e ao ângulo de incidência do aerofólio.

(5) Investigar a dependência do ruído do eslate em relação à configuração geométrica do aerofólio hiper-sustentador, determinada pelos parâmetros gap, overlap e ângulo de deflexão do eslate.

\subsection{Organização do Trabalho}

A apresentação do trabalho encontra-se estruturada da seguinte forma: 
Capítulo 2: apresenta uma revisão bibliográfica sobre ruído de eslate, procurando identificar os componentes típicos que caracterizam o espectro de ruído do eslate e seus prováveis mecanismos de geração.

Capítulo 3: apresenta uma descrição geral sobre o aparato experimental e os procedimentos técnicos adotados para as medições acústicas e aerodinâmicas.

Capítulo 4: apresenta a formulação teórica das técnicas de beam-forming convencional e DAMAS, que foram implementadas na forma de códigos computacionais para o processamento da base de dados experimentais. Também são apresentados alguns resultados de testes realizados para a avaliação de desempenho dos códigos implementados.

Capítulo 5: apresenta uma descrição geral sobre as estratégias adotadas para o processamento da base de dados com os códigos implementados, de forma a integrar diferentes etapas de cálculo ao fluxo do processamento. A definição do domínio espacial e da malha de pontos adotados para o mapeamento de fontes com o código DAMAS é apresentada em maiores detalhes, bem como uma descrição da região usada para a integração de fontes acústicas sobre o eslate.

Capítulo 6: são apresentadas comparações entre distribuição de pressão na superfície do aerofólio e espectros de ruído do eslate, obtidos pelo processamento da base de dados experimentais e por simulação computacional com o aerofólio 30P30N.

Capítulo 7: apresenta resultados descritivos do ruído aerodinâmico do eslate. Os resultados são apresentados na forma de espectros de ruído e mapas de beam-forming. As dependências do ruído do eslate em relação ao número de Mach do escoamento livre e ao ângulo de incidência do aerofólio são avaliadas. Do ponto de vista qualitativo, é possível identificar a ocorrência de componentes de ruído que dominam o espectro acústico do eslate em bandas de frequência bem definidas.

Capítulo 8: avalia a dependência do ruído do eslate em relação à configuração geométrica do aerofólio 30P30N, definida pelos parâmetros denominados gap, overlap e deflexão do eslate em relação ao elemento principal.

Capítulo 9: sintetiza as principias conclusões que decorrem da aplicação das metodologias experimentais e de processamento de dados adotadas, bem como da análise dos resultados obtidos durante o desenvolvimento deste trabalho. 
CAPÍTULO 2

Revisão Bibliográfica: Ruído de Eslate

\subsection{Uma Visão Geral Sobre o Ruído de Eslate}

A partir da década de 90 intensificam-se os estudos de natureza experimental e numérica para a caracterização do ruído gerado por aerofólios equipados com dispositivos de hiper-sustentação; (DOBRZYNSKI et al., 1998; HAYES et al., 1997; STORMS; HAYES; ROSS, 1994). Estes trabalhos evidenciaram a importância do eslate como fonte proeminente de ruído e indicaram a necessidade de estudos avançados para uma compreensão mais detalhada sobre seus mecanismos de geração e emissão.

Guo, Yamamoto e Stoker (2003) apresentam resultados de um estudo para o mapeamento de fontes acústicas em um perfil hiper-sustentador McDonnell-Douglas DC-11, com razão de escala de $4.7 \%$. Os experimentos foram realizados em túnel de vento e as medições acústicas contaram com o uso de uma antena de microfones. A caracterização das fontes de ruído é feita a partir do uso de um algoritmo de beam-forming convencional.

A Fig. 2.1 (a) mostra mapas de beam-forming representando fontes acústicas associadas aos diversos componentes do perfil hiper-sustentador DC-11. A Fig. 2.1 (a) também representa regiões definidas para a integração de níveis de pressão sonora sobre diferentes componentes do modelo. Cada região de integração define o domínio espacial no qual a fonte acústica associada a um dado componente do aerofólio se torna plenamente domi- 


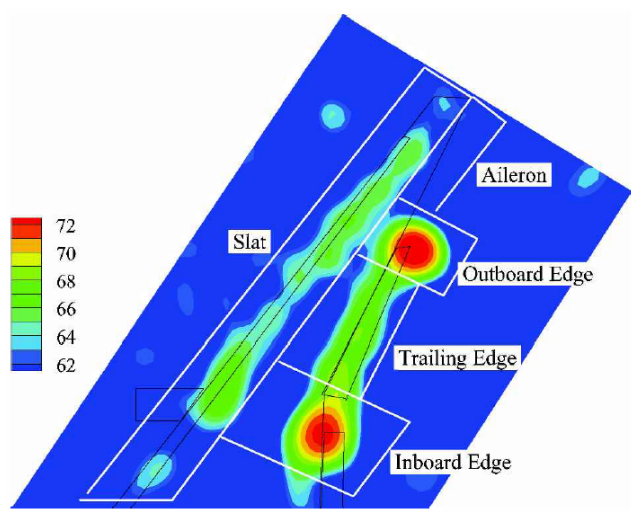

(a) Distribuição de fontes

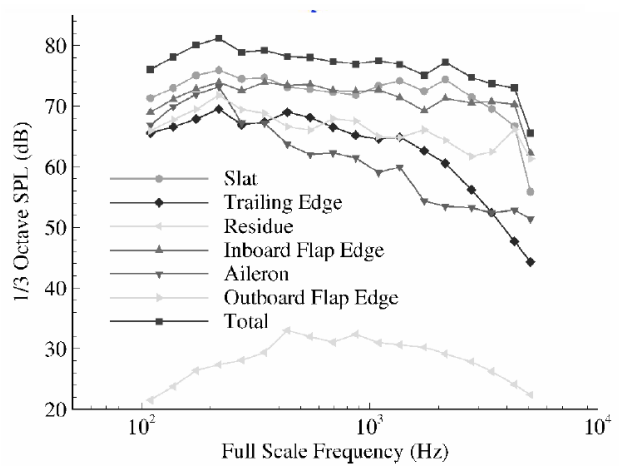

(b) Espectros de ruído

Figura 2.1: a) distribuição de fontes sobre componentes do perfil hiper-sustentador DC-11 mapeadas por algoritmo de beam-forming convencional na frequência de $10 \mathrm{kHz}, \mathrm{b}$ ) espectros de ruído mostrando a importância do ruído de eslate em relação aos demais componentes.

Fonte: Guo, Yamamoto e Stoker (2003).

nante em relação às fontes associadas aos demais componentes.

A Fig. 2.1(a) mostra claramente que as pontas de flape representam fontes bem localizadas e dominantes em amplitude, enquanto que o eslate representa uma fonte de menor amplitude, porém espacialmente distribuída ao longo de sua envergadura, ocupando uma área relativamente maior que aquela ocupada pela fonte de ponta de flape. Notadamente, as fontes de ponta de flape são responsáveis pelos picos de pressão sonora no mapa de beam-forming, mostrado na frequência de $10 \mathrm{kHz}$.

A Fig. 2.1(b) compara espectros de ruído obtidos pela integração de níveis de pressão sonora sobre cada componente do aerofólio, conforme indicado na Fig. 2.1 (a). Os resultados mostram claramente a importância do ruído de eslate em relação ao ruído produzido pelos demais componentes do aerofólio. Naturalmente, os resultados apresentados na Fig. 2.1 não são de validade geral, na medida em que dependem das características de projeto do aerofólio e da configuração geométrica adotada. Porém, mostram uma tendência geral para a classificação do ruído associado aos diversos componentes de um perfil hiper-sustentador.

Devido ao padrão de fontes espacialmente distribuídas, a contribuição do eslate para o nível total de ruído de uma aeronave depende da medida de sua envergadura. Em aviões de médio porte, a razão entre a envergadura da asa e as dimensões características de demais componentes de airframe torna-se maior do que aquela observada em aviões de grande porte. Neste caso, o controle de ruído de eslate é de particular interesse para a industria aeronáutica.

Guo e Joshi (2003) apresentam resultados acústicos obtidos em túnel de seção aberta 
com o modelo McDonnell-Douglas DC-10-30 em escala 4.7\%, com trem de pouso recolhido e sistema de hiper-sustentação composto por 2 pares de eslates e flapes. Medidas com microfones em campo distante mostram a presença de ruído de banda larga distribuído entre $100 \mathrm{~Hz}$ e $100 \mathrm{kHz}$. Os espectros de ruído escalam com a quinta potência do número de Mach em baixa e média frequência e com e sexta potência em alta frequência, sugerindo a atuação de diferentes mecanismos de emissão de ruído. As medidas foram realizadas em Mach $=0.275$ para diferentes ângulos de deflexão do eslate e do flape. Mapas de beam-forming indicam fontes de ruído de ponta de flape entre $5 \mathrm{kHz}$ e $20 \mathrm{kHz}$ (máxima frequência de processamento). O ruído de eslate é representado por uma fonte espacialmente distribuída ao longo da envergadura, na faixa de frequência entre $5 \mathrm{kHz}$ e $12 \mathrm{kHz}$.

Guo, Yamamoto e Stoker (2003) e Guo e Joshi (2003) representam uma visão geral sobre a descrição do ruído de eslate em perfis hiper-sustentadores e as metodologias usadas na abordagem de tal problema. Os resultados indicam que o espectro acústico do eslate é dominado por ruído de banda larga e os mapas de beam-forming apresentados sugerem uma distribuição uniforme de fontes ao longo de sua envergadura. No entanto, experimentos aeroacústicos realizados em túneis vento com uma grande variedade de perfis hiper-sustentadores em escala reduzida têm demonstrado que, em geral, o espectro acústico do eslate é determinado por uma combinação de diferentes componentes de ruído.

Imamura et al. (2009) apresentam resultados de um experimento realizado em um túnel de vento anecoico de seção aberta com um perfil hiper-sustentador em semi-envergadura composto por elemento principal e eslate. O espectro de ruído de eslate apresentado por Imamura et al. (2009), descrito em maiores detalhes na Fig. 2.2, mostra a ocorrência de múltiplos picos tonais de alta amplitude que dominam o espectro acústico em baixa frequência, ruído de banda-larga em média frequências e um único pico tonal em frequência mais alta, também denominado ruído tonal de banda larga, cujo formato se assemelha à uma corcova. O autor utiliza a nomenclatura MTP (Multiple Tonal Peaks), BB (Broadband Noise) e HT (High-frequency Tone) para designar os componentes de ruído dominantes em baixa, média e alta frequência, respectivamente.

Os resultados apresentados por Imamura et al. (2009) mostram a ocorrência de componentes de ruído de eslate que são comumente descritos na literatura, a saber: 1) ruído tonal de baixa frequência, ruído de banda larga e ruído tonal de alta frequência. Embora seja possível identificar certo padrão no espectro acústico do eslate, diferenças significativas nos resultados de caracterização do ruído podem ocorrer devido à diferenças de geometria dos modelos de teste e condições experimentais nas quais são realizadas as medições aeroacústicas. É oportuno destacar as semelhanças entre os espectros de ruído de eslate apresentados por Imamura et al. (2009) e aqueles apresentados neste trabalho, embora 

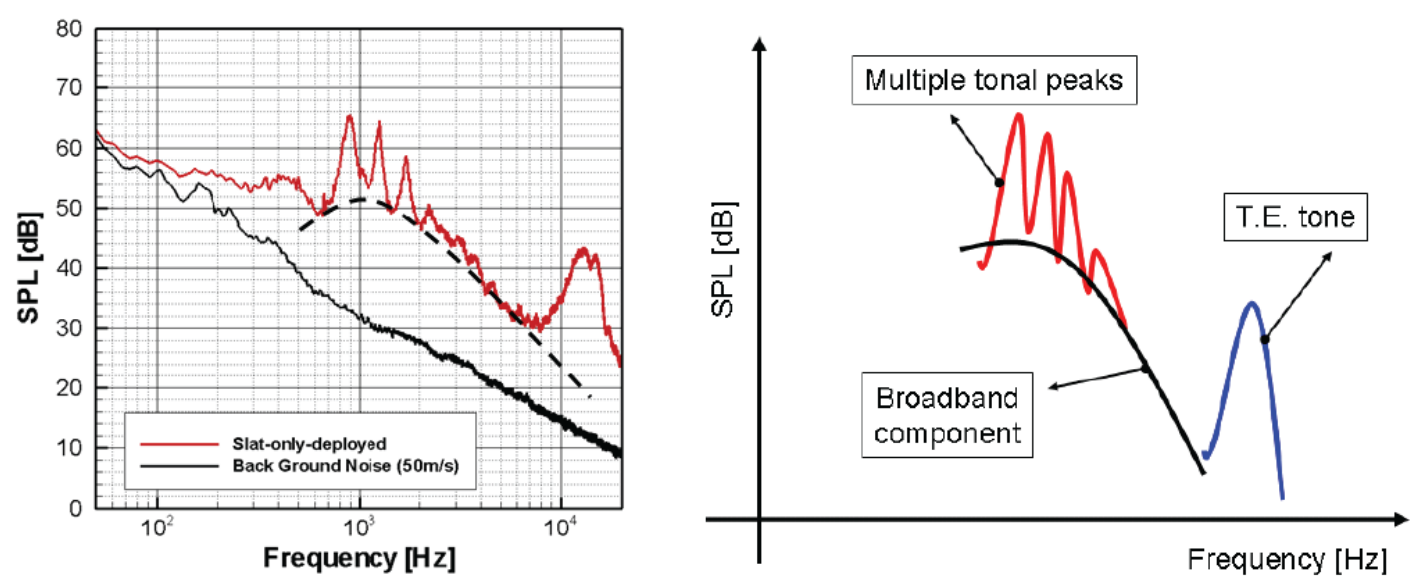

Figura 2.2: Espectro de ruído do eslate indicando a ocorrência dos componentes MTP, BB e HT. As medições foram feitas por um microfone em campo distante nas condições $U=50 \mathrm{~m} / \mathrm{s}$ e $\alpha=14^{\circ}$.

Fonte: Imamura et al. (2009).

representem resultados de medições aeroacústicas com modelos de geometrias distintas.

O ruído tonal de baixa frequência, que em geral se apresenta com um sequência de picos tonais não-harmônicos de alta amplitude, é atualmente alvo de intensa investigação. Alguns pesquisadores argumentam que esta componente de ruído é consequência dos baixos números de Reynolds alcançados em experimentos realizados em túneis de vento com modelos em escala. Sob esta perspectiva, os picos tonais de baixa frequência decorrem de limitações experimentais e não deveriam ser observados em aeronaves reais. No entanto, não há evidências conclusivas sobre a verdadeira origem do ruído tonal de baixa frequência. Atualmente, a ocorrência deste ruído tem sido associada a fenômenos de ressonância que ocorreriam na cova do eslate.

A ocorrência do ruído tonal de alta frequência tem sido observada em diversos experimentos. Estudos computacionais relacionam a ocorrência deste ruído ao fenômeno de desprendimento de vórtices no bordo de fuga do eslate. Diversos resultados sugerem que tal componente de ruído ocorre exclusivamente em modelos experimentais em escala, como consequência da grande espessura do bordo de fuga do eslate em relação à espessura da camada limite adjacente. Dobrzynski (2010) destaca que para um eslate em escala $1 / 10$, um bordo de fuga com espessura de aproximadamente $0.1 \mathrm{~mm}$ seria necessário para representar de forma realista o fenômeno de desprendimento de vórtices, conforme observado em condições de voo. No entanto, limitações técnicas de construção e manuseio de um modelo em escala restringem a espessura típica do bordo de fuga em algo variando entre 0.2 e $0.5 \mathrm{~mm}$.

A Fig. 2.3 representa a forma como a geometria do eslate influência o regime de escoamento no seu entorno e resulta na formação de estruturas fluido-dinâmicas que atuam 


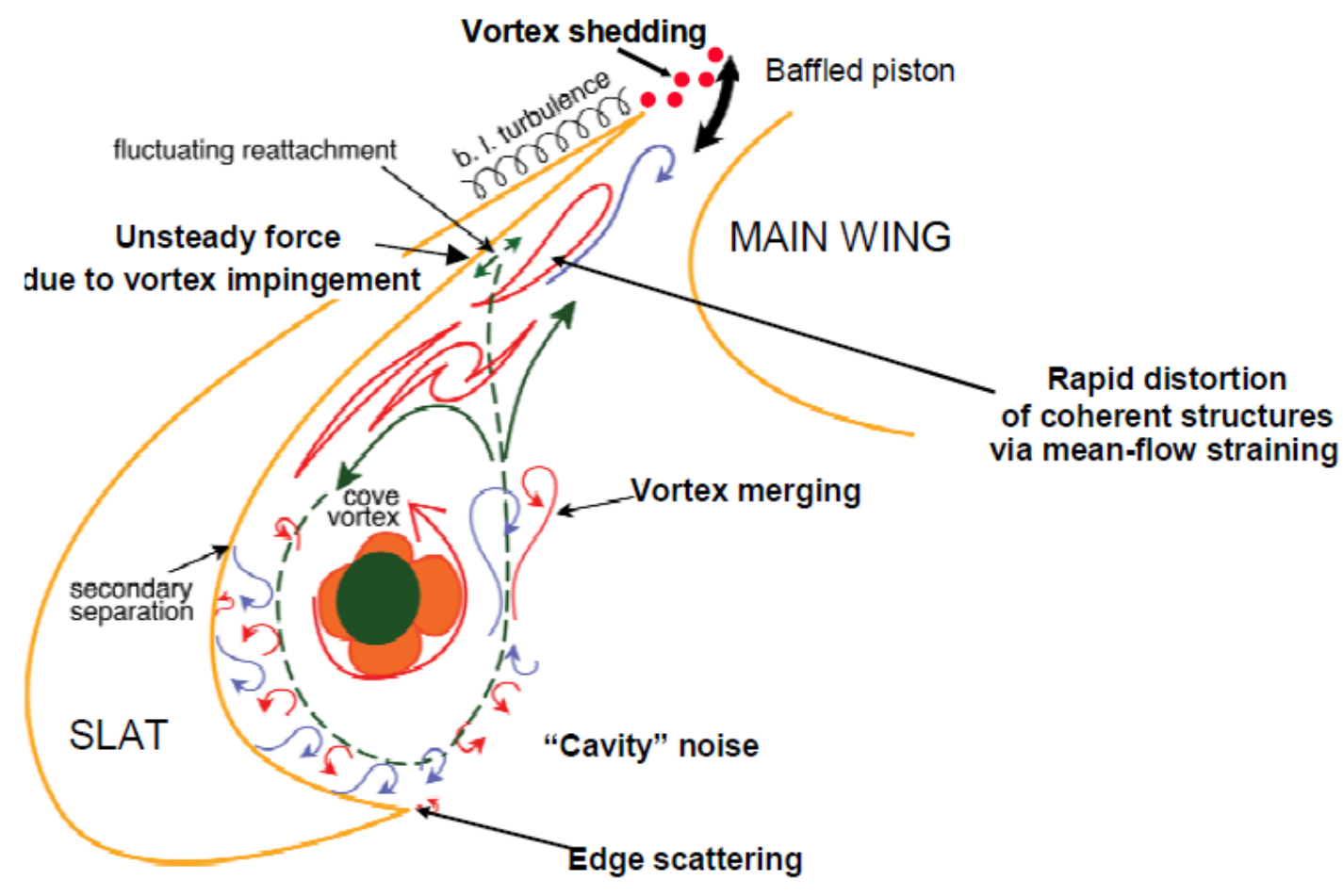

Figura 2.3: Representação da geometria do eslate e potenciais mecanismos de geração de ruído aerodinâmico.

Fonte: Choudhari e Khorrami (2006)

como potenciais mecanismos de geração de ruído aerodinâmico.

O principal ponto a ser destacado na Fig. 2.3 é o surgimento de diferentes regimes de escoamento não-permanente no entorno do eslate. A separação da camada limite na cúspide do eslate gera uma camada cisalhante instável que é responsável pela formação de estruturas vorticais. Esta camada cisalhante separa a região de recirculação na cova do eslate da região de escoamento adjacente que não recircula. As velocidades de escoamento nestas regiões são significativamente diferentes, conferindo propriedade de camada de mistura ao escoamento intermediário. A camada de mistura incide e recola na superfície interna da cova, próximo ao bordo de fuga do eslate, gerando uma região com grande flutuação de pressão e provável emissão de ruído. Uma parte dos vórtices espalhados no ponto de recolamento é acelerada através do gap e interage com o bordo de fuga do eslate, gerando um mecanismo de emissão de ruído que, em teoria, escala com a quinta potência do Mach do escoamento base.

A parte complementar desta revisão bibliográfica se concentra na análise de trabalhos voltados à caracterização dos principais componentes do ruído de eslate e seus prováveis mecanismos de geração. Desta forma, espera-se tornar esta revisão bibliográfica consistente com a proposta adotada neste trabalho, que consiste em apresentar um estudo descritivo do ruído de eslate sob várias condições experimentais e configurações geométricas 


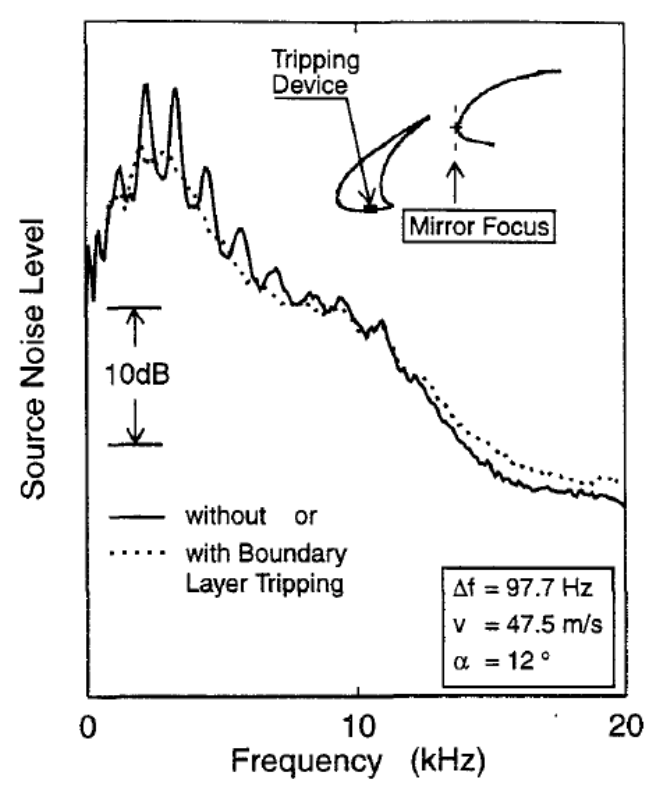

(a) Espectro de ruído acústico em campo distante

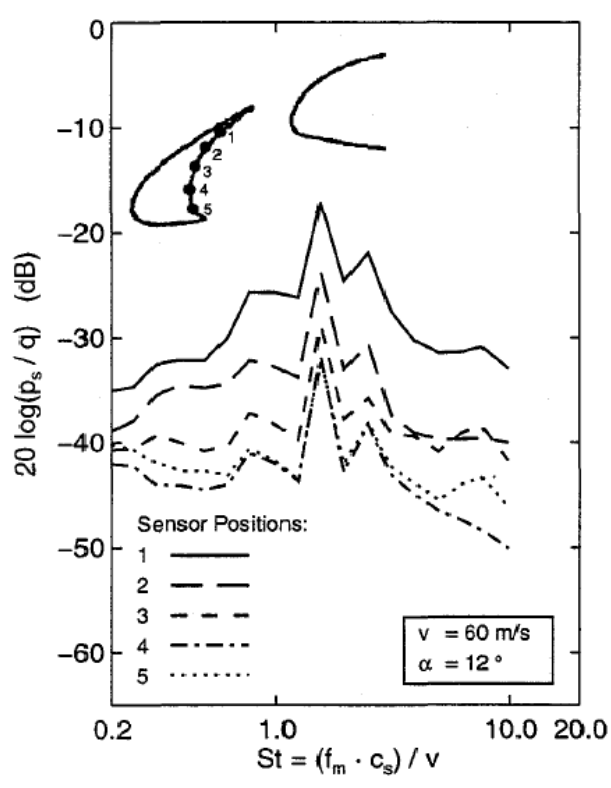

(b) Espectro de pressão em campo próximo

Figura 2.4: Comparação entre espectros de ruído do eslate antes e após a transição forçada da camada limite a montante da cúspide do eslate e representação de espectros de pressão estimados a partir de medições por sensores posicionados na cova do eslate.

Fonte: Dobrzynski et al. (1998)

do aerofólio hiper-sustentador 30P30N.

\subsection{Ruído Tonal de Baixa Frequência}

Dobrzynski et al. (1998) apresentam resultados experimentais para um modelo hipersustentador ALVAST em escala 1/10 (modelo 3D com perfil afilado e enflexado). Os experimentos ocorreram no DLR Aeroacoustics Wind Tunnel Brauschweig (AWB), com o aerofólio preferencialmente em configuração de pouso. As medições contaram com um espelho acústico e sensores de pressão alocados em posições estratégicas sobre a superfície do aerofólio. Os resultados indicam que eslate e flape são fontes dominantes de ruído.

A Fig. 2.4 (a) mostra o espectro de ruído obtido com o espelho acústico focado na região delimitada pelo bordo de fuga do eslate e o bordo de ataque do elemento principal do aerofólio. Nota-se claramente a presença de picos tonais em baixa frequência, bem como a sua supressão devido à instalação de uma pequena placa porosa no intradorso do eslate. A instalação deste dispositivo tem o efeito de forçar a transição da camada limite a montante do ponto separação (cúspide do eslate). A Fig. 2.4 (b) também mostra picos nos espectros da pressão medida por sensores instalados no interior da cova do eslate, que ocorrem em correspondência aos picos tonais no espectro acústico. 
Conforme a Fig. 2.4 (a), a eliminação dos picos tonais de baixa frequência resultou em um espectro dominado por ruído de banda larga com máximo de amplitude em St $\approx 2$. Este resultado tem motivado alguns autores a buscarem estratégias para suprimir os picos tonais e estudar de forma independente o comportamento do ruído de banda larga de baixa frequência.

Kolb et al. (2007) realizaram experimentos em um túnel anecoico com um modelo de asa 2D (escala 1:7,5) composto por elemento principal e eslate, dos quais resultou uma ampla base de dados aerodinâmicos e acústicos. Medições por transdutores de pressão espalhados na superfície do aerofólio e microfones posicionados em campo distante indicaram a ocorrência de picos tonais entre $1 \mathrm{kHz}$ e $3 \mathrm{kHz}(1 \leq S t \leq 4)$. Tentativas de suprimir o mecanismo de geração do ruído tonal de baixa frequência pelo forçamento da transição da camada limite à montante da cúspide do eslate se mostraram ineficazes para a supressão desta componente de ruído.

Imamura et al. (2009) também não obtiveram sucesso em sua tentativa de suprimir o ruído tonal de baixa frequência forçando a transição da camada limite à montante da cúspide do eslate em um perfil hiper-sustentador 2D em semi-envergadura. No entanto, a supressão do picos tonais ocorre pela instalação de um dispositivo denominado SCF (Slat Cove Filter) na cova do eslate, conforme a Fig. 2.5. A instalação deste "filtro" resultou em uma redução efetiva no nível de ruído entre $200 \mathrm{~Hz}(S t=0.4)$ e $5 \mathrm{kHz}(S t=9)$. Notoriamente, verifica-se a completa eliminação do ruído tonal.
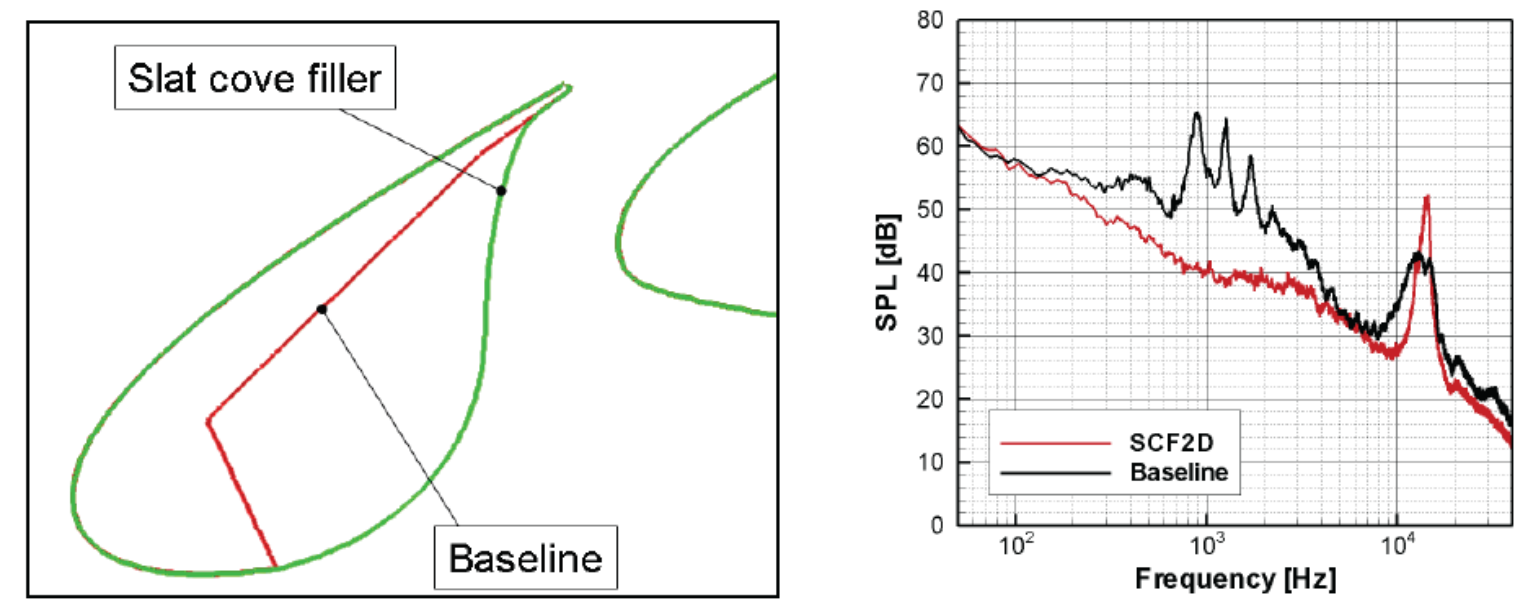

Figura 2.5: (Instalação do dispositivo SCF (Slat Cove Filter), projetado para eliminar efeitos da separação da camada limite na cúspide do eslate sobre o escoamento na cova. O filtro acoplado (linha verde) se adapta à região da cova do eslate, formando uma superfície aerodinamicamente contínua em relação à configuração baseline da cova (linha vermelha). Também está representado o efeito do dispositivo SCF sobre o ruído do eslate, com a notória supressão das componentes MTP e BB.

Fonte: Imamura et al. (2009)

O uso desta técnica para a supressão do ruído de eslate é atualmente um tema de 
estudos e a sua efetiva aplicação em aeronaves comerciais depende da relação final entre redução de ruído e desempenho aerodinâmico do aerofólio, o peso e questões de projeto e instalação.

Modelos de teste 3D são artefatos adequados para reproduzir de forma mais realista efeitos do escoamento na produção do ruído aerodinâmico verificado em aeronaves. No entanto, de acordo com Pott-Pollenske, Delfs e Reichenberger (2013), modelos 3D em escala, em geral, apresentam comprimento de corda recolhida bastante semelhante àqueles verificados em modelos $2 \mathrm{D}$. Tal fato restringe os experimentos aeroacústicos em túneis de vento com modelos $2 \mathrm{D}$ e $3 \mathrm{D}$ a regimes de Reynolds variando entre $1 \times 10^{6}$ e $3 \times 10^{6}$.

Guo, Yamamoto e Stoker (2003) chamam a atenção para o fato de que a extrapolação dos resultados obtidos com modelos em diferentes escalas, baseada na simples razão entre dimensões físicas, é realista sob a condição de que os mecanismos de geração de ruído sejam independentes da escala do modelo. A dependência do escoamento em relação à escala do modelo de testes é decorrente de variações do número de Reynolds.

A supressão do ruído tonal de baixa frequência em um modelo 3D obtida por Dobrzynski et al. (1998), forçando a transição da camada limite à montante da cúspide de laminar para turbulenta, sugere que a escala relevante para a geração do ruído tonal é determinada pelo número de Reynolds, e não pelas dimensões físicas do modelo. Tal hipótese tem sido investigada para modelos com diferentes geometrias, levando a resultados controversos.

Pott-Pollenske, Delfs e Reichenberger (2013) apresentam resultados de um experimento projetado para permitir medições aeroacústicas sob regimes de Reynolds compatíveis com aqueles alcançados por uma aeronave em condições típicas de pouso. A estratégia adotada consistiu em construir um modelo de testes com $1200 \mathrm{~mm}$ de corda recolhida e $7200 \mathrm{~mm}$ de envergadura, o que permitiu experimentos com número de Reynolds da ordem de até $5 \times 10^{6}$. Estas dimensões são incomuns para um perfil hiper-sustentador simulado em túnel de vento, o que exigiu a construção de uma câmara de testes dedicada ao experimento.

O aerofólio utilizado nos testes é uma versão de um modelo hiper-sustentador 2D baseado em uma asa 3D da Airbus, ampliada para possibilitar que altos Reynolds baseados no comprimento da corda recolhida do aerofólio sejam alcançados a partir de velocidades de escoamento típicas em túneis de vento. A Fig. 2.6 mostra o aerofólio posicionado para medições acústicas na câmara de ensaios do túnel de vento anecóico DWN (German-Dutch Wind Tunnel) e uma comparação entre espectros do ruído de eslate obtidos em diferentes regimes de Reynolds.

Os espectros de ruído observados na Fig. 2.6 (b) mostram que picos tonais discretos dominantes no espectro de baixa frequência são suprimidos em regimes de escoamento 


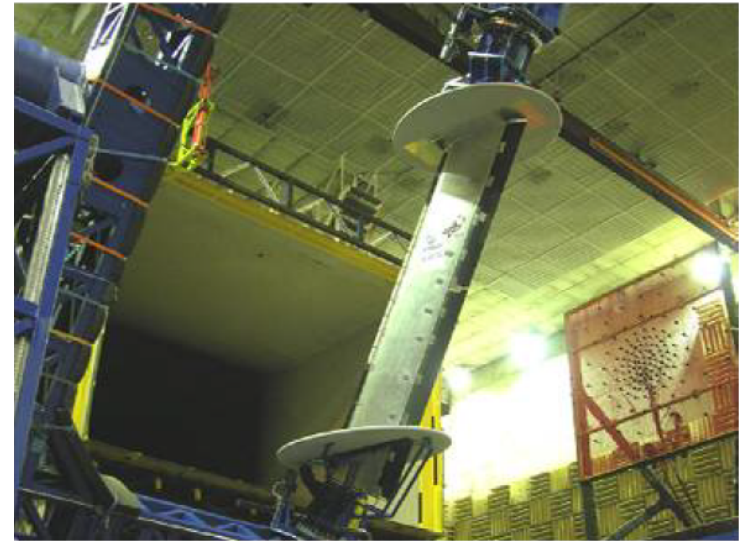

(a) Modelo de testes

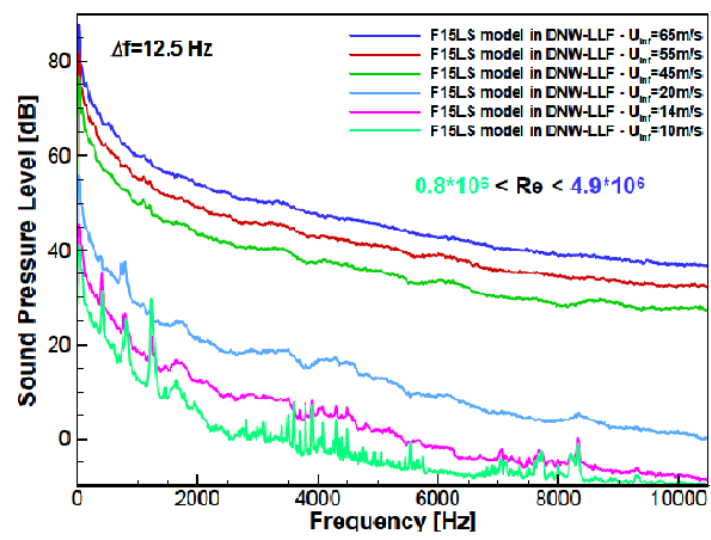

(b) Espectros de ruído

Figura 2.6: (a) perfil hiper-sustentador enflexado em $30^{\circ}$ e posicionado para medições aeroacústicas no túnel DWN e (b) espectros de ruído de eslate obtidos sob vários regimes de Reynolds. Fonte: Pott-Pollenske, Delfs e Reichenberger (2013).

com alto Reynolds.

Lockard e Choudhari (2012) mostram resultados numéricos para um modelo hipersustentador 2D com geometria 30P30N. O estudo teve como objetivo investigar a dependência do ruído de eslate com o número de Reynolds. Cinco casos de estudo são considerados, com Reynolds variando na faixa $\left(1,71 \times 10^{6} \leq R e \leq 12,0 \times 10^{6}\right)$. Em dois dos casos de estudo considera-se componentes de escoamento na direção da envergadura do aerofólio (cross-flow), reproduzindo o efeito do enflexamento da asa sobre o escoamento. A diretividade do campo acústico e o nível espectral de ruído em campo distante são calculados pela equação de Ffowcs Williams-Hawkings (FW-H) no domínio da frequência.

Os resultados obtidos por Lockard e Choudhari (2012) mostram que as variações do espectro de potência acústica para diferentes Reynolds está dentro das margens de incerteza assumidas na simulação, indicando que não há dependência dos mecanismos de geração de ruído do eslate em relação ao número de Reynolds e ao efeito de cross-flow. Em particular, não se verifica a supressão da componente de ruído tonal em alto Reynolds a partir dos resultados numéricos apresentados. Os resultados indicam que para um modelo hiper-sustentador 30P30N a ocorrência de picos tonais de baixa frequência é um fenômeno robusto dentro das margens de variação de parâmetros consideradas nesta análise. Possíveis causas para a discrepância destes resultados em relação àqueles que apontam para a supressão do ruído tonal em altos Reynolds são atribuídas a particularidades na geometria do aerofólio 30P30N, ou à incapacidade do modelo numérico adotado em descrever corretamente a física do problema.

Pott-Pollenske, Alvarez e Dobrzynski (2003) apresentam medidas acústicas obtidas por um espelho acústico elíptico com $1.4 \mathrm{~m}$ de diâmetro, referentes a uma asa em escala 


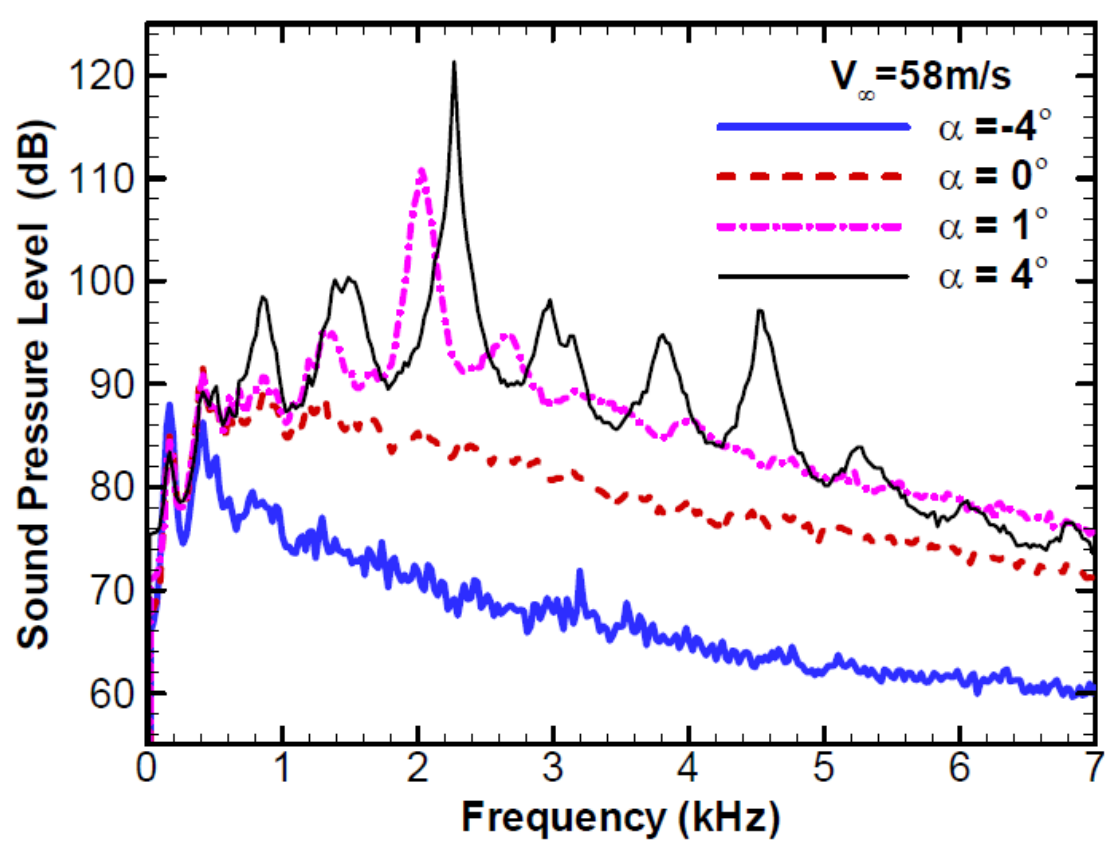

Figura 2.7: Espectro do ruído do eslate para vários ângulos de incidência do aerofólio, com velocidade de escoamento livre de $58 \mathrm{~m} / \mathrm{s}$.

Fonte: Pott-Pollenske, Alvarez e Dobrzynski (2003).

1/6 configurada com eslate, elemento principal e flape. O autor classifica a geometria do aerofólio como "quase 2D", devido à semi-envergadura do flape. Os experimentos foram realizados em um túnel de vento anecoico de seção aberta (Aeroacoustic Wind Tunnel Braunschweig - $A W B)$.

A Fig. 2.7 mostra o espectro de ruído estimado a partir de medidas feitas com o espelho acústico focado na região situada entre o bordo de fuga de eslate e o bordo de ataque do elemento principal. Os espectros de ruído são comparados para diferentes ângulos de ataque do aerofólio, corrigidos para compensar efeitos de downwash.

Os resultados apresentados na Fig. 2.7 mostram que o espectro acústico do eslate apresenta exclusivamente ruído de banda larga para os ângulos de ataque $\alpha=-4^{\circ}$ e $\alpha=0^{\circ}$. A partir de $\alpha=1^{\circ}$, a ocorrência de picos tonais torna-se evidente. Em $\alpha=4^{\circ}$ os tons são mais pronunciados. Os picos tonais observados para ângulos de ataque a partir de $\alpha=1^{\circ}$ não apresentam-se como múltiplos de uma frequência fundamental (harmônicos) e não mostram uma relação clara de dependência para com o ângulo de ataque do aerofólio.

Manoha et al. (2012) apresenta resultados de medições em túnel de vento anecoico e simulação computacional para um aerofólio de 2 elementos (eslate e elemento principal). O aerofólio foi geometricamente otimizado a partir de um modelo de 3-elementos, de forma a reproduzir no aerofólio com 2-elementos as características de escoamento na cova do eslate verificadas para o perfil de referência. Com perfil otimizado, o aerofólio com 2-elementos apresenta uma redução significativa em termos de coeficiente de sustentação 

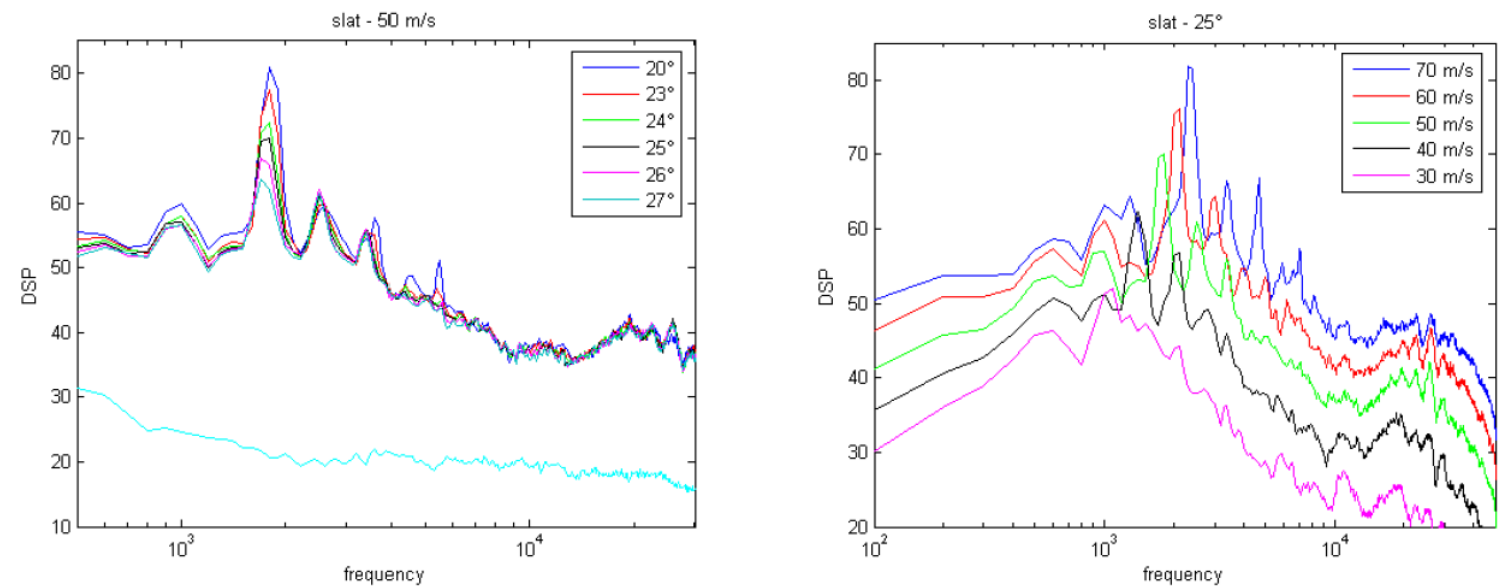

Figura 2.8: Espectros de ruído em campo distante para a) vários ângulos de ataque do aerofólio e b) várias velocidades de escoamento livre.

Fonte: Manoha et al. (2012).

e, consequentemente, verifica-se uma redução na deflexão média do escoamento.

A Fig. 2.8 mostra espectros de ruído obtidos com o uso de um microfone de referência. Comparações para diversos ângulos de incidência do aerofólio mostram que a amplitude do pico principal decai com o aumento do ângulo de ataque do aerofólio, sem deslocamento significativo na frequência. Por outro lado, os valores de pico crescem em amplitude e deslocam-se para frequências mais altas com o aumento da velocidade de escoamento livre.

\subsubsection{Mapas de Beam-forming para o Ruído Tonal de Baixa Frequência}

Esta subseção discute a caracterização da distribuição de fontes acústicas associadas ao componente de ruído tonal pelo uso de mapas de beam-forming. Foram encontrados apenas dois trabalhos abordando este tema, que é relevante no contexto deste trabalho pela presença do ruído tonal de baixa frequência no espectro de ruído do eslate do aerofólio $30 \mathrm{P} 30 \mathrm{~N}$.

Imamura et al. (2009) utilizou mapas de beam-forming para estudar a distribuição de fontes acústicas no eslate, nas frequências de ocorrência do ruído tonal e também em frequências intermediárias (mínimo local entre dois picos tonais). A Fig. 2.9 mostra mapas de beam-forming convencional representando a distribuição de fontes acústicas associadas ao pico tonal de máxima amplitude para diferentes ângulos de incidência do aerofólio. De acordo com a Fig. 2.9, a fonte acústica associada ao pico tonal no espectro de ruído do eslate aparece concentrada em diferentes posições ao longo de sua envergadura, quando são comparados mapas de beam-forming para diferentes ângulos de incidência do aerofólio.

A Fig. 2.10 compara mapas de beam-forming nas frequências de máxima amplitude 


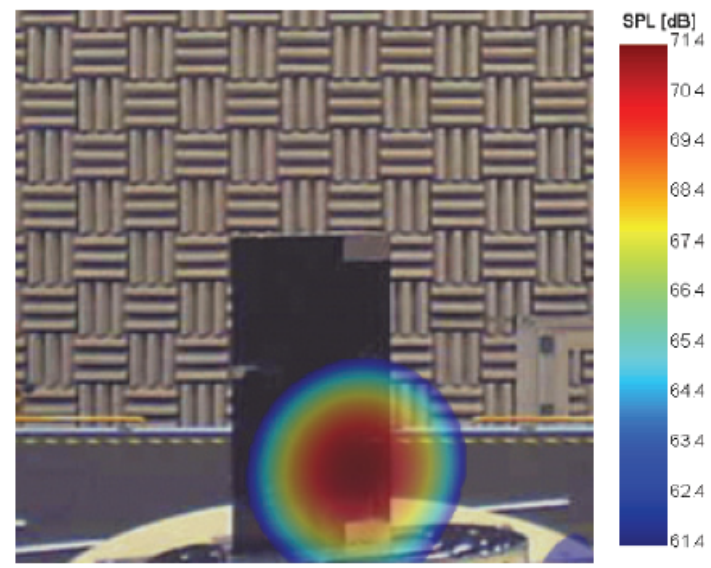

(a) $\mathrm{AoA}=10 \operatorname{deg}(f=912 \mathrm{~Hz})$

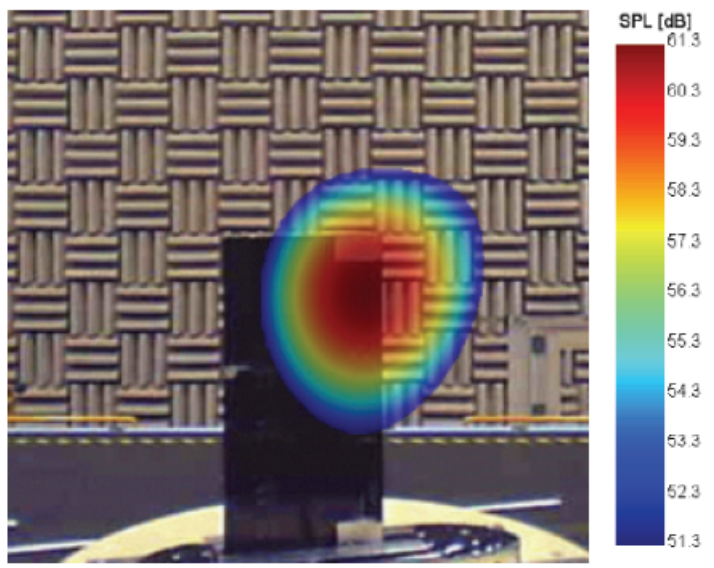

(b) $\mathrm{AoA}=18 \mathrm{deg}(f=832 \mathrm{~Hz})$

Figura 2.9: Representação de fontes acústicas associadas ao pico tonal de máxima amplitude para ângulos de incidência do aerofólio de $10^{\circ}$ e $18^{\circ},\left(U_{\infty}=50 \mathrm{~m} / \mathrm{s}\right)$.

Fonte: Imamura et al. (2009).

do pico tonal e mínimo adjacente.

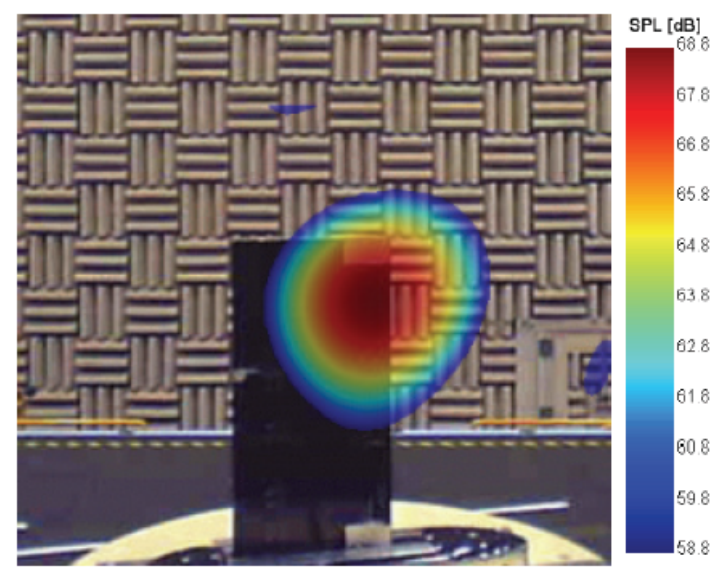

(a) Peak of multiple-tonal-peak (4m array, $f=880 \mathrm{~Hz})$

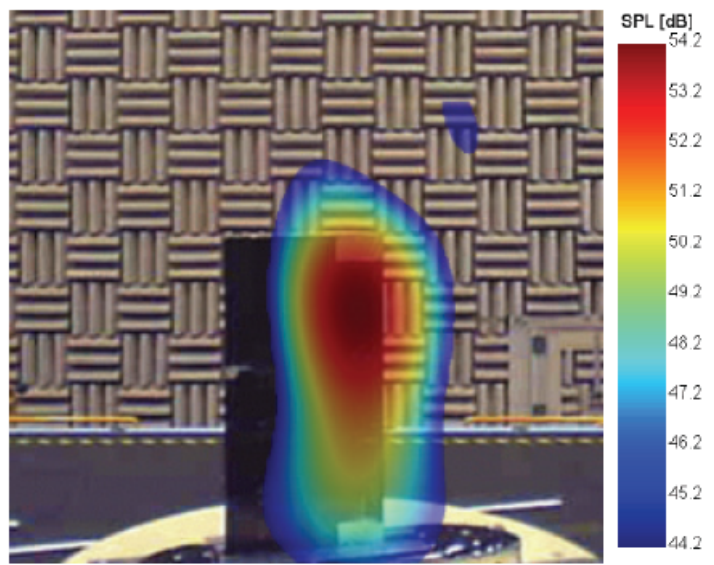

(b) Local minimum of multiple-tonal-peak (4m array, $f=1008 \mathrm{~Hz})$

Figura 2.10: Mapas de beam-forming convencional nas frequências de $880 \mathrm{~Hz}$ e $1008 \mathrm{~Hz}$, representando distribuições de fontes associadas a pontos de máxima e mínima amplitude de ruído na região de ocorrência de picos tonais $\left(\alpha=14^{\circ}\right.$ e $\left.U_{\infty}=50 \mathrm{~m} / \mathrm{s}\right)$.

Fonte: Imamura et al. (2009).

A análise dos mapas de beam-forming apresentados na Fig. 2.10 sugere padrões de distribuição de fontes distintos para as frequências de $880 \mathrm{~Hz}$ e $1008 \mathrm{~Hz}$. A fonte melhor distribuída ao longo da envergadura na frequência de $1008 \mathrm{~Hz}$ foi associada à ocorrência de ruído de banda larga. Em particular, pode-se notar que a localização das fontes acústicas associadas ao pico tonal coincide para $\alpha=14^{\circ}$ e $\alpha=18^{\circ}$, com diferença relativa de nível de $7.5 \mathrm{~dB}$.

Manoha et al. (2012) utilizou uma abordagem bastante semelhante àquela adotada 
por Imamura et al. (2009) para investigar o padrão típico de distribuições de fontes em frequências de ocorrência de ruído tonal e intermediárias. No entanto, obteve resultados notoriamente distintos, embora ambos os modelos possuíssem geometria 2D.

A Fig. 2.11 mostra resultados de mapeamento acústico do ruído de eslate utilizando o algoritmo DAMAS (Deconvolution Approach for the mapping of acoustic sources). Os mapas de beam-forming são apresentados nas frequências de $2300 \mathrm{~Hz}$ (frequência intermediária entre dois picos tonais) e $2500 \mathrm{~Hz}$ (ocorrência de pico tonal).
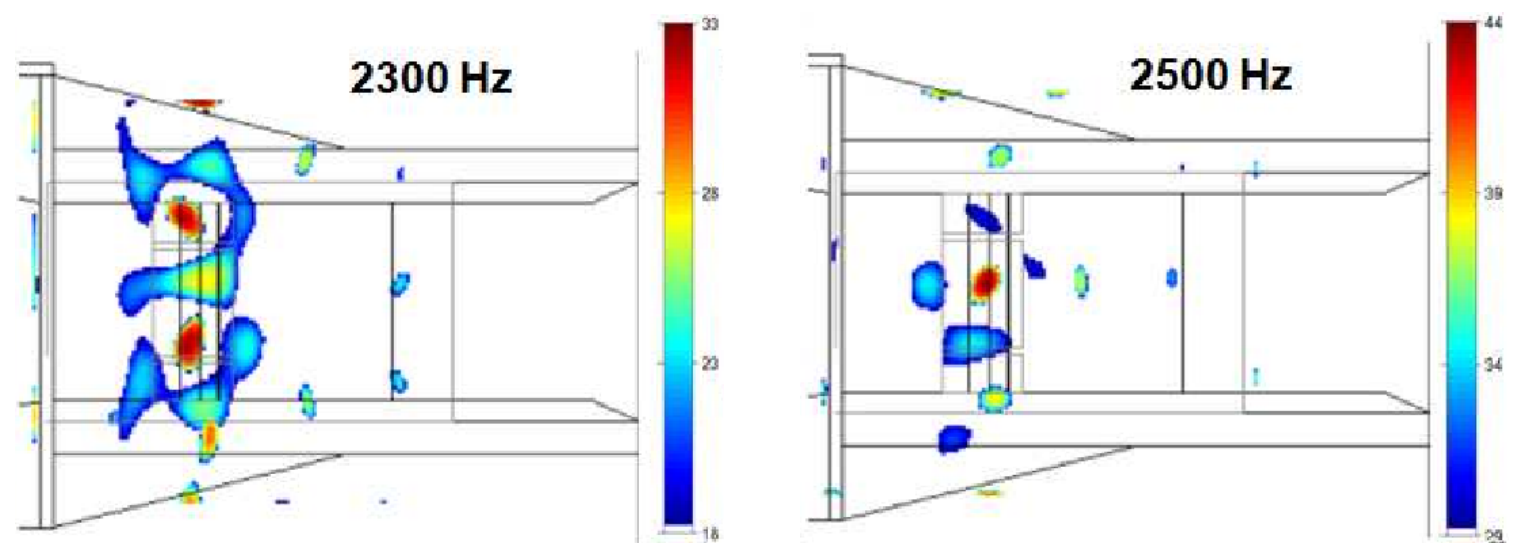

Figura 2.11: Representação de fontes de ruído sobre o eslate em frequências intermediária (2300 $\mathrm{Hz})$ e de ocorrência de pico tonal $(2500 \mathrm{~Hz})$, para velocidade de escoamento base de $U=50 \mathrm{~m} / \mathrm{s}$. Os mapas de beam-forming foram obtidos pelo método de deconvolução DAMAS.

Fonte: Manoha et al. (2012).

Os mapas de beam-forming indicam que na frequência de ocorrência do pico tonal $(2500 \mathrm{~Hz})$ as fontes de ruído estão localizadas na região central da envergadura do eslate. Em frequência intermediária $(2300 \mathrm{~Hz})$, o ruído dominante se concentra em regiões próximas às junções entre o aerofólio e sua base de sustentação, sugerindo a geração de ruído a partir da interação entre a camada limite da parede e o aerofólio. Conforme Manoha et al. (2012), os resultados apresentados na Fig. 2.11 representam uma tendência geral observada nos seus mapas de beam-forming em frequências de pico tonal e intermediária.

\subsection{Mecanismos de Geração de Ruído Tonal}

Kolb et al. (2007) utilizou o modelo de Rossiter para prever as frequências de pico do ruído tonal de baixa frequência. O modelo de Rossiter baseia-se em um mecanismo de retro-alimentação no qual ondas acústicas originadas no ponto de recolamento da camada de mistura propagam-se até o ponto de separação da camada limite, na região da cúspide do eslate, excitando a instabilidade hidrodinâmica. A Fig. 2.12 ilustra o mecanismo físico proposto para representar a geração de ruído tonal, baseado em (ROSSITER, 1964). 


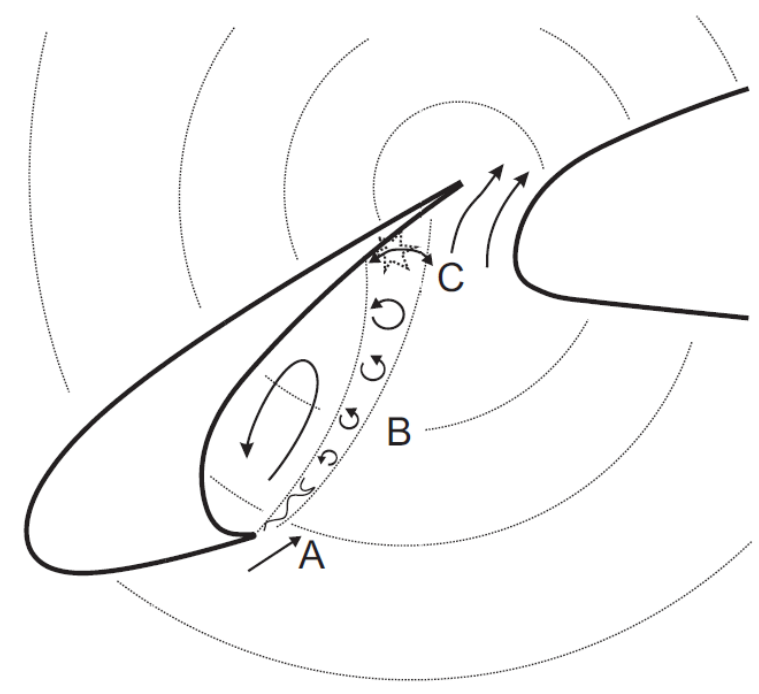

Figura 2.12: Vórtices gerados na camada de mistura a partir da cúspide do eslate (A) são amplificados e atingem o eslate um ponto próximo ao seu bordo de fuga (c). Ondas acústicas geradas no ponto $(\mathrm{c})$ propagam-se à montante, atingindo o ponto $(\mathrm{A})$. A incidência de ondas acústicas no ponto (A) excita instabilidade hidrodinâmica e o processo se torna auto-sustentável. Fonte: Kolb et al. (2007).

As frequências de ocorrência do ruído tonal obtidas experimentalmente apresentam boa correspondência com aquelas previstas pelo modelo de Rossiter para apenas um ângulo de incidência do aerofólio, $\alpha=23^{\circ}$. Este resultado tem sido atribuído ao fato de que o modelo de Rossiter não incorpora parâmetros que permitam representar particularidades da dinâmica do escoamento na cova do eslate sob diferentes condições experimentais e geométricas do aerofólio.

A Fig. 2.13 representa espectros acústicos de eslate para vários ângulos de ataque do aerofólio. Para $\alpha=23^{\circ}$, a frequência experimental do primeiro tonal é $1084 \mathrm{~Hz}$, que corresponde ao segundo pico previsto pelo modelo de Rossiter em $1098 \mathrm{~Hz}$. No experimento, a frequência do pico tonal de máxima amplitude é $1658 \mathrm{~Hz}$, enquanto que a frequência do tonal correspondente prevista pelo modelo de Rossiter é $1725 \mathrm{~Hz}$.

Terracol, Manoha e Lemoine (2011) apresentam resultados de um estudo no qual uma versão modificada do modelo de Rossiter é usada para prever as frequências de pico do ruído tonal de um perfil hiper-sustentador com dois elementos (eslate e elemento principal) e $30 \mathrm{~cm}$ de corda recolhida. A Fig. 2.14 representa o conceito físico e os parâmetros envolvidos na descrição do modelo proposto.

O mecanismo representado na Fig. 2.14 pode ser melhor entendido a partir da seguinte sequência de eventos:

(1) $n_{v}$ vórtices são convectados a partir da cúspide do eslate, em direção ao ponto de recolamento da camada de mistura cisalhante, com velocidade $U_{v}$. A distância média 


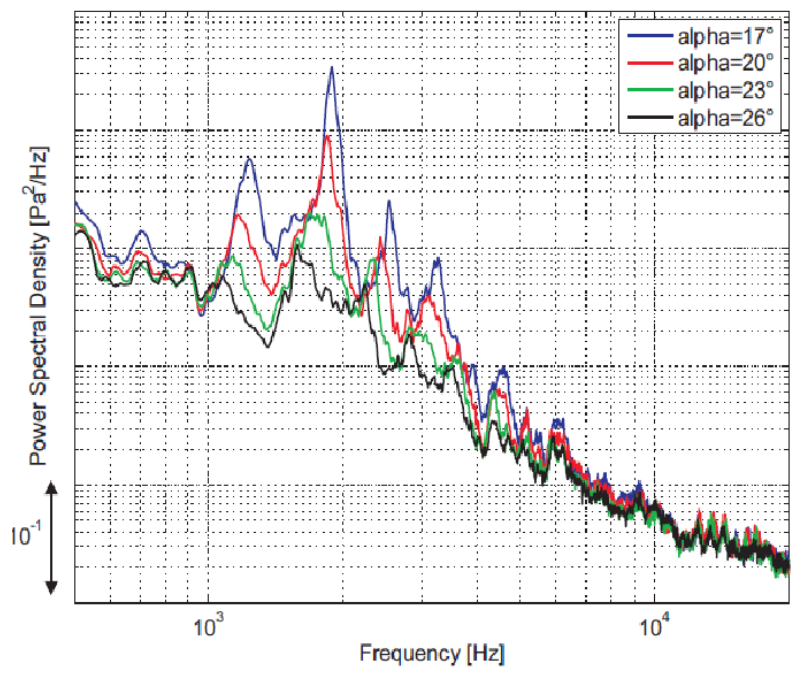

Figura 2.13: Espectros de ruído para vários ângulos de incidência do aerofólio, estimados a partir de medidas com um microfone em campo distante. Velocidade de escoamento livre de $50 \mathrm{~m} / \mathrm{s}$. Fonte: Kolb et al. (2007).
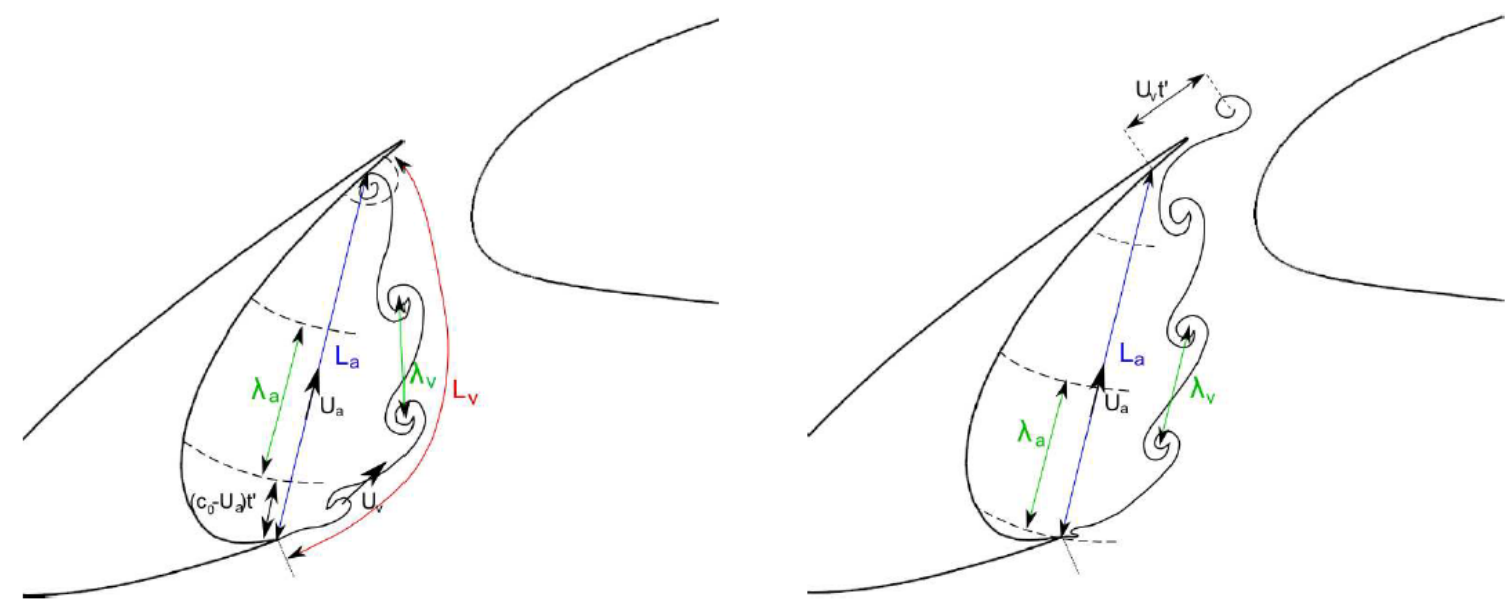

Figura 2.14: Representação detalhada de um possível mecanismo de geração de ruído tonal e definição dos parâmetros envolvidos na formulação.

Fonte: Terracol, Manoha e Lemoine (2011).

entre dois vórtices adjacentes é $\lambda_{v}$.

(2) vórtices atingem a superfície do eslate no ponto de recolamento da camada de mistura, após percorrer a distância $L_{v}$, gerando uma onda acústica com comprimento de onda $\lambda_{a}$ que se propaga através da cova do eslate em direção à cúspide. As ondas acústicas propagam-se com velocidade $c_{0}-U_{a}$, sendo $c_{0}$ a velocidade do som no meio considerado e $U_{a}$ a velocidade média do escoamento na cova.

(3) Após percorrer a distância $L_{a}$, uma frente de onda acústica atinge a região da cúspide e provoca o desprendimento de um novo vórtice, completando o circuito de retro- 
alimentação.

Com base no mecanismo apresentado, deduz-se a seguinte fórmula para a predição das frequências de ocorrência do ruído tonal.

$$
f_{n}=n \frac{U_{\infty}}{L_{a}}\left(\frac{1}{M+\alpha_{l} / k_{v}}\right)
$$

Na Eq. 2.1, $\alpha_{l}$ e $k_{v}$ são definidos pelas relações $L_{v} / L_{a}$ e $U_{v} / U_{\infty}$, respectivamente. Os parâmetros $\alpha_{l}$ e $k_{v}$ podem ser estimados a partir de medições experimentais ou simulações computacionais do escoamento e, em teoria, permitem o ajuste do modelo de predição de frequências tonais à uma condição particular de escoamento na cova do eslate.

A Fig. 2.15 representa a aplicação da Eq. 2.1 à predição das frequências de pico do ruído tonal. Os resultados são comparados com aqueles previstos pela aplicação do modelo de Rossiter, experimentais - decorrentes de medições com microfones em campo distante, e computacionais - obtidos pelo método de simulação numérica NLDE (NonLinear Disturbance Equations). Os parâmetros de escoamento $\alpha_{l}$ e $k_{v}$ foram estimados para uma velocidade média de escoamento $U_{\infty}=50 \mathrm{~m} / \mathrm{s}$ e o aerofólio foi ajustado para ângulo de incidência de $4^{\circ}$.
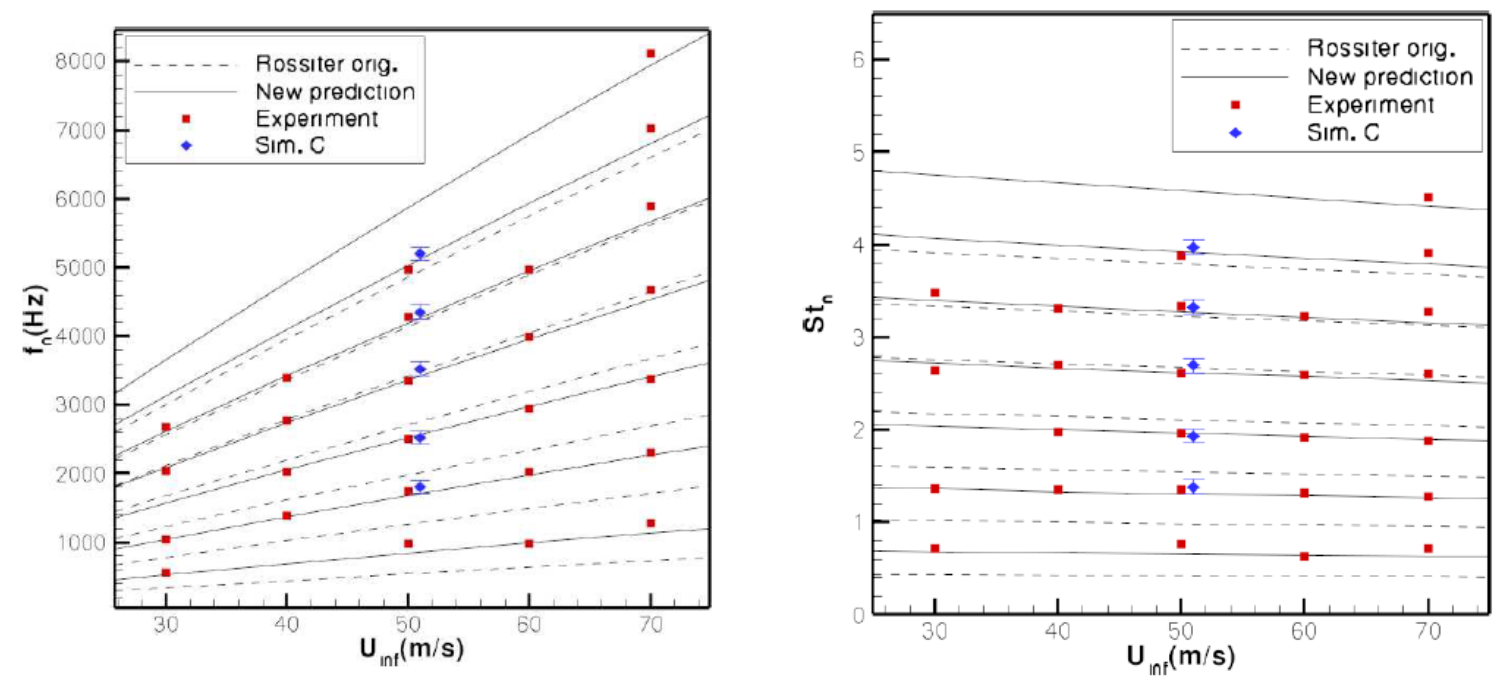

Figura 2.15: Comparação dos resultados para predição de frequências de ruído tonal com velocidades de escoamento livre variando entre $30 \mathrm{~m} / \mathrm{s}$ e $50 \mathrm{~m} / \mathrm{s}$.

Fonte: Terracol, Manoha e Lemoine (2011).

Os resultados apresentados na Fig. 2.15 sugerem que o modelo representado pela Eq. 2.1 prevê as frequências de geração do ruído tonal na faixa de velocidades de escoamento consideradas. No entanto, o resultados apresentados decorrem de uma única configuração 
de ângulo de ataque do aerofólio, não permitindo uma análise crítica de desempenho do modelo sob variação deste parâmetro.

\subsection{Ruído de Banda Larga de Eslate}

O ruído de banda larga é um componente acústico comumente observado em experimentos com eslates de aerofólios hiper-sustentadores com diferentes escalas e geometrias. Os resultados apresentados por Guo, Yamamoto e Stoker (2003) para o aerofólio McDonnell-Douglas DC-11, com razão de escala de 4.7\%, (Fig. 2.1(b)) mostram que o ruído de banda larga domina o espectro acústico do eslate nas bandas de baixa à média frequência, sem a ocorrência de componentes tonais. Imamura et al. (2009) apresenta um espectro acústico (Fig. 2.2) no qual o ruído de banda larga surge em banda média de frequência, delimitado por componentes tonais de baixa e alta frequência. Dobrzynski et al. (1998) mostram que a supressão dos picos tonais de baixa frequência, obtidos a partir de medições com o modelo hiper-sustentador ALVAST em escala 1/10 (modelo 3D com perfil afilado e enflexado), resulta em um espectro dominado por ruído de banda larga com máxima amplitude em $S t \approx 2$. Choudhari et al. (2002) (Fig. 2.20) apresentam resultados experimentais para o modelo hiper-sustentador EET (Efficient Energy Transport) que mostram o espectro de ruído do eslate dominado por ruído de banda larga em baixa e média frequência e um pico tonal de grande amplitude em alta frequência (A Fig. 2.20).

Estudos experimentais e numéricos indicam que a ocorrência do ruído de banda larga está associada ao escoamento turbulento com origem na cova do eslate. Dobrzynski e Pott-Pollenske (2001) apresentam resultados de um estudo abrangente sobre ruído de banda larga de eslate a partir dos dados acústicos do modelo hiper-sustentador ALVAST em escala 1/10. Os resultados mostram um bom colapso dos espectros em frequência mediante adimensionalização pela corda do eslate, indicando que a dimensão da fonte dominante escala com a estrutura vortical gerada pelo escoamento na cova do eslate. $\mathrm{O}$ colapso em amplitude dos espectros de ruído, quando normalizados pelo fator $M^{4.5},(\approx 5)$, sugere que o mecanismo de emissão do ruído de banda larga tem origem no espalhamento do escoamento turbulento pelo bordo de fuga do eslate. Medições de diretividade do ruído corroboram a hipótese de que o mecanismo de emissão pode ser representado por um dipolo compacto alinhado com o bordo de fuga do eslate.

Pott-Pollenske, Alvarez e Dobrzynski (2003) apresentam resultados de um estudo no qual o ruído de banda larga de eslate é relacionado ao perfil local da velocidade do escoamento medido nas regiões do bordo de fuga e da cúspide do eslate. O modelo utilizado é um aerofólio hiper-sustentador de três elementos com flape em semi-envergadura. Os parâmetros do escoamento foram obtidos por simulação computacional baseada no método 
RANS (Reynolds-averaged Navier-Stokes equations). O estudo considerou variações do gap do eslate em relação a um valor de referência, com o aerofólio em ângulos de ataque nominais de $0^{\circ}, 4^{\circ}$, e $8^{\circ}$, com $U_{\infty}=50 \mathrm{~m} / \mathrm{s}$. Para cada configuração de gap, o nível espectral de ruído foi normalizado em relação às velocidades locais de escoamento. $\mathrm{O}$ melhor colapso dos espectros de ruído, para diferentes gaps, ocorreu para as velocidades de escoamento calculadas no intradorso do bordo de fuga do eslate. Este resultado sustentou a conclusão de que o ruído de banda larga é gerado pelo escoamento turbulento originado na região de recolamento da camada de mistura e convectado através do gap do eslate, sendo o mecanismo de emissão do ruído de banda larga determinado pela interação entre o escoamento turbulento e o bordo de fuga do eslate.

Agarwal e Morris (2004) usaram um modelo semi-empírico para a previsão do ruído de banda larga baseado em parâmetros do escoamento turbulento na cova do eslate, determinados numericamente com o uso código Reynolds Averaged Navier Stokes (RANS). A função de Green utilizada para modelar a propagação do campo acústico, gerado por uma distribuição de fontes pontuais, supõe propagação em condição de escoamento uniforme mas leva em conta os efeitos da geometria da asa sobre o espalhamento das ondas acústicas emitidas a partir da região da cova do eslate. Os resultados obtidos pela aplicação do modelo semi-empírico de predição são comparados com um espectro de ruído experimental do eslate apresentado em Khorrami, Singer e Berkman (2002), conforme a figura 2.16 .

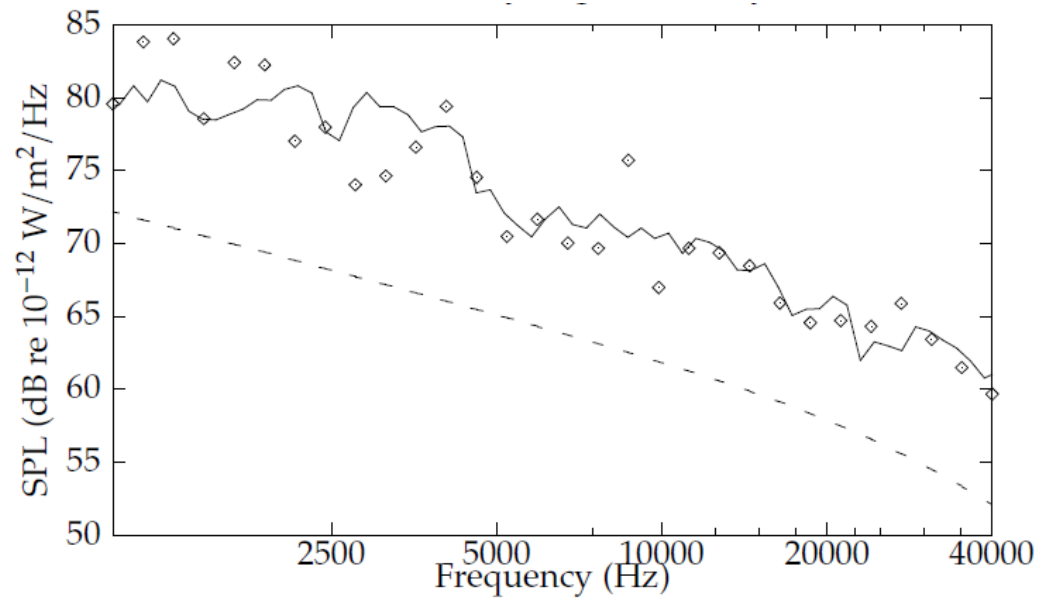

Figura 2.16: Comparação entre espectros de ruído de banda larga obtidos a partir de metodologias numérica e experimental. A linha contínua representa o resultado experimental. A linha tracejada representa o resultado numérico obtido sem a influência da asa e a curva com o símbolo (o) representa o resultado numérico com a influência da asa.

Fonte: (AGARWAL; MORRIS, 2004).

Os resultados mostram uma boa concordância entre resultados semi-empírico e experimental, quando se considera efeitos de espalhamento pela geometria da asa sobre a propagação acústica em campo distante. As maiores discrepâncias entre os resultados 
estão em torno de $5 \mathrm{~dB}$. Um outro aspecto a ser destacado é que a previsão com modelo semi-empírico representa a forma do espectro experimental. No caso do ruído previsto sem efeitos de espalhamento, Agarwal mostra que a amplitude do ruído banda larga é subestimada pelo método semi-empírico.

Khorrami, Singer e Berkman (2002) apresentam resultados de simulação 2D para o estudo do potencial acústico da camada cisalhante que se desenvolve a partir da cúspide do eslate. Em particular, o objetivo da investigação é avaliar a conjectura de que a amplificação de perturbações na camada cisalhante representa um mecanismo de geração de ruído de banda larga de baixa frequência. As simulações consideraram um aerofólio com geometria EET (Energy Efficient Transport). Os resultados foram obtidos com método RANS (Unsteady Reynolds-averaged Navier-Stokes), utilizando o modelo de turbulência $k-\omega$. O ruído em campo distante é obtido pela integração da equação de Ffowcs Williams e Hawkings (FW-H). Simulações foram realizadas nas condições $M=0.2, \operatorname{Re}=7,2 \times 10^{6} \mathrm{e}$ $\alpha=8^{\circ}$. Resultados de simulações utilizando perturbações numéricas para a excitação da camada de cisalhante mostraram que os vórtices gerados dissipavam-se de forma prematura, antes que algum mecanismo de geração de ruído pudesse ser consolidado. Um termo de forçamento harmônico foi então usado para induzir oscilações na camada de mistura que resultaram na formação de estruturas vorticais discretas. Embora os resultados mostrem que a amplificação dos modos de instabilidade na camada de mistura atua com fonte de ruído em baixa frequência, o ruído aerodinâmico se mostra altamente correlacionado com o ruído gerado pela ação do termo forçante.

Na sequência do trabalho apresentado por Khorrami, Singer e Berkman (2002), Khorrami, Singer e Lockard (2002) desconsideram os termos de geração de turbulência em seu modelo numérico. O escoamento na cova do eslate em condição quasi-laminar, mas altamente instável, suprime a dissipação prematura de vórtices e amplifica naturalmente as estruturas vorticais oriundas da camada cisalhante, sem a necessidade de excitação externa. Alterações significativas na dinâmica do escoamento na cova do eslate são notadas, particularmente na comparação entre resultados de simulações para $\alpha=6^{\circ}$ e $\alpha=8^{\circ}$. Ao contrário do que se observa para $\alpha=8^{\circ}$, resultados para $\alpha=6^{\circ}$ mostram o aprisionamento de vórtices na região de recirculação da cova do eslate, que se misturam e contribuem para a formação de um vórtice central. Uma vez estabelecido, o vórtice central é constantemente alimentado pela incorporação de novos vórtices. Por conseguinte, a presença do vórtice central modifica o padrão de escoamento na camada de mistura. Os resultados numéricos obtidos por (KHORRAMI; SINGER; LOCKARD, 2002), baseados em escoamento laminar 2D, não são considerados conclusivos para a determinação da camada cisalhante como fonte do ruído de banda larga do eslate. 


\subsection{Noções Básicas Sobre o Escoamento 2D na Cova do Eslate}

Takeda et al. (2001) realizaram experimentos com PIV (Particle Image Velocity) e LDA (Laser Doppler Anenometry) para estudar o escoamento não-estacionário no entorno do elemento eslate em um aerofólio 2D. Os experimentos foram realizados em túnel de vento de seção fechada com números de Reynolds e Mach de aproximadamente 1,5 milhão e 0.088, respectivamente. A Fig. 2.17 mostra a geometria do modelo de testes e as regiões mapeadas por PIV (cova e região do escoamento de esteira do eslate).

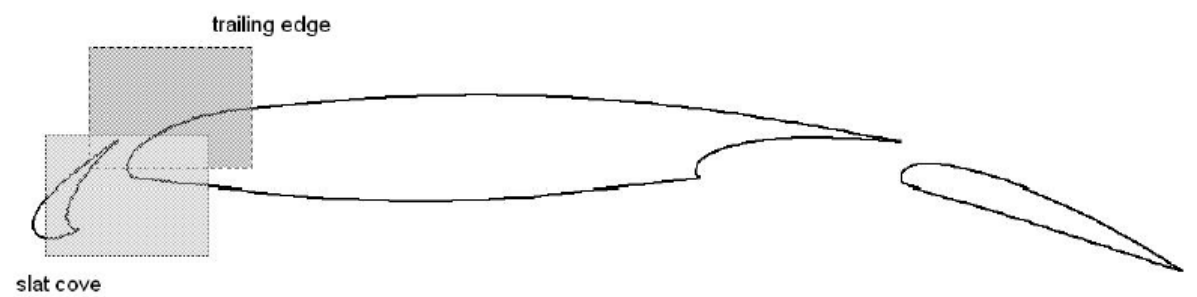

Figura 2.17: Geometria do modelo de testes 2D em configuração de eslate e flape denominada L1T2. As regiões mapeadas pela técnica de PIV encontram-se hachuradas.

Fonte: Takeda et al. (2001).

A análise do escoamento médio mostra: 1) a formação de uma fina camada de mistura a partir da cúspide do eslate e a formação subsequente de estruturas vorticais coerentes no seu interior, 2) a formação de uma região de recirculação de baixa velocidade no interior da cova do eslate e 3) parte do escoamento sendo impelido através da região entre o bordo de fuga do eslate e o bordo de ataque do elemento principal (gap do eslate). A representação do escoamento instantâneo mostra a evolução de diferentes estados de instabilidade do escoamento na cova do eslate. É possível verificar a formação de um vórtice com diâmetro semelhante à largura da camada de mistura. Há um escoamento altamente turbulento na região onde a camada de mistura incide e recola sobre a superfície interna à cova do eslate, próxima ao seu bordo de fuga.

Os resultados também mostram que a camada de mistura no bordo de fuga do eslate assemelha-se àquela observada a partir da cúspide do eslate. Formação de estruturas vorticais coerentes devido à instabilidade da camada de mistura não foram observadas ao longo de um segmento de esteira equivalente à uma corda do eslate. No entanto, alguns resultados de PIV representando imagens do contorno de vorticidade instantânea mostram a presença de estruturas vorticais coerentes de grande escala na região entre a camada de mistura que se origina no bordo de fuga do eslate e a superfície do elemento principal. Porem há indícios de que vórtices originados na região da cova são convectados através do gap do eslate. 
Khorrami, Singer e Berkman (2002) apresentam resultados de simulações do campo de vorticidade formado pelo escoamento na região da cova do eslate. Para o caso $\alpha=6^{\circ}$, é possível verificar a presença de pares de vórtices co-rotativos na região do gap, entre o bordo de fuga do eslate o e bordo de ataque do elemento principal (Fig. 2.18). Os vórtices são então espalhados pela região do gap sem deformações significativas em sua estrutura. A Fig. 2.18 também permite comparar a dinâmica de formação e amplificação de estruturas vorticais nas condições de escoamento turbulento e quasi-laminar instável na cova do eslate.

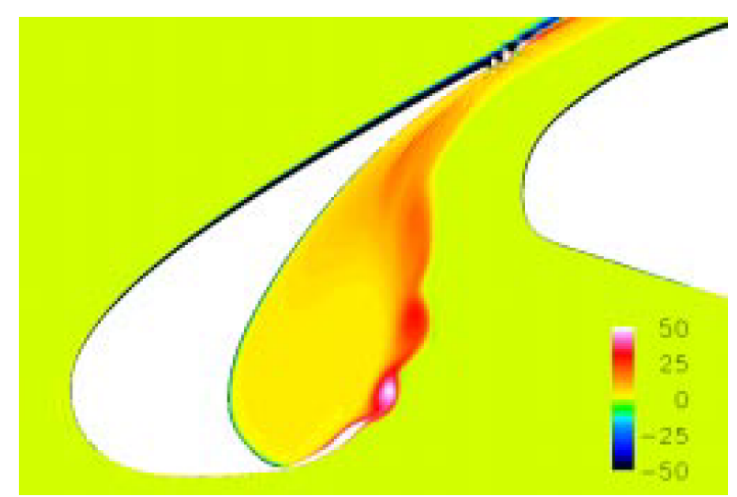

(a) turbulento com $\alpha=8^{\circ}$

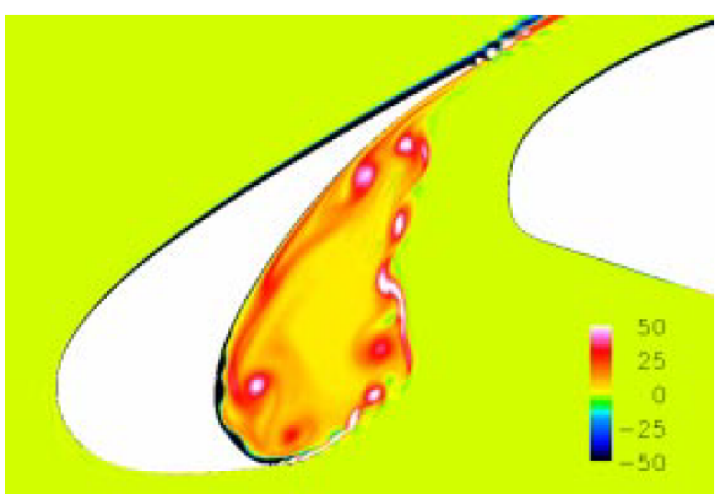

(b) quase-laminar com $\alpha=8^{\circ}$

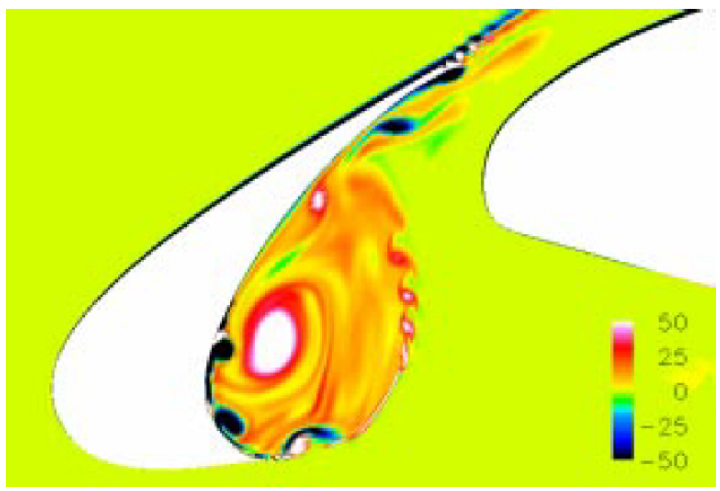

(c) quase-laminar com $\alpha=6^{\circ}$

Figura 2.18: (a) representação do campo de vorticidade instantâneo na cova do eslate com escoamento turbulento para $\alpha=8^{\circ}$. (b) campo de vorticidade instantâneo na cova do eslate com escoamento quasi-laminar para $\alpha=8^{\circ}$ e (c) campo de vorticidade instantâneo na cova do eslate com escoamento quasi-laminar para $\alpha=6^{\circ}$.

Fonte: Khorrami, Singer e Berkman (2002).

Jenkins, Khorrami e Choudhari (2004) utilizaram a técnica de PIV (Particle Image Velocimetry) para estudar a dinâmica do escoamento não-estacionário na cova e no bordo de fuga do eslate em um modelo hiper-sustentador 2D com geometria 30P30N. Os experimentos foram realizados no túnel de vento BART (NASA-Langley Basic Aerodynamics Research Tunnel), no contexto do projeto QAT (Quiet Aircraft Technology Program). Medições foram realizadas para ângulos de incidência de $4^{\circ}, 6^{\circ}$ e $8^{\circ}$, com Reynolds de $3 \times 10^{6}$. Este trabalho precede uma iniciativa de estudos mais sistemáticos envolvendo 
a caracterização do escoamento no elemento eslate de um modelo hiper-sustentador com geometria $30 \mathrm{P} 30 \mathrm{~N}$.

Os resultados mostram: 1) vórtices co-rotativos discretos na camada de mistura originada pela separação da camada limite na cúspide do eslate, 2) o recolamento da camada de mistura na região da cova próxima ao bordo de fuga e 3) uma região de recirculação do escoamento na cova do eslate. Medidas de vorticidade instantânea identificam diferentes estados de instabilidade da camada de mistura na cova do eslate, bem como diferentes regimes de desprendimento de vórtices no bordo de fuga do eslate. Na cova do eslate, após os vórtices serem convectados a partir da cúspide em direção à região de recolamento da camada de mistura, verificam-se situações na quais: 1) alguns vórtices adentram na região de circulação e outros são convectados através do gap do eslate a partir de ponto recolamento, 2) maior quantidade de vórtices fluem através do gap do eslate, intensificando a interação dos vórtices com o bordo de fuga do eslate.

Este estudo também possibilitou a identificação de alguns efeitos do ângulo de incidência do aerofólio sobre o escoamento na cova do eslate. A Fig. 2.19 mostra a variação de posição do ponto de recolamento da camada de mistura para diferentes ângulos de ataque do aerofólio, com a consequente variação no tamanho da região de recirculação na cova do eslate.

Em particular, observou-se que uma redução no ângulo de incidência favorece o estado de escoamento na cova do eslate para o qual se verifica maior aprisionamento de vórtices na região de recirculação.

\subsection{Ruído Tonal de Alta Frequência}

Storms, Hayes e Ross (1994) mostram resultados experimentais e numéricos para um modelo hiper-sustentador 2D com geometria NACA 632-215 e flape em semi-envergadura. Os experimentos foram realizados no túnel de vento Ames Research Center na NASA. Medições aeroacústicas com uma antena de microfones permitem a caracterização do ruído de eslate sob várias condições experimentais e confirmam sua condição de fonte dominante para o modelo em estudo. Os espectros de ruído do eslate mostram a dominância de um ruído tonal de banda-larga com máximo de intensidade localizado ao redor de $\mathrm{St}=2$. As frequências são adimensionalizadas pela velocidade de escoamento no gap do eslate e pela espessura do bordo de fuga do eslate, e os espectros de ruído são normalizados pelo número de Mach com expoente 5. O colapso em Strouhal, para Mach =0,10 e 0,15, indica que os espectros de ruído escalam com o tamanho típico de estruturas turbulentas geradas pelo desprendimento de vórtices no bordo de fuga do eslate. Particular discordância no colapso em Strouhal para Mach $=0.2$ sugere a ação de mecanismos distintos na geração 


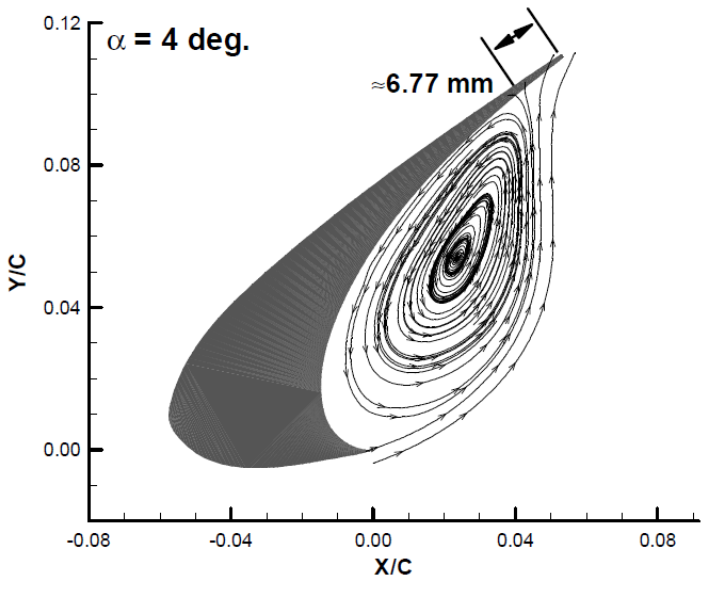

(a) $\alpha=4^{\circ}$

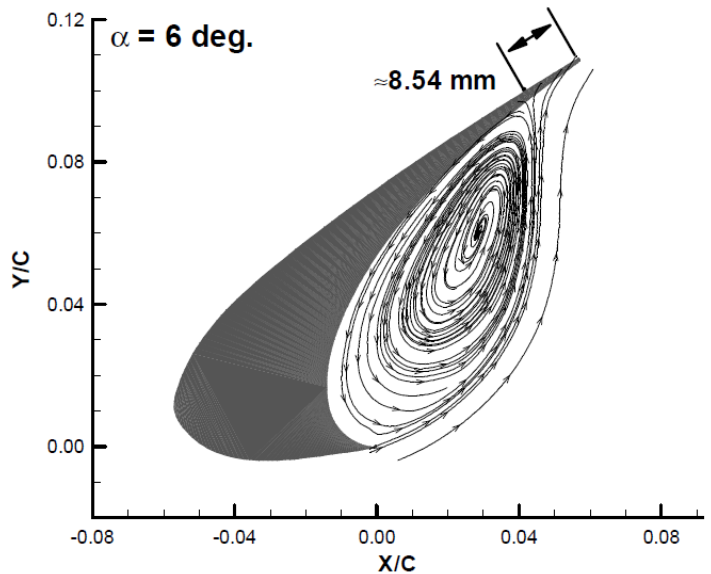

(b) $\alpha=6^{\circ}$

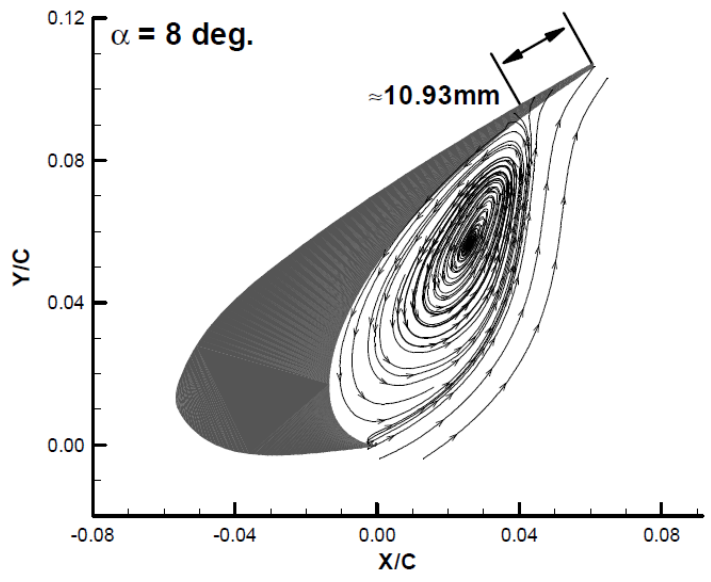

(c) $\alpha=8^{\circ}$

Figura 2.19: Afastamento do ponto médio de recolamento da camada de mistura e achatamento da região de recirculação com o aumento do ângulo de ataque do aerofólio. Em $\alpha=4^{\circ}$ e $\alpha=8^{\circ}$ os pontos de recolamento são estimados a $6.77 \mathrm{~mm}$ e $10.93 \mathrm{~mm}$ da ponta do bordo de fuga do eslate.

Fonte: Jenkins, Khorrami e Choudhari (2004).

do ruído de eslate. Embora o ruído tonal associado ao desprendimento de vórtices no bordo de fuga do eslate seja comumente descrito como um ruído de alta frequência, o resultados experimentais apresentados por Storms, Hayes e Ross (1994) parecem ser um caso de exceção.

Entre os anos de 1998 e 1999, uma série de experimentos acústicos e aerodinâmicos foram realizados no túnel de vento LTPT (Low-Turbulence Pressure Tunnel), localizado no centro de pesquisas da LaRC (NASA Langley Research Center). Os experimentos foram realizados com um perfil hiper-sustentador genérico denominado EET (Energy Efficient Transport). O EET é um modelo de três elementos, cuja corda recolhida era de aproximadamente $10 \%$ da corda aerodinâmica média do aerofólio de um Boing 757 . A análise dos resultados dos experimentos realizados com o modelo EET, referentes ao ruído de eslate, 
fomentaram um série de estudos subsequentes dedicados à investigação dos mecanismos de geração de ruído via simulação computacional.

Choudhari et al. (2002) apresentam resultados de uma extensa campanha de experimentos aerodinâmicos e aeroacústicos realizados com o modelo hiper-sustentador EET, no túnel de vento LTPT. De particular interesse para esta revisão são os resultados decorrentes da campanha de experimentos realizadas em abril de 1988, relativas à caracterização do ruído de eslate. Medições acústicas foram feitas por uma antena de microfones, cuja descrição se encontra no mesmo trabalho. Resultados acústicos mostram que o espectro de ruído do eslate é dominado por ruído de banda larga em baixa e média frequências e por um pico de grande amplitude em alta frequência $(\approx 50 \mathrm{kHz})$, particularmente observado com o eslate defletido em $30^{\circ}$. A Fig. 2.20 apresenta um mapa com a distribuição de fontes no eslate para a frequência de $48.697 \mathrm{~Hz}$, detalhes sobre a geometria do perfil hiper-sustentador EET, e os espectros de ruído obtidos com o eslate defletido em $\delta_{s}=20^{\circ}$ e $30^{\circ}$, na condição $\alpha=10^{\circ}, R e=7.2 \times 10^{6}$ e $M=0.2$.

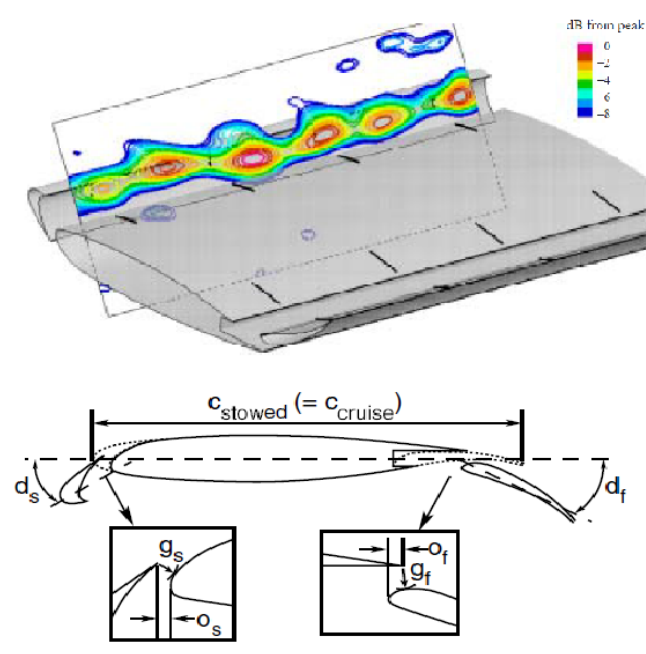

(a) Mapas de fontes e geometria EET

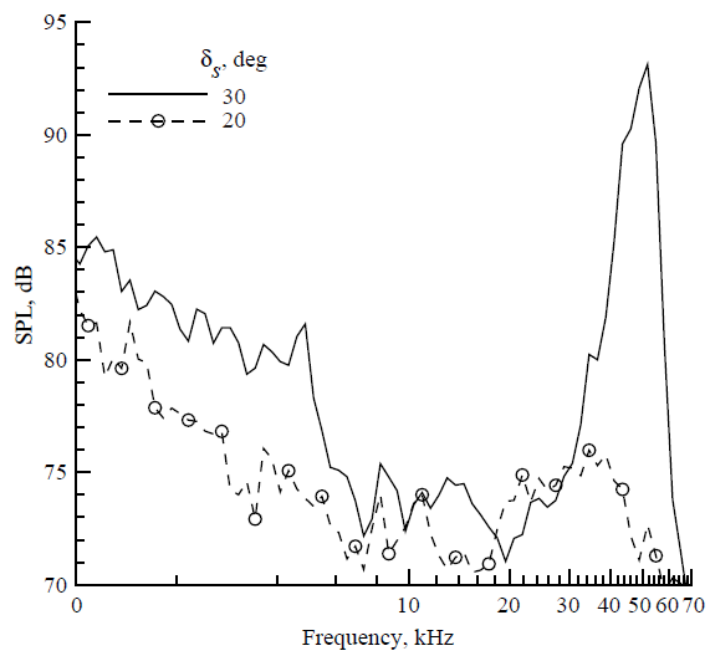

(b) Espectros de ruído para $\delta_{s}=20^{\circ}$ e $\delta_{s}=30^{\circ}$

Figura 2.20: (a) mapa de beam-forming representando a ruído de eslate em $48.697 \mathrm{~Hz}$ e detalhes da geometria do modelo hiper-sustentador EET, (b) espectros de ruído mostrando ruído de banda larga em baixas e médias frequências e um ruído tonal de grande amplitude com pico em $48.697 \mathrm{~Hz}$ para a configuração $\delta_{s}=30^{\circ}$.

Fonte: Choudhari et al. (2002).

Khorrami, Berkman e Choudhari (2000) apresentam resultados de um estudo computacional baseado no método URANS e dedicado a investigar os fenômenos aerodinâmicos que atuam como mecanismos de geração de ruído tonal de alta frequência. As simulações computacionais envolveram o modelo hiper-sustentador EET, com espessuras do bordo de fuga do slat representativas da geometria experimental (0.39 mm e $0.5 \mathrm{~mm})$. Simulações foram realizadas para $M=0,2$ e $R e=7,2 \times 10^{6}$. Os resultados numéricos indicam um in- 
tenso desprendimento de vórtices no bordo de fuga do eslate para a configuração $\delta_{s}=30^{\circ}$ e uma forte supressão dos mecanismos de geração de som para a configuração $\delta_{s}=20^{\circ}$. As frequências de desprendimento de vórtices na configuração $\delta_{s}=30^{\circ}$ mostram-se em boa correspondência com aquelas nas quais observa-se a componente tonal no espectro do ruído experimental do eslate $[40 \mathrm{kHz}-50 \mathrm{kHz}]$. O mecanismo de geração do ruído tonal foi associado a esteira do eslate. Concluiu-se que o perfil da esteira na configuração $\delta_{s}=30^{\circ}$ determina um intenso desprendimento de vórtices associado a um fenômeno de instabilidade absoluta. Na configuração $\delta_{s}=20^{\circ}$, o perfil da esteira no bordo de fuga do eslate torna-se altamente assimétrico e favorece a transição da instabilidade absoluta para a convectiva, que passa a dominar o fenômeno de desprendimento de vórtices e suprime o ruído tonal de alta frequência. A Fig. 2.21 mostra a flutuação instantânea do campo de pressão e vorticidade no bordo de fuga do eslate de um perfil com geometria EET, simulados pelo método URANS.

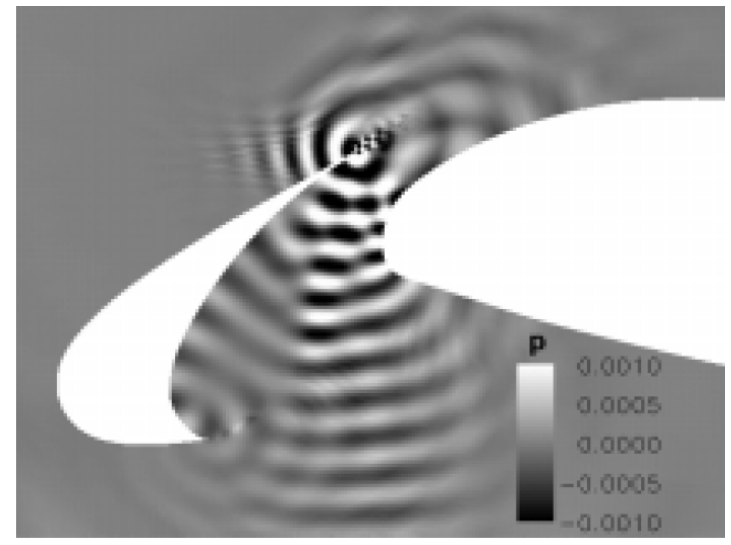

(a) Campo de pressão

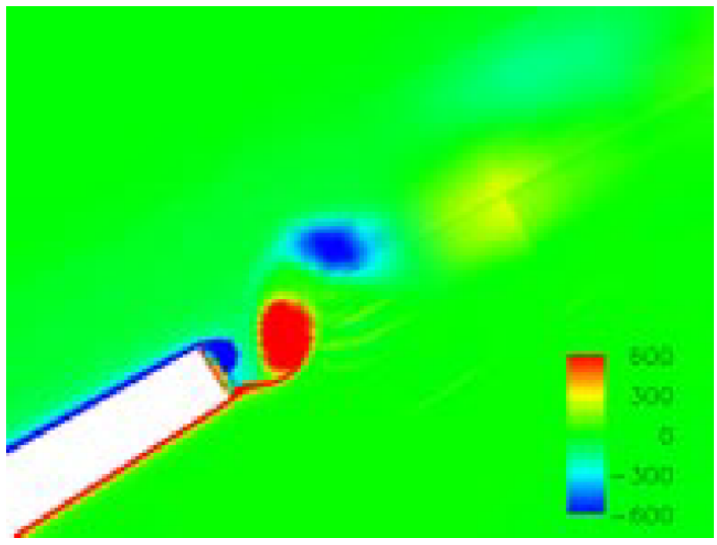

(b) Geração de vórtices

Figura 2.21: (a) flutuação instantânea do campo de pressão e (b) vorticidade no bordo de fuga do eslate mostrando o fenômeno de desprendimento de vórtices.

Fonte: Khorrami, Berkman e Choudhari (2000).

Os resultados apresentados por Khorrami, Berkman e Choudhari (2000) foram decisivos para a determinação da origem do ruído tonal do eslate em alta frequência. Não obstante, o ruído tonal associado ao desprendimento de vórtices no bordo de fuga do eslate é considerado um fenômeno acústico restrito a modelos de teste em escala reduzida. Tal ruído deve-se à dificuldade técnica de se construir modelos em escala cuja relação entre as espessuras do bordo de fuga do eslate e da camada limite local seja representativa daquela verificada para aerofólios reais sob condições operacionais. 


\subsection{Configurações Geométricas e o Ruído de Eslate}

Alguns estudos têm focado na investigação da dependência do ruído de eslate em relação à configuração geométrica determinada pelos valores de gap e overlap e deflexão do eslate em relação ao elemento principal do aerofólio. O objetivo destes estudos é avaliar possíveis configurações operacionais de um aerofólio que correspondam à emissões mínimas de ruído. No entanto, a configuração afeta o desempenho acústico de um aerofólio, assim com o desempenho aerodinâmico, e ambas devem ser avaliadas em conjunto.

Os resultados apresentados por Olson, Thomas e Nelson (2000) para um aerofólio 2D com elemento principal e eslate indicam a ocorrência de mecanismos de geração de ruído associados com fenômenos de desprendimento de vórtices e mecanismos de ressonância auto-sustentáveis. No entanto, a supressão ou majoração destes mecanismos de geração se mostram fortemente dependentes dos valores de gap, overlap e deflexão do eslate em relação ao elemento principal do aerofólio.

Pott-Pollenske, Alvarez e Dobrzynski (2003) estudou o efeito de variações na largura do gap sobre o ruído de eslate. Os experimentos foram realizados no Aeroacoustic Wind Tunnel Braunschweig (AWB), utilizando como modelo de testes um aerofólio hiper-sustentador 2D em escala 1:6, com flape em semi-envergadura. Medições acústicas e aerodinâmicas foram realizadas com o aerofólio em ângulo de incidência nominal de zero grau e velocidade de escoamento livre de $50 \mathrm{~m} / \mathrm{s}$. Nestas condições experimentais, o espectro acústico do eslate é dominado por ruído de banda larga. Os resultados mostram que reduções de $9 \%$ e $15 \%$ na largura do gap do eslate, em relação ao valor adotado como referência, resultam reduções de até 7 dB e 10 dB no nível do ruído de banda larga, respectivamente. A redução de $10 \mathrm{~dB}$ no ruído do eslate é acompanhada por uma redução de até $4 \%$ no coeficiente de máxima sustentação do aerofólio.

Guo e Joshi (2003) mostram que variações no nível de ruído decorrentes de variações no ângulo de deflexão do flape em uma asa Mcdonnell Douglas DC-10-30 em escala 4.7 (trem de pouso recolhido) são dependentes do ângulo de deflexão do eslate. Na condição $\delta_{s}=0$ (eslate recolhido), verificou-se aumento no nível de ruído com a deflexão do flape em ampla faixa de frequência e uma tendência de aumento do nível de ruído com a frequência. Na condição $\delta_{s}=20$, aumentos no nível de ruído decorrentes do aumento na deflexão do flape foram restritos à frequências acima de $10 \mathrm{kHz}$. Comparações de resultados para as condições $\delta_{s}=0$ e $\delta_{s}=20$ mostram que o aumento do nível de ruído com o ângulo de deflexão do eslate foi restrito à faixa média de frequência e independente do ângulo de deflexão do flape $\left(\delta_{f}=35\right.$ ou $\left.\delta_{f}=50\right)$. Exceção foi verificada para o caso $\delta_{f}=25$, no qual o aumento na deflexão do eslate foi significativo para o aumento do nível de ruído em alta frequência, devido ao baixo nível de emissão acústica na região do flape em condição de baixo ângulo de deflexão. Tal fato chama atenção para a importância do ruído de eslate 
em modelos de aeronaves com sistemas de flape simples que operam em baixo ângulo de deflexão. Resultados quantitativos obtidos com uma antena de microfones para a configuração $\delta_{s}=20$ e $\delta_{f}=50$ mostraram-se consistentes com aqueles obtidos a partir de microfones em campo distante, indicando domínio do ruído de eslate em baixa e média frequências e de ruído de ponta de flape em alta frequência.

Mendoza, Brooks e Humphreys (2002) apresentam medições aeroacústicas e aerodinâmicas realizadas em um túnel de vento anecoico de seção aberta QFF (Quiet Flow Facility) com um modelo de testes 2D com geometria NACA 632-215 contendo elemento principal e eslate. Uma antena móvel tipo SADA (Small Aperture Directional Array) foi utilizada para medições polares focando diferentes posições ao longo da corda do modelo de testes. Os espectros de ruído do eslate mostram a dominância de ruído de banda larga em baixas e médias frequências e de ruído tonal em alta frequência. Resultados obtidos a partir de variações de parâmetros geométricos do aerofólio mostram que variações no ângulo de deflexão do eslate impactam sobre o ruído tonal de alta frequência, enquanto que variações na razão gap/overlap impactam sobre o ruído puro de banda larga, particularmente abaixo de $10 \mathrm{kHz}$. Sob ângulo de incidência fixo, um aumento no ângulo de deflexão do eslate ocasiona um aumento no nível de ruído tonal e um ligeiro deslocamento do pico de amplitude para frequências mais altas. É verificado que o aumento no nível do ruído tonal coincide com o aumento da velocidade de escoamento através do gap do eslate.

\subsection{Considerações Gerais}

Esta revisão bibliográfica representa uma amostragem abrangente dos trabalhos que embasam vários temas de pesquisa voltados à identificação e caracterização do ruído aerodinâmico de eslate. Os resultados sugerem que há uma grande dependência do ruído aerodinâmico de eslate em relação às condições experimentais e à configuração geométrica do modelo de testes.

Atualmente, poucos experimentos aeroacústicos têm sido realizados em túnel de vento de seção fechada, o que em grande parte se deve ao ceticismo sobre a qualidade destes experimentos. Desta forma, há uma base de dados escassa sobre ruído de eslate que permita a reprodução dos resultados experimentais com base em métodos numéricos e a posterior comparação entre resultados.

Experimentos com modelos em escala mostram a ocorrência de ruído tonal. O ruído tonal de baixa frequência ocorre para modelos 2D e 3D e tem sido associado à condição de baixo Reynolds. É interessante notar que Dobrzynski et al. (1998) suprimiu picos tonais forçando a transição da camada limite a montante da cúspide do eslate para um modelo 3D 
(enflexado e afilado), em experimento realizado com Reynolds de 1 milhão. No entanto, Imamura et al. (2009) e Kolb et al. (2007) não obtiveram sucesso na supressão dos picos tonais induzindo a transição da camada limite do eslate em modelos sem afilamento e enflexamento, embora os experimentos tenham sido realizados sob Reynolds de 2 milhões e 1,4 milhões, respectivamente.

Estudos para a identificação dos mecanismos de geração do ruído de banda larga têm se baseado no uso de técnicas experimentais não intrusivas para medição de flutuações de pressão em campo próximo e simulação computacional do campo de escoamento que se desenvolve na cova e no gap do eslate. Neste segmento, a comparação entre resultados experimentais e numéricos parece ser uma via natural de validação, o que reforça a necessidade por medições aeroacústicas em túneis de vento de seção fechada.

A dependência do ruído de eslate em relação à configuração geométrica do aerofólio tem sido pouco investigada e os resultados são de difícil generalização devido às diferentes geometrias dos modelos utilizados. Em particular, os trabalhos encontrados não discutem o efeito da geometria do aerofólio sobre o ruído tonal de baixa frequência, cuja importância tem se mostrado crescente no contexto da aeroacústica de eslate para modelos em escala. Neste segmento, o presente trabalho representa uma contribuição.

O perfil hiper-sustentador 30P30N tem sido caracterizado do ponto de vista aerodinâmico. Estudos recentes têm abordado o problema da geração de ruído em um perfil hiper-sustentador 30P30P a partir de um enfoque predominantemente computacional. No entanto, torna-se evidente, a partir de uma revisão bibliográfica, a escassez de estudos experimentais voltados à caracterização do ruído de eslate para esta geometria. 
CAPÍTULO 3

\section{Aparato e Procedimentos Experimentais}

\subsection{Descrição do Túnel de Vento Utilizado}

O túnel de vento LAE-1 integra o Laboratório de Aerodinâmica da Escola de Engenharia de São Carlos (LAE). Este túnel entrou em funcionamento no ano de 2002 e, desde então, vem sendo utilizado predominantemente para ensaios aerodinâmicos com modelos e dispositivos aeronáuticos. Esta seção apresenta uma descrição básica sobre aspectos técnicos do túnel de vento LAE-1, no qual foram realizados os experimentos aeroacústicos que são objeto de estudo nesta tese. A Fig. 3.1 mostra uma vista superior do túnel de vento LAE-1.

Este túnel de vento possui razão de contração de 1:8, que é definida como a razão entre a menor e a maior área de seção transversal ao longo do circuito do túnel. Neste caso, a razão de contração é dada pela razão entre as áreas de seção da câmara de ensaios e da câmara de estabilização. A câmara de ensaios possui $1.30 \mathrm{~m}$ de altura (vertical) na parte central, $1.70 \mathrm{~m}$ de largura e $3 \mathrm{~m}$ de comprimento (direção do escoamento). O túnel de vento LAE-1 conta com um ventilador axial de oito pás, impulsionado por um motor elétrico de $110 \mathrm{Hp}$, acionado por meio de um controlador digital. Quatro guias de curva atuam na redução da perda de carga e uniformização do escoamento ao longo do circuito do túnel de vento. A câmara de ensaios possui uma parede lateral de acrílico que funciona como uma porta basculante, facilitando o acesso do modelo de teste ao seu interior. Furos de ventilação laterais tentam equalizar a pressão na câmara de ensaios à pressão atmosférica na câmara externa, que também tem a função de isolar acusticamente 


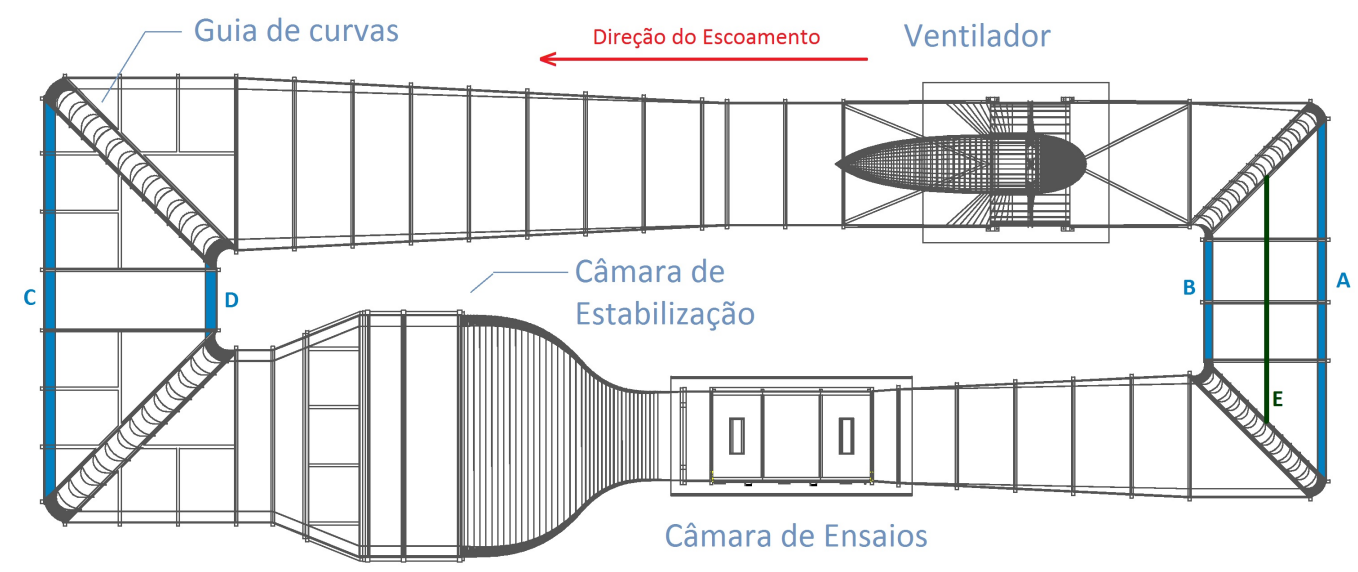

Figura 3.1: Desenho esquemático do túnel de vento LAE-1 com alguns detalhes de projeto. As letras de $\mathrm{A}$ até $\mathrm{E}$ indicam os locais onde foram realizados tratamento acústico.

o local de medições. O túnel possui apenas uma tela localizada no difusor de grande ângulo da câmara de estabilização, e não possui colmeia.

\subsubsection{Tratamento Acústico do Túnel de Vento LAE-1}

A capacitação do túnel de vento LAE-1 para a realização de experimentos aeroacústicos representou a primeira etapa das atividades práticas do projeto Aeronave Silenciosa junto à Escola de Engenharia de São Carlos (DANTAS, 2010). A metodologia adotada observou alguns procedimentos até então realizados com êxito em túneis de vento de seção fechada, e cumpriu o objetivo de reduzir o ruído de fundo do túnel de vento sem alterar significativamente as suas características aerodinâmicas originais.

A primeira etapa no processo de tratamento acústico do túnel de vento LAE-1 consistiu na instalação de espumas de melanina recobertas por um filme de poliuretano, com objetivo de absorção de ondas acústicas. Espumas com $2 \mathrm{~cm}\left(13.5 \mathrm{~m}^{2}\right.$ de área instalada nas paredes A e B) e $5 \mathrm{~cm}$ de espessura ( $18 \mathrm{~m}^{2}$ de área instalada nas paredes C e D) foram instaladas, conforme representado na Fig. 3.1. A segunda etapa da capacitação consistiu basicamente da instalação de um "abafador acústico"entre as paredes A e B (linha E na Fig. 3.1), bem como no tratamento acústico do ventilador.

O abafador acústico utilizou como material base placas de Eucatex com $3.5 \mathrm{~cm}$ de espessura, comumente empregadas como divisória de ambientes. Na superfície das placas foram feitos furos circulares com $80 \mathrm{~mm}$ de diâmetro. Como resultado, expôs-se a camada interna de lã de vidro na proporção aproximada de $62 \%$ da superfície total das placas, com objetivo de aumentar a sua capacidade de absorção acústica. As placas foram então 
recobertas por uma lâmina de espuma de poliuretano com $1 \mathrm{~cm}$ de espessura, de forma a tornar as superfícies de contato com o fluxo de ar suficientemente lisas para minimizar efeitos de geração de turbulência.

O tratamento acústico do ventilador consistiu em 1) revestimento interno da carenagem (spinner) dianteira por uma espuma de poliuretano com $2 \mathrm{~cm}$ de espessura (o spinner possui formato elíptico e permanece estático quando o ventilador se encontra operante), 2) revestimento parcial da parte interna da carenagem traseira do ventilador e 3) aplicação de espumas e isopor nas paredes do túnel adjacentes às pás do ventilador, de forma a reduzir e uniformizar a folga livre entre a parede e as pás.

A eficácia do tratamento acústico realizado no túnel de vento LAE-1 foi avaliada com base na redução dos níveis de ruído de fundo após diferentes etapas do tratamento acústico. As medições de ruído de fundo foram feitas com microfones imersos no escoamento e posicionados na parte central da câmara de ensaios, por meio de uma haste vertical. Naturalmente, tais medidas requerem que a câmara de ensaios esteja totalmente vazia, e devem ser realizadas de forma a verificar a dependência do ruído de fundo com a velocidade de operação do túnel.

Como resultado do tratamento acústico, verificou-se que a instalação de espumas nas câmaras não difusoras resultou em uma redução do nível de ruído de aproximadamente 3 dB para frequências até $2 \mathrm{kHz}$, com reduções mais discretas para frequências mais altas. A instalação do abafador acústico e o tratamento do ventilador contribuíram para uma redução adicional no nível de ruído em frequências acima de $3 \mathrm{kHz}$, com desempenho particularmente notável (redução em torno de $3 \mathrm{~dB}$ ) para a banda de frequência de $3 \mathrm{kHz}$ até $10 \mathrm{kHz}$ (DANTAS, 2010).

Embora medições de ruído de fundo com microfones imersos no escoamento seja uma prática adotada para avaliar os efeitos do tratamento acústico em túneis de vento, vale ressaltar que tais medidas não representam o ruído residual em uma medição com arrays ${ }^{1}$ de microfones. Microfones posicionados na parede de um túnel de vento têm suas membranas expostas ao efeito da camada limite turbulenta. Medições com microfones imersos no escoamento, por sua vez, podem ser afetadas pelo ruído gerado devido a contato do ar com o suporte ou o próprio corpo do microfone (MUELLER, 2002).

\subsection{Descrição do Perfil Hiper-Sustentador}

O aerofólio hiper-sustentador utilizado nas medições acústicas e aerodinâmicas corresponde ao modelo MacDonnell Douglas (MDA-30P30N). Este modelo é também de-

\footnotetext{
${ }^{1} \mathrm{O}$ termo array é de uso comum na literatura de aeroacústica experimental para designar uma rede de sensores, em analogia a uma antena de microfones
} 
nominado 30P30N, devido à sua configuração de referência com flape e eslate defletidos em $30^{\circ}$ com relação à corda do aerofólio. O modelo utilizado possui geometria 2D (sem enflexamento e afilamento), e é composto por três elementos; elemento principal, flape e eslate. A aerodinâmica do perfil hiper-sustentador 30P30N encontra-se bem documentada na literatura; (CHIN et al., 1993; KLAUSMEYER; LIN, 1997; RUMSEY; LEE-RAUSCH; WATSON, 2003; ROGERS et al., 1994).

Os seguintes parâmetros determinam a configuração geométrica de um aerofólio hipersustentador: 1) deflexão do eslate (flape) em relação à linha da corda do aerofólio, 2) gap e overlap do eslate (flape) em relação ao elemento principal do aerofólio, dados como porcentagem da corda recolhida do aerofólio (corda do aerofólio com eslate e flape recolhidos). A tabela 2.1 mostra os valores adotados para os ângulos de deflexão, gap e overlap dos elementos eslate e flape, com o aerofólio em configuração de referência. As cordas dos elementos eslate e flape representam $15 \%$ e $30 \%$ da corda recolhida do aerofólio, respectivamente.

Tabela 3.1: Configuração geométrica do aerofólio 30P30N

\begin{tabular}{|c|c|c|c|c|}
\cline { 2 - 5 } \multicolumn{1}{c|}{} & deflexão & gap & overlap & corda \\
\hline eslate & $30^{\circ}$ & $2,95 \%$ & $-2,50 \%$ & $15 \%$ \\
\hline flape & $30^{\circ}$ & $1,27 \%$ & $0,25 \%$ & $30 \%$ \\
\hline
\end{tabular}

A configuração geométrica descrita na tabela 2.1 será referida ao longo deste trabalho como configuração de referência do aerofólio, ou configuração baseline. A Fig. 3.2 representa a secção transversal do aerofólio com os elementos flape e eslate em configuração de referência. A configuração com eslate e flape recolhidos também é apresentada.

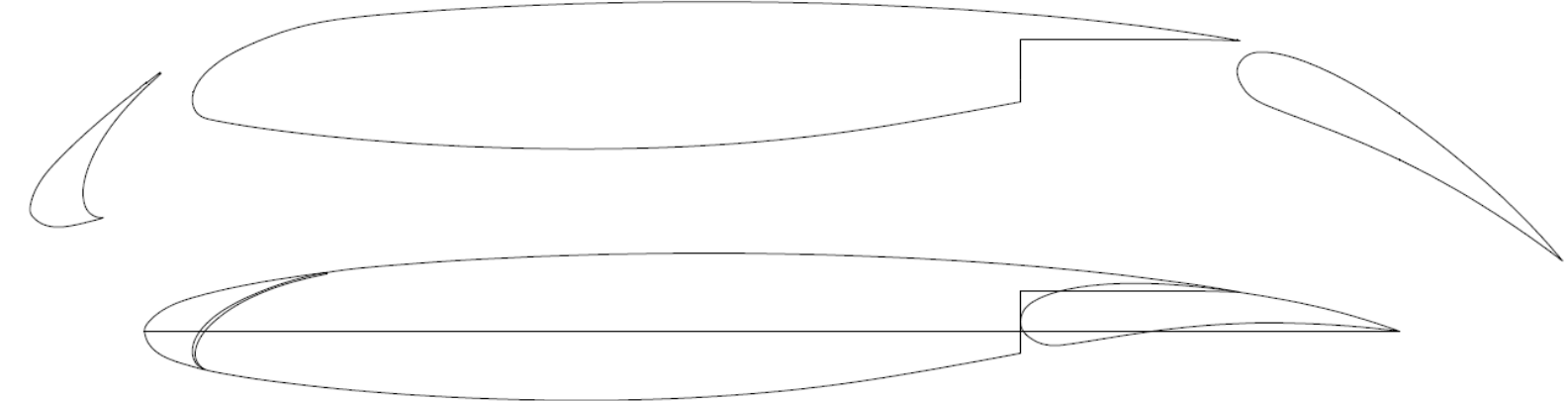

Figura 3.2: Representação do aerofólio em configuração de referência (acima) e recolhida (abaixo). Na parte dianteira, à esquerda do elemento principal, encontra-se o eslate. Na parte traseira, encontra-se o flape.

A Fig. 3.3 representa esquematicamente a definição dos parâmetros de configuração geométrica gap, overlap e deflexão para o elemento eslate, com o aerofólio em configuração de referência e ângulo de ataque de $0^{\circ}$. 


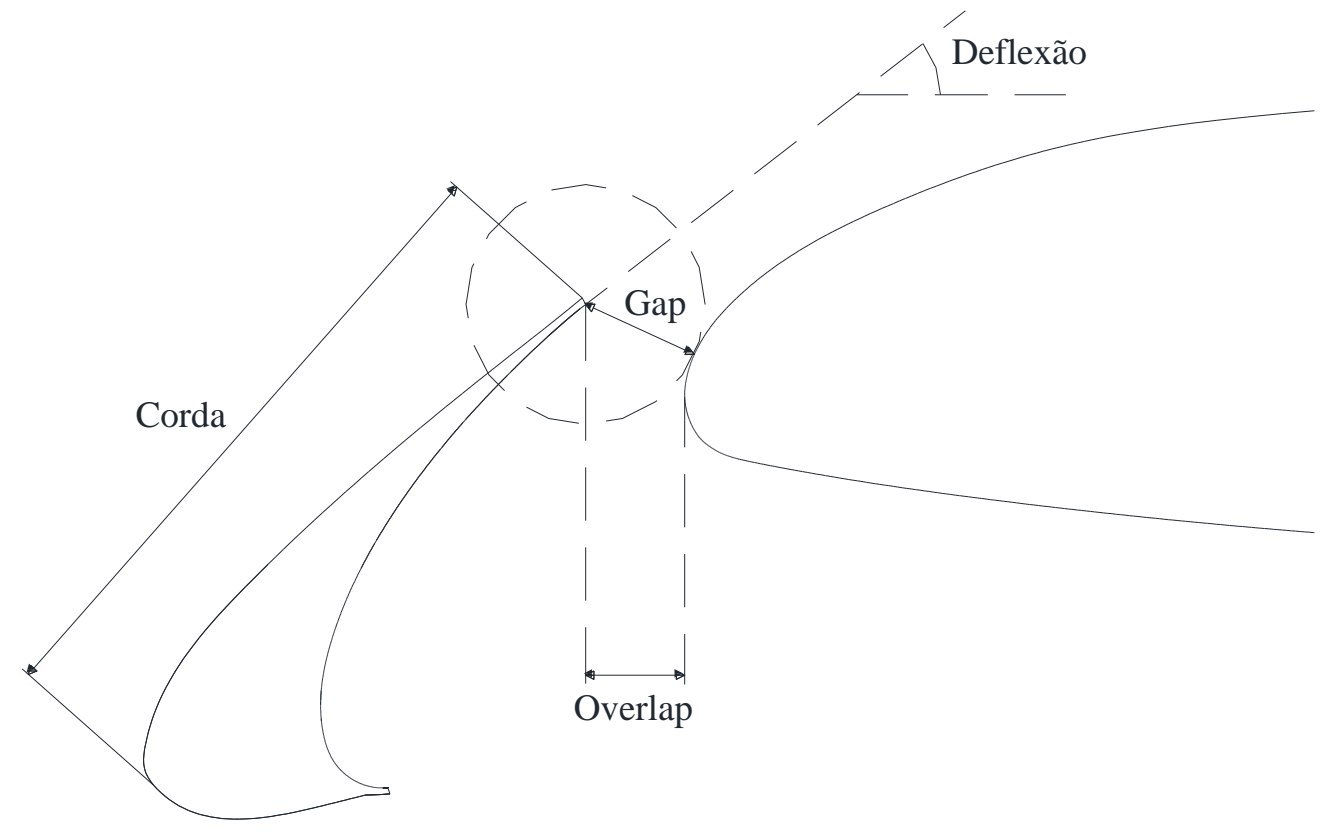

Figura 3.3: Representação esquemática dos parâmetros gap, overlap e deflexão do elemento eslate, com o aerofólio hiper-sustentador em sua configuração geométrica de referência.

De acordo com as definições apresentadas na Fig. 3.3, o gap é a menor distância entre o bordo de fuga do eslate e a superfície do elemento principal, o overlap é dado pela distância entre o bordo de fuga do eslate e o bordo de ataque do elemento principal, medida na direção da corda do aerofólio, e a deflexão é o ângulo de ataque do eslate em relação à orientação da corda do aerofólio.

\subsubsection{Fabricação e Instrumentação do Aerofólio 30P30N}

O aerofólio 30P30N foi construído em liga de alumínio, tendo dimensões de $0.50 \mathrm{~m}$ (corda recolhida) e $1.30 \mathrm{~m}$ (envergadura). Os elementos eslate e flape são presos ao elemento principal pelo uso de quatro suportes de fixação. Alguns estudos mostram que os suportes podem representar uma importante fonte de ruído aerodinâmico (POTTPOLLENSKE; DELFS; REICHENBERGER, 2013). No presente estudo, não foram observados efeitos significativos dos suportes sobre o ruído característico do eslate. A Fig. 3.4 mostra detalhes de projeto da superfície de sucção do aerofólio (intradorso), na qual estão instalados os suportes de fixação.

O aerofólio foi instrumentado de forma a permitir tomadas de pressão estática ao longo de sua corda, através de uma linha de orifícios no ponto médio da envergadura. As medições de pressão no eslate e no flape foram feitas através de peças de prototipagem acopladas. Duas linhas de orifícios dispostas verticalmente, uma na região do bordo de ataque e outra na região do bordo de fuga do elemento principal, permitem a medição 

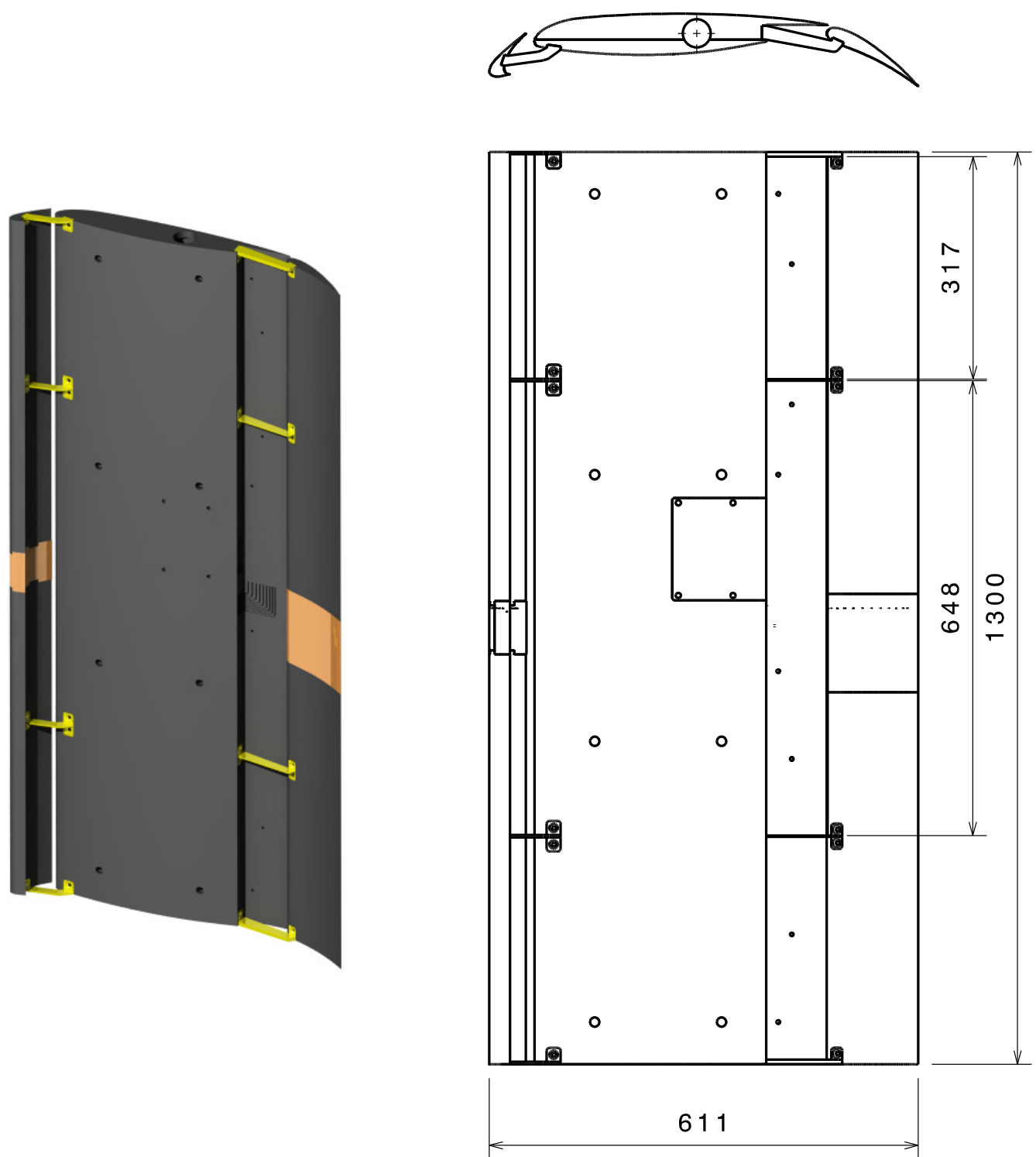

Figura 3.4: Detalhes do intradorso do aerofólio 30P30N. Na vista em perspectiva, à esquerda, estão representadas as peças de prototipagem (em alaranjado) na parte central e os suportes de fixação (em amarelo) do eslate (à esquerda) e do flape (à direita). Na vista do intradorso do aerofólio, à direita, estão representadas a posição e as distâncias entre os suportes, bem como a corda do aerofólio estendido; 611. Dimensões em mm.

de pressão estática ao longo da envergadura do aerofólio. No total, ao longo da corda do aerofólio, são 110 pontos de tomada de pressão no elemento principal, 27 no eslate e 27 no flape. Ao longo da envergadura, são 21 pontos de tomada de pressão na região do bordo de ataque e 21 na região do bordo de fuga. Medidas de pressão ao longo da corda são necessárias para a determinação dos coeficientes de sustentação e arrasto do aerofólio, nas condições do experimento. Por outro lado, tomadas de pressão ao longo da envergadura do aerofólio representam uma medida do quão uniforme na direção da envergadura é a distribuição de pressão superficial induzida pelo escoamento circundante. A Fig. 3.5 ilustra a instrumentação do aerofólio 30P30N, com a instalação de tubos para 
a medição de pressão estática na superfície do aerofólio.

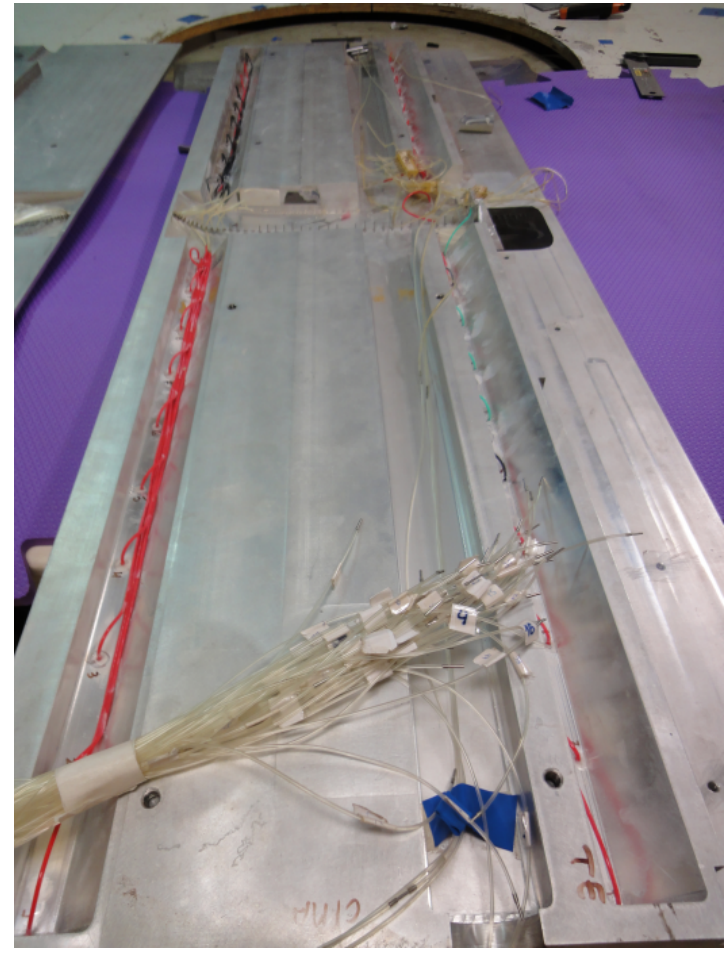

(a)

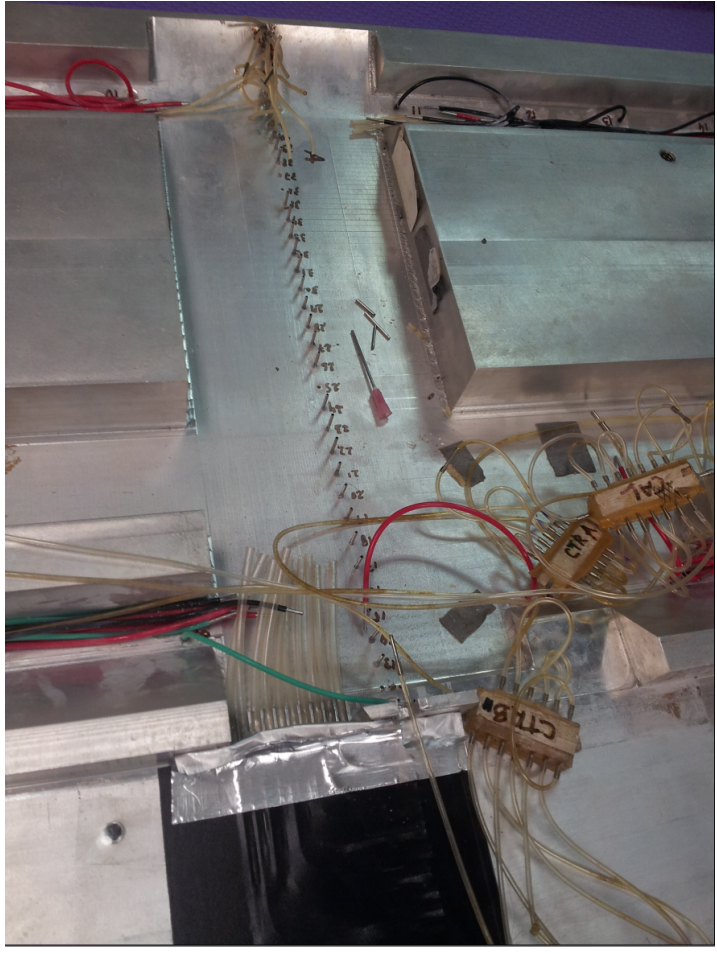

(b)

Figura 3.5: Vista interior do modelo 30P30P durante a instalação de pequenos tubos para medida de pressão: (a) ao longo da envergadura e (b) ao longo da corda do aerofólio.

\subsection{Posicionamento do Aerofólio na Câmara de En- saios}

O aerofólio é fixado verticalmente à mesas giratórias horizontais (turntable) para medições aerodinâmicas/aeroacústicas na câmara de ensaios do túnel de vento LAE-1. A mesa horizontal inferior permite o uso de um dispositivo mecânico para ajustes no ângulo de incidência geométrico do aerofólio. Posicionado desta forma, o aerofólio ocupa toda a extensão vertical da câmara de ensaios $(\approx 1,30 \mathrm{~m})$. As mesas giratórias possuem diâmetro aproximado de $0.80 \mathrm{~m}$, e o centro das mesmas encontra-se à $0.85 \mathrm{~m}$ da parede na qual está instalada a antena de microfones. Nas partes centrais de cada mesa giratória há uma conexão cilíndrica que permite a fixação do aerofólio e a passagem de dutos para medidas de pressão estática na superfície do aerofólio.

$\mathrm{Na}$ parte central de cada mesa giratória há uma região retangular com dimensões de $0.165 \mathrm{~m}$ em largura e $0.575 \mathrm{~m}$ em comprimento, totalmente recoberta por uma chapa de aço inoxidável regularmente perfurada com orifícios circulares. A aplicação de sucção para o controle da camada limite da parede é feita através de uma faixa estreita e contínua ao 
longo de todo o extradorso do elemento principal e parte do flape, bem como na parte frontal do eslate.

A Fig. 3.6 mostra detalhes do posicionamento do aerofólio na câmara de ensaios do túnel de vento LAE-1. A Fig. 3.6(a) mostra o extradorso do perfil hiper-sustentador, com destaque para o eslate posicionado na parte frontal do aerofólio. Também é possível observar o posicionamento do aerofólio à montante da antena de microfones, as mesas circulares que sustentam o aerofólio e a placa porosa para sucção da camada limite na junção entre a truntable e o aerofólio. A Fig. 3.6(b) mostra detalhes do intradorso do perfil hiper-sustentador, podendo-se observar os suportes de fixação do flape e do eslate e as peças de prototipagem para tomada de pressão estática na parte central da envergadura do flape e do eslate.

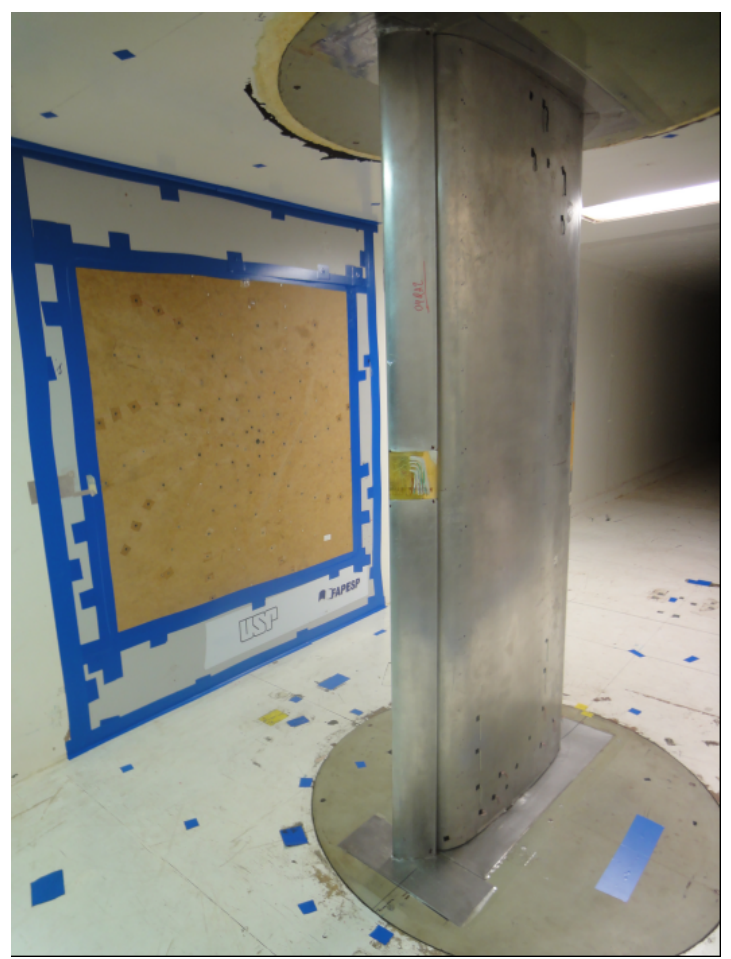

(a) Vista parical do extradorso

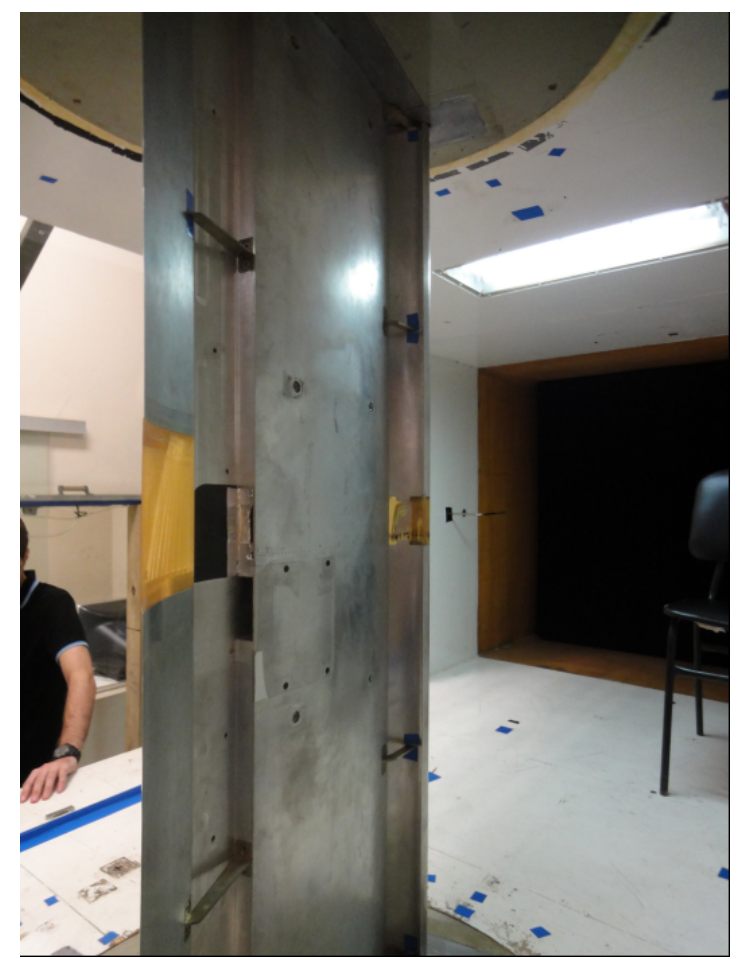

(b) Vista parcial do intradorso

Figura 3.6: Posicionamento do perfil hiper-sustentador 30P30N na câmara de ensaios do túnel de vento LAE-1: (a) vista parcial do extradorso do perfil a partir de uma posição à montante do aerofólio e (b) vista parcial do intradorso a partir de uma posição à jusante. 


\subsection{Referenciamento de Posição do Aerofólio em Re- lação à Antena de Microfones}

A representação de uma distribuição de fontes na forma de um mapa de beam-forming tem por objetivo situar as fontes em relação às regiões nas quais ocorrem mecanismos de geração/emissão de ruído aerodinâmico, que supostamente são determinados pela interação entre partes de um modelo de testes e o escoamento. Para que tal associação seja possível, é necessário representar as coordenadas dos pontos de mapeamento de fontes e do modelo de testes em relação a um sistema de referência em comum. O sistema de referência geralmente adotado é aquele em relação ao qual estão determinadas as coordenadas dos microfones, chamado aqui de sistema de coordenadas da antena, e que é fixo em relação ao túnel de vento.

As coordenadas dos pontos da malha usada para o mapeamento espacial de fontes são definidas em relação ao sistema de referência da antena. Para que a correspondência entre as posições das fontes e cada parte do modelo de testes seja possível, é necessário que a posição do modelo seja determinada em relação ao sistema de referência da antena, o que requer o uso de um método adequado de referenciamento espacial. Desta forma, a incerteza no posicionamento das fontes em relação a um ponto de referência sobre o modelo de testes é determinada pelo erro inerente o processo de medida da posição do modelo em relação à antena. Neste trabalho, o nível de ruído gerado pelo eslate é determinado pela integração de valores discretos de pressão sonora associados aos pontos da malha do mapa de beam-forming que correspondem à posição física do eslate. Este procedimento permite estimar a contribuição relativa, entre partes distintas do modelo, para a determinação do ruído total.

Neste trabalho, o posicionamento do aerofólio em relação ao sistema de referência da antena é determinado pelo uso do sistema de referenciamento Leica Nova MS50 MultiStation. Este sistema gera uma nuvem de pontos que representa a discretização espacial do objeto sob referenciamento. As coordenadas de cada ponto na nuvem são determinadas em relação a um conjunto de pontos de controle, com coordenadas conhecidas em relação ao sistema de referência da antena.

A Fig. 3.7 representa o processo de escaneamento 3D a laser com o sensor MS50 e a reconstrução do perfil hiper-sustentador em termos de uma nuvem de pontos. Este resultado foi obtido pelo método conhecido como estação livre, que usa as coordenadas da nuvem de pontos mapeada em um primeiro estágio (posicionamento) para recalcular a posição da estação em um segundo estágio do mapeamento. Tal estratégia foi adotada como forma de mapear completamente o extradorso do perfil hiper-sustentador, em um ambiente com restrições para o posicionamento adequado do sensor de escaneamento. $\mathrm{O}$ 
modo de medição utilizado foi a varredura a $1000 \mathrm{~Hz}$, que de acordo com as especificações técnicas do fabricante proporciona uma precisão de posicionamento de $0.8 \mathrm{~mm}$.

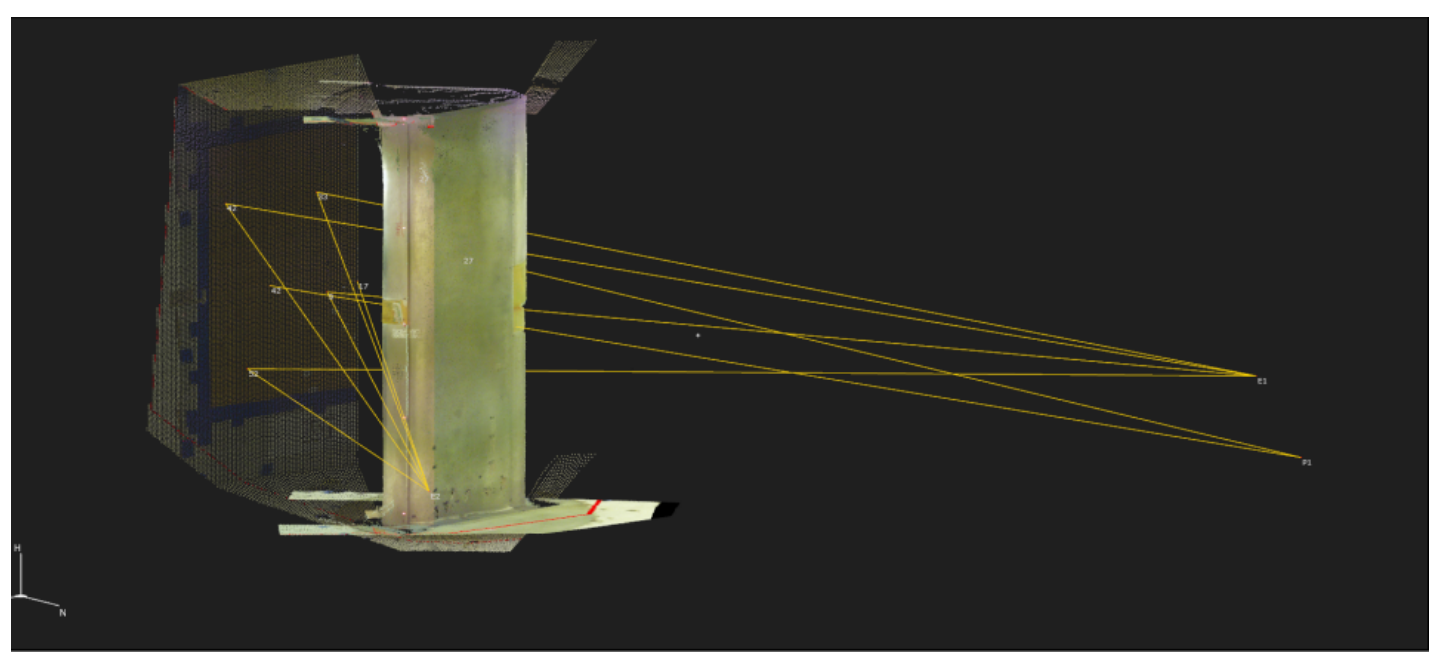

Figura 3.7: Imagem gerada pelo instrumento de medição Leica Nova MS50 MultiStation. O feixe de linhas representado na figura liga pontos de observação (posicionamento do aparelho de medição) às posições de alguns microfones na antena. As posições dos microfones são consideradas como pontos de referência, ou controle, cujas coordenadas são previamente conhecidas em relação ao sistema de referência da antena.

A Fig. 3.8 representa a posição do aerofólio em relação à antena de microfones, conforme determinada pelo sistema de referenciamento utilizado. Também encontra-se representada a projeção do eslate sobre a antena de microfones. O aerofólio está representado com ângulo de ataque de zero graus, em configuração de referência.

Como resultado do referenciamento, o bordo de fuga do eslate se encontra $0.313 \mathrm{~m}$ distante do centro geométrico da antena. Com o aerofólio em ângulo de ataque de $4^{\circ}$ e o eslate defletido em $30^{\circ}$, a corda do eslate projetada sobre antena é $0.0560 \mathrm{~m}$. As coordenadas do aerofólio em relação ao sistema de referência da antena, obtidas pelo uso do sensor de escaneamento Leica Nova MS50 MultiStation, foram utilizadas para representar a posição do elemento eslate nos mapas de beam-forming apresentados no capítulo 6. 


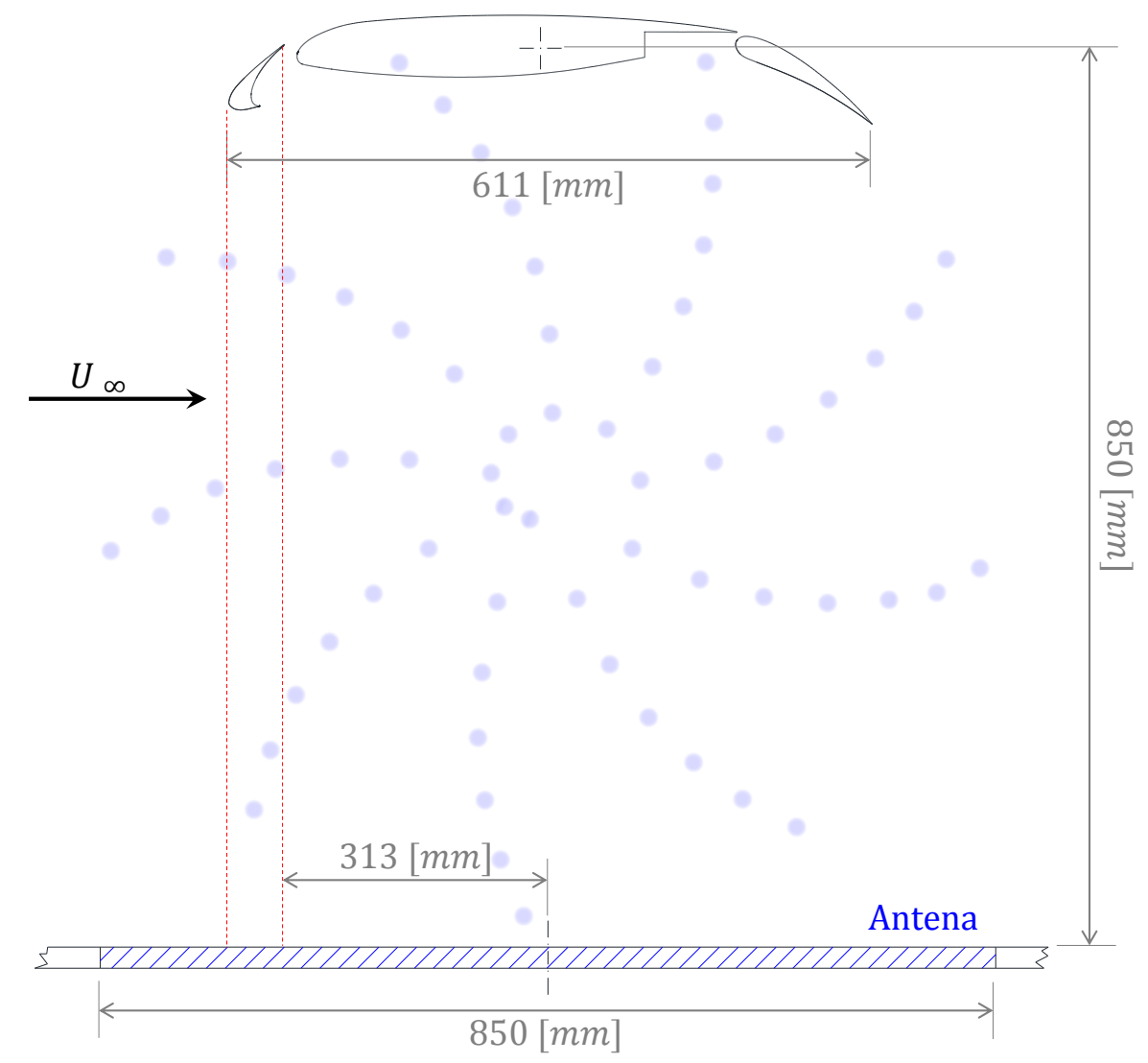

Figura 3.8: Posição do aerofólio em relação ao sistema de referência da antena e dimensões típicas. A antena está projetada ao fundo para representar a sua dimensão em relação ao aerofólio e à distância relativa entre ambos. A figura representa o ponto de vista de um observador que verifica o escoamento da esquerda para a direita.

\subsubsection{Diretividade do Ruído de Eslate}

Análises de dados experimentais por Dobrzynski e Pott-Pollenske (2001), Mendoza, Brooks e Humphreys (2002), Kolb et al. (2007), resultados com modelos semi-empíricos por Guo (2010) e simulação computacional com modelos numéricos por Guo (2001), Khorrami, Singer e Berkman (2002), Choudhari et al. (2002), têm demonstrado que a diretividade polar do ruído de eslate, conforme medido por um observador em solo na tragetória de voo, é caracterizada por emissão perpendicular à corda, em direção à parte traseira da aeronave. Dobrzynski e Pott-Pollenske (2001) propõem um modelo de emissão para explicar a diretividade do ruído de eslate, que é baseado em um dipolo compacto posicionado no bordo de fuga, com eixo de emissão normal à direção da corda, conforme a Fig 3.9.

Os resultados apresentados por Dobrzynski e Pott-Pollenske (2001) mostram boa correspondência entre a diretividade do ruído de banda larga de um eslate, medida em campo distante, e a diretividade de um dipolo compacto. No entanto, a diretividade de um dipolo compacto mostra uma região de emissão limitada em relação à diretividade do ruído de eslate medido nas direções polar e azimutal (lateral). Guo (2010) sugere que tal discor- 
dância pode ocorrer em casos onde o comprimento da envergadura do eslate, em relação à distância entre a antena e o modelo, é grande o suficiente para caracterizar uma medição em campo próximo, do ponto de vista geométrico, apesar da condição de medição em campo acústico distante ser satisfeita. Efeitos de dispersão também podem ocorrer pela refração de ondas acústicas na região do gap do eslate, devido à aceleração do escoamento, e à influência do elemento principal em situações nas quais o comprimento de onda é da ordem de grandeza da corda do eslate.

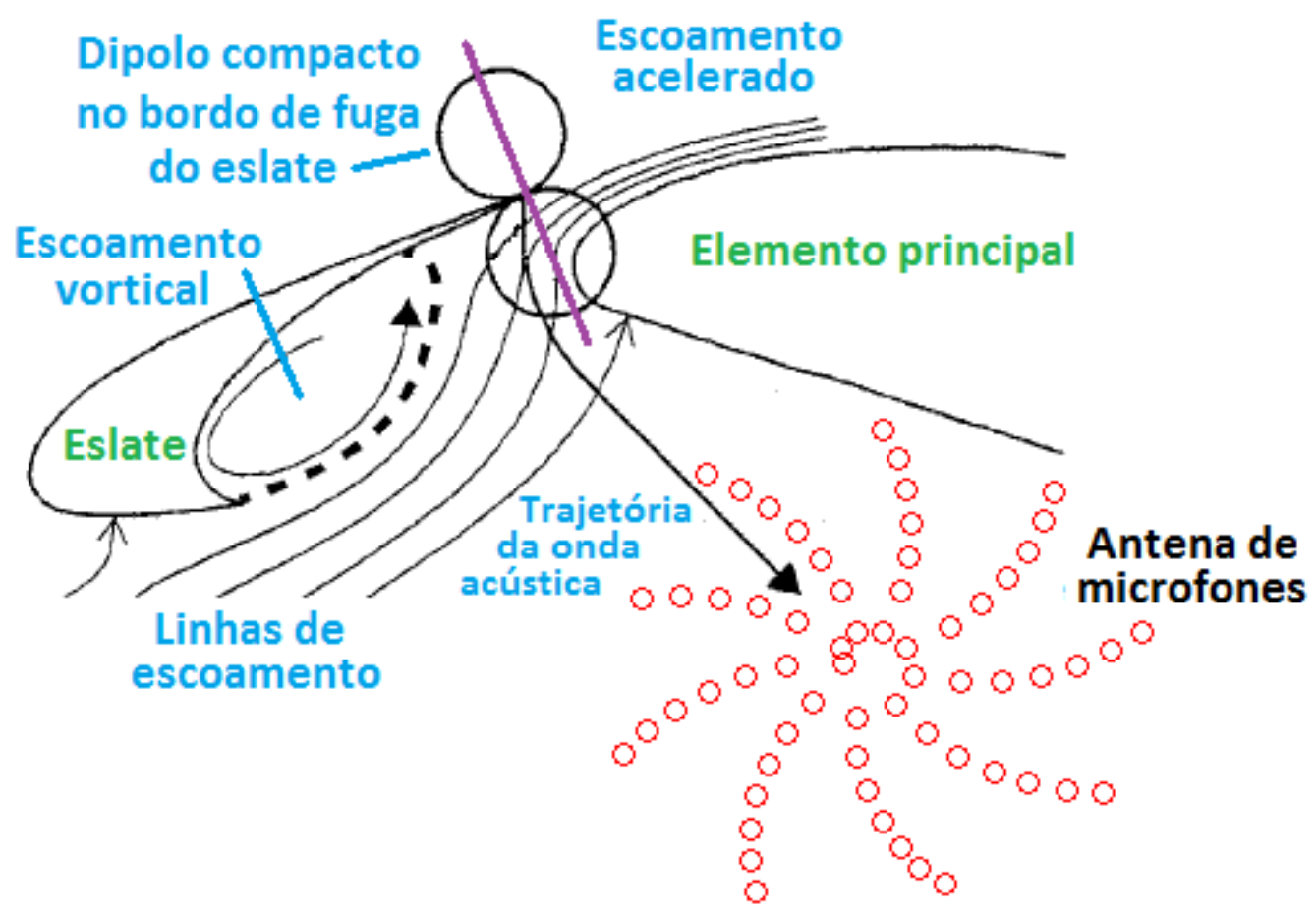

Figura 3.9: Modelo de dipolo representando o padrão de diretividade do ruído aerodinâmico de eslate.

Fonte: Dobrzynski e Pott-Pollenske (2001) (Adaptado).

A Fig. 3.10 representada resultados de diretividade do ruído de eslate apresentados por (KOLB et al., 2007). Medições de nível de ruído para diferentes ângulos polares, feitas em túnel de vento anecoico com microfones posicionados em campo distante, mostram padrões de diretividade bem definidos.

Conforme a Fig. 3.8, a antena de microfones está posicionada de forma a medir preferencialmente o ruído emitido a partir do intradorso do aerofólio, à jusante do ponto de emissão. Desta forma, a posição da antena simula, de forma realista, a posição de um observador sob a trajetória de voo da aeronave, e sob um ângulo representativo daquele determinado pela diretividade de um dipolo, em relação à corda do eslate. 

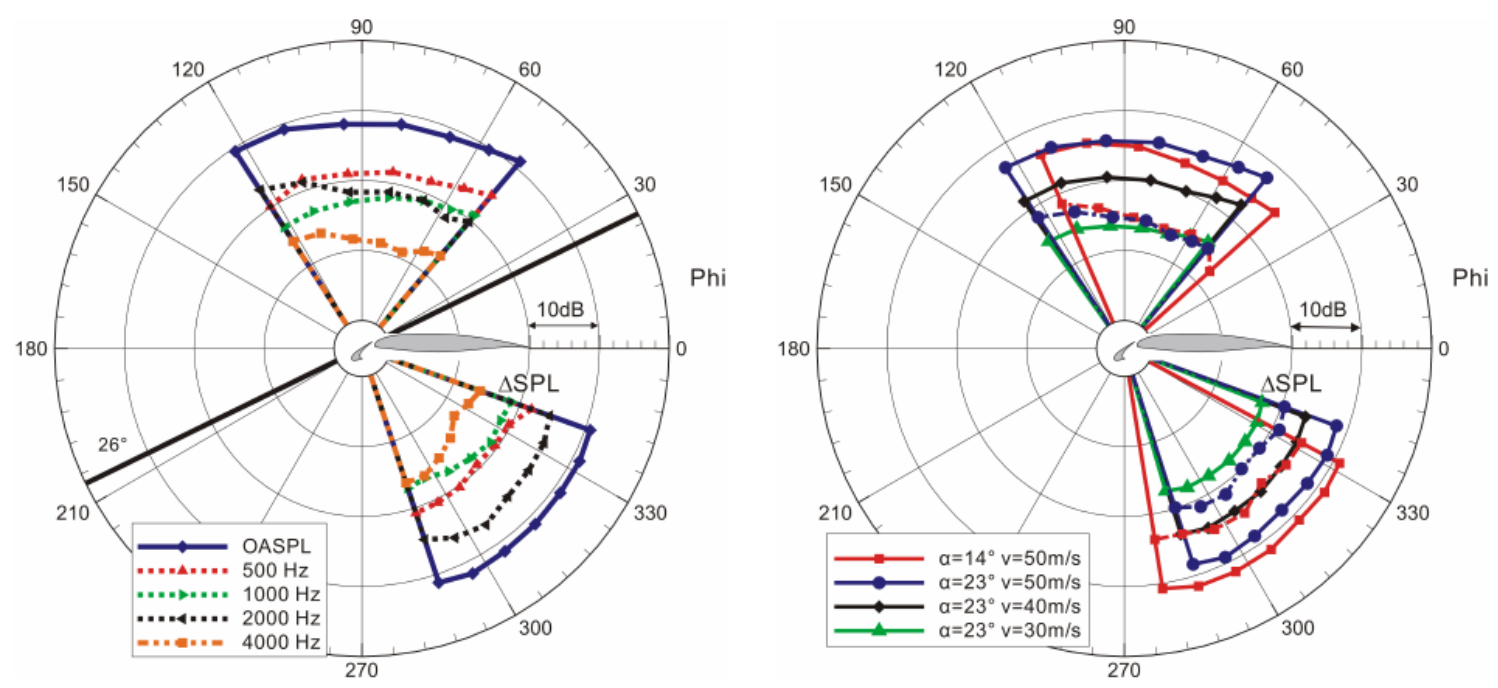

Figura 3.10: Representação polar da diretividade do ruído de eslate em bandas de $1 / 3$ de oitava sob várias condições operacionais e bandas de frequência. A linha contínua em $26^{\circ}$ (figura à esquerda) representa a linha pela corda do eslate, usada como referência para a representação polar da diretividade do ruído de eslate.

Fonte: Kolb et al. (2007).

\subsection{Projeto e Geometria da Antena de Microfones}

A antena, ou array de microfones, é o instrumento de medição através do qual realizamos a amostragem discreta dos sinais de pressão sonora que contêm as informações necessárias para o mapeamento de fontes com técnicas de beam-forming. No entanto, a geometria que determina o posicionamento dos sensores é um aspecto fundamental no projeto de uma antena para medições aeroacústicas (MUELLER, 2002).

Arrays com geometria regular (sensores regularmente espaçados) chamam a atenção pela simplicidade de seu projeto. No entanto, o fenômeno de aliasing espacial ocorre para a condição $\lambda \leq 2 d_{s}$, onde $\lambda$ é o comprimento de onda da onda incidente e $d_{s}$ representa o espaçamento regular entre os sensores. Desta forma, a máxima frequência de análise para a qual as imagens acústicas estarão livres dos efeitos de aliasing espacial é dada por $f_{\max }=c / 2 d_{s}$. O fenômeno de aliasing é responsável pelo surgimento de um padrão de lóbulos espúrios, que são reproduções, ou imagens fantasmas, dos lóbulos da função de forma do array, e que ocorrem devido a condição de sub-amostragem espacial dos sinais medidos. Tal restrição pode ser bastante severa para aplicações em aeroacústica, nas quais a distribuição de fontes pode ocorrer em banda larga de frequência.

Ao passo que arrays regulares com pequenos espaçamento entre sensores seriam necessários para o mapeamento de fontes acústicas em alta frequência, grandes aberturas são recomendadas para uma boa resolução de fontes em baixa frequência. A observância destas duas condições resultaria em arrays com um grande número de sensores, o que é 
impraticável na maioria dos casos, por questões técnicas ou financeiras.

Segundo Pumphrey (1993), o uso de arrays esparsos representa uma alternativa para a redução no número de sensores a partir de um projeto de array regular. Arrays esparsos são formados a partir da eliminação de elementos (sensores) com espaçamentos repetidos em um array com geometria regular. Tal estratégia é bastante eficaz para a redução do número de sensores inicialmente alocados em uma geometria regular. No entanto, efeitos de assimetria e aumento na amplitude dos lóbulos laterais podem ocorrer (UNDERBRINK, 1995).

A estratégia utilizada para a se evitar os efeitos de aliasing espacial consiste na eliminação de periodicidades, ou redundâncias, no posicionamento dos sensores (STEINBERG, 1976). A periodicidade em uma rede de sensores se caracteriza pela repetição de um padrão espacial no posicionamento dos sensores. Arrays com mínima redundância são denominados arrays irregulares, ou aperiódicos.

Arrays irregulares podem ser obtidos via posicionamento randômico de sensores sobre uma área alvo Steinberg (1976), ou pelo uso de uma estratégia que assegure redundância zero no espaçamento entre os sensores. A segunda opção é geralmente adotada por favorecer um maior controle sobre a alocação de sensores em áreas com restrições de posicionamento, e possibilitar a aplicação de otimização paramétrica ao projeto de array.

Geometrias irregulares, por sua vez, podem apresentar diferentes capacidades de resolução de fontes e supressão de lóbulos laterais para uma dada abertura e um número fixo de sensores. Algumas geometrias têm sido avaliadas com base em critérios objetivos de desempenho, com particular interesse para aplicações em aeroacústica (PRIME; DOOLAN, 2013). A geometria da antena de microfones utilizada nas medições acústicas que são objeto de estudos deste trabalho foi otimizada a partir de uma geometria base na forma de uma espiral de Arquimedes. Maiores detalhes sobre a geometria e o processo de otimização podem ser encontrados em (FONSECA et al., 2010). O projeto final resultou em uma antena com 64 microfones e abertura diametral de aproximadamente $0.85 \mathrm{~m}$. A geometria da antena utilizada nos experimentos (montada com 62 microfones por questões técnicas) encontra-se representada na Fig. 3.11. 


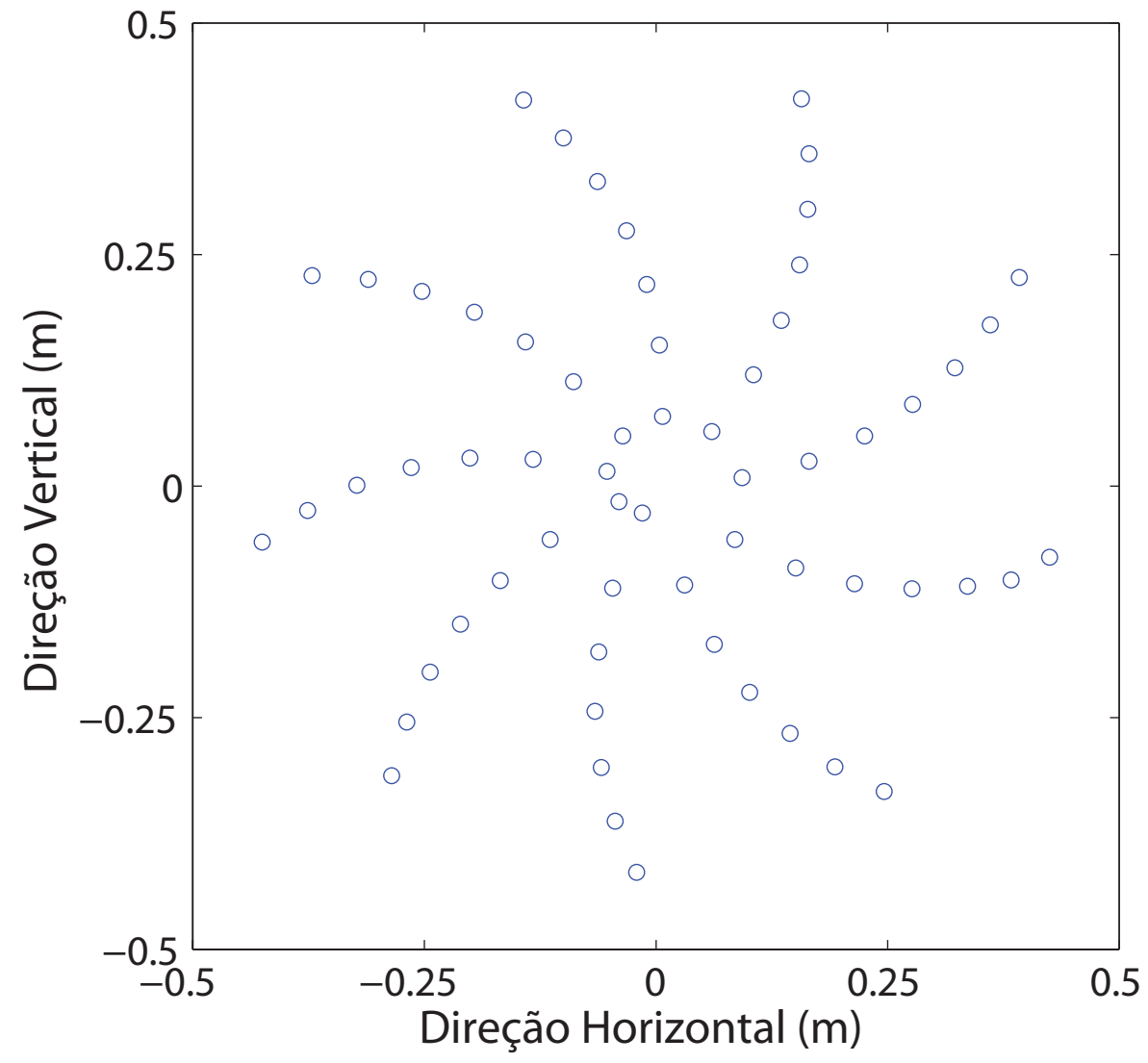

Figura 3.11: Representação da geometria de antena com 62 microfones utilizada nos experimentos aeroacústicos para medição do ruído de eslate.

\subsubsection{Avaliação do Projeto da Antena: Beam-width e Faixa Di- nâmica}

A capacidade de uma antena para separar fontes e reduzir lóbulos laterais pode ser avaliada a partir da análise do beam-width e da faixa dinâmica do seu padrão de resposta, ou point spread function (psf), que determina a função de forma pela qual a antena representa espacialmente uma fonte pontual de amplitude unitária. Devido à abertura finita e uma amostragem espacial discreta das frentes de onda, o padrão de resposta de uma dada geometria apresenta um lóbulo principal espacialmente alargado, com a ocorrência de múltiplos lóbulos laterais, em geral irregularmente distribuídos.

As propriedades do padrão de resposta de um array, em condição de campo distante (incidência de ondas planas), dependem essencialmente de sua abertura, geometria, e do ângulo de incidência da onda acústica. Considerando apenas incidência perpendicular à superfície da antena, o padrão de resposta é basicamente determinado pelas características de projeto da antena, o que facilita a comparação entre resultados obtidos a partir de diferentes antenas (MUELLER, 2002). Em condição de campo próximo (incidência de ondas esféricas), as estimativas de largura do lóbulo e faixa dinâmica dependem da posição 
do ponto focal em relação à antena de microfones.

Em última análise, a resolução e a faixa dinâmica efetivas em um mapa de beamforming serão determinadas pelo algoritmo de deconvolução aplicado ao processamento da base de dados. Em condição de campo próximo, o padrão de resposta de um array, ou $p s f$, calculado para a frequência $f$, com ponto de máximo dado pelo vetor de posição $\vec{x}_{s}$, pode ser definido na forma

$$
\operatorname{psf}\left(\vec{x}_{k}, \vec{x}_{s}, f\right)=\left|\frac{\mathbf{g}^{\dagger}\left(\vec{x}_{k}, f\right)}{\left\|\mathbf{g}\left(\vec{x}_{k}, f\right)\right\|} \frac{\mathbf{g}\left(\vec{x}_{s}, f\right)}{\left\|\mathbf{g}\left(\vec{x}_{s}, f\right)\right\|}\right|^{2},
$$

onde $\vec{x}_{k}$ denota o vetor de posição de um ponto focal na malha, com índice $k$. O vetor $\mathbf{g}\left(\vec{x}_{k}, f\right)$ denota a função de transferência para uma fonte do tipo monopolo, para o qual cada componente modela a propagação acústica desde o ponto focal até cada microfone da antena. O vetor $\mathbf{g}\left(\vec{x}_{k}, f\right)$ adotado neste trabalho será definido na Eq. 4.19.

É interessante notar que a Eq. 3.1 representa uma construção puramente geométrica para o padrão de resposta de uma geometria, normalizada para assumir um valor de pico unitário quando $\vec{x}_{k}=\vec{x}_{s}$. Idealmente, o mapa do padrão de resposta do array deveria mostrar um valor unitário no ponto focal (auto-correlação da fonte pontual), e valores nulos para os demais pontos da malha. No entanto, a capacidade finita de resolução do array "espalha" a energia acústica da fonte pontual e determina um padrão de resposta com largura de lóbulo principal finita e uma distribuição típica de lóbulos laterais (BAHR et al., 2011).

O beam-width (ou largura do lóbulo) é, em geral, definido como a largura do lóbulo principal do padrão de resposta do array à $-3 \mathrm{~dB}$ do seu valor de pico. A definição ora adotada para a largura do lóbulo principal, normalizado para um valor de pico unitário, determina o plano $z=-3 d B$ à meia altura do pico (em escala linear), conforme

$$
\triangle d B=10 \log _{10}(1)-10 \log _{10}(1 / 2) \simeq 3 d B
$$

Segundo Johnson e Dudgeon (1993), a estimativa da largura do lóbulo principal à meia altura do pico é consistente com o padrão de resposta espacial de um array, e propõem um método para a estimativa da largura do lóbulo a partir dos parâmetros de uma parábola ajustada ao formato do lóbulo principal, quando este for radialmente simétrico.

No presente estudo, as estimativas para a largura do lóbulo principal e a faixa dinâmica são feitas a partir do padrão de resposta para a geometria apresentada na Fig. 3.11, utilizando uma malha de pontos uniforme. A Fig. 3.12 representa a definição da largura do lóbulo, ou beamwidth, a partir da largura do lóbulo principal à -3 dB do pico, e decorre da aplicação da Eq. 3.1 ao cálculo do padrão de resposta do array para a frequência de $1 \mathrm{kHz}$. 


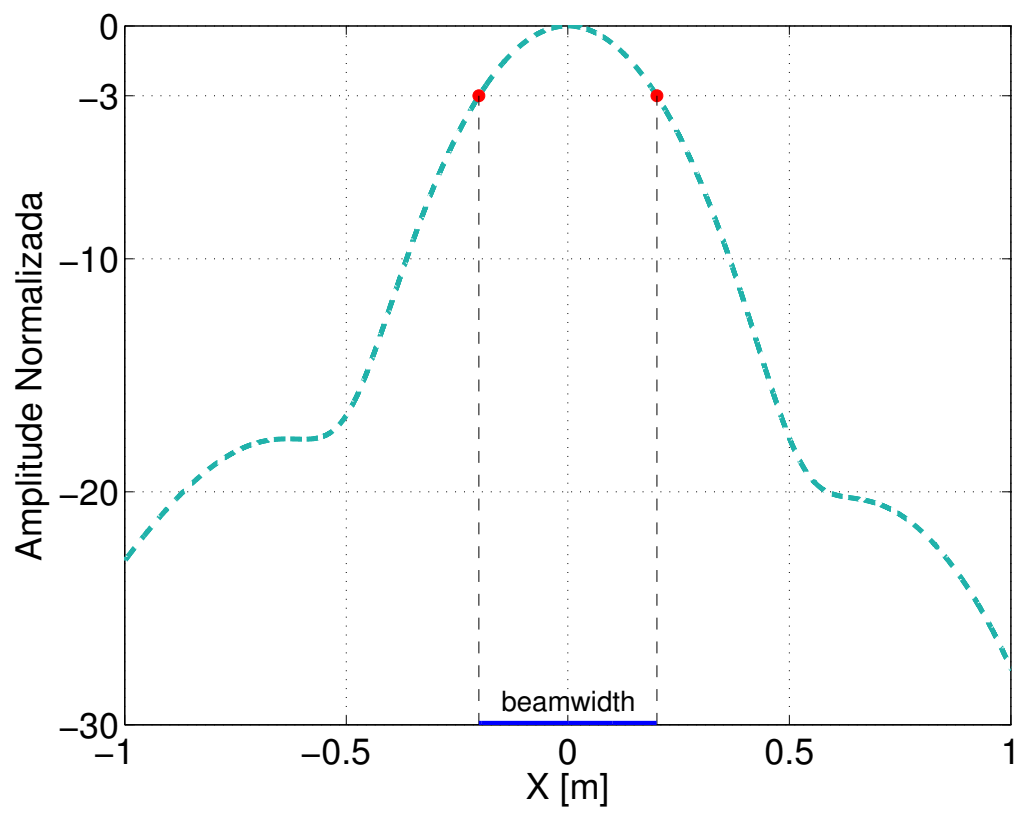

Figura 3.12: Representação gráfica do critério utilizado para a determinação da largura do lóbulo do array. A curva representa um corte transversal no lóbulo principal, na direção x, do padrão de resposta (pfs) do array de 62 microfones descrito na seção anterior, e dois pontos indicando a altura do lóbulo determinada para o cálculo da largura. O padrão de resposta do array é representado em escala de dB.

Para a estimativa da largura do lóbulo; 1) o padrão de resposta do array é representado por valores de nível $z(x, y)$, onde $x$ e $y$ são as coordenadas dos pontos da malha, 2) um sistema de referência é adotado com centro no ponto $(x=0, y=0)$, que por definição representa as coordenadas do ponto focal no centro da malha, 3) as coordenadas $\left( \pm x_{-3 d B}, \pm y_{-3 d B}\right)$, que representam os valores $z\left( \pm x_{-3 d B}, 0\right)=-3 d B$ e $z\left(0, \pm y_{-3 d B}\right)=-3 d B$ são estimadas nas direções $y=0$ e $x=0$, simetricamente à posição do pico do lóbulo principal em $(0,0)$, e 4) a largura do lóbulo principal, $B$, é a média entre as larguras do lóbulo estimadas nas direções $x,(y=0)$ e $y,(x=0)$, conforme

$$
B=\frac{\left[x_{-3 d B}^{(+)}-x_{-3 d B}^{(-)}\right]+\left[y_{-3 d B}^{(+)}-y_{-3 d B}^{(-)}\right]}{2},
$$

sendo $x_{-3 d B}^{(-)}$e $x_{-3 d B}^{(+)}$os valores de $x$ para os quais $z\left(-x_{-3 d B}, 0\right)=-3 d B$ e $z\left(x_{-3 d B}, 0\right)=-3 d B$, respectivamente. Naturalmente, a mesma definição se aplica à variável $y$. Por conta da distribuição discreta de pontos na malha, cada um dos valores $x_{-3 d B}^{(-)}, x_{-3 d B}^{(+)}, y_{-3 d B}^{(-)}$e $y_{-3 d B}^{(+)}$ é estimado pela média dos valores imediatamente inferior e superior ao mesmo.

Em caso de malhas pouco refinadas, pode-se interpolar os vetores que representam retas no domínio do mapa de contorno contendo os pontos $\left(x_{-3 d B}^{(-)}\right.$e $\left.x_{-3 d B}^{(+)}\right)$e $\left(y_{-3 d B}^{(-)}\right.$e $\left.y_{-3 d B}^{(+)}\right)$, e de forma correspondente os vetores com valores de nível, $z$, associados aos valores dos pontos selecionados para interpolação nas direções $x$ e $y$. Tal procedimento permite 
reduzir erros na estimativa do parâmetro $B$, tendo sido usado no contexto deste trabalho.

A faixa dinâmica de um array é definida como a diferença (em dB) entre os valores de pico do lóbulo principal e do lóbulo secundário de maior amplitude. Para a estimativa da faixa dinâmica, dividimos o mapa da função de forma do array nos domínios $\mathscr{D}_{0}$ e $\mathscr{D}$. O domínio $\mathscr{D}_{0}$ representa o lóbulo principal, enquanto que o domínio $\mathscr{D}$ representa o complemento do domínio $\mathscr{D}_{0}$. A fronteira entre os domínios $\mathscr{D}_{0}$ e $\mathscr{D}$ é definida como sendo o lugar geométrico dos pontos de mínimo no entorno do lóbulo principal. Para delimitar a influência do lóbulo principal no mapa da função de forma do array, estima-se a distância entre o ponto de máximo global e os pontos da fronteira mais afastados nas direções $x$ e $y$, que são os pontos nos quais a curva representativa do lóbulo principal inverte a sua tendência de descida. Em seguida, estima-se o pico de amplitude do lóbulo secundário como sendo o máximo global no domínio $\mathscr{D}$, e a faixa dinâmica como a diferença, em unidades de $\mathrm{dB}$, entre os máximos globais nos domínios $\mathscr{D}_{0}$ e $\mathscr{D}$.

A Fig. 3.13 representa estimavas de beam-width e faixa dinâmica para a antena de 62 microfones cuja geometria é descrita na Fig. 3.11, em condição de incidência acústica em campo próximo, como descrito acima.

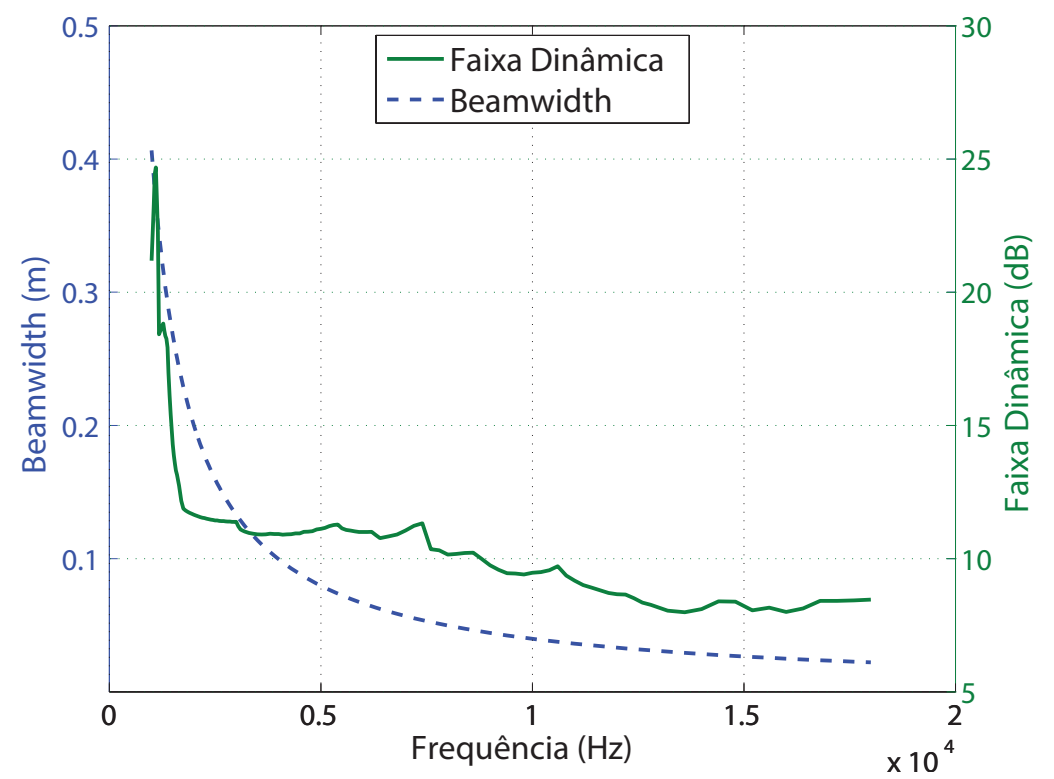

Figura 3.13: Estimativa de beamwidth e faixa dinâmica da antena de microfones (Fig. 3.11) na banda de frequência entre $500 \mathrm{~Hz}$ e $18 \mathrm{kHz}$, com resolução em frequência dada pela tabela 5.1.

\subsubsection{Construção, Instalação e Aplicações da Antena da Micro- fones}

A geometria da antena de microfones foi traçada sobre uma placa de material MDF com 1,8 cm de espessura. A furação da placa para o posicionamento dos microfones foi 
realizada com uma máquina de precisão, de forma a reduzir erros nas coordenadas dos microfones. A placa foi então posicionada verticalmente em uma das paredes laterais da câmara de ensaios. A Fig. 3.14(a) mostra a superfície da antena em contato com o escoamento no interior da câmara de ensaios, e a Fig. 3.14(b) representa a antena em fase de montagem, com o cabeamento dos microfones 46BD.

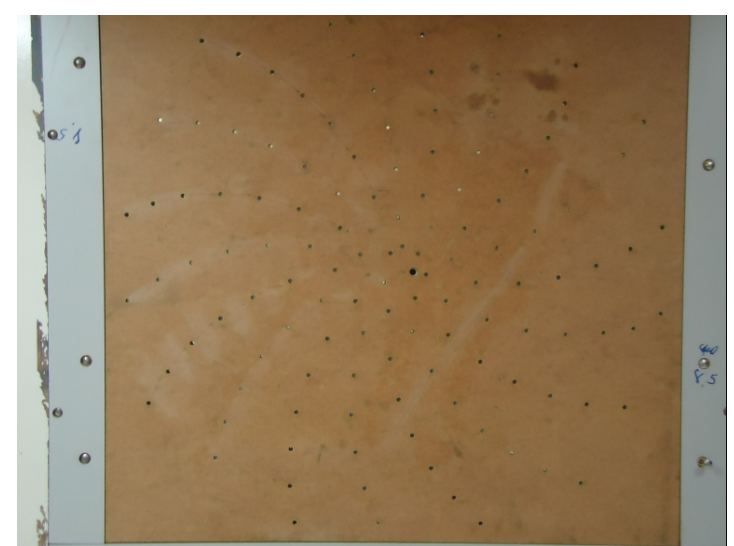

(a) Vista frontal

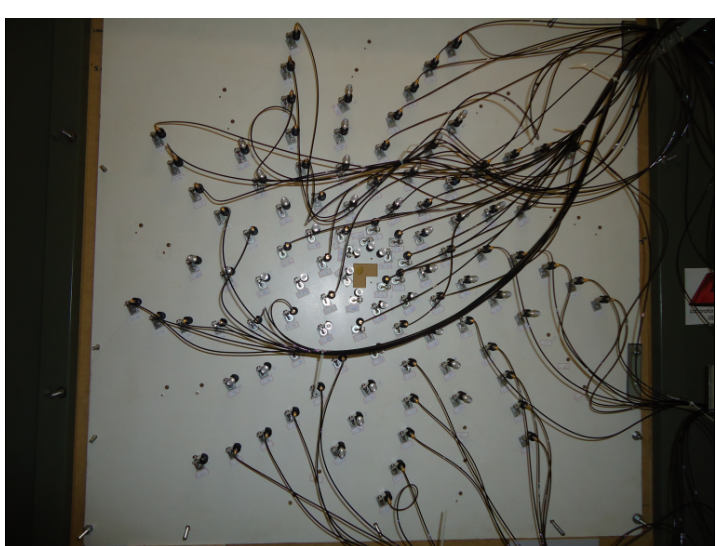

(b) Vista posterior

Figura 3.14: Antena de microfones em processo de montagem no túnel de vento LAE-1: (a) parte frontal com superfície em contato com o escoamento e (b) instalação/cabeamento dos microfones 46BD.

Os microfones foram montados sem suas grades frontais de proteção e alinhados com a superfície da antena em contato com o escoamento. A utilização dos microfones, sem uma interface de proteção aerodinâmica e sem qualquer recuo em relação à superfície do escoamento, expõe suas membranas ao contato direto com a camada limite turbulenta que se desenvolve sobre a superfície da antena. A camada limite turbulenta atinge a membrana dos microfones como flutuações de pressão local, que não caracterizam a propagação de uma onda acústica. Este fenômeno representa uma das fontes características de contaminação por ruído hidrodinâmico para medições acústicas em túneis de vento de secção fechada (SHIN et al., 2007).

Tais flutuações estão associadas à formação de estruturas turbulentas coerentes na camada limite do escoamento sobre a antena. Este ruído hidrodinâmico é evidenciado na auto-correlação entre sinais medidos pelos microfones do array, assim como na correlação cruzada entre sinais de dois microfones espaçados por uma distância menor que o comprimento médio de correlação espacial das estruturas turbulentas coerentes.

Jaeger, Horne e Allen (2000) aplicaram um material flexível, poroso e altamente tensionado, conhecido como Kevlar, atuando como uma superfície aerodinâmica de cobertura sobre a parte frontal dos microfones. O objetivo do Kevlar é atenuar o efeito das flutuações locais de pressão sobre medições acústicas, porém sem alterar a uniformidade do escoamento e sem bloquear a incidência de ondas acústicas sobre a antena. Apesar dos 
resultados promissores, esta técnica é de difícil aplicação.

Uma série de testes foram realizados, no contexto deste trabalho, com o objetivo de caracterizar os espectros de ruído de fundo medidos por antenas de microfones instaladas no túnel de vento LAE-1. A comparação dos valores de coerência entre sinais medidos por microfones com diferentes espaçamentos relativos indicou que o comprimento típico de correlação para a turbulência de camada limite é pequeno em relação ao espaçamento médio entre os microfones na antena. Desta forma, o ruído hidrodinâmico permanece correlacionado para um número reduzido de pares de microfones e o espaçamento típico entre os microfones na antena atua como um filtro espacial para este tipo de ruído (SHIN et al., 2007). Outro ponto favorável é que o ruído de camada limite parece estar restrito à regiões de baixa frequência.

A Fig. 3.15 representa os resultados de testes realizados para avaliar o efeito de médias temporais sobre os espectros de ruído de fundo. Para tal estudo, o ruído de fundo foi medido durante $\mathrm{T}=60 \mathrm{~s}$. Os sinais medidos foram particionados em tamanhos de $\mathrm{T} / 1, \mathrm{~T} / 2, \mathrm{~T} / 4, \mathrm{~T} / 8, \mathrm{~T} / 16, \mathrm{~T} / 32$, e processados de forma independente para o cálculo das matrizes de espectros cruzados $(\mathrm{CSM})^{2}$. Estas matrizes são estimadas pelo método de Welch Welch (1967), a partir da média de um grande número de blocos de dados de tamanho fixo, conforme descrito na seção 4.10, o que reduz o efeito do ruído acústico aleatório. O número de médias usado na estimativa espectral está diretamente relacionado ao tempo de medição dos sinais, de acordo com a Eq. 4.65.

A Fig. 3.15(a) mostra a média dos espectros cruzados de todos os pares de microfones da antena para diferentes tempos de medição dos sinais. A Fig. 3.15(b) mostra a diferença entre os espectros de ruído mostrados na Fig. 3.15(a). A 3.15(c) mostra a diferença entre integrais do nível de pressão sonora em mapas de beam-forming (convencional) do ruído de fundo. Os espectros com nível médio em torno de zero nas Figs. 3.15(b) e (c) representam o nível de referência para sinais com duração de T s. Os espectros com nível médio em torno de 1.5 dB representam a variação no nível de ruído para sinais com duração de $\mathrm{T} / 2$ s, em relação aos espectros de sinas com duração de T s, e assim por diante.

Os mapas de beam-forming foram estimados a partir da CSM calculada com sinais de diferentes durações, e considerando um malha discreta de pontos aproximadamente sobre a posição do modelo de testes. Os resultados apresentados na Fig. 3.15 decorrem de medições com uma antena de 96 microfones, com geometria em espiral simples e com microfones montados sem recuo em relação à superfície da antena, em contato direto com o escoamento à $27 \mathrm{~m} / \mathrm{s}$.

A Fig. 3.15(a) mostra um espectro de ruído de fundo de banda larga, sem a presença

\footnotetext{
${ }^{2}$ Em termos de nomenclatura, a matriz de espectros cruzados é comumente denominada CSM, que decorre da terminologia usada na língua inglesa para Cross Spectral Matrix.
} 


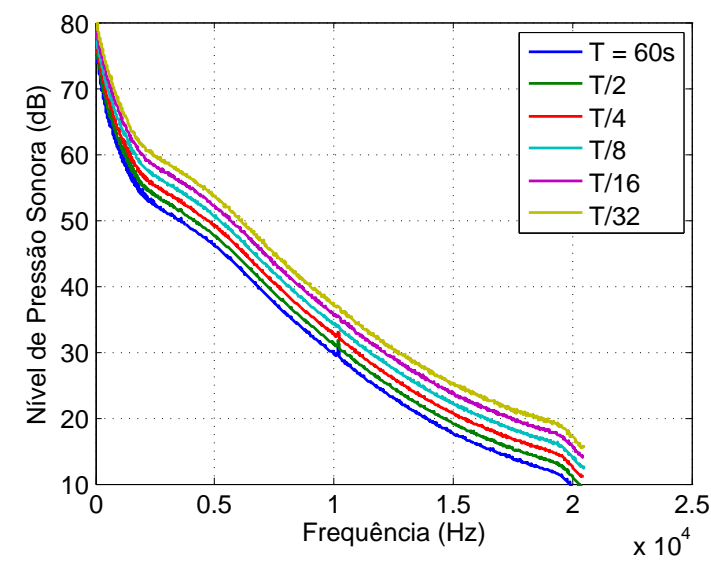

(a) Espectros de ruído de fundo

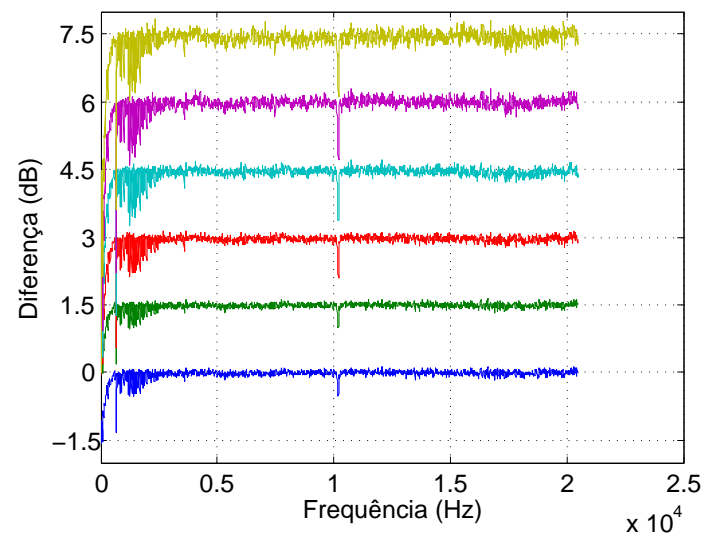

(b) Diferença entre Espectros

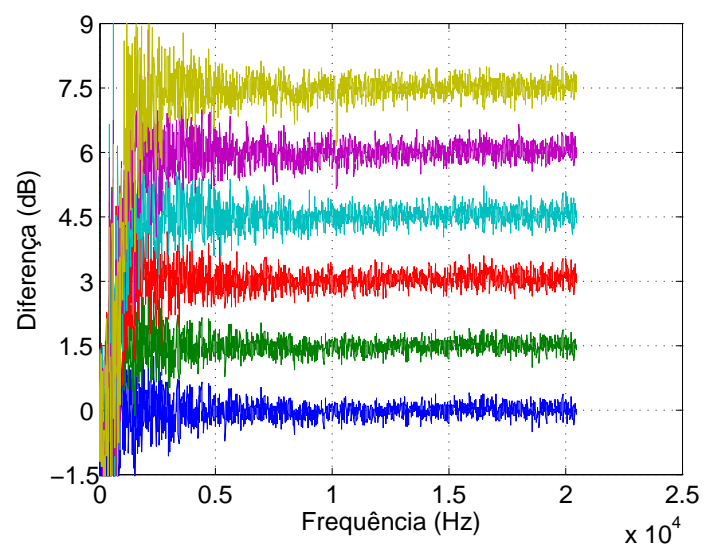

(c) Diferença entre ruído integrado em mapas de beam-forming

Figura 3.15: (a) espectros de ruído representando a média dos sinais correlacionados para uma antena de 96 microfones, (b) diferença entre espectros de ruído e (c) diferenças entre integrais de nível de pressão sonora do ruído de fundo estimadas a partir de mapas de beam-forming convencional. Os sinais em cada microfone foram medidos durante $\mathrm{T}=60$ s e particionados em sinais com duração $\mathrm{T} / 2, \mathrm{~T} / 4, \mathrm{~T} / 8, \mathrm{~T} / 16, \mathrm{~T} / 32$ para posterior processamento. Os sinais foram amostrados em $40960 \mathrm{~Hz}$ e processados com resolução em frequência de $10 \mathrm{~Hz}$.

de ruído tonal em frequências específicas, porém com níveis relativamente altos em baixa frequência.

A banda de frequência em que o ruído de fundo cai $1.5 \mathrm{~dB}$, quando o tempo de medição é duplicado, é dominada por ruído randômico com provável origem na turbulência do escoamento livre. Conforme mostrado na Fig. 3.15, o ruído randômico pode ser filtrado tomando-se a média de blocos de dados em quantidade adequada. Os resultados apresentados nas Figs. 3.15(a) e 3.15(b) reproduzem resultados apresentados por Shin et al. (2007), em estudo similar para a avaliação da viabilidade da realização de medições aeroacústicas em um túnel de vento de seção fechada. A Fig. 3.15(c) representa um resultado que, até onde sabemos, não encontra-se documentado na literatura. Este resultado mostra que os níveis do ruído randômico residual em um mapa de beam-forming podem 
ser reduzidos pelo número de médias tomadas na estimação espectral, tal como ocorre para o espectro-cruzado entre sinais randômicos medidos por diferentes microfones.

Em suma, a principal ação para reduzir o efeito combinado de diversos componentes do ruído de fundo sobre medições com uma antena de microfones em túnel de vento de seção fechada consiste na remoção dos elementos da diagonal principal da matriz de espectros cruzados, que representam auto-espectros para os sinais dos microfones. Como passo seguinte à remoção dos auto-espectros, os resultados apresentados nesta seção mostram que uma redução adicional no ruído que permanece nos espectros cruzados pode ser obtida pela média de um grande número de blocos de dados, que estarão disponíveis após um tempo de medição adequado.

\subsection{Sistema de Aquisição de Dados}

Para a medição de dados com a antena de microfones foram utilizadas placas de aquisição de dados com especificações NI PXI-4496 e NI PXI-4498, da Fabricante National Instruments. As placas foram acondicionadas em um rack PXI-1042Q, com capacidade para sete módulos (slots) independentes de aquisição e um de transmissão de dados. Cada placa de aquisição possui 16 canais com capacidade para amostragem simultânea de até $204.8 \mathrm{kS} / \mathrm{s}(\mathrm{kS} / \mathrm{s}=1000$ amostras/segundos), totalizando 112 canais de coleta de dados disponíveis no rack PXI-1042Q.

As placas NI PXI-4496 e NI PXI-4498 possuem 24 bits de resolução ADCs com 114 dB de faixa dinâmica e filtros anti-alising ajustáveis. A principal diferenciação entre as placas NI PXI-4496 e NI PXI-4498 fica por conta do ganho e da faixa dinâmica de entrada: a placa NI PXI 4496 possui ajustes de ganho de até $+20 \mathrm{~dB}$ para faixa dinâmica de entrada analógica entre $\pm 1 \mathrm{~V}$ e $\pm 10 \mathrm{~V}$, enquanto que a placa NI PXI 4498 possui ajustes de ganho de até $+30 \mathrm{~dB}$ para faixa dinâmica de entrada analógica entre $\pm 316 \mathrm{mV}$ e $10 \mathrm{~V}$. A placa PXI 8336 é responsável pela transmissão de dados, via fibra óptica, entre as placas NI PXI-4496/NI PXI-4498 e o controlador NI 8353. De acordo com o fabricante, a placa PXI 8336 garante isolamento elétrico entre o controlador NI 8353 e o rack PXI-1042Q, com taxa de transmissão nominal de dados de $132 \mathrm{MB} / \mathrm{s}$ no pico e $78 \mathrm{MB} / \mathrm{s}$ em regime sustentado.

O controlador NI 8353 é o computador responsável por gerenciar o processo de aquisição e armazenar os dados medidos. A configuração utilizada dispõe de um processador Intel Core 2 Quad Q6600 (2.4 GHz quad core), barramento RAID 0, que maximiza a velocidade de transmissão de dados entre os processadores, 4 GB de memória RAM e quatro discos rígidos SATA II HDD com 250 GB por disco. 


\subsubsection{Microfones}

As medições acústicas foram realizadas com sensores de pressão 46BD, da fabricante G.R.A.S. Cada unidade consiste de um microfone 40BD e um pré-amplificador 26CB, ambos com 1/4 de polegadas, dispondo de um cabo conector coaxial. Cada unidade dispõe de TEDS (Transducer Electronic Data Sheet standard) de acordo com as especificações IEEE-1451.4. O microfone 40BD é indicado para medições em ambiente pressurizado. A Fig. 3.16 mostra o conjunto microfone/amplificador 46BD, conectado ao cabo coaxial e ainda com o grid de proteção na parte frontal.

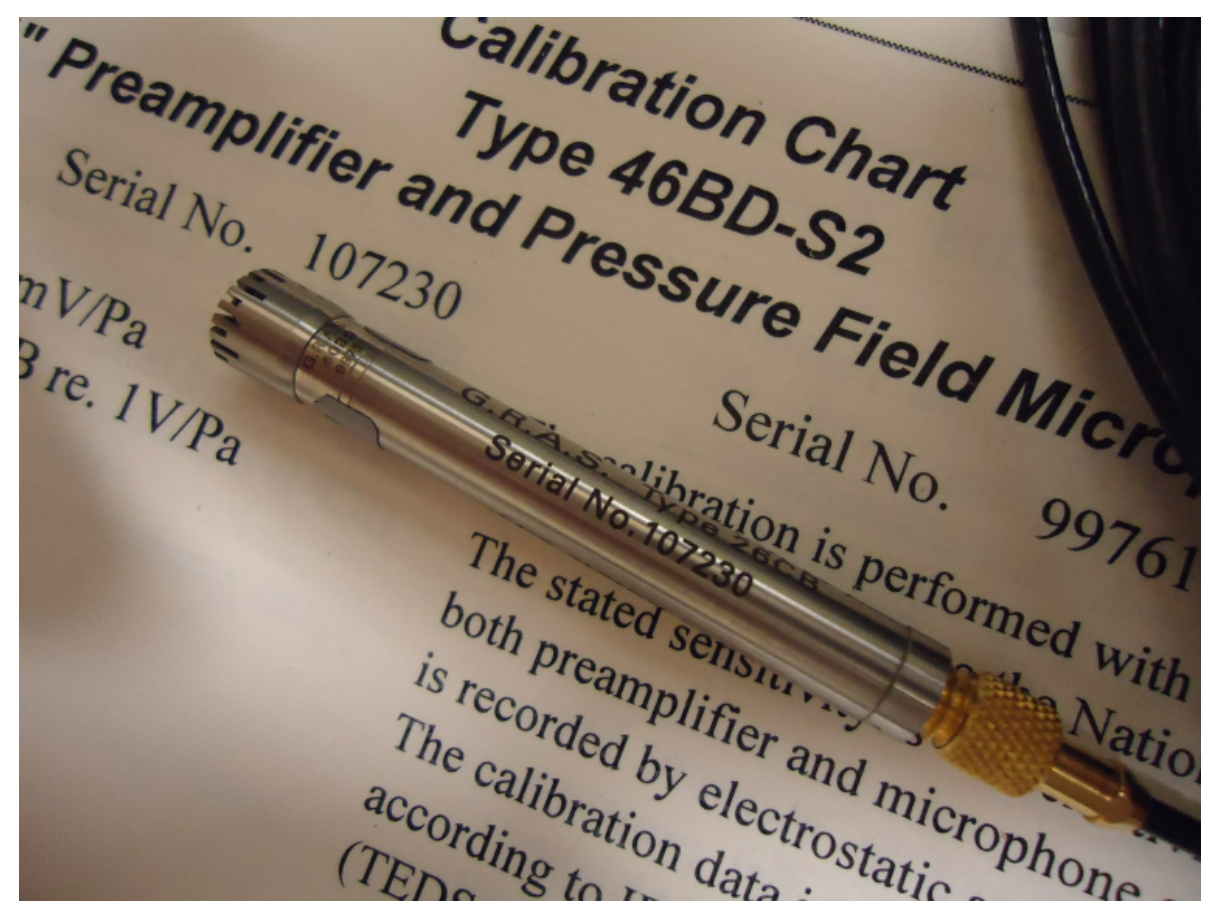

Figura 3.16: Representação do conjunto microfone/amplificador 46BD.

O conjunto possui impedância de saída inferior à 50 ohms e um furo lateral para equalização de pressão na parte traseira. Abaixo estão relacionadas as principais especificações acústicas do sensor de pressão 46BD, de acordo com a nota técnica da fabricante.

(1) banda útil de frequência $( \pm 1 \mathrm{~dB})$ : de 10 até $25 \mathrm{kHz}$.

(2) banda útil de frequência $( \pm 2 \mathrm{~dB})$ : de 4 até $70 \mathrm{kHz}$.

(3) Limite inferior de faixa dinâmica com pré-amplificador G.R.A.S: 44 dB(A). 
(4) Limite superior de faixa dinâmica com pré-amplificador CCP G.R.A.S: 168 dB.

(5) Sensibilidade nominal @ 250Hz $( \pm 3 \mathrm{~dB}): 1,45 \mathrm{mV} / \mathrm{Pa}$

\subsection{Procedimentos Para Medições Experimentais}

Esta secção tem por objetivo apresentar uma descrição geral sobre os procedimentos experimentais adotados para a realização de medições aeroacústicas e aerodinâmicas com o perfil hiper-sustentador 30P30N, no túnel de vento LAE-1. A metodologia adotada consistiu em elaborar uma planilha de testes que permitisse a execução de uma matriz de ensaios e o registro das medições aerodinâmicas/aeroacústicas correspondentes a cada caso experimental. Cada caso experimental é determinado por um conjunto de parâmetros de configuração geométrica do eslate e do flape (deflexão, gap, overlap) e configuração operacional do aerofólio (ângulo de incidência do aerofólio e velocidade de escoamento livre).

A tabela 3.2 representa os parâmetros do aerofólio que determinam variações entre casos experimentais. As variáveis relacionadas na tabela 3.3 determinam as condições experimentais na câmara de ensaios. A frequência de rotação do ventilador determina a velocidade de escoamento livre na câmara de ensaios e a potência do sistema de sucção determina a vazão volumétrica para o controle da camada limite da parede na junção com o aerofólio.

Tabela 3.2: Parâmetros de configuração experimental e geométrica do aerofólio

\begin{tabular}{|c|c|c|}
\hline elemento principal & eslate & flape \\
\hline \hline ângulo de ataque & deflexão/gap/overlap & deflexão/gap/overlap \\
\hline
\end{tabular}

Tabela 3.3: Parâmetros de controle do experimento

\begin{tabular}{|l|l|}
\hline Frequência de rotação do ventilador & Potência do sistema de sucção \\
\hline
\end{tabular}

Os experimentos foram realizados com velocidades de escoamento livre de $24 \mathrm{~m} / \mathrm{s}, 27$ $\mathrm{m} / \mathrm{s}, 31 \mathrm{~m} / \mathrm{s}$ e $34 \mathrm{~m} / \mathrm{s}$. Os ângulos de incidência do aerofólio variam no máximo entre $-4^{\circ}$ e $20^{\circ}$, com passo de $2^{\circ}$. Porém, as medições acústicas se concentram principalmente em casos com o ângulo de incidência do aerofólio variando entre $2^{\circ}$ e $10^{\circ}$. Uma descrição geral sobre os procedimentos adotados para as medições aeroacústicas e aerodinâmicas é apresentada na sequência. 


\subsubsection{Medições Acústicas}

Um ponto crítico no processo de montagem do arranjo experimental em medições acústicas com antenas de microfones é a definição de uma correspondência inequívoca entre um sinal medido e a posição do microfone responsável pela respectiva medição. Do ponto de vista operacional, os microfones devem ser conectados ao sistema de aquisição de dados de forma que cada canal de entrada corresponda a um microfone com posição $(\mathrm{x}, \mathrm{y})$ conhecida.

Cada medição acústica resulta em um arquivo com codificação binária contendo: 1) um cabeçalho com informações sobre os parâmetros adotados na medição dos sinais (número de canais ativos, frequência de amostragem, tempo de aquisição, etc.), 2) os arquivos de dados dos microfones dispostos sequencialmente de acordo com a ordem de entrada dos canais de medição. Em uma etapa de pós-processamento dos dados acústicos pela técnica de beam-forming, cada arquivo de entrada com o sinal medido por um microfone dever ser corretamente associado às coordenadas que especificam a posição deste microfone, em relação ao sistema de referência da antena.

A Fig. 3.17 representa uma planilha de controle utilizada na montagem da antena e conexão dos microfones com o sistema de aquisição de dados.

\begin{tabular}{|c|c|c|c|c|c|c|c|c|c|}
\hline$\Delta$ & A & B & c & D & $\mathrm{E}$ & $\mathrm{F}$ & G & $\mathrm{H}$ & 1 \\
\hline 1 & \multicolumn{6}{|c|}{63 mics 46BD - S2 } & & & \\
\hline \multicolumn{10}{|l|}{2} \\
\hline 3 & mic & $\mathrm{x}$ & $\mathbf{Y}$ & Z & mic_serial & ne do cabo & mic_sensitivity & PXI-1042Q "chassis 8" & microfone \\
\hline 4 & 1 & 0,015 & $-0,029$ & 0 & 107230 & 0 & 1,7881913 & NI PXI-4498 PXI1Solt2/ai0 & $46 \mathrm{BD}-\mathrm{S} 2$ \\
\hline 5 & 2 & 0,04 & $-0,017$ & 0 & 107248 & 1 & 1,5321445 & NI PXI-4498 PXI1Solt2/ai1 & $46 B D-S 2$ \\
\hline 6 & 3 & 0,053 & 0,016 & 0 & 107271 & 2 & 1,5286919 & NI PXI-4498 PXI1Solt2/ai2 & $46 B D-S 2$ \\
\hline 7 & 4 & 0,036 & 0,054 & 0 & 107242 & 3 & 1,1307692 & NI PXI-4498 PXI1Solt2/ai3 & $46 B D-S 2$ \\
\hline 8 & 5 & $-0,007$ & 0,075 & 0 & 107267 & 4 & 1,701414 & NI PXI-4498 PXI1Solt2/ai4 & $46 \mathrm{BD}-\mathrm{S} 2$ \\
\hline 9 & 6 & $-0,06$ & 0,059 & 0 & 107255 & 5 & 1,671951 & NI PXI-4498 PXI1Solt2/ai5 & $46 B D-S 2$ \\
\hline 10 & 7 & $-0,093$ & 0,009 & 0 & 107273 & 6 & 1,2464566 & NI PXI-4498 PXI1Solt2/ai6 & $46 B D-S 2$ \\
\hline 11 & 8 & $-0,085$ & $-0,058$ & 0 & 107263 & 7 & 1,647755 & NI PXI-4498 PXI1Solt2/ai7 & $46 \mathrm{BD}-\mathrm{S} 2$ \\
\hline 12 & 9 & $-0,031$ & $-0,107$ & 0 & 107243 & 8 & 1,3600475 & NI PXI-4498 PXI1Solt2/ai8 & $46 B D-S 2$ \\
\hline 13 & 10 & 0,047 & $-0,11$ & 0 & 107259 & 9 & 1,597565 & NI PXI-4498 PXI1Solt2/ai9 & $46 B D-S 2$ \\
\hline 14 & 11 & 0,114 & $-0,058$ & 0 & 107214 & 10 & 1,8049676 & NI PXI-4498 PXI1Solt2/ai10 & $46 B D-S 2$ \\
\hline 15 & 12 & 0,133 & 0,029 & 0 & 107225 & 11 & 1,534716 & NI PXI-4498 PXI1Solt2/ai11 & $46 B D-S 2$ \\
\hline 16 & 13 & 0,089 & 0,113 & 0 & 107272 & 12 & 1,5504107 & NI PXI-4498 PXI1Solt2/ai12 & $46 B D-S 2$ \\
\hline 17 & 14 & $-0,004$ & 0,152 & 0 & 107232 & 13 & 1,509126 & NI PXI-4498 PXI1Solt2/ai13 & $46 \mathrm{BD}-\mathrm{S} 2$ \\
\hline 18 & 15 & $-0,105$ & 0,12 & 0 & 107257 & 14 & 1,390264 & NI PXI-4498 PXI1Solt2/ai14 & $46 \mathrm{BD}-\mathrm{S} 2$ \\
\hline 19 & 16 & $-0,165$ & 0,027 & 0 & 107266 & 15 & 1,29 & NI PXI-4498 PXI1Solt2/ai15 & $46 B D-S 2$ \\
\hline 20 & 17 & $-0,151$ & $-0,088$ & 0 & 107261 & 16 & 1,191245 & NI PXI-4498 PXI1Solt3/ai0 & $46 B D-S 2$ \\
\hline 21 & 18 & $-0,214$ & $-0,105$ & 0 & 107277 & 17 & 1,423835 & NI PXI-4498 PXI1Solt3/ai1 & $46 B D-S 2$ \\
\hline 22 & 19 & $-0,276$ & $-0,111$ & 0 & 107270 & 18 & 1,443164 & NI PXI-4498 PXI1Solt3/ai2 & $46 B D-S 2$ \\
\hline 23 & 20 & $-0,336$ & $-0,108$ & 0 & 107246 & 19 & 1,359406 & NI PXI-4498 PXI1Solt3/ai3 & $46 B D-S 2$ \\
\hline 24 & 21 & $-0,383$ & $-0,101$ & 0 & 107276 & 20 & 1,900784 & NI PXI-4498 PXI1Solt3/ai4 & $46 B D-S 2$ \\
\hline
\end{tabular}

Figura 3.17: Na planilha de controle, o microfone de número 1, com posição $\mathrm{x}=0,015 \mathrm{~m}$ e y $=$ -0.029 m, identificado pelo número de série 107230, e com sensibilidade de calibração 1.7881913 é associado ao canal de leitura de dados com índice 0. Esta identificação permite uma associação entre a posição física do microfone no sistema de referência da antena e um índice de posição do sinal medido no arquivo de saída do sistema de aquisição de dados, bem como a leitura correta de sua sensibilidade. 
Um pré-teste para avaliar a funcionalidade dos módulos de aquisição e canais é altamente recomendado antes do início de uma campanha com um grande número de casos experimentais, o que pode ser feito no decorrer de um dia, se houver a necessidade de substituição ou realocação de módulos de aquisição ou a substituição de cabos de conexão ou microfones.

O software para aquisição de dados acústicos utilizado na campanha de ensaios de 2013 foi desenvolvido na UFSC (Universidade Federal de Santa Catarina). No decorrer das medições, o software utilizado permitia o monitoramento dos sinais medidos em cada canal de aquisição. Isto possibilitava a inspeção visual da qualidade dos sinais e indicava a necessidade de reparos pontuais no sistema de aquisição de dados, cabos e microfones. Fenômenos transientes, tais como ruído excessivo ou oscilações de baixa frequência foram ocasionalmente observados em alguns canais. Tais fenômenos não tiveram impacto sobre as medições porque se mostravam transientes ou puderam ser controlados após ajustes no sistema de medição. O ganho dos microfones foi devidamente calibrado antes do início dos experimentos. Os sinais medidos são convertidos de unidades de volt (V) para unidades de Pascal (Pa), no próprio software de aquisição da dados, utilizando os valores de sensibilidade aferidos no processo de calibração de ganho dos microfones.

\subsubsection{Medições Aerodinâmicas}

Uma das principais vantagens decorrentes do uso de túneis de vento de secção fechada é a possibilidade de associar medições aeroacústicas com medições aerodinâmicas. Embora medições aeroacústicas e aerodinâmicas sejam independentes do ponto de vista operacional, as medidas aerodinâmicas devem representar as condições do escoamento sob as quais se desenvolvem os mecanismos de geração do ruído aerodinâmico que é objeto de medições aeroacústicas. A realização simultânea destas medidas supõe que ambas sejam mutuamente não intrusivas, no sentido de que medidas aerodinâmicas não comprometam a qualidade das medidas aeroacústicas, e vice-versa.

Medições aerodinâmicas permitem associar os níveis de emissão de ruído do aerofólio em uma dada configuração geométrica ao seu desempenho aerodinâmico em termos da razão entre sustentação e arrasto, bem como mapear os campos de pressão e velocidade no escoamento em que se desenvolvem os mecanismos físicos de geração de ruído aerodinâmico.

A tabela 3.4 enumera algumas grandezas derivadas da pressão dinâmica, $p_{\infty}$, e da temperatura, $T$ (na escala absoluta), e que são aplicadas ao estudo do ruído aerodinâmico em uma fase de pós-processamento dos dados. A pressão dinâmica é definida pela diferença entre as pressões de estagnação, $p_{\text {est }}$, e a pressão estática, $p_{\text {est }}$. Esta diferença foi medida com o uso de um tubo de Pitot estático. A tabela 3.5 mostra exemplos de grandezas que 
são calculadas a partir da velocidade de escoamento livre, com aplicações subsequentes ao estudo de ruído aerodinâmico.

Tabela 3.4: Grandezas medidas indiretamente a partir de $p_{\infty}$ e $T$

\begin{tabular}{|c|c|}
\hline$p_{\infty}(P a)$ & $T(K)$ \\
\hline \hline$U_{\infty}=\sqrt{2 p_{\infty} / \rho}$ & $c=\sqrt{\gamma R T}, \mu=C_{1} T^{3 / 2} /\left(T+C_{2}\right), \rho=p_{e s t} / R T$ \\
\hline
\end{tabular}

Tabela 3.5: Grandezas derivadas da velocidade de escoamento livre

$$
\begin{array}{|c|c|}
\hline\left(U_{\infty}, c\right) & \left(U_{\infty}, \rho\right) \\
\hline \hline M=U_{\infty} / c & R e=\rho U_{\infty} L / \mu \\
\hline
\end{array}
$$

As relações apresentadas nas tabelas 3.4 e 3.5 são derivadas sob a hipótese de que o ar, em condições atmosféricas, se comporta como um gás ideal. O parâmetro $U_{\infty}$ representa a velocidade de escoamento livre, em unidades de $\mathrm{m} / \mathrm{s}$. A velocidade do som, $c(\mathrm{~m} / \mathrm{s})$, depende da temperatura medida na câmara de ensaios, sendo $\gamma$ o coeficiente de expansão adiabática do ar, definido pela razão entre o calor específico a pressão constante e o calor específico a volume constante. $R=286,996(J / K g \times K)$ é a constante universal dos gases perfeitos para o ar, considerando uma composição molecular de $78 \%$ de nitrogênio, $21 \%$ de oxigênio e $1 \%$ de argônio. A viscosidade dinâmica, ou absoluta, $\mu$, em unidades de $\mathrm{Kg} / \mathrm{m} \times s$, é calculada a partir da lei de Sutherland, sendo $C_{1}=1,458 \times 10^{-6}(\mathrm{Kg} / \mathrm{m} \times$ $\left.s \times K^{1 / 2}\right)$ e $C_{2}=110,4(K)$. A densidade do ar, $\rho$, em unidades de $K g / m^{3}$, é calculada a partir da lei dos gases ideais.

O número de Mach é um parâmetro adimensional que representa a relação entre a velocidade de escoamento livre e a velocidade do som nas condições do experimento. $\mathrm{O}$ número de Reynolds, Re, é determinado em termos da corda do modelo recolhido. A tabela 3.6 mostra valores típicos de números de Mach e Reynolds obtidos para as velocidades de escoamentos praticadas nos experimentos. Para o cálculo do número de Reynolds, utilizou-se $c_{s}=0.5 \mathrm{~m}$ para a corda recolhida do aerofólio.

Tabela 3.6: Valores típicos dos números de Mach e Reynolds

\begin{tabular}{|c|c|c|}
\hline Velocidade $(\mathrm{m} / \mathrm{s})$ & Mach & Reynolds \\
\hline \hline 24 & 0,0695 & $7,06 \times 10^{5}$ \\
\hline 27,1 & 0.0777 & $7,75 \times 10^{5}$ \\
\hline 31,3 & 0,0895 & $8,83 \times 10^{5}$ \\
\hline 33,9 & 0,0977 & $9,62 \times 10^{5}$ \\
\hline
\end{tabular}


CAPÍTULO 4

\section{Fundamentos de Beam-forming Acústico}

\subsection{Introdução}

Neste capítulo apresentam-se os principais conceitos que embasam a aplicação das técnicas de beam-forming convencional e deconvolução DAMAS ao problema de mapeamento de fontes em aeroacústica. Detalhes sobre a metodologia de processamento adotada neste trabalho são apresentados e discutidos. Alguns resultados são apresentados com a finalidade de avaliar o desempenho dos códigos implementados. 


\subsection{Considerações Gerais}

Beam-forming ${ }^{1}$ acústico é uma técnica de mapeamento de fontes que, baseada na otimização de uma função objetivo Suzuki (2010), procura minimizar o erro na reconstrução de uma distribuição de fontes a partir de um número limitado de medidas discretas de pressão amostradas em um campo acústico. Os sinais de pressão sonora são transformados para o domínio da frequência, ou domínio de Fourier para o caso de ondas planas, projetados linearmente sobre uma base de vetores que representa um modelo de propagação de ondas acústicas e somados. O resultado de tal operação representa uma estimativa de posição e amplitude de fontes como solução de um problema inverso em acústica.

A medição dos níveis de flutuação de pressão em campo distante não representa informação suficiente para a determinação unívoca da fonte (DOWLING; WILLIAMS, 1983). Desta forma, fontes distintas podem produzir o mesmo padrão de distribuição de pressão sonora sobre a superfície de uma antena de microfones. Por outro lado, o campo acústico gerado por uma fonte conhecida é bem determinado. Desta forma, métodos analíticos dedicados à solução de problemas inversos em acústica geralmente assumem que o campo sonoro amostrado pode ser representado por um modelo de fonte e uma função de transferência associada.

Em geral, algoritmos de beam-forming baseiam-se em um modelo matemático que descreve a propagação de ondas acústicas em um meio com propriedades físicas bem definidas. Tais modelos são, em geral, bastante simplificados em relação à complexidade envolvida nos fenômenos de geração e propagação do som. O modelo de beam-forming considerado neste trabalho assume a propagação de frentes de ondas esféricas em condição de campo livre e com origem em uma distribuição de fontes pontuais decorrelacionas, do tipo monopolo. Os efeitos da contaminação do sinal de interesse por ruído de naturezas diversas são desconsiderados neste modelo. Estas simplificações são premissas comuns à grande maioria dos modelos de beam-forming e, em tese, não representam restrições severas à aplicação desta metodologia, desde que baseada em um processamento de sinais adequado.

\footnotetext{
${ }^{1}$ A palavra beam se refere ao lóbulo principal do padrão de resposta de um array de sensores (JOHNSON; DUDGEON, 1993). O termo beam-forming parece ser uma referência à sua propriedade do filtro espaço-temporal. Embora haja trabalhos relacionados ao conceito de beam-forming na literatura nacional, não é do conhecimento do autor uma tradução livre e de uso comum para o termo beam-forming.
} 


\subsection{Beam-forming Convencional: Formulação Teó- rica}

A técnica de beam-forming convencional no domínio da frequência pode ser entendida como uma variante da técnica elementar denominada delay-and-sum, e tem se mostrado uma metodologia promissora para aplicações em aeroacústica (OERLEMANS, 2009). A expressão

$$
b\left(\vec{r}_{o, s}, \omega_{l}\right)=\mathbf{h}^{\dagger}\left(\vec{r}_{m, s}, \omega_{l}\right)\left\langle\mathbf{u}\left(\vec{r}_{o, m}, \omega_{l}\right) \mathbf{u}^{\dagger}\left(\vec{r}_{o, m}, \omega_{l}\right)\right\rangle \mathbf{h}\left(\vec{r}_{m, s}, \omega_{l}\right)
$$

representa uma formulação geral de beam-forming no domínio da frequência, que é comumente descrita na literatura (SARRADJ, 2012). Esta formulação é adequada ao processamento de dados aeroacústicos medidos com o uso de uma antena de microfones (MUELLER, 2002). Particularidades da metodologia de beam-forming convencional adotada neste trabalho serão discutidas na seção 4.4.

Na Eq. 4.1, o escalar $b\left(\vec{r}_{o, s}, \omega_{l}\right)$ representa uma estimativa de pressão sonora para uma fonte $(s)$, com vetor de posição dado por $\vec{r}_{o, s}$ em relação a um ponto de referência arbitrário $o$. Os vetores coluna $\mathbf{h}\left(\vec{r}_{m, s}, \omega_{l}\right)$ e $\mathbf{u}\left(\vec{r}_{o, m}, \omega_{l}\right)$ têm dimensão $M \times 1$ e elementos complexos, sendo $M$ o número de sinais medidos, ou de microfones ativos na antena. O vetor $\mathbf{u}\left(\vec{r}_{o, m}, \omega_{l}\right)$ reúne estimativas espectrais de pressão sonora, que representam as transformadas de Fourier dos sinais no tempo medidos por sensores com vetores de posição $\vec{r}_{o, 1}, \vec{r}_{o, 2}, \ldots, \vec{r}_{o, m}, \ldots, \vec{r}_{o, M}$, em relação ao ponto de referência $o$. O vetor $\mathbf{h}\left(\vec{r}_{m, s}, \omega_{l}\right)$ reúne os steering vectors, que são funções de transferência normalizadas que modelam a propagação de uma onda acústica desde o ponto focal com vetor posição $\vec{r}_{o, s}$ até cada microfone da antena, sendo $\vec{r}_{m, s}$ o vetor deslocamento entre a posição do microfone de índice $m$ e o ponto focal $(s)$. O simbolo $\omega_{l}$ indica que o vetor $\mathbf{u}\left(\vec{r}_{o, m}, \omega_{l}\right)$ contém os coeficientes da transformada de Fourier para a frequência $f_{l}=\omega_{l} / 2 \pi$. Portanto, os steering vectors representam funções de transferência para a frequência $f_{l}$, e o escalar $b\left(\vec{r}_{o, s}, \omega_{l}\right)$ representa uma estimativa de pressão sonora para a respectiva frequência. O produto externo $\left\langle\mathbf{u}\left(\vec{r}_{o, m}, \omega_{l}\right) \mathbf{u}^{\dagger}\left(\vec{r}_{o, m}, \omega_{l}\right)\right\rangle$ resulta na matriz de espectros cruzados, aqui representada por $\mathbf{C}\left(\omega_{l}\right)$. Os vetores $\vec{r}_{o, m}$ e $\vec{r}_{o, s}$ são definidos em relação ao sistema de referência da antena. Por fim, os símbolos $(\langle\rangle)$ e $(\dagger)$ denotam o valor esperado de uma medida e o operador Hermitiano, ou complexo conjugado, respectivamente.

O escalar $u_{m}\left(\vec{r}_{o, m}, \omega_{l}\right)$, que é um elemento do vetor $\mathbf{u}\left(\vec{r}_{o, m}, \omega_{l}\right)$, é definido como

$$
u_{m}\left(\vec{r}_{o, m}, \omega_{l}\right)=\sum_{k=1}^{K} g_{k}\left(\vec{r}_{m, k}, \omega_{l}\right) q_{k}\left(\vec{r}_{o, k}, \omega_{l}\right)=\mathbf{g}^{\dagger}\left(\vec{r}_{m, k}, \omega_{l}\right) \mathbf{q}\left(\vec{r}_{o, k}, \omega_{l}\right)
$$

e representa a estimativa espectral de pressão sonora do sinal medido pelo microfone de índice $m$, e que, por modelagem, é o resultado da sobreposição de ondas acústicas emitidas 
por um número $K$ de fontes puntuais do tipo monopolo, decorrelacionadas e espacialmente distribuídas.

O termo $q_{k}\left(\vec{r}_{o, k}, \omega_{l}\right)$ representa a amplitude de uma fonte sonora $(k)$ distante $\vec{r}_{o, k}$ de uma posição de referência $o$, sendo $g_{k}\left(\vec{r}_{m, k}, \omega_{l}\right)$ a função de transferência que modela a propagação de uma onda de pressão da fonte $(k)$ até o microfone com vetor de posição $\vec{r}_{o, m}$. Por generalização, os vetores $\mathbf{g}^{\dagger}\left(\vec{r}_{m, k}, \omega_{l}\right)$ e $\mathbf{q}\left(\vec{r}_{o, k}, \omega_{l}\right)$ reúnem, respectivamente, todas as funções de transferência e amplitudes complexas necessárias para modelar a propagação das ondas acústicas geradas por uma distribuição de $K$ fontes discretas do tipo monopolo até o microfone com vetor de posição $\vec{r}_{o, m}$.

A matriz $\mathbf{G}\left(\vec{r}_{m, k}, \omega_{l}\right), \mathbf{G} \in \mathbb{C}^{M \times K}$, sendo $\mathbb{C}^{M \times K}$ o espaço das matrizes complexas com dimensão $M \times K$, é definida como

$$
\mathbf{G}\left(\vec{r}_{m, k}, \omega_{l}\right)=\left[\begin{array}{cccc}
g\left(\vec{r}_{1,1}, \omega_{l}\right) & g\left(\vec{r}_{1,2}, \omega_{l}\right) & \cdots & g\left(\vec{r}_{1, K}, \omega_{l}\right) \\
g\left(\vec{r}_{2,1}, \omega_{l}\right) & g\left(\vec{r}_{2,2}, \omega_{l}\right) & \cdots & g\left(\vec{r}_{2, K}, \omega_{l}\right) \\
\vdots & \vdots & \ddots & \vdots \\
g\left(\vec{r}_{M, 1}, \omega_{l}\right) & g\left(\vec{r}_{M, 2}, \omega_{l}\right) & \cdots & g\left(\vec{r}_{M, K}, \omega_{l}\right)
\end{array}\right]
$$

A definição da matriz $\mathbf{G}\left(\vec{r}_{m, k}, \omega_{l}\right)$, conforme a Eq. 4.3, é conveniente para a representação matricial da metodologia de beam-forming. De acordo com a Eq. 4.3, cada linha da matriz $\mathbf{G}\left(\vec{r}_{m, k}, \omega_{l}\right)$ reúne as funções de transferência que modelam a propagação de frentes de onda desde de cada uma das $K$ fontes até um dado microfone, enquanto que cada coluna representa a propagação de uma dada fonte sobre todos os microfones da antena.

O vetor $\mathbf{u}\left(\vec{r}_{o, m}, \omega_{l}\right)$ pode então ser definido como o produto da matriz $\mathbf{G}_{M, K}$ pelo vetor $\mathbf{q}\left(\vec{r}_{o, k}, \omega_{l}\right)$, dado por

$$
\mathbf{u}\left(\vec{r}_{o, m}, \omega_{l}\right)=\mathbf{G}\left(\vec{r}_{m, k}, \omega_{l}\right) \mathbf{q}\left(\vec{r}_{o, k}, \omega_{l}\right)
$$

Sendo $u_{m}\left(\vec{r}_{o, m}, \omega_{l}\right)$ um elemento de $\mathbf{u}\left(\vec{r}_{o, m}, \omega_{l}\right)$, a Eq. 4.4 representa a generalização da Eq. 4.2 para uma antena com $M$ microfones.

Substituindo a Eq. 4.4 na Eq.4.1, pode-se então representar a solução de beam-forming em termos do modelo de propagação de ondas acústicas dado pela Eq. 4.2, conforme

$$
b\left(\vec{r}_{o, s}, \omega_{l}\right)=\mathbf{h}^{\dagger}\left(\vec{r}_{m, s}, \omega_{l}\right)\left\langle\mathbf{G}\left(\vec{r}_{m, k}, \omega_{l}\right) \mathbf{q}\left(\vec{r}_{o, k}, \omega_{l}\right)\left(\mathbf{G}\left(\vec{r}_{m, k}, \omega_{l}\right) \mathbf{q}\left(\vec{r}_{o, k}, \omega_{l}\right)\right)^{\dagger}\right\rangle \mathbf{h}\left(\vec{r}_{m, s}, \omega_{l}\right)
$$

que pode ser reescrita na seguinte forma:

$$
b\left(\vec{r}_{s}, \omega_{l}\right)=\left(\mathbf{h}^{\dagger}\left(\vec{r}_{m, s}\right) \mathbf{G}\left(\vec{r}_{m, k}, \omega_{l}\right)\right)\left\langle\mathbf{q}\left(\vec{r}_{o, k}, \omega_{l}\right) \mathbf{q}^{\dagger}\left(\vec{r}_{o, k}, \omega_{l}\right)\right\rangle\left(\mathbf{h}^{\dagger}\left(\vec{r}_{m, s}\right) \mathbf{G}\left(\vec{r}_{m, k}, \omega_{l}\right)\right)^{\dagger}
$$


O produto externo $\left\langle\mathbf{q}\left(\vec{r}_{o, k}, \omega_{l}\right) \mathbf{q}^{\dagger}\left(\vec{r}_{o, k}, \omega_{l}\right)\right\rangle$ resulta na matriz

$$
\left[\begin{array}{cccc}
\left\langle q\left(\vec{r}_{o, 1}\right) q^{*}\left(\vec{r}_{o, 1}\right)\right\rangle & \left\langle q\left(\vec{r}_{o, 1}\right) q^{*}\left(\vec{r}_{o, 2}\right)\right\rangle & \cdots & \left\langle q\left(\vec{r}_{o, 1}\right) q^{*}\left(\vec{r}_{o, K}\right)\right\rangle \\
\left\langle q\left(\vec{r}_{o, 2}\right) q^{*}\left(\vec{r}_{o, 1}\right)\right\rangle & \left\langle q\left(\vec{r}_{o, 2}\right) q^{*}\left(\vec{r}_{o, 2}\right)\right\rangle & \cdots & \left\langle q\left(\vec{r}_{o, 2}\right) q^{*}\left(\vec{r}_{o, K}\right)\right\rangle \\
\vdots & \vdots & \ddots & \vdots \\
\left\langle q\left(\vec{r}_{o, K}\right) q *\left(\vec{r}_{o, 1}\right)\right\rangle & \left\langle q\left(\vec{r}_{o, K}\right) q^{*}\left(\vec{r}_{o, 2}\right)\right\rangle & \cdots & \left\langle q\left(\vec{r}_{o, K}\right) q^{*}\left(\vec{r}_{o, K}\right)\right\rangle
\end{array}\right]
$$

na qual o índice $\omega_{l}$ foi omitido e o símbolo $(*)$ denota o complexo conjugado de um escalar. Modelos de beam-forming, em sua grande maioria, consideram distribuições de fontes acústicas espacialmente decorrelacionadas. A condição de decorrelação para duas fontes unitárias se aplica na forma (MUELLER, 2002)

$$
\left\langle q\left(\vec{r}_{o, k}, \omega_{l}\right) q\left(\vec{r}_{o, s}, \omega_{l}\right)\right\rangle=\delta\left(\vec{r}_{o, k}-\vec{r}_{o, s}\right)
$$

condição na qual a matriz na Eq. 4.7 torna-se uma matriz diagonal cujos termos representam as auto-correlações entre as amplitues das fontes, e a Eq. 4.6 se escreve na forma:

$$
b\left(\vec{r}_{o, s}, \omega_{l}\right)=\sum_{k=1}^{K}\left(\mathbf{h}^{\dagger}\left(\vec{r}_{m, s}\right) \mathbf{G}_{k}\left(\vec{r}_{m, k}\right)\right)\left(\mathbf{h}^{\dagger}\left(\vec{r}_{m, s}\right) \mathbf{G}_{k}\left(\vec{r}_{m, k}\right)\right)^{\dagger}\left\langle q_{k}\left(\vec{r}_{o, k}\right) q_{k}^{\dagger}\left(\vec{r}_{o, k}\right)\right\rangle
$$

Na Eq. $4.9, \mathbf{G}_{k}\left(\vec{r}_{m, k}, \omega_{l}\right)$ é o vetor com os elementos da $k$-ésima coluna da matriz $\mathbf{G}\left(\vec{r}_{m, k}, \omega_{l}\right)$, definida na Eq. 4.3. O produto $\mathbf{h}^{\dagger}\left(\vec{r}_{m, s}, \omega_{l}\right) \mathbf{G}_{k}\left(\vec{r}_{m, k}, \omega_{l}\right)$ determina o $k$-ésimo elemento do vetor $\mathbf{h}^{\dagger}\left(\vec{r}_{m, s}, \omega_{l}\right) \mathbf{G}\left(\vec{r}_{m, k}, \omega_{l}\right)$, cujo quadrado da norma representa a função de forma do array ( $p s f)$, estimada em relação ao ponto focal com vetor posição $\vec{r}_{o, s}$. Define-se o steering vector como.

$$
\mathbf{h}\left(\vec{r}_{m, s}, \omega_{l}\right)=\frac{\mathbf{G}_{s}\left(\vec{r}_{m, s}, \omega_{l}\right)}{\left\|\mathbf{G}_{s}\left(\vec{r}_{m, s}, \omega_{l}\right)\right\|}
$$

Substituindo-se a Eq. 4.10 na Eq. 4.9, decorre que

$$
\begin{aligned}
b\left(\vec{r}_{o, s}, \omega_{l}\right) & = \\
& =\frac{\sum_{k=1}^{K}\left(\mathbf{G}_{s}^{\dagger}\left(\vec{r}_{m, s}\right) \mathbf{G}_{k}\left(\vec{r}_{m, k}\right)\right)\left(\mathbf{G}_{s}^{\dagger}\left(\vec{r}_{m, s}\right) \mathbf{G}_{k}\left(\vec{r}_{m, k}\right)\right)^{\dagger}\left\langle q_{k}\left(\vec{r}_{m, k}\right) q_{k}^{\dagger}\left(\vec{r}_{m, k}\right)\right\rangle}{\left\|\mathbf{G}_{s}\left(\vec{r}_{m, s}\right)\right\|^{2}}
\end{aligned}
$$

A Eq. 4.11 pode ser reescrita na forma

$$
\begin{aligned}
b\left(\vec{r}_{o, s}, \omega_{l}\right) & =\left\|\mathbf{G}_{s}\left(\vec{r}_{m, s}, \omega_{l}\right)\right\|^{2}\left\langle q\left(\vec{r}_{o, s}, \omega_{l}\right) q^{\dagger}\left(\vec{r}_{o, s}, \omega_{l}\right)\right\rangle \\
& +\frac{\sum_{k=1, k \neq s}^{K}\left\|\mathbf{G}_{s}^{\dagger}\left(\vec{r}_{m, s}, \omega_{l}\right) \mathbf{G}_{k}\left(\vec{r}_{m, k}, \omega_{l}\right)\right\|^{2}\left\langle q_{k}\left(\vec{r}_{o, k}, \omega_{l}\right) q_{k}^{\dagger}\left(\vec{r}_{o, k}, \omega_{l}\right)\right\rangle}{\left\|\mathbf{G}_{s}\left(\vec{r}_{m, s}, \omega_{l}\right)\right\|^{2}}
\end{aligned}
$$

onde o primeiro termo à direita representa a contribuição da fonte acústica na posição 
focal, e o segundo termo a contribuição das demais fontes para o espectro de pressão sonora estimado pelo método de beam-forming convencional.

Para uma melhor interpretação da Eq. 4.12, seja o desenvolvimento da Eq. 4.4 na forma

$$
\left\|\mathbf{G}_{s}\left(\vec{r}_{m, s}, \omega_{l}\right)\right\|^{2}\left\langle q\left(\vec{r}_{m, s}, \omega_{l}\right) q^{\dagger}\left(\vec{r}_{m, s}, \omega_{l}\right)\right\rangle=\left\langle\mathbf{u}^{\dagger}\left(\vec{r}_{m, s}, \omega_{l}\right) \mathbf{u}\left(\vec{r}_{m, s}, \omega_{l}\right\rangle\right)
$$

Em termos da Eq. 4.13, a Eq. 4.12 se escreve na forma:

$$
\begin{aligned}
b\left(\vec{r}_{o, s}, \omega_{l}\right) & =\left\langle\mathbf{u}^{\dagger}\left(\vec{r}_{m, s}, \omega_{l}\right) \mathbf{u}\left(\vec{r}_{m, s}, \omega_{l}\right\rangle\right) \\
& +\frac{\sum_{k=1, k \neq s}^{K}\left\|\mathbf{G}_{s}^{\dagger}\left(\vec{r}_{m, s}, \omega_{l}\right) \mathbf{G}_{k}\left(\vec{r}_{m, k}, \omega_{l}\right)\right\|^{2}\left\langle q_{k}\left(\vec{r}_{o, k}, \omega_{l}\right) q_{k}^{\dagger}\left(\vec{r}_{o, k}, \omega_{l}\right)\right\rangle}{\left\|\mathbf{G}_{s}\left(\vec{r}_{m, s}, \omega_{l}\right)\right\|^{2}}
\end{aligned}
$$

Na Eq. 4.14 o termo $\left\langle\mathbf{u}^{\dagger}\left(\vec{r}_{m, s}, \omega_{l}\right) \mathbf{u}\left(\vec{r}_{m, s}, \omega_{l}\right\rangle\right)$ representa o valor esperado da soma das auto-correlações dos espectros dos sinais de pressão que são medidos pelos microfones devido à fonte na posição focal $\vec{r}_{o, s}$. Este termo representa a principal contribuição para o resultado obtido pelo método de beam-forming e sugere um ganho de valor $M$, semelhante ao que se verifica no método delay-and-sum (MUELLER, 2002). O segundo termo no lado direito da Eq. 4.14 representa a contribuição das demais fontes ao resultado beamforming. Este termo é um resíduo do processamento beam-forming e a capacidade em rejeitá-lo depende das propriedades de filtro espaço-temporal da técnica de beam-forming utilizada.

É oportuno salientar que as equações de beam-forming apresentadas nesta seção não são utilizadas diretamente no processamento de dados cujos resultados são discutidos neste trabalho. No entanto, alguns conceitos apresentados são necessários para uma discussão mais realista sobre o código de beam-forming implementado e aplicado ao processamento dos dados de ruído do eslate.

\subsubsection{Integração de Fontes na Formulação de Beam-forming Convencional}

A aplicação da Eq. 4.1 no domínio discreto de uma malha de pontos permite a estimativa do nível de pressão sonora de uma fonte pontual a partir de seu valor de pico (HORNE et al., 2000). De forma geral, esta ideia é válida para um conjunto de fontes esparsas. Para o caso de fontes espacialmente distribuídas, a estimativa do nível de pressão sonora das fontes sobre um domínio espacial pode ser feita pela integração de valores discretos de pressão sonora (BROOKS; HUMPHREYS, 1999). Para a formulação de beam-forming convencional, a integral dos valores de pressão sonora em um domínio 
discreto $\Omega$ é dado por

$$
\begin{aligned}
\sum_{s \in \Omega} b\left(\vec{r}_{o, s}, \omega_{l}\right) & = \\
& =\frac{\sum_{s \in \Omega} \sum_{k=1}^{K}\left(\mathbf{h}^{\dagger}\left(\vec{r}_{m, s}\right) \mathbf{G}_{k}\left(\vec{r}_{m, k}\right)\right)\left(\mathbf{h}^{\dagger}\left(\vec{r}_{m, s}\right) \mathbf{G}_{k}\left(\vec{r}_{m, k}\right)\right)^{\dagger}\left\langle q_{k}\left(\vec{r}_{o, k}\right) q_{k}^{\dagger}\left(\vec{r}_{o, k}\right)\right\rangle}{\sum_{s \in \Omega} \sum_{k=1}^{K}\left(\mathbf{h}^{\dagger}\left(\vec{r}_{m, s}\right) \mathbf{G}_{k}\left(\vec{r}_{m, k}\right)\right)\left(\mathbf{h}^{\dagger}\left(\vec{r}_{m, s}\right) \mathbf{G}_{k}\left(\vec{r}_{m, k}\right)\right)^{\dagger}}
\end{aligned}
$$

O denominador na Eq. 4.15 representa a integração de uma fonte unitária, para a qual as características do lóbulo principal e da distribuição de lóbulos secundários, em uma dada frequência, são determinados essencialmente pela geometria da antena de microfones (MUELLER, 2002). É interessante notar que a Eq. 4.15 representa a normalização da integral das fontes mapeadas pela integral de uma fonte de amplitude unitária, ambas as integrais definidas no domínio $\Omega$. Esta normalização tem por objetivo tornar o resultado da integração independente da largura do lóbulo das fontes em uma dada frequência. Tal procedimento permite a comparação entre resultados obtidos com antenas de diferentes geometrias, o que seria inconsistente sem a devida normalização.

Um segundo aspecto a ser considerado é que a representação de uma fonte unitária na forma de uma mapa de beam-forming reproduz aos lóbulos secundários que são determinados pela geometria da antena, tal como ocorre em um mapa gerado por fontes físicas. Desta forma, ocorre que a energia dos lóbulos secundários eventualmente contabilizados na integração de um mapa de beam-forming será potencialmente compensada pela integração da energia dos lóbulos secundários da fonte unitária.

\subsubsection{Faixa Dinâmica para Integração de Fontes}

O domínio de integração para uma distribuição de fontes pode ser escolhido de forma a separar fontes de interesse de fontes espúrias, ou seja, fontes que não têm relação com os mecanismos de geração sob estudo. Uma vez escolhido o domínio de integração, é possível excluir fontes de menor amplitude, que podem representar fontes espúrias, ou mesmo lóbulos secundários de fontes com origem externa ao domínio de integração. Este procedimento determina a integração de fontes com valores acima de um valor de referência estabelecido. A diferença entre o valor de pico no mapa de beam-forming e o valor de referência adotado é definida coma a faixa dinâmica de integração, aqui denominada $D r$, em unidades de dB. Desta forma, serão contabilizados na integração todos os pontos da malha com nível de pressão sonora não inferior à $\operatorname{Dr}(\mathrm{dB})$ em relação o nível de pressão sonora da fonte de maior amplitude no domínio de integração. Para a formalização deste conceito, seja $I\left(\omega_{l}\right)$ a integral sobre o domínio $\Omega$, definido pela Eq. 4.15. A condição de uma faixa dinâmica de integração pode ser posta na forma 


$$
\left\{\begin{array}{l}
I\left(\omega_{l}\right)=\sum_{k=1}^{K}\left|b\left(k, \omega_{l}\right)\right| \\
\text { se } 10 \log 10\left(\frac{\max \left|b\left(k, \omega_{l}\right)\right|}{\left|b\left(k, \omega_{l}\right)\right|}\right) \geq \operatorname{Dr}\left(\omega_{l}\right)
\end{array}\right.
$$

A faixa dinâmica de integração é arbitrária, no sentido de que pode assumir qualquer valor abaixo do máximo nível de pressão sonora. No entanto, é desejável que a faixa dinâmica de integração não seja superior à faixa dinâmica da antena, que é definida como a diferença, em dB, entre os níveis do lóbulo principal e do lóbulo secundário de maior amplitude no padrão de resposta da antena. Desta forma, pode-se adotar para a faixa dinâmica de integração um valor próximo daquele da faixa dinâmica da antena (quando esta é conhecida), de forma a se evitar a influência de lóbulos laterais na estimativa do nível de pressão sonora das fontes de interesse. Quando métodos de deconvolução são aplicados ao processamento dos dados acústicos, há uma redução na amplitude do lóbulos laterais, por conta da redução dos efeitos da geometria da antena sobre os resultados de beam-forming, o que potencialmente representa um ganho de faixa dinâmica.

\subsection{Implementação do Algoritmo de Beam-forming Convencional}

Nesta seção é apresentada a formulação de beam-forming convencional adotada para o processamento das medições experimentais realizadas com uma antena de microfones. Para a sequência do desenvolvimento, o produto externo $\left\langle\mathbf{u}\left(\vec{r}_{o, m}, \omega_{l}\right) \mathbf{u}^{\dagger}\left(\vec{r}_{o, m}, \omega_{l}\right)\right\rangle$, (Eq. 4.1), é definido como a matriz de espectros cruzados, para a frequência $\omega_{l}$, aqui denotada por $\mathbf{C}\left(\omega_{l}\right)$. O produto externo $\left\langle\mathbf{u}\left(\vec{r}_{o, m}, \omega_{l}\right) \mathbf{u}^{\dagger}\left(\vec{r}_{o, m}, \omega_{l}\right)\right\rangle$ pode ser desenvolvido na forma

$$
\mathbf{C}\left(\omega_{l}\right)=\left[\begin{array}{cccccccc}
\left\langle u_{1} u_{1}^{\dagger}\right\rangle & \left\langle u_{1} u_{2}^{\dagger}\right\rangle & \cdots & \left\langle u_{1} u_{m}^{\dagger}\right\rangle & \cdots & \left\langle u_{1} u_{n}^{\dagger}\right\rangle & \cdots & \left\langle u_{1} u_{M}^{\dagger}\right\rangle \\
\left\langle u_{2} u_{1}^{\dagger}\right\rangle & \left\langle u_{2} u_{2}^{\dagger}\right\rangle & \cdots & \left\langle u_{1} u_{m}^{\dagger}\right\rangle & \cdots & \left\langle u_{2} u_{n}^{\dagger}\right\rangle & \cdots & \left\langle u_{2} u_{M}^{\dagger}\right\rangle \\
\vdots & \vdots & \ddots & \vdots & \ddots & \vdots & \ddots & \vdots \\
\left\langle u_{m} u_{1}^{\dagger}\right\rangle & \left\langle u_{m} u_{2}^{\dagger}\right\rangle & \cdots & \left\langle u_{m} u_{m}^{\dagger}\right\rangle & \cdots & \left\langle u_{m} u_{n}^{\dagger}\right\rangle & \cdots & \left\langle u_{m} u_{M}^{\dagger}\right\rangle \\
\vdots & \vdots & \ddots & \vdots & \ddots & \vdots & \ddots & \vdots \\
\left\langle u_{n} u_{1}^{\dagger}\right\rangle & \left\langle u_{n} u_{2}^{\dagger}\right\rangle & \cdots & \left\langle u_{n} u_{m}^{\dagger}\right\rangle & \cdots & \left\langle u_{n} u_{n}^{\dagger}\right\rangle & \cdots & \left\langle u_{n} u_{M}^{\dagger}\right\rangle \\
\vdots & \vdots & \ddots & \vdots & \ddots & \vdots & \ddots & \vdots \\
\left\langle u_{M} u_{1}^{\dagger}\right\rangle & \left\langle u_{M} u_{2}^{\dagger}\right\rangle & \cdots & \left\langle u_{M} u_{m}^{\dagger}\right\rangle & \cdots & \left\langle u_{M} u_{n}^{\dagger}\right\rangle & \cdots & \left\langle u_{M} u_{M}^{\dagger}\right\rangle
\end{array}\right]
$$


sendo $u_{m}$ e $u_{n}$, componentes do vetor $\mathbf{u}$. O índices $m$ e $n$ são números inteiros que podem variar entre 1 e $M$. A Eq. 4.17 foi escrita de forma a tornar evidente que o vetor $\mathbf{u}\left(\vec{r}_{o, m}, \omega_{l}\right)$ contem informações de todos os microfones.

A particularidade na formulação de beam-forming convencional adotada neste trabalho, que é baseada na Eq. 4.1, consiste na definição do steering vector, na seguinte forma

$$
\mathbf{h}\left(\vec{r}_{m, s}, \omega_{l}\right)=\frac{\mathbf{g}\left(\vec{r}_{m, s}, \omega_{l}\right)}{\sqrt{\sum_{n=1}^{M} \sum_{m=1}^{M}\left|g_{m} \| g_{n}\right|}}
$$

O steering vector, conforme definido na Eq. 4.18, é dado por uma normalização do vetor de funções de transferência $\mathbf{g}\left(\vec{r}_{m, s}, \omega_{l}\right)$. Os termos $g_{m}$ e $g_{n}$ são funções de transferência definidas para os microfones de índices $m$ e $n$, e o ponto focal $(s)$, com vetor de posição $\vec{r}_{o, s}$. É oportuno observar que a normalização do vetor de funções de transferência, conforme a Eq. 4.18, leva em conta o número de produtos, ou elementos da matriz de espectros cruzados, que são efetivamente somados para a obtenção do resultado.

O vetor de funções de transferência é definido como

$$
\mathbf{g}\left(\vec{r}_{m, s}, \omega_{l}\right)=\left[\begin{array}{c}
\frac{r_{s, o}}{r_{s, 1}} e^{-i \omega_{l}\left(r_{s, 1}-r_{s, o}\right) / c} \\
\frac{r_{s, o}}{r_{s, 2}} e^{-i \omega_{l}\left(r_{s, 2}-r_{s, o}\right) / c} \\
\vdots \\
\frac{r_{s, o}}{r_{s, M}} e^{-i \omega_{l}\left(r_{s, M}-r_{s, o}\right) / c}
\end{array}\right]
$$

de forma a modelar a propagação de uma onda esférica emitida por uma fonte do tipo monopolo, em condição de campo livre, com vetor de posição $\vec{r}_{o, s}$, e recebida por cada microfone da antena nas posições $\vec{r}_{o, m}, m=1,2, \ldots, n, \ldots, M$. De acordo com a Eq. 4.19, a pressão sonora propagada desde a fonte até cada microfone é normalizada pela pressão sonora propagada desde a fonte até um ponto de referência $o$, que geralmente coincide com a origem do sistema de referência adotado para a antena. Tal normalização das funções de transferência é de uso comum para aplicações de beam-forming em aeroacústica (SARRADJ, 2012). O uso dos vetores de posição sem a sobreposição pela flecha indica que os valores absolutos estão sendo usados. A Fig. 4.1 representa geometricamente os vetores de posição utilizados na formulação de beam-forming convencional adotada.

A seguinte expressão representa o desenvolvimento da Eq. 4.1, a partir da definição de steering vector dada pela Eq. 4.18

$$
b\left(\vec{r}_{o, s}, \omega_{l}\right)=\frac{\left|\sum_{n=1, n \neq m}^{M} \sum_{m=1, m \neq n}^{M}\left(g_{m}^{*}\right)\left[C_{m, n}\right]\left(g_{n}\right)\right|}{\sum_{n=1, n \neq m}^{M} \sum_{m=1, m \neq n}^{M}\left|g_{m}\right|\left|g_{n}\right|},
$$

na qual $C_{m, n}=\left\langle u_{m} u_{n}^{\dagger}\right\rangle$ é o termo da matriz de espectros cruzados dado pelas transformadas 


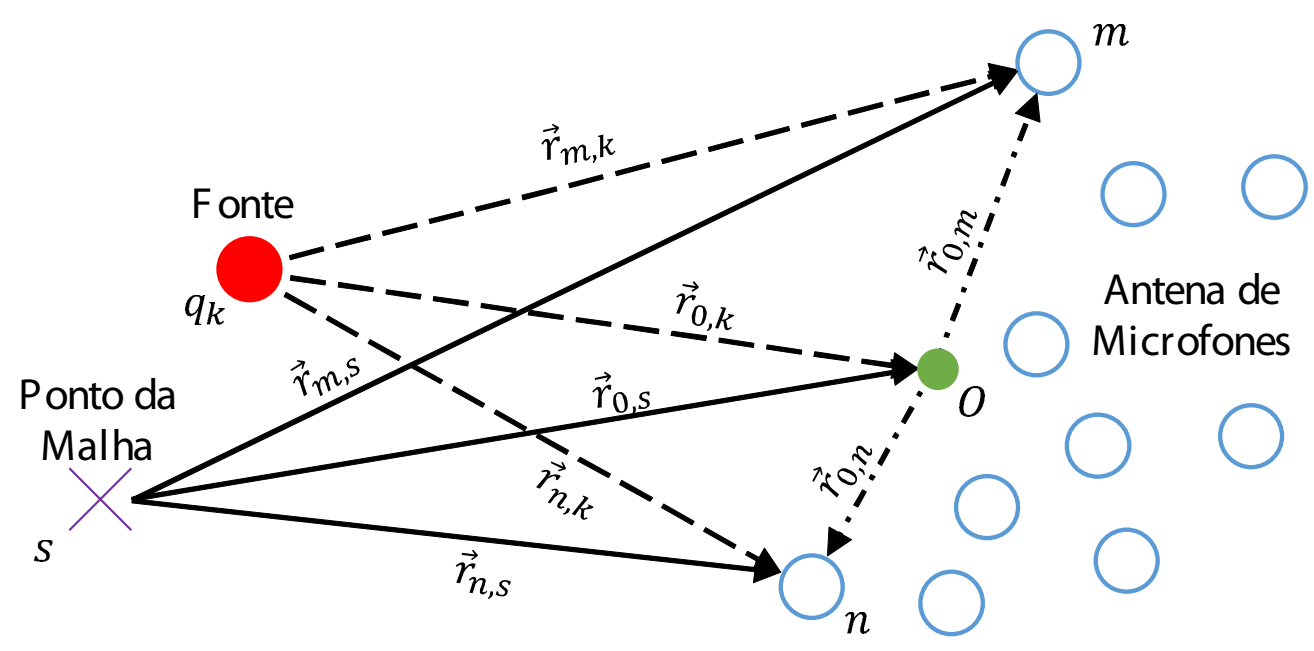

Figura 4.1: Representação geométrica das quantidades vetoriais usadas na formulação de beamforming acústico adotada neste trabalho. O ponto designado pela letra $s$ é um ponto focal, que se define para cada ponto de uma malha, a partir da qual é determinado o mapa de beam-forming. Na ilustração, a identificação da fonte $q_{k}$ ocorre para a condição $s=k$.

de Fourier dos sinais medidos pelos microfones de índices $m$ e $n$, para a frequência $\omega_{l}$. A Eq. 4.20 tem a forma de uma soma ponderada com $M^{2}$ termos, ou $M^{2}-M$, caso os elementos da diagonal principal da martriz $\mathbf{C}$ sejam removidos. Cada termo no numerador da Eq. 4.20 representa o produto entre sinais de um dado par de microfones, com correção de fase determinada pelos números complexos $g_{m}$ e $g_{n}$, de forma que todos os termos somem-se construtivamente para o sinal de uma fonte na posição $\vec{r}_{o, s}$, quando o sinal é emitido na frequência $\omega_{l}$. A forma do denominador na Eq. 4.20 também é consequência da definição do steering vector dada pela Eq. 4.18, de maneira que as ponderações nas amplitudes dos sinais, determinadas pelos números $g_{m}$ e $g_{n}$, sejam compensadas pela soma no denominador, o que torna a estimativa de pressão sonora, obtida a partir dos dados experimentais, representativa de um microfone de referência na antena. A condição $n \neq m$ determina a exclusão dos termos que representam o auto-espectro entre os sinais dos microfones, de forma que apenas as contribuições dos $M^{2}-M$ termos de espectros cruzados são consideradas. O sobrescrito $\left(^{*}\right)$ denota o complexo conjugado de um escalar.

\subsection{Mapeamento de uma Fonte Monopolo com o Al- goritmo de Beam-forming Convencional}

Nesta seção, a formulação de beam-forming convencional apresentada na seção 4.4 é aplicada ao mapeamento de uma fonte do tipo monopolo, com dimensões desprezíveis em relação à distância e ao diâmetro da antena de microfones. Esta bordagem permite avaliar a capacidade teórica da formulação em estimar a amplitude e a posição de uma fonte conhecida (SARRADJ, 2012), sendo bastante didática para ilustrar os conceitos 
4.5. Mapeamento de uma Fonte Monopolo com o Algoritmo de Beam-forming Convencional

matemáticos envolvidos no processamento. Para tal, assume-se que o sinal do m-ésimo microfone é modelado na forma $u_{m}\left(\vec{r}_{o, m}, \omega_{l}\right)=g\left(\vec{r}_{m, k}, \omega_{l}\right) q_{k}\left(\omega_{l}\right)$, que representa a medida de pressão sonora para uma única fonte com amplitude $q_{k}\left(\omega_{l}\right)$ e vetor de posição $\vec{r}_{o, k}$. Substituindo-se na Eq. 4.1 o steering vector definida na Eq. 4.18, decorre

$$
b\left(\vec{r}_{o, s}, \omega_{l}\right)=\frac{\mathbf{g}^{\dagger}\left(\vec{r}_{m, s}, \omega_{l}\right)\left[\mathbf{g}\left(\vec{r}_{m, k}, \omega_{l}\right) \mathbf{g}^{\dagger}\left(\vec{r}_{m, k}, \omega_{l}\right)\right] \mathbf{g}\left(\vec{r}_{m, s}, \omega_{l}\right)\left\langle q_{k}\left(\omega_{l}\right) q_{k}^{\dagger}\left(\omega_{l}\right)\right\rangle}{\sum_{n=1}^{M} \sum_{m=1}^{M}\left|g_{m} \| g_{n}\right|} .
$$

Reagrupando os termos no numerador e levando-se em conta a relação $g^{\dagger} q=\left(q^{\dagger} g\right)^{\dagger}$, a Eq. 4.21 pode ser reescrita na seguinte forma

$$
b\left(\vec{r}_{o, s}, \omega_{l}\right)=\frac{\mathbf{g}^{\dagger}\left(\vec{r}_{m, s}, \omega_{l}\right) \mathbf{g}\left(\vec{r}_{m, k}, \omega_{l}\right)\left[\mathbf{g}^{\dagger}\left(\vec{r}_{m, s}, \omega_{l}\right) \mathbf{g}\left(\vec{r}_{m, k}, \omega_{l}\right)\right]^{\dagger}\left\langle q_{k}\left(\omega_{l}\right) q_{k}^{\dagger}\left(\omega_{l}\right)\right\rangle}{\sum_{n=1}^{M} \sum_{m=1}^{M}\left|g_{m} \| g_{n}\right|} .
$$

Utilizando a relação

$$
\mathbf{g}^{\dagger}\left(\vec{r}_{m, s}, \omega_{l}\right) \mathbf{g}\left(\vec{r}_{m, k}, \omega_{l}\right)\left[\mathbf{g}^{\dagger}\left(\vec{r}_{m, s}, \omega_{l}\right) \mathbf{g}\left(\vec{r}_{m, k}, \omega_{l}\right)\right]^{\dagger}=\left|\left[\mathbf{g}^{\dagger}\left(\vec{r}_{m, s}, \omega_{l}\right) \mathbf{g}\left(\vec{r}_{m, k}, \omega_{l}\right)\right]^{2}\right|,
$$

e escrevendo o produto escalar no membro direito da Eq. 4.23 como uma soma de componentes, a Eq. 4.22 escreve-se na forma

$$
b\left(\vec{r}_{o, s}, \omega_{l}\right)=\frac{\left|\left[\sum_{m=1}^{M} g_{m}^{\dagger}\left(\vec{r}_{m, s}, \omega_{l}\right) g_{m}\left(\vec{r}_{m, k}, \omega_{l}\right)\right]^{2}\right|\left\langle q_{k}\left(\omega_{l}\right) q_{k}^{\dagger}\left(\omega_{l}\right)\right\rangle}{\sum_{n=1}^{M} \sum_{m=1}^{M}\left|g_{m}\right|\left|g_{n}\right|}
$$

Tendo-se em conta a função de transferência normalizada de acordo com a Eq. 4.19 e assumindo $\left\langle q_{k}\left(\omega_{l}\right) q_{k}^{\dagger}\left(\omega_{l}\right)\right\rangle=1$, temos que a Eq. 4.24 escreve-se na seguinte forma

$$
b\left(\vec{r}_{o, s}, \omega_{l}\right)=\frac{\left|\left\{\sum_{m=1}^{M}\left(r_{o, s} / r_{m, s}\right)\left(r_{o, k} / r_{m, k}\right) e^{i \omega / c\left[\left(r_{m, s}-r_{m, k}\right)+\left(r_{o, s}-r_{o, k}\right)\right]}\right\}^{2}\right|}{\left[\sum_{m=1}^{M}\left(r_{o, s} / r_{s, m}\right)\right]^{2}}
$$

A Eq. 4.25 representa uma descrição geométrica da Eq. 4.1 em termos das coordenadas dos vetores de posição dos pontos da malha e dos microfones no plano do array. Teoricamente, espera-se que o valor de máximo da Eq. 4.25 ocorra quando o ponto focal coincidir com a posição física da fonte, ou seja

$$
b\left(\vec{r}_{o, s}=\vec{r}_{o, k}, \omega_{l}\right)>b\left(\vec{r}_{o, s} \neq \vec{r}_{o, k}, \omega_{l}\right)
$$

A condição representada na Eq. 4.26 pode ser verificada analiticamente, tomando-se nula as derivadas parciais da Eq. 4.25, em relação às variáveis $\vec{r}_{o, s}$ e $\vec{r}_{o, k}$.

A Fig. 4.2 representa a imagem acústica de uma fonte puntual de amplitude unitária, mapeada pelo método de beam-forming representado pela Eq. 4.25. A localização 
da fonte é dada pelo vetor posição $\left(x_{k}=0.3425, y_{k}=0, z_{k}=0.85\right)$, satisfazendo à condição $\vec{r}_{m, k}=\sqrt{\left(x_{m}-0.3425\right)^{2}+\left(y_{m}-0\right)^{2}+\left(z_{m}-0.85\right)^{2}}$, para um microfone de coordenadas $\left(x_{m}, y_{m}, z_{m}\right)$. O ponto escolhido para a localização da fonte corresponde aproximadamente a um ponto no centro da região ocupada pelo eslate, com o aerofólio posicionado em ângulo de ataque de 4 graus. Os mapas de beam-forming são gerados variando-se o índice $s$, do vetor $\vec{r}_{m, s}$, no domínio $\Omega=\{1,2, \ldots, l, \ldots, L\}$, sendo $L$ o número total de pontos na malha. A fonte acústica foi simulada nas frequências de $1 \mathrm{kHz}, 2 \mathrm{kHz}, 4 \mathrm{kHz}$ e $8 \mathrm{kHz}$, em uma malha uniforme com centro na posição $(x=0.3425, y=0, z=0.85)$ e espaçamento de $1 \mathrm{~cm}$ entre pontos. As dimensões da malha permitem representar o padrão dos lóbulos laterais no entorno da fonte. A Fig. 4.3 mostra cortes do lóbulo principal da fonte ao longo dos planos $x=0$ e $y=0$.

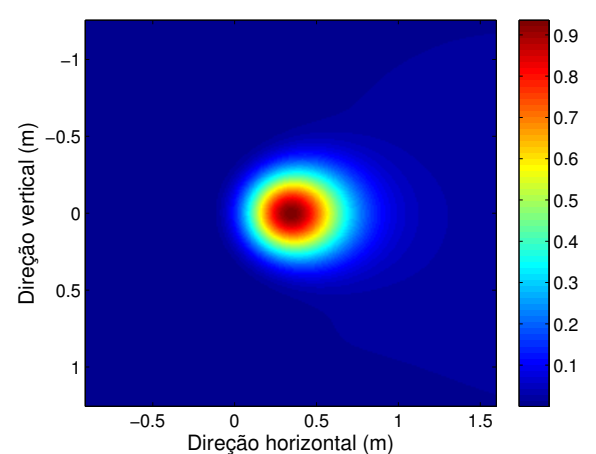

(a) $1 \mathrm{kHz}$

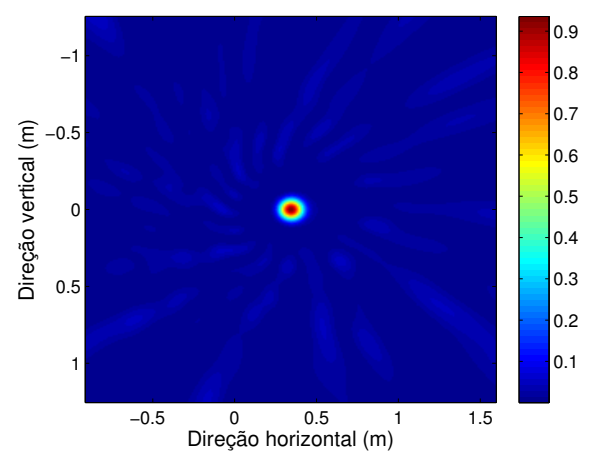

(c) $4 \mathrm{kHz}$

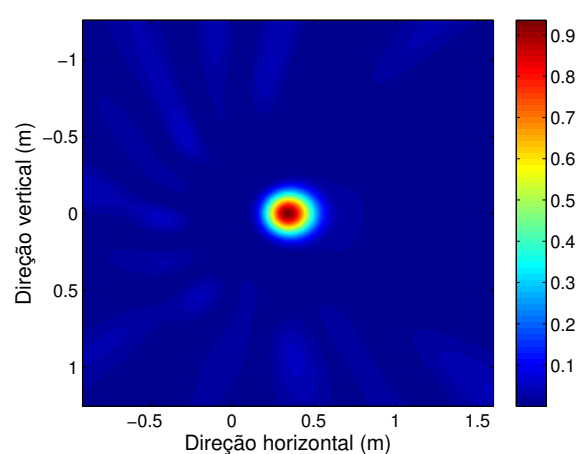

(b) $2 \mathrm{kHz}$

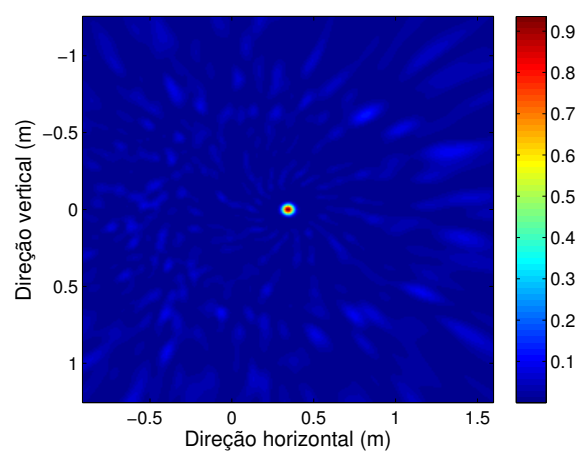

(d) $8 \mathrm{kHz}$

Figura 4.2: Imagens acústicas de uma fonte puntual de amplitude unitária nas frequências e 1 $\mathrm{kHz}, 2 \mathrm{kHz}, 4 \mathrm{kHz}$ e $8 \mathrm{kHz}$, obtidas pela aplicação da metodologia de beam-forming representada na Eq. 4.25 .

A Fig. 4.3 mostra que o pico de amplitude do lóbulo principal ocorre para $\left(x_{s}=\right.$ $\left.0.3452, y_{s}=0, z_{s}=0.85\right)$, medidos no sistema de referência da antena de microfones. Para esta posição, verifica-se que $\vec{r}_{m, s}=\vec{r}_{m, k}$ e $\vec{r}_{o, s}=\vec{r}_{o, k}, m=1,2, \ldots, M$, mostrando graficamente que o máximo global é encontrado quando o ponto focal coincide com a posição real da fonte. 

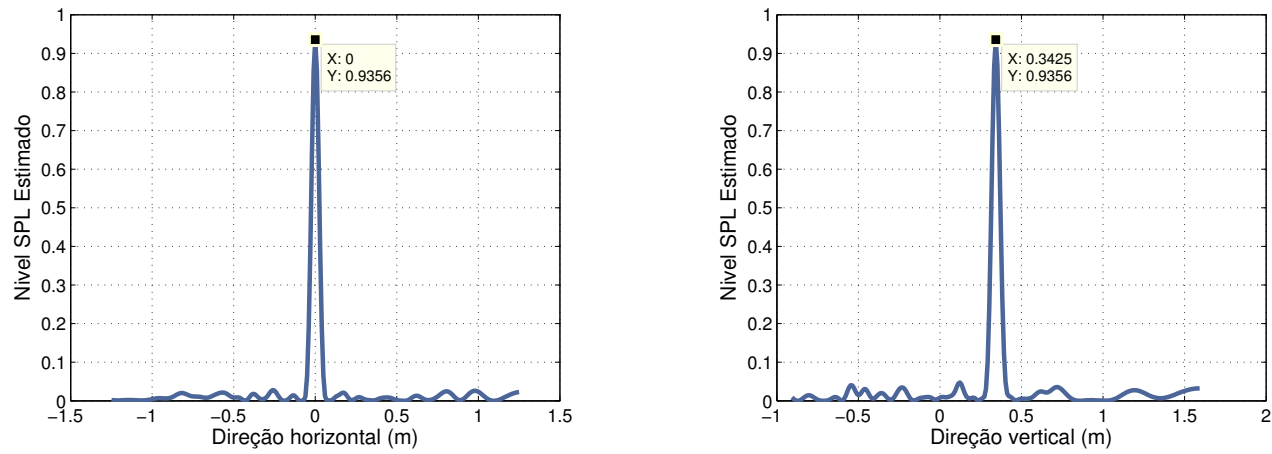

Figura 4.3: Cortes transversais no lóbulo principal da fonte, pelo seu ponto de máximo, ao longo das direções x e y.

Substituindo-se $\vec{r}_{m, s}=\vec{r}_{m, k}$ e $\vec{r}_{o, s}=\vec{r}_{o, k}$ na Eq. 4.25 , tem-se a estimativa da amplitude da fonte na posição de máximo. Assim, a Eq. 4.25 se reduz para a forma:

$$
b\left(\vec{r}_{o, s}, \omega_{l}\right)=\frac{\left[\sum_{m=1}^{M}\left(r_{o, s} / r_{m, s}\right)^{2}\right]^{2}}{\left[\sum_{m=1}^{M}\left(r_{o, s} / r_{m, s}\right)\right]^{2}}=\left(r_{o, s}\right)^{2} \frac{\left[\sum_{m=1}^{M}\left(1 / r_{m, s}\right)^{2}\right]^{2}}{\left[\sum_{m=1}^{M}\left(1 / r_{m, s}\right)\right]^{2}}
$$

A Eq. 4.27 mostra que a estimativa da amplitude da fonte sonora no ponto de máximo, derivada da aplicação da Eq. 4.25, é da forma $b\left(\vec{r}_{o, s}, \omega_{l}\right)=\alpha\left\langle q_{k}\left(\vec{r}_{o, k}, \omega_{l}\right) q_{k}^{\dagger}\left(\vec{r}_{o, k}, \omega_{l}\right)\right\rangle$, sendo $\alpha$ uma função dos parâmetros $\left|\vec{r}_{m, s}\right|$ e $\left|\vec{r}_{o, s}\right|$. Teoricamente, a melhor estimativa para o nível da fonte ocorreria quando $\alpha=1$. A equação

$$
\triangle L=10 \log 10\left(\left\langle q(\omega) q(\omega)^{\dagger}\right\rangle\right)-10 \log 10\left(\alpha\left\langle q(\omega) q(\omega)^{\dagger}\right\rangle\right)=10 \log 10(1 / \alpha)
$$

representa o erro, em unidades de $\mathrm{dB}$, que ocorre na estimativa da amplitude de uma fonte monopolo pela metodologia de beam-forming convencional descrita nesta seção, em termos do parâmetro $\alpha$.

Resolvendo-se a 4.28 para o valor de $\alpha$ calculado a partir da Eq. 4.27, considerando uma fonte de amplitude arbitrária na posição $\left(x_{k}=0.3425, y_{k}=0, z_{k}=0.85\right)$, decorre que $\triangle L=0.2892 d B$. Este erro é inerente à metodologia de beam-forming adotada e é sensível apenas à variação de parâmetros geométricos, tais com a posição dos microfones e do ponto focal em relação ao sistema de referência adotado.

\subsection{Correção do Efeito Convectivo de Escoamento Li- vre Sobre a Propagação de Ondas Acústicas}

O conceito envolvido na correção do efeito convectivo de um escoamento uniforme sobre a propagação de ondas acústicas, com vistas à aplicação de técnicas de beam-forming 
em aeroacústica, é relativamente simples, embora raramente seja apresentado de forma clara e didática na literatura. O efeito convectivo pode ser compensado com uma simples mudança de referencial, conforme o desenvolvimento subsequente.

A Fig. 4.4 representa o efeito convectivo que o escoamento uniforme exerce sobre a propagação oblíqua de uma frente de onda esférica que incide sobre um microfone de referência.

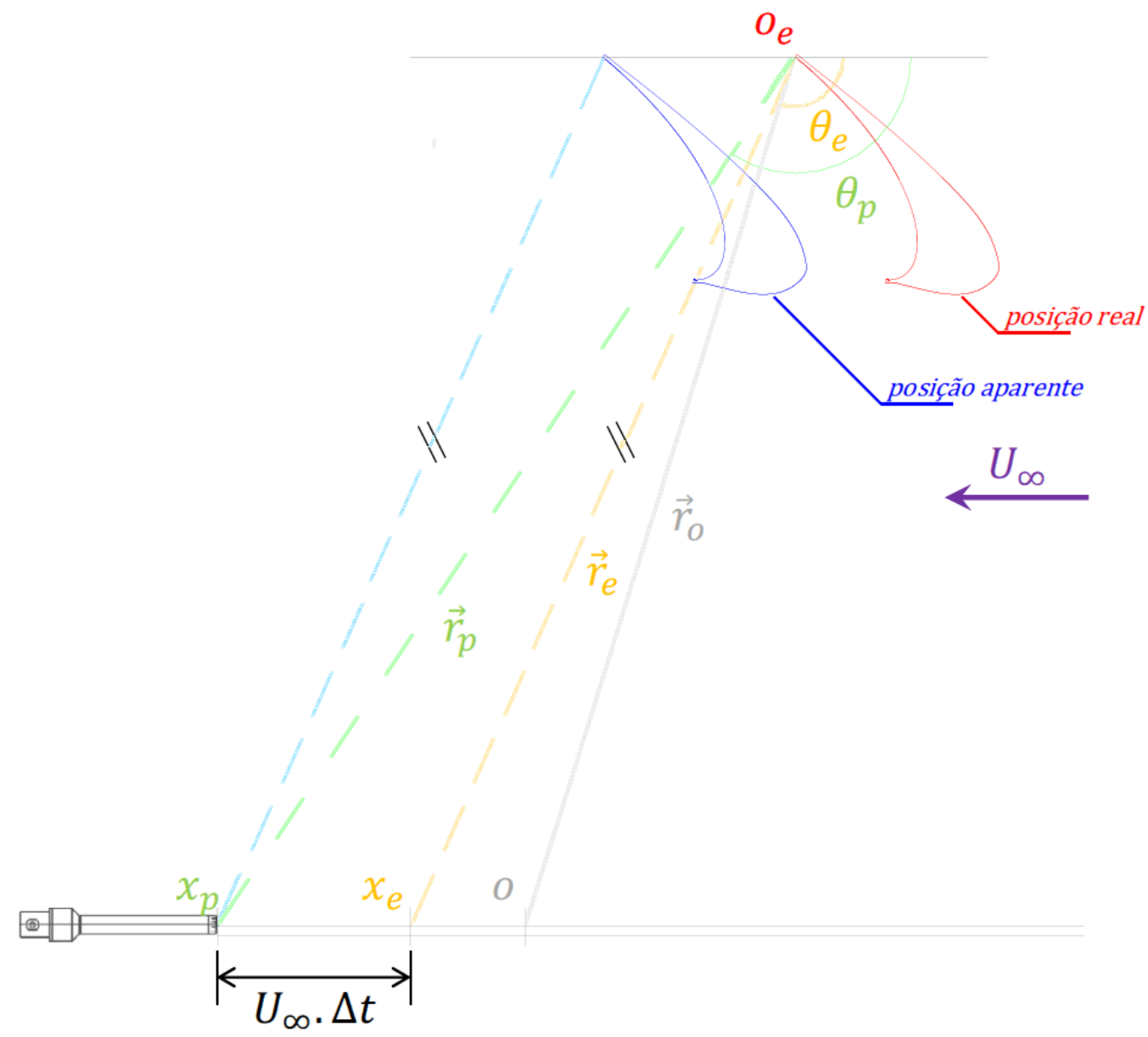

Figura 4.4: A onda sonora emitida sob o ângulo $\theta_{e}$ é detectada sob o ângulo $\theta_{p}$, em uma posição aparente deslocada de $U_{\infty} \Delta t$ à jusante de sua posição real, devido ao efeito convectivo do escoamento uniforme.

De acordo com a Fig. 4.4, a onda acústica emitida sob o ângulo $\theta_{e}$ sofre efeito convectivo devido a sua imersão no escoamento, atingindo o microfone situado no ponto $x_{p}$. Sob as hipóteses de escoamento estacionário durante o tempo de propagação da frente de onda, e homogêneo entre os pontos de emissão e recepção do sinal acústico, a trajetória da frente de onda pode ser aproximada pela reta $\vec{r}_{p}$. A partir da trajetória $\vec{r}_{p}$, define-se o ângulo efetivo de propagação $\theta_{p}$, que representa o ângulo entre a linha do escoamento e a trajetória da frente de onda convectada. É interessante notar que, embora o percurso efetivo da frente de onda seja representado pela reta $\vec{r}_{p}$, o vetor de propagação (normal ao plano da frente de onda) permanece paralelo à reta $\vec{r}_{e}$ durante todo o percurso. Não 
obstante, a onda acústica atinge o ponto $x_{p}$ no mesmo instante em que atingiria o ponto $x_{e}$, na ausência de escoamento.

Ao longo do percurso $\vec{r}_{p}$, a onda se propaga efetivamente através da distância $r_{e}$, com variação de fase correspondente a este percurso. Torna-se, então, evidente o porquê de não podermos utilizar a relação $\triangle t=r_{p} / c$ no cálculo da correção de fase para aplicação no algoritmo de beam-forming, apesar de a frente de onda percorrer a distancia $r_{p}$ no intervalo de tempo $\triangle t$.

Quando a correção de fase utilizada na metodologia de beam-forming for baseada na relação $\triangle t=r_{p} / c$, a fonte será identificada em uma posição aparente deslocada de $\left\|\overrightarrow{U_{\infty}} \triangle t\right\|$ à jusante de sua posição real. Também vale destacar que o deslocamento da posição aparente, em relação à posição real da fonte, se dá ao longo de uma reta paralela à velocidade de escoamento, devido à hipótese de escoamento unidimensional.

A correção ao efeito convectivo de escoamento livre é necessária para a correta representação de uma distribuição espacial de fontes acústicas e pode ser facilmente realizada por uma simples mudança de referencial. Isto consiste em representar a função transferência de uma onda acústica em relação a um referencial que se move solidário ao escoamento, conforme

$$
g\left(\vec{r}_{e}, \omega_{l}\right)=\frac{r_{o}}{r_{e}} e^{-i \omega_{l}\left(r_{e}-r_{o}\right) / c}
$$

Neste referencial, as ondas acústicas se propagam tal como o fazem na ausência de escoamento; livres de efeitos convectivos. Na prática, a formulação espacial do problema de beam-forming é feita a partir do uso das coordenadas $\theta_{p}$ e $r_{p}$, em relação às quais são definidas as posições dos microfones e dos pontos focais. A adequação do problema para o uso prático da Eq. 4.29 requer o uso de transformações do tipo $\theta_{e}=f\left(\theta_{p}\right)$ e $r_{e}=f\left(r_{p}\right)$. $\mathrm{Na}$ formulação ora descrita, necessitamos apenas da transformação $r_{e}=f\left(r_{p}\right)$.

As transformações $\theta_{e}=f\left(\theta_{p}\right)$ e $r_{e}=f\left(r_{p}\right)$ podem ser deduzidas a partir de relações geométricas aplicadas à figura Fig. 4.4. A lei dos cossenos aplicada ao triângulo com vértices nos pontos $\left(x_{p}, x_{e}, o_{e}\right)$ permite-nos determinar o tempo de percurso $\triangle t$, a partir da seguinte equação vetorial

$$
(c \triangle t)^{2}=\left\|\left(\overrightarrow{x_{p}}-\overrightarrow{r_{0}}\right)\right\|^{2}+\left(U_{\infty} \Delta t\right)^{2}-2\left[\left(\overrightarrow{x_{p}}-\overrightarrow{r_{0}}\right) \cdot \overrightarrow{U_{\infty}}\right] \triangle t
$$

onde $\overrightarrow{x_{p}}$ e $\overrightarrow{r_{0}}$ são vetores deslocamento entre a origem adotada e os pontos $x_{p}$ e $\boldsymbol{o}_{\boldsymbol{e}}$, respectivamente. A Eq. 4.30 pode ser escrita na forma de uma equação do segundo grau na variável $\triangle t$

$$
\left(c^{2}-U_{\infty}^{2}\right) \triangle t^{2}+2\left[\left(\overrightarrow{x_{p}}-\overrightarrow{r_{0}}\right) \cdot \overrightarrow{U_{\infty}}\right] \triangle t-\left\|\left(\overrightarrow{x_{p}}-\overrightarrow{r_{0}}\right)\right\|^{2}=0
$$


A solução da Eq. 4.31 para $\Delta t>0$ é da forma

$$
\Delta t=\frac{-2\left[\left(\overrightarrow{x_{p}}-\overrightarrow{r_{0}}\right) \cdot \overrightarrow{U_{\infty}}\right]+\sqrt{4\left[\left(\overrightarrow{x_{p}}-\overrightarrow{r_{0}}\right) \cdot \overrightarrow{U_{\infty}}\right]^{2}+4\left(c^{2}-U_{\infty}^{2}\right)\left\|\left(\overrightarrow{x_{p}}-\overrightarrow{r_{0}}\right)\right\|^{2}}}{2\left(c^{2}-U_{\infty}^{2}\right)}
$$

Utilizando a relação $U_{\infty}=M a \times c$, podemos representar a Eq. 4.32 em termos do número de Mach do escoamento livre $(M a)$, e da velocidade de propagação do som no meio considerado (c).

$$
\Delta t=\frac{-\left[\left(\overrightarrow{x_{p}}-\overrightarrow{r_{0}}\right) \cdot \overrightarrow{M a}\right]+\sqrt{\left[\left(\overrightarrow{x_{p}}-\overrightarrow{r_{0}}\right) \cdot \overrightarrow{M a}\right]+\left(1-M a^{2}\right)\left\|\left(\overrightarrow{x_{p}}-\overrightarrow{r_{0}}\right)\right\|^{2}}}{\left(1-M a^{2}\right) c}
$$

O próximo passo consiste em representar as grandezas vetoriais $\vec{x}_{p}$ e $\vec{r}_{0}$ em termos de suas componentes cartesianas. Por simplicidade de notação, sejam $\overrightarrow{x_{p}}=x_{1} \vec{i}+x_{2} \vec{j}+x_{3} \vec{k}$ e $\overrightarrow{r_{0}}=r_{1} \vec{i}+r_{2} \vec{j}+r_{3} \vec{k}$. As seguintes relações permitem escrever a Eq. $4.33 \mathrm{em}$ termos de componentes cartesianas

$$
\begin{aligned}
\left(\overrightarrow{x_{p}}-\overrightarrow{r_{0}}\right) \cdot \overrightarrow{M a} & =M a\left(x_{1}-r_{1}\right) \\
\left\|\left(\overrightarrow{x_{p}}-\overrightarrow{r_{0}}\right)\right\|^{2} & =\left(x_{1}-r_{1}\right)^{2}+\left(x_{2}-r_{2}\right)^{2}+\left(x_{3}-r_{3}\right)^{2}
\end{aligned}
$$

Substituindo-se as Eqs. 4.34 na Eq. 4.33, tem-se uma forma conveniente para a aplicação do parâmetro $\triangle t$ ao processamento de dados aeroacústicos

$$
\Delta t=\frac{-M a\left(r_{1}-x_{1}\right)+\sqrt{\left(r_{1}-x_{1}\right)^{2}+\left(1-M a^{2}\right)\left[\left(r_{2}-x_{2}\right)^{2}+\left(r_{3}-x_{3}\right)^{2}\right]}}{\left(1-M a^{2}\right) c}
$$

O parâmetro $\Delta t$ pode ser usado no cálculo da Eq. 4.29, dado que para cada microfone com vetor posição $x_{p}$ verifica-se $\Delta t=\left\|\overrightarrow{r_{p}}-\overrightarrow{r_{0}}\right\| / c$.

O leitor mais atento pode ter percebido a ausência do fator $\left(1-M a \cos \theta_{e}\right)$ no denominador da função de transferência definida na Eq. 4.29. Este fator é de uso corrente em textos que discutem correções para efeitos convectivos, sendo aplicado para a correção de um efeito denominado amplificação Doppler (RUIJGROK, 2004). Decorre que na formulação de beam-forming adotada neste trabalho, tal fator, se considerado na definição da função transferência (Eq. 4.29) seria cancelado devida às operações de normalização aplicadas. Outro ponto a ser destacado é que para medições em túnel de vento, com fontes estacionárias e escoamento uniforme, não há deslocamento Doppler na frequência, tal qual ocorre para uma fonte em movimento (DOWLING; WILLIAMS, 1983). 


\subsection{Implementação Numérica do Algoritmo de Beam- forming Convencional}

A equação

$$
b\left(\vec{r}_{o, s}, \omega_{l}\right)=\frac{\mathbf{g}^{\dagger}\left(\vec{r}_{m, s}, \omega_{l}\right)\left(\mathbf{C}\left(\omega_{l}\right) \circ \mathbf{1}_{M, M}\right) \mathbf{g}\left(\vec{r}_{m, s}, \omega_{l}\right)}{\left|\mathbf{g}^{\dagger}\left(\vec{r}_{m, s}, \omega_{l}\right)\right|\left(\mathbf{1}_{M, M}\right)\left|\mathbf{g}\left(\vec{r}_{m, s}, \omega_{l}\right)\right|}
$$

representa a implementação numérica para a formulação de beam-forming convencional adotada neste trabalho. Esta equação é conceitualmente equivalente à Eq. 4.20. A matriz $\mathbf{1}_{M, M}$, de ordem $M$, possui todos os elementos com valor unitário. O símbolo (o) representa o produto de Hadamard (produto elemento a elemento entre duas matrizes de mesma ordem). A remoção dos elementos da diagonal principal da matriz $\mathbf{C}\left(\omega_{l}\right)$ pode ser feita anulando-se os elementos da diagonal principal da matriz $\mathbf{1}_{M, M}$.

Para a Eq. 4.36, a função de transferência $\mathbf{g}\left(\vec{r}_{m, s}, \omega_{l}\right)$ é calculada de acordo com a Eq. 4.19, com correção para efeito convectivo conforme a seção 4.6. A matriz de espectros cruzados é calculada conforme a seção 4.10. Os resultados obtidos pela aplicação da Eq. 4.36, na forma de mapas de beam-forming para as frequências de interesse, representam o ponto de partida para a aplicação do método de deconvolução DAMAS.

\subsection{Métodos de Deconvolução em Aeroacústica}

Esta secção tem por objetivo apresentar uma ideia geral sobre os conceitos que norteiam alguns dos principais métodos de deconvolução atualmente aplicados em aeroacústica. Desta forma, espera-se prover ao leitor uma ideia mais concreta sobre os principais conceitos envolvidos na formulação do método DAMAS.

Mapas de beamforming convencional são representações do campo acústico convolvido com o padrão de resposta determinado pela geometria da antena, ou psf. O padrão de resposta teórico é uma construção geométrica que leva em conta as características de projeto da antena, mas em geral desconsidera qualquer influência exercida pelo ambiente externo, tal como as condições de fronteira que determinam a propagação de ondas acústicas. Métodos de deconvolução têm por objetivo eliminar a influência geométrica da antena de microfones sobre a representação espacial das fontes de ruído em mapas de beam-forming. 


\subsubsection{CLEAN-SC - CLEAN Based on Spatial Source Cohe- rence}

Sijtsma (2007) apresenta a formulação do método CLEAN-SC (CLEAN Based on Spatial Source Coherence) e os resultados de sua aplicação ao mapeamento de fontes em um modelo Airbus A340 em escala 1:10.6. O método CLEAN-SC foi desenvolvido para aplicações em aeroacústica e representa uma versão aperfeiçoada do método CLEAN tradicional Hogbom (1974), que foi desenvolvido para aplicações em astronomia. O método CLEAN-SC tem se mostrado eficiente na eliminação de lóbulos secundários que são coerentes com o lóbulo principal das fontes dominantes no mapa de beam-forming. Tal ação, em tese, torna possível a identificação de fontes aerodinâmicas de ruído com níveis abaixo dos níveis dos lóbulos secundários das fontes dominantes.

O método CLEAN-SC requer o pós-processamento dos resultados obtidos pelo método de beam-formingconvencional. O processo iterativo para o método CLEAN-SC iniciase com a determinação do valor de pico da fonte dominante no mapa de beam-forming convencional. A formulação do método CLEAN-SC tem por base a equação

$$
\mathbf{h}^{\dagger} \mathbf{C}^{(j-1)} \mathbf{h}_{k}^{(j)}=\mathbf{h}^{\dagger} \mathbf{C}^{(j)} \mathbf{h}_{k}^{(j)}
$$

onde $\mathbf{C}$ representa a matriz de espectros cruzados e $j$ é o índice que determina o número da iteração corrente. Na iteração $j=1$, a matriz $\mathbf{C}$ decorre do processamento dos sinais medidos experimentalmente com uma antena de microfones. Sijtsma (2007) define o steering vector, $\mathbf{h}$, como

$$
\mathbf{h}\left(\omega_{l}\right)=\frac{\mathbf{g}\left(\omega_{l}\right)}{\left(\sum_{n=1}^{M} \sum_{m=1}^{M}\left|g_{m}\right|^{2}\left|g_{n}\right|^{2}\right)^{1 / 2}},
$$

sendo $\mathbf{g}\left(\omega_{l}\right)$ a função de transferência para uma fonte do tipo monopolo, definida para a frequência $\left(\omega_{l}\right)$, a partir de então omitida. A Eq. 4.37 representa o método de crossbeamforming Horne et al. (2000), aplicado para determinar o nível de correlação entre a fonte em uma dada posição e as demais fontes mapeadas no domínio espacial discretizado. Na formulação CLEAN-SC, o interesse recai sobre a fonte dominante no mapa de beamforming, para cada iteração calculada. Desta forma, o índice $k$ indica que o steering vector $\mathbf{h}_{k}$ é calculado a partir do vetor de posição da fonte dominante, enquanto que h varia sobre todos os pontos da malha. O uso da Eq. 4.37, baseada na formulação de cross-beamforming, representa a diferença conceitual entre os métodos CLEAN-SC e CLEAN.

A solução da Eq. 4.37 na iteração $j$ é determinada pela condição

$$
\mathbf{C}^{(j-1)} \mathbf{h}_{k}^{(j)}=\mathbf{C}^{(j)} \mathbf{h}_{k}^{(j)}
$$


A (Eq. 4.39) não possui solução única. No entanto, dado que o termo $\mathbf{C}^{(j-1)} \mathbf{h}_{k}^{(j)}$ representa a projeção das fontes presentes na matriz $\mathbf{C}^{(j-1)}$ sobre a auto-função que representa a fonte dominante, $\mathbf{h}_{k}^{(j)}$, a solução $\mathbf{C}^{(j)}$ procurada pode ser determinada na forma

$$
\mathbf{C}_{k}^{(j)}=b_{k}^{(j-1)}\left[\xi^{(j)} \xi^{\dagger(j)}-\mathbf{C}_{\xi}^{(j)}\right]
$$

onde $\mathbf{C}_{k}^{(j)}$ é a matriz de espectros cruzados modelada para representar a informação física, na forma de amplitude e fase, da fonte dominante contida na matriz $\mathbf{C}^{(j-1)}$. A matriz $\mathbf{C}_{k}^{(j)}$ é determinada em termos do vetor $\xi^{(j)}$, que na formulação CLEAN-SC representa a função de transferência que modela a propagação do sinal da fonte dominante até os microfones da antena. O escalar $b_{k}^{(j-1)}$ é o valor de pico da fonte dominante, extraído do mapa de beamformming na iteração $(j-1)$. Finalmente, $\mathbf{C}_{\xi}^{(j)}$ é a matriz de espectros cruzados obtida a partir do produto externo $\xi^{(j)} \xi^{\dagger(j)}$, com os elementos da diagonal principal removidos. Para maiores detalhes sobre remoção da diagonal principal na formulação CLEAN-SC, veja (SIJTSMA, 2007).

Substituindo-se a Eq. 4.40 na Eq. 4.39 decorre, após alguma manipulação algébrica, uma solução em termos de $\xi$ na forma

$$
\xi^{(j)}=\frac{1}{\left(1+\mathbf{h}_{k}^{\dagger(j)} \mathbf{C}_{\xi}^{(j)} \mathbf{h}_{k}^{(j)}\right)^{1 / 2}}\left(\frac{\mathbf{C}^{(j-1)} \mathbf{h}_{k}^{(j)}}{b_{k}^{(j-1)}}+\mathbf{C}_{\xi}^{(j)} \mathbf{h}_{k}^{(j)}\right)
$$

A Eq. 4.41 também deve ser resolvida de forma iterativa, dado que a variável $\xi^{(j)}$ aparece de forma implícita na variável $\mathbf{C}_{\xi}^{(j)}$. A partir dos valores de $\xi^{(j)}$ obtidos da Eq. 4.41 , calcula-se a matriz de espectros cruzados para a interação $j$ na forma

$$
\mathbf{C}^{(j)}=\mathbf{C}^{(j-1)}-\mathbf{C}_{k}^{(j)}=\mathbf{C}^{(j-1)}-b_{k}^{(j-1)}\left[\xi^{(j)} \xi^{\dagger(j)}-\mathbf{C}_{\xi}^{(j)}\right]
$$

A subtração determinada na Eq. 4.42 tem por objetivo eliminar, da matriz $\mathbf{C}^{(j)}$, a influência da fonte dominante na iteração $j-1$ (lóbulo principal e lóbulos laterais correlacionados). A matriz $\mathbf{C}^{(j)}$, calculada pela Eq. 4.42, é usada no cálculo de um novo mapa de fontes pelo método de beam-forming convencional, dando sequência ao processo iterativo com o método de deconvolução CLEAN-SC.

O critério da parada sugerido para o método CLEAN-SC consiste na comparação entre as normas das matrizes de espectros cruzados obtidas em iterações consecutivas, o que pode ser feito com base no seguinte critério

$$
\sum_{m=1}^{M} \sum_{m=1}^{M}\left|C_{m, n}^{(j)}\right| \geq \sum_{m=1}^{M} \sum_{m=1}^{M}\left|C_{m, n}^{(j-1)}\right|
$$


sendo $C_{m, n}^{(j)}$ e $C_{m, n}^{(j-1)}$ escalares componentes das matrizes de espectros cruzados calculadas nas interações $j$ e $j-1$, respectivamente. A condição dada pela Eq. 4.43 é satisfeita quando a matriz $\mathbf{C}^{(j-1)}$ já está suficientemente degradada para conter informações físicas relevantes sobre a distribuição de fontes, o que determina a parada do processo iterativo.

Uma vez alcançada a convergência pelo método CLEAN-SC, é possível estimar o nível de pressão sonora associado ao mapa de fontes, o que pode ser feito a partir da informação contida no traço da matriz de espectros cruzados $\mathbf{C}_{k}^{(j)}$. Na equação

$$
P=\sum_{j=1}^{J} \frac{1}{M} \sum_{m=1}^{M} C_{k, m}^{(j)},
$$

$P$ representa a soma dos valores de pressão sonora associados às fontes de ruído mapeadas pelo método CLEAN-SC. De acordo com a Eq. 4.44, $P$ é dado pela soma, de $J$ elementos, da média dos auto-espectros dos sinais que representam as fontes reconstruídas na matriz $\mathbf{C}_{k}^{(j)}$, a partir das informações das fontes físicas contidas na matriz $\mathbf{C}^{(j)}$. O termo $C_{k, m}^{(j)}$ designa o auto-espectro na matriz $\mathbf{C}_{k}^{(j)}$, para o microfone de índice $m$, e o parâmetro $J$ representa o número de iterações decorrido para a convergência do algoritmo.

De acordo com o conceito do método CLEAN-SC, os mapas de beam-forming deconvolvidos podem ser construídos de forma a representar a distribuição de fontes dominantes sem a influência dos lóbulos laterais correlacionados. Isto pode ser feito usando funções de forma para a reconstrução de cada fonte dominante, bem como pelo uso de uma técnica adequada, tal como a convolução de uma imagem das fontes com um pulso Gaussiano ou uma janela Hanning bidimensional.

É interessante notar que a determinação do vetor $\xi$, com base na Eq. 4.39, consiste basicamente na determinação da função de transferência que melhor representa, em cada iteração, às características da fonte dominante no mapa beam-forming, determinado a partir da dados experimentais. Neste aspecto, o método CLEAN-SC difere-se do método DAMAS, que pressupõe uma distribuição de fontes decorrelacionadas do tipo monopolo em cada ponto da malha que discretiza do domínio espacial definido para o mapeamento de fontes.

\subsubsection{DAMAS - Denconvolution Approach for the Mapping of Acoustic Sources}

Brooks e Humphreys (2006) apresentam o método de deconvolução DAMAS (Deconvolution Approach for the Mapping of Acoustic Sources). Muitos autores consideram o surgimento deste método um divisor de águas na aplicação de técnicas de deconvolução para a caracterização de fontes aerodinâmicas. 
O método DAMAS assume que a estimativa de pressão sonora no ponto focal, com vetor de posição $\vec{r}_{o, k}$, resulta da convolução entre o campo acústico discreto, na forma $q_{k}\left(\omega_{l}\right) q_{k}^{*}\left(\omega_{l}\right)$, e a resposta discreta da antena à uma fonte puntual na mesma posição, representada como $\operatorname{psf}\left(\vec{r}_{o, m}, \vec{r}_{o, k}, \omega_{l}\right)$, de forma que

$$
b\left(\vec{r}_{o, k}, \omega_{l}\right)=\sum_{k=1}^{K}\left[q_{k}\left(\omega_{l}\right) q_{k}\left(\omega_{l}\right)^{*}\right] \operatorname{psf}\left(\vec{r}_{o, m}, \vec{r}_{o, k}, \omega_{l}\right)
$$

A generalização da Eq. 4.45 para um mapa discreto representando uma distribuição de fontes decorrelacionadas resulta no seguinte sistema de sistema equações lineares

$$
\left[\begin{array}{c}
b\left(\vec{r}_{o, 1}, \omega_{l}\right) \\
b\left(\vec{r}_{o, 2}, \omega_{l}\right) \\
\vdots \\
b\left(\vec{r}_{o, K}, \omega_{l}\right)
\end{array}\right]=\left[\begin{array}{cccc}
A_{1,1} & A_{1,2} & \cdots & A_{1, K} \\
A_{2,1} & A_{2,2} & \cdots & A_{2, K} \\
\vdots & \vdots & \ddots & \vdots \\
A_{K, 1} & A_{K, 2} & \cdots & A_{K, K}
\end{array}\right]\left[\begin{array}{c}
X_{1}\left(\omega_{l}\right) \\
X_{2}\left(\omega_{l}\right) \\
\vdots \\
X_{K}\left(\omega_{l}\right)
\end{array}\right]
$$

No sistema de equações $4.46, X_{k}\left(\omega_{l}\right)=q_{k}\left(\omega_{l}\right) q_{k}^{*}\left(\omega_{l}\right)$ é a amplitude dada pela autocorrelação de fontes, e os coeficientes $A_{s, k}, s=1,2, \ldots, K$ representam os valores da resposta da antena (psf) para um ponto focal de índice $k$. A partir do desenvolvimento apresentado na seção 4.3 , os coeficiente $A_{s, k}$ tem a forma

$$
A_{s, k}=\left(\mathbf{G}_{s}^{\dagger}\left(\vec{r}_{m, s}, \omega_{l}\right) \mathbf{G}_{k}\left(\vec{r}_{m, k}, \omega_{l}\right)\right)\left(\mathbf{G}_{s}^{\dagger}\left(\vec{r}_{m, s}, \omega_{l}\right) \mathbf{G}_{k}\left(\vec{r}_{m, k}, \omega_{l}\right)\right)^{\dagger}
$$

No método DAMAS, os coeficientes $A_{s, k}$ representam pontos da resposta discreta do array à uma distribuição de fontes puntuais decorrelacionadas, em condição de campo livre. Esta hipótese é assumida no método DAMAS, independentemente da natureza física das fontes e das condições de fronteira no ambiente de medição. Maiores detalhes sobre a formulação DAMAS e o método numérico utilizado para a solução da Eq. 4.46 são encontrados na seção 4.9 .

O método de deconvolução DAMAS foi escolhido para implementação e aplicação ao processamento da base de dados acústicos analisada neste trabalho. DAMAS é um método bem descrito na literatura e com bons resultados em estimativas de espectros de ruído e representação de fontes, conforme Brooks, Humphreys Jr e Plassman (2010), Dougherty (2005a). No entanto, vale destacar que há poucos trabalhos avaliando o desempenho deste método em condições de medição com altos níveis de reverberação e ruído de fundo.

No decorrer dos trabalhos que constam na pauta de desenvolvimento do projeto Aeronave Silenciosa, alguns testes foram realizados com a finalidade de avaliar o desempenho de diferentes métodos de deconvolução quando aplicados ao mapeamento de uma fonte em linha sintética. O modelo de fonte utilizado é descrito em maiores detalhes na subseção 
4.11.1. O estudo envolveu uma colaboração com a Embraer e avaliou os métodos de deconvolução DAMAS, CLEAN-SC, e TIDY, em versões disponíveis no software comercial Image-Jplugins. Os resultados deste estudo mostram que o método DAMAS é capaz de representar uma fonte em linha composta por 2041 fontes puntuais descorrelacionadas com boa uniformidade, e com a menor variância de amplitude das fontes entre os métodos considerados.

Este resultado foi considerado um indicativo da viabilidade do uso do método DAMAS ao processamento do ruído de eslate, para o qual se espera um representação de fontes em linha ao longo de sua envergadura sob condições de escoamento uniforme. Ademais, uma menor variância no nível das fontes permite a integração sob uma faixa dinâmica mais conservadora, reduzindo a influência de lóbulos laterais e fontes espúrias sobre o nível de pressão sonora estimado.

\subsubsection{Variações do Método DAMAS}

A aplicação do método DAMAS requer que cada ponto da malha seja o ponto focal para o cálculo de uma psf. Naturalmente, o número de $p s f s$ calculadas corresponde ao número de pontos na malha. Este procedimento é justificado em condições nas quais a forma da $p s f$ varia significativamente quando calculada em diferentes pontos do domínio da malha, o que ocorre quando as dimensões da região mapeada são comparáveis à distância em relação à antena de microfones. Embora esta suposição seja bastante realista para aplicações da técnica de beam-forming em medições obtidas em túneis de vento de seção fechada, onde o modelo de teste encontra-se relativamente próximo da antena, o cálculo repetido da psf é responsável por grande parte da demanda computacional inerente ao método DAMAS.

Em 2005 Dougherty (2005b) apresenta o método DAMAS-2, que é uma versão modificada do método DAMAS, com a proposta de uma drástica redução no custo computacional de processamento. Este método assume que a forma da $p s f$ é invariante por translação no domínio definido para o mapeamento de fontes. Sob esta hipótese, a Eq.4.45 se escreve na forma

$$
b\left(x_{k}, y_{k}, \omega_{l}\right)=\sum_{k=1}^{K} \sum_{k=1}^{K}\left(q_{k}\left(\omega_{l}\right) q_{k}^{*}\left(\omega_{l}\right)\right) p s f\left(x_{k}-x_{s}, y_{k}-y_{s}, \omega_{l}\right)
$$

onde $\left(x_{s}, y_{s}\right)$ e $\left(x_{k}, y_{k}\right)$ denotam as coordenas cartesianas dos pontos com vetores de posição $\vec{r}_{o, s}$ e $\vec{r}_{o, k}$, respectivamente. O problema de deconvolução posto na forma da Eq. 4.48 pode ser tratado pelo uso de técnicas espectrais baseadas nas transformadas de Fourier bidimensional direta e inversa (EHRENFRIED; KOOP, 2007).

$$
b\left(x_{k}, y_{k}, \omega_{l}\right) \approx \mathscr{F}^{-1}\left[\mathscr{F}\left(q_{k}\left(\omega_{l}\right) q_{k}^{*}\left(\omega_{l}\right)\right) \mathscr{F}\left(p s f\left(x_{k}-x_{s}, y_{k}-y_{s}, \omega_{l}\right)\right) \psi\left(k_{x}, k_{y}\right)\right]
$$


sendo $\psi\left(k_{x}, k_{y}\right)$ um filtro espacial. A aplicação da Eq. 4.49 para a solução dos sistema 4.46 é responsável pelo ganho em velocidade de processamento aclamado pelo método DAMAS-2. A aplicação das transformadas de Fourier é computacionalmente mais eficiente que a solução numérica de grandes sistemas de equações lineares, embora tais métodos ainda exijam a aplicação de um processo iterativo para a determinação do valores $X_{k}\left(\omega_{l}\right)=q_{k}\left(\omega_{l}\right) q_{k}^{*}\left(\omega_{l}\right)$. A suposição de uma psf invariante por translação é comumente feita em áreas como a astronomia, em situações nas quais a distância entre a fonte e a antena receptora do sinal é muito grande em relação às dimensões da própria antena. Em problemas de aeroacústica, a suposição de uma $p s f$ invariante por translação não é válida, em geral.

Em 2006 Brooks e Humphreys Jr (2006) apresentam o método de deconvolução DAMAS-C, que representa uma generalização do método DAMAS para o caso de uma distribuição de fontes coerentes. A base conceitual do método DAMAS-C consiste em postular que a medida de correlação entre duas fontes é uma variável independente na formulação de um problema de deconvolução. A estimativa do nível de correlação entre duas fontes é feita pelo cálculo de um beam-forming de termos cruzados (cross-beamforming), conforme proposto por (HORNE et al., 2000). A desvantagem desta metodologia é que a inclusão dos termos cruzados aumenta consideravelmente o tamanho do sistema de equações que representa o problema de deconvolução. Tal fato torna o método DAMAS-C uma opção de alto custo computacional.

\subsection{Formulação Matemática do Método DAMAS}

O método de deconvolução DAMAS estima os valores $q\left(\vec{r}_{o, k}, \omega_{l}\right), k=1,2, \ldots, K$, resolvendo iterativamente o sistema de equações lineares (Eq. 4.46) pelo método de GaussSeidel modificado por um vínculo de positividade, de forma a evitar que valores negativos de pressão sonora sejam obtidos. O desenvolvimento formal do algoritmo DAMAS aqui descrito é baseado em (BROOKS; HUMPHREYS, 2006).

O modelo de propagação acústica adotado na formulação do método DAMAS é dado por

$$
P_{m}\left(\vec{r}_{m, k}, \omega_{l}\right)=q\left(\vec{r}_{o, k}, \omega_{l}\right)\left(g_{m}^{-1}\left(\vec{r}_{m, k}, \omega_{l}\right)\right)
$$

sendo $P_{m}\left(\vec{r}_{m, k}, \omega_{l}\right)$ o coeficientes da transformada de Fourier do sinal de pressão sonora no microfone de índice $m$, para a frequência $\omega_{l}, q_{k}\left(\omega_{l}\right)=q\left(\vec{r}_{o, k}, \omega_{l}\right)$ a amplitude da fonte emissora com vetor de posição $\vec{r}_{o, k}$, e $g_{m}^{-1}\left(\vec{r}_{m, k}, \omega_{l}\right)$ a função de transferência que modela a propagação da onda acústica entre a fonte e o sensor de índice $m$. O parâmetro $g_{m}\left(\vec{r}_{m, k}, \omega_{l}\right)$ é definido conforme a Eq. 4.19. A correlação espectral entre medidas de pressão sonora 
nos microfones $m$ e $n$ é dada por

$$
\begin{aligned}
C_{m, n}\left(\omega_{l}\right) & =\left[P_{m}\left(\vec{r}_{m, k}, \omega_{l}\right)\right]^{*}\left[P_{n}\left(\vec{r}_{n, k}, \omega_{l}\right)\right] \\
& =q_{k}^{*}\left(\omega_{l}\right) q_{k}\left(\omega_{l}\right)\left[g_{m}^{-1}\left(\vec{r}_{m, k}, \omega_{l}\right)\right]^{*}\left[g_{n}^{-1}\left(\vec{r}_{n, k}, \omega_{l}\right)\right],
\end{aligned}
$$

sendo $C_{m, n}\left(\omega_{l}\right)$ um elemento da matriz de espectros cruzados sintética definida na metodologia DAMAS. A matriz de espectros cruzados completa pode ser obtida pelo produto externo $\mathbf{P}\left(\vec{r}_{m, k}, \omega_{l}\right) \mathbf{P}^{\dagger}\left(\vec{r}_{m, k}, \omega_{l}\right)$, onde $\mathbf{P}$ agrupa os coeficientes das transformadas de Fourier dos sinais de pressão medidos por todos os microfones da antena, à frequência $\omega_{l}$, conforme

$$
\mathbf{C}=\mathbf{g}^{-1}\left(\vec{r}_{m, k}, \omega_{l}\right)\left[\mathbf{g}^{-1}\left(\vec{r}_{m, k}, \omega_{l}\right)\right]^{\dagger} X_{k}\left(\omega_{l}\right)
$$

onde $X_{k}\left(\omega_{l}\right)=\left\langle\left(q_{k}\left(\omega_{l}\right)\right)^{\dagger} q_{k}\left(\omega_{l}\right)\right\rangle$ representa o valor esperado para a amplitude da fonte de índice $k$. A matriz de espectros cruzados dada pela Eq. 4.52 se apresenta na forma

$$
\mathbf{C}=X_{k}\left(\omega_{l}\right)\left[\begin{array}{cccc}
\left(g_{1}^{-1}\right)^{\dagger} g_{1}^{-1} & \left(g_{1}^{-1}\right)^{\dagger} g_{2}^{-1} & \ldots & \left(g_{1}^{-1}\right)^{\dagger} g_{M}^{-1} \\
\left(g_{2}^{-1}\right)^{\dagger} g_{1}^{-1} & \left(g_{2}^{-1}\right)^{\dagger} g_{2}^{-1} & \ldots & \left(g_{2}^{-1}\right)^{\dagger} g_{M}^{-1} \\
\vdots & \vdots & \ddots & \vdots \\
\left(g_{M}^{-1}\right)^{\dagger} g_{1}^{-1} & \left(g_{M}^{-1}\right)^{\dagger} g_{2}^{-1} & \ldots & \left(g_{M}^{-1}\right)^{\dagger} g_{M}^{-1}
\end{array}\right]
$$

onde os subscritos em $g$ denotam índices de microfones e os demais índices de posição e frequência foram omitidos por simplicidade de notação. Na Eq. 4.53, o termo $X_{k}\left(\omega_{l}\right)$ deve ser entendido como um escalar multiplicando cada termo da matriz. A Eq. 4.52 representa uma forma computacionalmente eficiente para se gerar a matriz de espectros cruzados sintética quando os vetores $\mathbf{g}\left(\vec{r}_{m, k}, \omega_{l}\right)$ estão disponíveis para o pós-processamento.

A resposta de beamforming convencional para o modelo de propagação considerado na formulação DAMAS é então dado por:

$$
Y\left(\vec{r}_{o, s}, \omega_{l}\right)=\frac{\sum_{k=1}^{K} \mathbf{g}^{\dagger}\left(\vec{r}_{m, s}, \omega_{l}\right)\left\{\mathbf{g}^{-1}\left(\vec{r}_{m, k}, \omega_{l}\right)\left[\mathbf{g}^{-1}\left(\vec{r}_{m, k}, \omega_{l}\right)\right]^{\dagger}\right\} \mathbf{g}\left(\vec{r}_{m, s}, \omega_{l}\right) X_{k}\left(\omega_{l}\right)}{M^{2}}
$$

A conexão entre a Eq. 4.54 e o sistema de equações lineares representado pela Eq. 4.46 torna-se evidente reescrevendo-se a primeira na forma:

$$
Y\left(\vec{r}_{o, s}, \omega_{l}\right)=\frac{\sum_{k=1}^{K} \mathbf{g}^{\dagger}\left(\vec{r}_{m, s}, \omega_{l}\right)\left(\mathbf{g}^{-1}\left(\vec{r}_{m, k}, \omega_{l}\right)\right)\left[\mathbf{g}^{\dagger}\left(\vec{r}_{m, s}, \omega_{l}\right)\left(\mathbf{g}^{-1}\left(\vec{r}_{m, k}, \omega_{l}\right)\right)\right]^{\dagger} X_{k}\left(\omega_{l}\right)}{M^{2}}
$$

A Eq. 4.55 mostra claramente a forma do coeficiente $A_{s, k}$, definido na formulação do método DAMAS.

$$
A_{s, k}=\frac{\mathbf{g}^{\dagger}\left(\vec{r}_{m, s}, \omega_{l}\right)\left(\mathbf{g}^{-1}\left(\vec{r}_{m, k}, \omega_{l}\right)\right)\left[\mathbf{g}^{\dagger}\left(\vec{r}_{m, s}, \omega_{l}\right)\left(\mathbf{g}^{-1}\left(\vec{r}_{m, k}, \omega_{l}\right)\right)\right]^{\dagger}}{M^{2}},
$$


Na equação seguinte, a operação matemática implícita na Eq. 4.56 é apresentada em termos de somas nos componentes de índices $m$ e $n$, de forma a tornar claro ao leitor a necessidade da normalização pelo fator $M^{2}$.

$$
A_{s, k}=\frac{\sum_{m=1}^{M} \sum_{n=1}^{M} g^{\dagger}\left(\vec{r}_{m, s}, \omega_{l}\right)\left\{g^{-1}\left(\vec{r}_{n, k}, \omega_{l}\right)\left[g^{-1}\left(\vec{r}_{m, k}, \omega_{l}\right)\right]^{\dagger}\right\} g\left(\vec{r}_{n, s}, \omega_{l}\right)}{M^{2}}
$$

Na implementação do código DAMAS realizada neste trabalho, calcula-se o conjunto de coeficientes $A_{s, k}$ a partir da relação

$$
A_{s, k}=\frac{\mathbf{g}^{\dagger}\left(\vec{r}_{m, s}, \omega_{l}\right)\left\{\mathbf{g}^{-1}\left(\vec{r}_{m, k}, \omega_{l}\right)\left[\mathbf{g}^{-1}\left(\vec{r}_{m, k}, \omega_{l}\right)\right]^{\dagger}\right\} \mathbf{g}\left(\vec{r}_{m, s}, \omega_{l}\right)}{M^{2}}
$$

que são empregados no cálculo de um mapa de beam-forming sintético para uma fonte de amplitude unitária, de acordo com o modelo de convolução dado por

$$
Y\left(\vec{r}_{o, s}, \omega_{l}\right)=\sum_{k=1}^{K} A_{s, k} X_{k}=A_{s, 1} X_{1}+A_{s, 2} X_{2}+\ldots A_{s, k} X_{k} \ldots+A_{s, K} X_{K}
$$

A deconvolução de um mapa de beam-forming via algoritmo DAMAS, para uma dada frequência espectral $\omega_{l}$, requer que a Eq. 4.58 seja processada $K^{2}$ vezes, no domínio $s=1,2, \ldots, K$ e $k=1,2, \ldots, K$, de forma a gerar todos os coeficientes necessários à solução do sistema de equações 4.46. Este processamento intensivo decorre da hipótese de que a psf não é invariante por translação no domínio espacial definido para o mapeamento de fontes.

\subsubsection{Implementação Numérica do Algoritmo DAMAS}

O método de deconvolução DAMAS requer a solução de um sistema de equações lineares do tipo $\left(A_{K \times K}\right) X=Y$. Em casos nos quais a matriz $A$ é não-singular e bem condicionada, a solução direta para tal sistema é da forma $X=\left(A^{-1}\right) Y$. Em geral, problemas envolvendo a aplicação de técnicas de deconvolução ao mapeamento de fontes em aeroacústica são mal condicionados e requerem solução a partir de um método indireto que tenha convergência assegurada sob certas condições.

Brooks e Humphreys (2006) propõem resolver o sistema $A X=Y$ pelo método iterativo

de Gauss-Seidel, modificado por uma restrição que torna nula todas as soluções $X_{k}^{(i)}$ com valores negativos, sendo $i$ o índice que denota o número da iteração corrente. Esta restrição atribui sentido físico a um problema puramente numérico, de forma a impedir que estimativas de amplitude de fontes acústicas assumam valores negativos. Para a aplicação do método DAMAS à base de dados experimentais, assume-se $Y\left(\vec{r}_{o, s}, \omega_{l}\right)=b\left(\vec{r}_{o, s}, \omega_{l}\right)$, sendo $b\left(\vec{r}_{o, s}, \omega_{l}\right)$ calculado conforme a Eq. 4.36 . 
A variável $X_{k^{\prime}}$ pode ser isolada a partir da Eq. 4.59

$$
X_{k^{\prime}}=b_{k^{\prime}}-\left[\sum_{k=1}^{k^{\prime}-1} A_{k^{\prime}, k} X_{k}+\sum_{k=k^{\prime}+1}^{K} A_{k^{\prime}, k} X_{k}\right],
$$

onde $k^{\prime}$ representa um índice auxiliar para o número de iterações e $A_{k, k}=1$. A variável $X_{k^{\prime}}$ aproximado na i-ésima iteração pelo método iterativo de Gauss-Seidel com restrição de positividade tem a forma

$$
X_{k^{\prime}}^{(i)}=b_{k^{\prime}}-\left[\sum_{k=1}^{k^{\prime}-1} A_{k^{\prime}, k} X_{k}^{(i)}+\sum_{k=k^{\prime}+1}^{K} A_{k^{\prime}, k} X_{k}^{(i-1)}\right], X_{k^{\prime}}^{(i)} \geq 0
$$

A Eq. 4.61 é implementada numericamente conforme as seguintes etapas

$$
\begin{aligned}
& X_{1}^{(i)}=b_{1}-\left[0+\sum_{k=2}^{K} A_{1, k} X_{k}^{(i-1)}\right], X_{1}^{(i)} \geq 0 \\
& X_{k^{\prime}}^{(i)}=b_{k^{\prime}}-\left[\sum_{k=1}^{k^{\prime}-1} A_{k^{\prime}, k} X_{k}^{(i)}+\sum_{k=k^{\prime}+1}^{K} A_{k^{\prime}, k} X_{k}^{(i-1)}\right], X_{k^{\prime}}^{(i)} \geq 0 \\
& X_{K}^{(i)}=b_{K}-\left[\sum_{k=1}^{K-1} A_{K, k} X_{k}^{(i)}+0\right], X_{K}^{(i)} \geq 0
\end{aligned}
$$

A Eq. 4.62 mostra que o valor aproximado de $X_{1}^{(i)}$ é calculado a partir de $(K-1)$ aproximações para as variáveis $X_{k^{\prime}}^{(i)},\left(k^{\prime}=2, \ldots, K-1\right)$, obtidas na iteração de número $(i-1)$. A Eq. 4.63 calcula as soluções $X_{k^{\prime}}^{(i)},\left(k^{\prime}=2, \ldots, K-1\right)$, utilizando as $\left(k^{\prime}-1\right)$ aproximações anteriores calculadas na interação atual, $(i)$, e as $\left[K-\left(k^{\prime}+1\right)\right]$ aproximações restantes calculadas na iteração anterior, $(i-1)$. A Eq. 4.64 mostra que a aproximação $X_{K}^{(i)}$ é calculada a partir das $(K-1)$ aproximações anteriores calculadas na iteração $(i)$. As aproximações $X_{k^{\prime}}^{(i)}$ são calculadas na iteração $(i=2)$ considerando um vetor de elementos nulos como entrada na interação $(i=1)$.

Em geral, o processo iterativo se mantém até que se atinja uma solução com erro de convergência dentro de uma tolerância estabelecida. O critério de parada usado neste trabalho se baseia na convergência da integral da pressão sonora estimado pelo algoritmo DAMAS e será discutido em maiores detalhes no capítulo seguinte. Algumas tentativas foram feitas para resolver o sistema $A X=b$ de forma direta, mas os resultados obtidos não foram satisfatórios. 


\subsection{Cálculo da Matriz de Espectros Cruzados}

O cálculo da matriz de espectros cruzados $(\mathbf{C})$ é necessário para a aplicação das técnicas de beam-forming utilizadas neste trabalho. A matriz $\mathbf{C}$ é calculada a partir de estimativas espectrais não-paramétricas, que são baseadas na metodologia proposta por (WELCH, 1967). O conteúdo apresentado neste tópico aborda os principais conceitos envolvidos no processamento da matriz $\mathbf{C}$.

Medições aeroacústicas consistem na aquisição de dados por uma antena de microfones durante um período limitado de tempo. Os sinais medidos são considerados estacionários, de forma que seus momentos estatísticos de primeira e segunda ordem; média e variância, respectivamente, permanecem constantes no tempo. Sinais estacionários podem ser representados em termos de Densidade Espectral de Potência - PSD (do ingles, Power Spectral Density).

Medições acústicas com taxa de amostragem constante, $f_{a}$, resultam na digitalização de valores de pressão sonora uniformemente amostradas à cada $\Delta t$. O número de amostras medidas após um tempo $T$ é dado por $f_{a} \times T$. Para fins de estimação da Densidade Espectral de Potência, via transformada de Fourier, o sinal de cada sensor é dividido sequencialmente em um número inteiro $H$ de blocos de dados de tamanho $L$ cada. $\mathrm{O}$ número $H$ de blocos depende do número total de amostras do sinal e da sobreposição entre blocos, definida pela quantidade de amostras compartilhadas entre dois blocos de dados contíguos. Assim, suponha que a amostra de índice $l$, no bloco $\mathbf{b}_{h}$, esteja deslocada de $(1-\beta) L$ em relação à amostra de índice correspondente no bloco $\mathbf{b}_{h+1}$, onde $\beta$ é a percentagem de sobreposição entre os blocos de índices $\mathbf{b}_{h}$, e $\mathbf{b}_{h+1}$. Nestas condições, o número total de blocos gerados pela partição do sinal é dado por (YARDIBI et al., 2009):

$$
H=\left[1+\frac{N-L}{L(1-\beta)}\right]
$$

Cada bloco é então transformado do domínio do tempo para o domínio da frequência via um algoritmo de FFT (Fast Fourier Transform), após ter a sua componente DC removida, o que é feito subtraindo-se de cada amostra o valor médio do conjunto de amostras do respectivo bloco de dados. Para uma representação formal, seja $\mathbf{u}_{h}(\lambda \Delta f)$ a transformada de Fourier do sinal $\mathbf{u}_{h}[l \Delta t]$, que resulta do produto ponto a ponto entre o bloco de dados $\mathbf{b}_{h}[l \Delta t]$ e a função de janelamento $\mathbf{w}[l \Delta t]$. O componente espectral de índice $\lambda$ do vetor $\mathbf{u}_{h}(\lambda \Delta f)$ é dado por

$$
u_{h}(\lambda)=\frac{1}{L} \sum_{l=0}^{L-1} u_{h}(l) \times e^{-2 \pi i \lambda l / L}
$$


O termo $e^{-2 \pi i \lambda l / L}$ é uma exponencial complexa que representa auto-funções no espaço de Fourier, $\Delta f=f_{a} / L$ é a resolução em frequência para o espectro e $\lambda$ é o índice que determina a posição do componente espectral $u_{h}(\lambda)$ no bloco de dados $\mathbf{u}_{h}=$ $\left[u_{h}(0), u_{h}(1), \ldots, u_{h}(\lambda), \ldots, u_{h}(L-1)\right]$. A transformada discreta de Fourier (TDF) de um sinal real resulta em um espectro no qual $u_{h}(\lambda)$ e $u_{h}(L-\lambda)$ são números complexos conjugados, de forma que apenas os valores $\mathbf{u}_{h}=\left[u_{h}(0), u_{h}(1), \ldots, u_{h}(\lambda), \ldots, u_{h}(L / 2)\right]$ são necessários para a representação espectral do sinal.

No caso de um sinal supostamente estacionário, em que se deseja reduzir a variância do componente randômico do ruído, a Densidade Espectral de Potência pode ser calculada a partir dos espectros cruzados de cada par de microfones, como a média dos produtos $\left[u_{m}(\lambda) u_{n}^{\dagger}(\lambda)\right]_{h}$, conforme

$$
\hat{C}_{m, n}(\lambda)=\frac{2 w_{c}}{H \Delta f} \sum_{h=0}^{H-1}\left[u_{m}(\lambda) u_{n}^{\dagger}(\lambda)\right]_{h},
$$

onde $m$ e $n$ são índices que denotam microfones e a média é tomada sobre o número de blocos de dedos $H$. Na Eq. 4.67, o termo $w_{c}$ é um fator de correção de energia usado para compensar o efeito da ponderação do sinal pela função de janelamento. O cálculo de $w_{c}$ depende da forma da função de janelamento aplicada, e será deduzido para a janela Hanning utilizada em nosso processamento de dados. O fator 2 compensa a perda de energia devido ao descarte de estimativas espectrais em frequências negativas.

A matriz de espectros cruzados é formada a partir dos valores $C_{m, n}(\lambda)$, calculados com o uso da Eq. 4.67. De forma a levar em conta todos os componentes espectrais em uma banda de frequência de interesse, a matriz $\mathbf{C}$ é estruturada na forma de uma matriz 3D, para a qual cada matriz 2D corresponde a um índice $\lambda$. Cada matriz $2 \mathrm{D}$ agrupa $\left(M^{2}-M\right)$ correlações cruzadas e $M$ auto-correlações entre os espectros dos microfones, estando as auto-correlações distribuídas sobre a diagonal principal da matriz.

A matriz de espectros cruzados é Hermitiana positiva definida. A propriedade de ser Hermitiana assegura que a matriz $\mathbf{C}$ é idêntica à sua transposta conjugada, de forma que $C_{m, n}=C_{n, m}^{*}$. Esta propriedade deve ser levada em conta no processamento da matriz $\mathbf{C}$, pois apenas o cálculo dos elementos de uma matriz triangular - inferior ou superior - é necessário. A matriz completa pode ser obtida, por exemplo, definindo-se cada elemento na diagonal superior como sendo o conjugado do elemento correspondente na diagonal inferior. Esta estratégia reduz significativamente a demanda computacional exigida para o processamento da matriz $\mathbf{C}$, que pode ser da ordem de horas em casos de medições relativamente longas com o uso de dezenas de microfones.

O cálculo das matrizes $\mathbf{C}$ usadas neste trabalho é feito a partir de um código que procura minimizar o número de vezes que a transformada de Fourier de um bloco de 
dados deve ser calculada. Funções internas do Matlab, usadas para o cálculo da PSD, tal como a cpsd (Cross power spectral density), requerem dois sinais de entrada. Isto significa que, no cálculo da PSD entre o sinal do microfone de índice (1), por exemplo, com os dos demais $M$ microfones, o cálculo da transformada da Fourier do sinal do microfone (1) é repetido $M$ vezes.

O código utilizado neste trabalho é estruturado de forma que, em um primeiro laço (externo), calcula-se as transformadas de Fourier de todos os blocos de dados resultantes da segmentação do sinal correspondente ao sensor de índice $m, m=1,2, \ldots, M$. Os dados de cada bloco correspondentes aos componentes de frequência positivos são ordenadamente armazenados em um vetor. Em um segundo laço (interno), é feito o processamento dos sinais correspondentes aos sensores de índices $n, n=1,2, \ldots, m$. Durante o processamento do sinal de cada sensor no laço interno, é feito o produto, bloco a bloco, com o sinal do sensor processado no laço externo. Desta forma, o processamento do sinal efetuado no laço externo não precisa ser repetido para o cálculo do produto deste sinal com os demais. Este procedimento permite que o número de sinais processados individualmente seja reduzido de $M(M+1)$, quando é usada um função interna do Matlab, para um total de $M(M+3) / 2$, para cada índice de frequência $\lambda$. Para uma antena com 62 microfones $(M=62)$, isto significa um redução no número de sinais processados de 3096 para 2015, para cada índice de frequência $\lambda$. Vantagens adicionais decorrentes do uso do código implementado para o cálculo da matriz $\mathbf{C}$ consistem em maior autonomia para a definição de parâmetros do processamento, tais como a porcentagem de sobreposição de dados e a função de janelamento.

A Fig. 4.5 representa o código utilizado para o processamento da matriz de espectros cruzados na forma de um diagrama de blocos. O código utiliza as funções fft e hanning, disponíveis no software Matlab. 


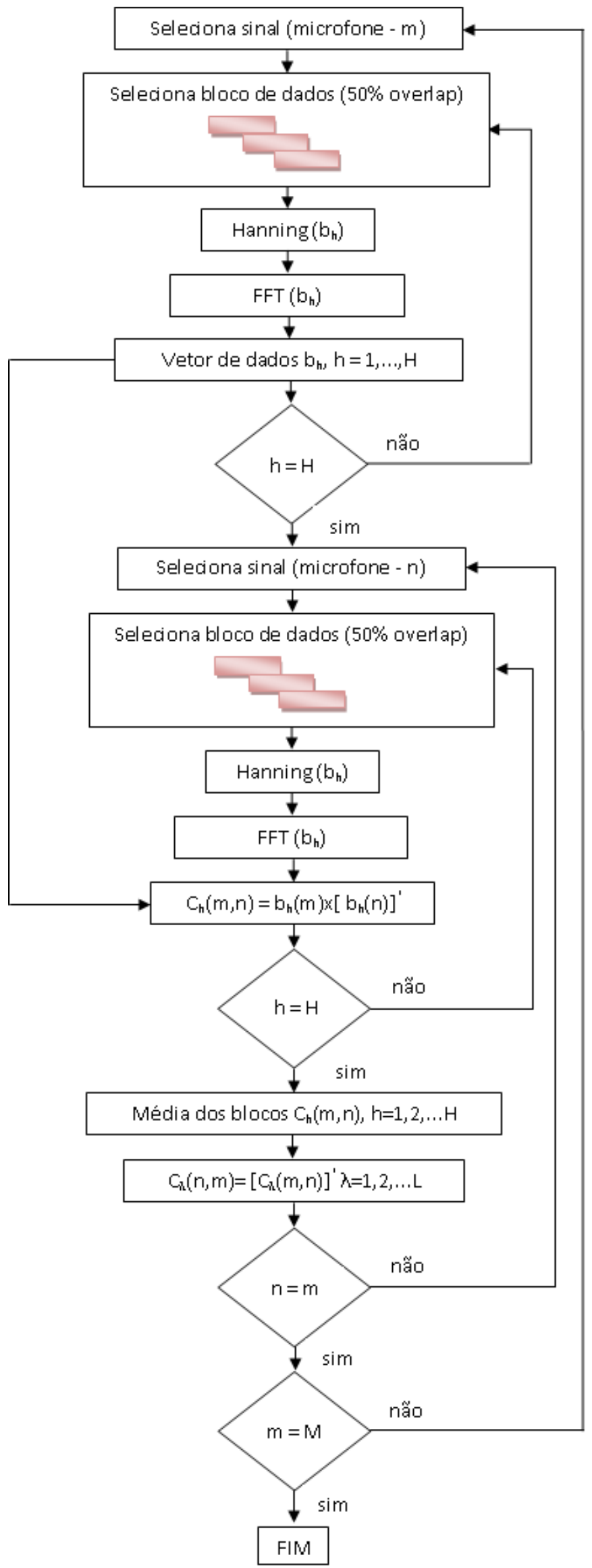

Figura 4.5: Representação em diagrama de blocos do código utilizado para o processamento da matriz de espectros cruzados. 


\subsubsection{Cálculo do Fator de Correção de Energia para a Aplica- ção da Função de Janelamento Hanning}

A aplicação de uma função de janelamento é uma prática vantajosa em processamentos que envolvem a partição de um sinal em blocos de dados. A aplicação da função de janelamento periodiza a série temporal, de forma a satisfazer a condição de periodicidade imposta pela Transformada de Fourier e reduzir o fenômeno conhecido por vazamento espectral, que consiste no espalhamento indevido de energia espectral para outras bandas de frequência.

Neste trabalho, utiliza-se a função de janelamento Hanning, descrita na forma

$$
\mathbf{w}_{h}(t)=\frac{1}{2}\left(1-\cos \frac{2 \pi t}{T}\right), 0 \leq t \leq T
$$

O fator de correção de energia a ser aplicado ao sinal janelado pode ser obtido a partir da integral do produto de um sinal $\mathbf{u}(t)$ pela função de janelamento $\mathbf{w}_{h}(t)$,

$$
\mathbf{u}_{w}(\omega)=\frac{1}{2} \int_{0}^{T}\left(1-\cos \omega_{0} t\right) \mathbf{u}(t) e^{-i \omega t} d t
$$

sendo $\omega_{0}=2 \pi / T$.

A Eq. 4.69 pode ser desenvolvida na forma

$$
\mathbf{u}_{w}(\omega)=\frac{1}{2} \int_{0}^{T} \mathbf{u}(t) e^{-i \omega t} d t+\frac{1}{2} \int_{0}^{T} \mathbf{u}(t)\left(\frac{e^{-i \omega_{0} t}+e^{-i \omega_{0} t}}{2}\right) e^{-i \omega t} d t
$$

A partir das relações

$$
\begin{aligned}
\mathbf{u}_{w}(\omega) & =\int_{0}^{T} \mathbf{u}(t) e^{-i \omega t} d t \\
\mathbf{u}_{w}\left(\omega \pm \omega_{0}\right) & =\int_{0}^{T} \mathbf{u}(t) e^{-i\left(\omega \pm \omega_{0}\right) t} d t
\end{aligned}
$$

a Eq. 4.70 pode ser representada como

$$
\mathbf{u}_{w}(\omega)=\frac{1}{2} \mathbf{u}(\omega)-\frac{1}{4} \mathbf{u}\left(\omega-\omega_{0}\right)-\frac{1}{4} \mathbf{u}\left(\omega+\omega_{0}\right)
$$

A Eq. 4.72 mostra que o valor do componente espectral $\mathbf{u}_{w}$ é ponderado na frequência $f=\omega / 2 \pi$ pelo fator $1 / 2$, devido à aplicação da função de janelamento Hanning, enquanto que ponderado pelo fator $1 / 4$ nas frequências vizinhas $\omega-\triangle \omega$ e $\omega+\Delta \omega$

Em termos da Eq. 4.72, a PSD para um espectro com frequências positivas (one side), 
considerando o sinal medido pelo microfone de índice $m$, pode ser estimada na forma

$$
\hat{C}_{m, m}=\frac{2}{H \triangle f} \sum_{h=0}^{H-1}\left(\frac{1}{4}|u(\omega)|^{2}+\frac{1}{16}\left|\mathbf{u}\left(\omega-\omega_{0}\right)\right|^{2}+\frac{1}{16}\left|\mathbf{u}\left(\omega+\omega_{0}\right)\right|^{2}+\ldots\right)_{h}
$$

Os termos restantes na Eq. 4.73 são termos cruzados da forma $\mathbf{u}(\omega) \times \mathbf{u}\left(\omega \pm \omega_{0}\right)$. Os valores esperados dos termos cruzados podem ser considerados nulos pela hipótese de que o sinal comporta-se como um ruído branco de banda limitada Bendat e Piersol (1980), conforme

$$
\begin{aligned}
\left\langle\mathbf{u}_{w}(\omega) \mathbf{u}_{w}^{*}\left(\omega_{0}\right)\right\rangle & =0 \text { se } \omega \neq \omega_{0} \\
& =1 \text { se } \omega=\omega_{0}
\end{aligned}
$$

Supondo uma distribuição suave de valores de PSD em frequências vizinhas para este tipo de ruído, temos a seguinte aproximação: $\mathbf{u}_{w}(\omega) \approx \mathbf{u}_{w}\left(\omega-\omega_{0}\right) \approx \mathbf{u}_{w}\left(\omega+\omega_{0}\right)$. Nestas condições, a Eq.4.73 se escreve na forma

$$
\hat{C}_{w} \cong \frac{3}{8} \frac{2}{H \triangle f} \sum_{h=0}^{H-1}|\mathbf{u}(\omega)|_{h}^{2}=\frac{3}{8} \hat{C}
$$

A Eq. 4.75 mostra que o efeito de dispersão de energia causado pela ponderação de um sinal pela função de janelamento Hanning pode ser corrigido pela aplicação do fator $w_{c}=8 / 3$. O símbolo sobrescrito na variável $\hat{C}_{w}$ indica que esta variável representa uma estimativa do valor real. No caso de uma variável estimada por médias, o valor estimado tende ao valor real, à medida em que o número de médias se torna suficientemente grande.

\subsection{Avaliação dos Códigos de Beam-forming Con- vencional e DAMAS}

Nesta secção são apresentados resultados de alguns estudos realizados com o objetivo de avaliar e validar os códigos de beam-forming convencional e deconvolução DAMAS implementados no contexto deste trabalho. O objetivo é avaliar a capacidade dos algoritmos para estimar corretamente o nível de pressão sonora de uma fonte e identificar uma fonte em linha, simulando o comportamento ideal de uma fonte 2D distribuída ao longo da envergadura do eslate.

Embora diferentes modelos de fontes sintéticas tenham sido usados ao longo do desenvolvimento deste trabalho, apresenta-se um estudo baseado em um modelo de fontes em linha disponibilizado pela Equipe de Ruído da EMBRAER. 


\subsubsection{Fonte Sintética: Monopolos em Linha}

Este estudo de caso considera uma distribuição de fontes em linha constituída por 2041 fontes puntuais descorrelacionadas e igualmente espaçadas em $0.0005 \mathrm{~m}$ ao longo de $1.2 \mathrm{~m}$. As fontes encontram-se sobre um plano deslocado de $0.85 \mathrm{~m}$ perpendicularmente ao plano da antena. A distribuição de fontes determina uma linha vertical deslocada em aproximadamente $0.38 \mathrm{~m}$ à montante do centro da antena. Os sinais foram sintetizados de forma a gerar $2^{21}$ amostras randômicas representando a distribuição de pressão sonora em cada fonte. As amostras foram simuladas a uma taxa de aquisição de $102400 \mathrm{~Hz}$, de forma a gerar um sinal com 20.48 s de duração. Cada sinal foi transformado para o domínio de Fourier, gerando espectros com $2^{21}$ pontos com parte real e imaginária, normalizados de forma que cada componente espectral tivesse amplitude unitária. Os sinais gerados possuem fase randômica e distribuição uniforme de amplitudes. Um ruído browniano é então produzido normalizando-se o valor absoluto de cada componente espectral pelo valor da frequência central da respectiva banda.

O sinal sintetizado em cada fonte é propagado para os microfones da antena, de acordo com o modelo de propagação

$$
\hat{p}_{o, m, \text { brown }}=A_{m, k}\left(\hat{p}_{o, k, \text { brown }}\right) e^{-i \omega d_{m, k} / c},
$$

onde $\hat{p}_{o, m, \text { brown }}$ e $\hat{p}_{o, k \text {,brown }}$ representam os níveis de pressão sonora dos espectro de ruído no microfone de índice $m$ e na fonte de índice $k$, respectivamente. O termo $A_{m, k}=1 / d_{m, k}$ quantifica o decaimento de amplitude da fonte devido ao espalhamento esférico da frente de onda, sendo $d_{m, k}=\sqrt{\left(x_{o, k}-x_{o, m}\right)^{2}+\left(y_{o, k}-y_{o, m}\right)^{2}+\left(z_{o, k}-z_{o, m}\right)^{2}}$ a distância cartesiana entre a fonte $k$, de coordenadas $\left(x_{o, k}, y_{o, k}, z_{o, k}\right)$ e o microfone $m$, de coordenadas $\left(x_{o, m}, y_{o, m}, z_{o, m}\right)$. É interessante notar que cada componente no espectro $\hat{p}_{o, s, b r o w n}$ é gerado com fase randômica na fonte e propagado ao microfone com deslocamento de fase dado por $\omega\left(d_{m, k} / c\right)$.

Uma vez propagados aos microfones, os sinais são transformados novamente para o domínio do tempo, de acordo com a seguinte equação

$$
p_{m, k, \text { brown }}=\mathscr{R}\left\{\mathscr{F}^{-1}\left(\hat{p}_{m, k, \text { brown }}\right)\right\}-\overline{\mathscr{R}\left\{\mathscr{F}^{-1}\left(\hat{p}_{m, k, \text { brown }}\right)\right\}},
$$

A Eq. 4.77 representa a medição física de um sinal sintético com duração de 20.48 s, à taxa amostragem de $102.400 \mathrm{~Hz}$. O sinal resultante em cada um dos microfones é composto pela superposição dos sinais emitidos por cada uma das 2041 fontes puntuais que determinam a distribuição de fontes em linha, conforme representado por

$$
p_{m}(n \Delta t)=\sum_{k=1}^{2401} p_{m, k}(n \Delta t), n=0,1, \ldots, 2^{21}-1,
$$


onde $\Delta t$ representa o tempo transcorrido em duas amostragens consecutivas do sinal.

A simulação desta fonte sintética não envolve a adição de ruído e os microfones podem ser considerados em condição de campo livre. Os sinais sintéticos foram processados com os códigos de beam-forming implementados no contexto deste trabalho, com o objetivo de avaliar a capacidade dos mesmos de representar uma distribuição de fontes em linha e recuperar, por integração de níveis discretos de pressão sonora, a amplitude do sinal medido no microfone de referência. A diagonal principal da CSM, representando os autoespectros dos microfones, foi removida de forma a utilizar o mesmo processamento usado para os dados experimentais.

A Fig. 4.6 mostra uma comparação entre mapas acústicos representando a distribuição de fontes em linha simulada com a metodologia acima descrita. Os mapas de fontes foram processados com os códigos de beam-forming convencional e deconvolução DAMAS. Vê-se que ambos os métodos de beam-forming convencional e DAMAS são capazes de identificar uma distribuição de fontes em linha. No entanto, o resultado da deconvolução mostra que a influência do padrão de resposta da antena sobre a representação das fontes foi significativamente reduzido. Os mapas obtidos com o método DAMAS permitem maior precisão na localização das fontes e melhor definição de seus contornos, o que decorre do estreitamento do lóbulo principal e da redução da amplitude dos lóbulos secundários das fontes. A partir dos resultados apresentados na Fig. 4.6, torna-se evidente as vantagens do uso de um método de deconvolução para a separação entre fontes concorrentes e a definição de uma região de integração que permita avaliar a contribuição relativa de cada distribuição de fontes para o ruído global de um modelo de testes.

A Fig. 4.7 mostra o resultado de uma simulação realizada para avaliar a capacidade do código de deconvolução DAMAS em quantificar o nível de ruído gerado pela distribuição de fontes em linha, a partir da integração de níveis discretos de pressão sonora sobre o domínio da fonte. Para tal avaliação, o nível de ruído integrado para cada componente de frequência na banda de interesse é comparado com o auto-espectro de um microfone de referência na respectiva banda. Esta abordagem é possível porque os microfones não estão contaminados por ruído de fundo. Para compensar efeitos de diretividade e decaimento esférico devido às diferentes posições dos microfones em relação à fonte, que decorre da abordagem de beam-forming para campo próximo, o nível de ruído no microfone de referência é representado pela média dos auto-espectros de todos os 62 microfones da antena.

A tabela 4.1 mostra valores de erro que representam o desvio dos níveis integrados de pressão sonora em relação ao nível estimado no microfone de referência (Fig. 4.7) para alguns componentes de frequência do espectro.

Os resultados mostram que os níveis de ruído da fonte estimados pelo código DAMAS 


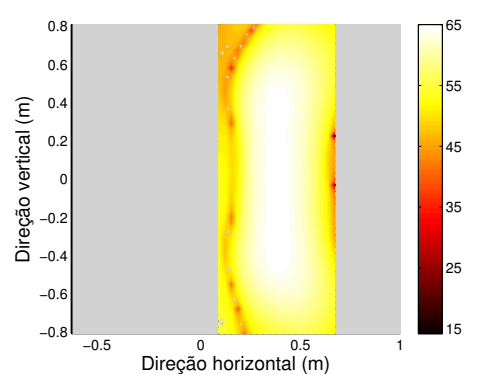

(a) Beam-forming Conv. - $2 \mathrm{kHz}$

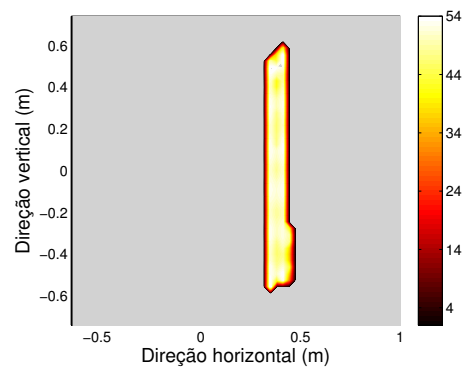

(d) DAMAS - $2 \mathrm{kHz}$

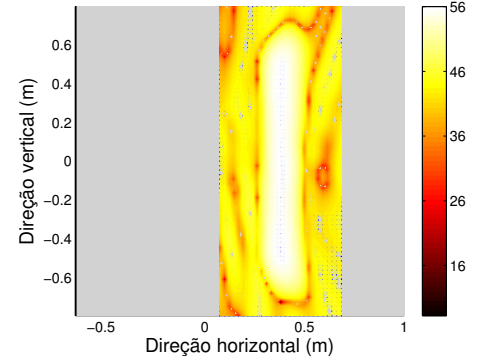

(b) Beam-forming Conv. - 4kHz

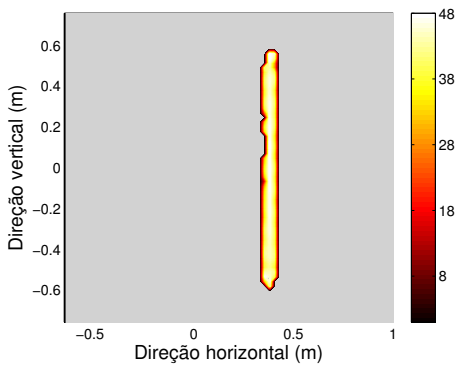

(e) DAMAS - $4 \mathrm{kHz}$

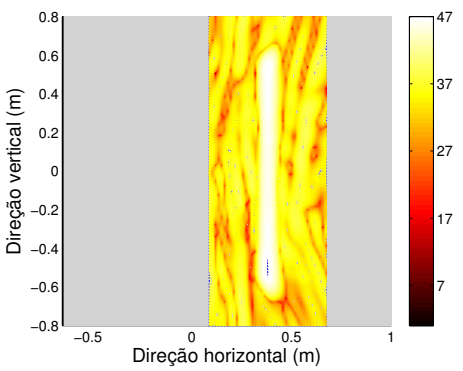

(c) Beam-forming Conv. - $8 \mathrm{kHz}$

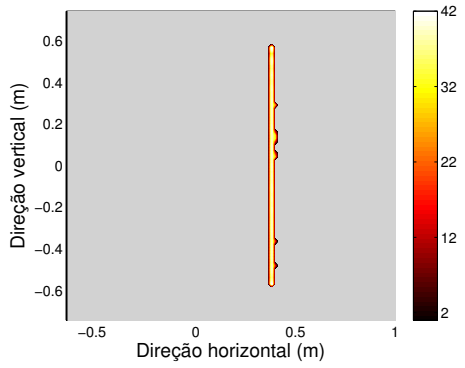

(f) DAMAS - $8 \mathrm{kHz}$

Figura 4.6: Imagens acústicas representando distribuições de fontes em linha nas frequências de $2 \mathrm{kHz}, 4 \mathrm{kHz}$ e $8 \mathrm{kHz}$. Os resultados foram obtidos pela aplicação dos códigos de beam-forming convencional e deconvolução DAMAS.

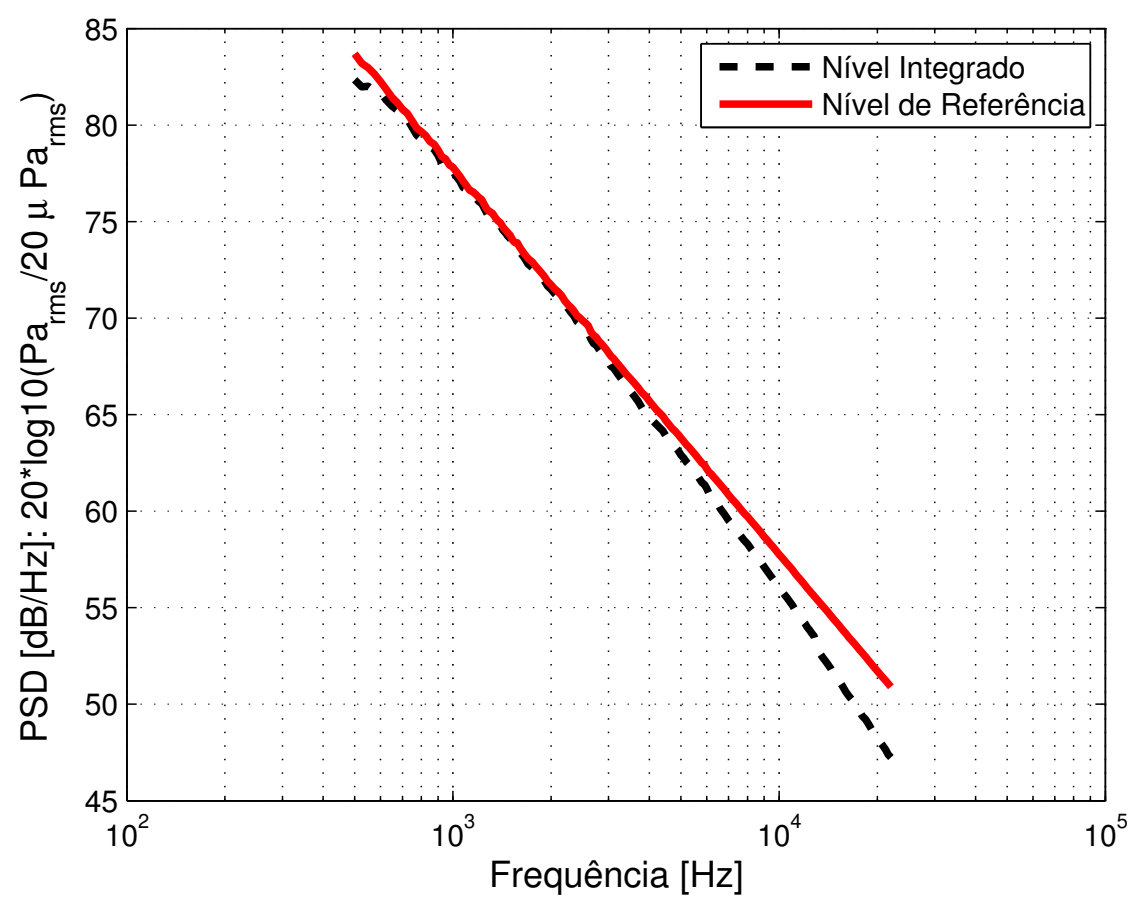

Figura 4.7: Comparação entre o espectro de ruído obtido por integração dos níveis de pressão sonora sobre o domínio da fonte com o código DAMAS e a média dos auto-espectros dos 62 microfones. 
Tabela 4.1: Erro para diferentes frequências

\begin{tabular}{|c|c|}
\hline Frequência $(\mathrm{Hz})$ & Erro $(\mathrm{dB})$ \\
\hline 1000 & 0,230 \\
\hline 2000 & 0,232 \\
\hline 4000 & 0,822 \\
\hline 8000 & 1,415 \\
\hline 16000 & 3,016 \\
\hline
\end{tabular}

são representativos dos níveis de ruído no microfone de referência, que representa uma medida do nível médio de pressão sonora que incide sobre a superfície da antena. O resultado é particularmente bom para frequências em torno de $2 \mathrm{kHz}$, com um erro em relação o nível de referência em torno de $0.25 \mathrm{~dB}$. Estudo similar realizado com uma fonte física relativamente compacta, representada por um tweeter, mostrou que os algoritmos de beam-forming convencional e DAMAS foram capazes de recuperar o nível estimado pelo microfone de referência sem qualquer viés de erro em altas frequências. Uma possível explicação para o maior desvio observado em frequências mais altas pode ser o baixo nível de correlação entre sinais medidos por diferentes microfones, que é observado em altas frequências para o caso da distribuição de fontes em linha.

\subsubsection{Estudos para a Calibração de Fase dos Microfones}

A calibração de fase dos microfones de uma antena é um procedimento técnico recomendado em experimentos aeroacústicos, como forma de reduzir incertezas em estimativas de níveis de pressão sonora e posição de fontes (YARDIBI et al., 2009). Nesta subseção são apresentados os resultados decorrentes de um estudo exploratório para avaliar a necessidade de calibração de fase dos microfones da antena utilizada na campanha de medição do ruído do aerofólio 30P30N. Para tal, são comparadas as fases que resultam da correlação entre sinais sintéticos e experimentais medidos pelos microfones da antena em condições tão idênticas quanto possível.

Em geral, a calibração de fase tem por objetivo corrigir erros associados com imprecisões no posicionamento dos microfones, medidas de temperatura e outros fatores influenciam na fase de um sinal medido. Mueller (2002) apresenta uma metodologia de calibração que é amplamente citada na literatura e que consiste em determinar experimentalmente as funções de transferência que modelam a propagação de uma onda acústica desde o ponto de emissão até as posições ocupadas pelos microfones da antena. A metodologia seguida neste trabalho é apresentada por Brooks, Humphreys Jr e Plassman (2010), sob o nome de CSM Phase Conditioning. Em termos práticos, coloca-se uma fonte física - fonte de teste: idealmente uma fonte puntual do tipo monopolo, em uma posição conhecida na região onde se pretende realizar o mapeamento de fontes reais. Então, mede-se o sinal da 
fonte de teste com a antena de microfones e utiliza-se um modelo de sinal sintético para o condicionamento, ou correção, das fases obtidas pela correlação espectral entre sinais de cada par de microfones.

A correlação espectral entre os sinais medidos por dois microfones, (com índices $m$ e $n$ ), é uma sequência de números complexos cuja fase em uma dada frequência é determinada pela diferença de percurso entre duas frentes de ondas que se propagam desde a fonte até os dois microfones em diferentes posições, bem como pelo comprimento de onda. Chamamos a fase da correlação entre sinais medidos de fase experimental, denotada por $\left(\varphi_{m, n}\left(\omega_{l}\right)\right)_{\text {exp }}$. A forma da correlação espectral entre os microfones de índices $m$ e $n$ é pela por

$$
S_{m, n}=\left|S_{m, n}\right| \exp \left[i\left(\varphi_{m, n}\left(\omega_{l}\right)\right)_{\exp }\right] .
$$

Conhecendo-se a posição da fonte acústica de referência e as condições atmosféricas na câmara de ensaios, pode-se facilmente calcular a diferença de fase teórica entre os sinais recebidos pelos microfones de índices $m$ e $n,\left(\varphi_{m, n}\left(\omega_{l}\right)\right)_{c a l}$, de acordo com

$$
\left(\varphi_{m, n}\left(\omega_{l}\right)\right)_{c a l}=\left(\varphi_{m}\left(\omega_{l}\right)\right)_{c a l}-\left(\varphi_{n}\left(\omega_{l}\right)\right)_{c a l}=2 \pi f r_{o, m} / c-2 \pi f r_{o, n} / c
$$

As fases $\left(\varphi_{m}\right)_{c a l}$ e $\left(\varphi_{n}\right)_{c a l}$ são usadas na formulação teórica de beam-forming para a definição do steering vector.

O desvio da fase experimental em relação à fase teórica é dado por $\left(\varphi_{m, n}\left(\omega_{l}\right)\right)_{c a l}$ $\left(\varphi_{m, n}\left(\omega_{l}\right)\right)_{\text {exp }}$. O uso da fase teórica $\left(\varphi_{m, n}\left(\omega_{l}\right)\right)_{c a l}$ como fase de referência para a correção de erros nas fases experimentais parece ser uma escolha razoável quando se conhece o posicionamento dos microfones com boa precisão, embora a incerteza na determinação da posição da fonte em relação à antena seja algo difícil de se prever.

Brooks, Humphreys Jr e Plassman (2010) definem a expressão usada para o condicionamento, ou correção, de fase da matriz de espectros cruzados, conforme

$$
\left(S_{m, n}\right)_{c o n d}=\left|S_{m, n}\right| \exp \left\{i\left(\varphi_{m, n}\left(\omega_{l}\right)\right)_{m e s}+i\left[\left(\varphi_{m, n}\left(\omega_{l}\right)\right)_{c a l}-\left(\varphi_{m, n}\left(\omega_{l}\right)\right)_{e x p}\right]_{p s}\right\}
$$

O termo $\left(\varphi_{m, n}\left(\omega_{l}\right)\right)_{m e s}$ representa a fase que se deseja corrigir pela aplicação da técnica CSM phase conditioning. De acordo com a Eq. 4.81, a correção no erro de fase é feita pela adição do termo $\left[\left(\varphi_{m, n}\left(\omega_{l}\right)\right)_{c a l}-\left(\varphi_{m, n}\left(\omega_{l}\right)\right)_{\text {exp }}\right]_{p s}$. O índice $p s$ indica que o parâmetro $\left(\varphi_{m, n}\left(\omega_{l}\right)\right)_{\exp }$ é determinado a partir da correlação entre sinais medidos e o parâmetro $\left(\varphi_{m, n}\left(\omega_{l}\right)\right)_{c a l}$ a partir de um modelo de propagação que leva em conta a posição de uma fonte de teste usada como referência para a calibração da antena.

Em geral, as técnicas de calibração baseadas no uso de uma fonte de teste assumem que o erro de fase estimado na posição da fonte representa o erro que seria medido para 
um sinal emitido a partir de qualquer ponto da região de mapeamento. Esta suposição é válida para medições em condição de campo distante, em que a distância entre as fontes e a antena é consideravelmente maior que a dimensão da antena ou da distribuição de fontes. No caso em estudo, em que a distância entre a antena e o plano de fontes é da mesma ordem de grandeza que a abertura da antena $(\approx 0.85 m)$, a calibração feita com a fonte de teste em apenas um ponto de referência pode apresentar um resultado limitado.

A Fig. 4.8 é apresentada por Brooks, Humphreys Jr e Plassman (2010), e mostra a correspondência entre as fases $\left(\varphi_{1,29}\right)_{m e s}$ e $\left(\varphi_{1,29}\right)_{c a l}$, para os microfones de índices 1 e 29 , antes e após a calibração da fase de sua antena. O resultado apresentado na Fig. 4.8 (b) mostra a correção de um erro sistemático de fase (Fig. 4.8 (a)) pela aplicação da técnica de calibração apresentada na Eq. 4.81 .

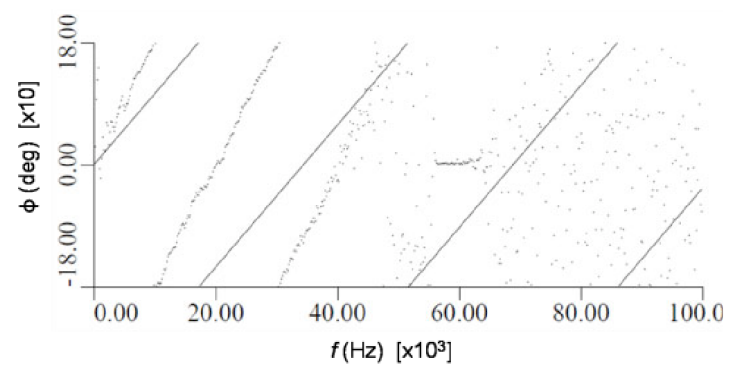

(a) $\left(\varphi_{m, n}\right)_{m e s} \times\left(\varphi_{m, n}\right)_{c a l}$ - antes da calibração

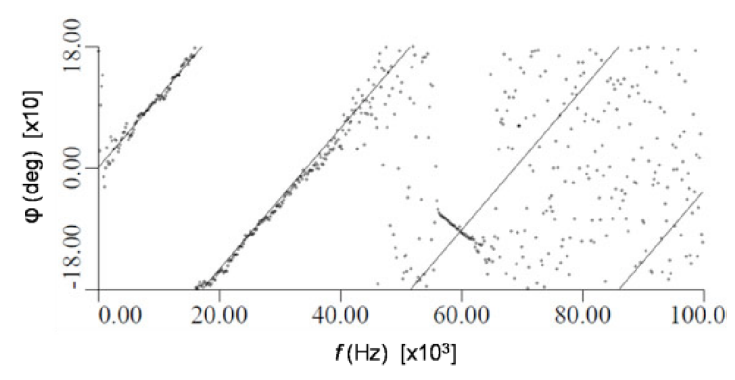

(b) $\left(\varphi_{m, n}\right)_{m e s} \times\left(\varphi_{m, n}\right)_{c a l}-$ depois da calibração

Figura 4.8: Correspondência entre $\left(\varphi_{1,29}\right)_{\text {mes }}$ e $\left(\varphi_{1,29}\right)_{\text {cal }}$ para os microfones de índices 1 e 29, antes (a) e depois (b) da aplicação da calibração de fase, conforme definida na Eq. 4.81. A linha contínua representa a variação de $\left(\varphi_{m, n}\right)_{c a l}$ com a frequência, enquanto que a nuvem de pontos representa estimativas de $\left(\varphi_{m, n}\right)_{m e s}$.

Um estudo foi realizado para avaliar a correspondência entre as fases experimental, $\left(\varphi_{m, n}\right)_{\text {exp }}$, e teórica, $\left(\varphi_{m, n}\right)_{c a l}$, para a antena com 62 microfones utilizada nas medições experimentais que são objeto de estudo deste trabalho. As medições foram realizadas na ausência de escoamento, ou seja, com o túnel de vento desligado.

Os valores de $\left(\varphi_{m, n}\right)_{\text {exp }}$ foram obtidos a partir da medição de ruído branco emitido por um tweeter posicionado no centro da região ocupada pelo eslate quando o aerofólio está configurado para ângulo de ataque de $4^{\circ}$. Para a determinação da posição da fonte em relação à antena, o tweeter foi alinhado com um ponto de referência utilizando um marcador a laser e sua distância em relação ao plano da antena foi medida com uma trena a laser. Os valores da fase teórica, $\left(\varphi_{m, n}\right)_{c a l}$, foram obtidos a partir do uso de um modelo de propagação que considera frentes de ondas emitidas por uma fonte monopolo na mesma posição ocupada pelo tweeter, e recebidas por cada microfone na antena. As condições de pressão atmosférica e temperatura medidas experimentalmente na câmara de ensaios foram usadas no cálculo da fase teórica. 
Isolamento acústico foi realizado no entorno da fonte e da antena para mitigar efeitos de reverberação na câmara de ensaios e garantir que o tweeter representasse a fonte dominante de forma indúbia. Para avaliar o efeito da instalação de espumas sobre a medição do ruído branco emitido pelo teweeter, algumas medições foram repetidas após a retirada das espumas. A Fig. 4.9 mostra a razão entre os dois auto-valores dominantes nas matrizes de espectros cruzados que representam medições com e sem a instalação de espumas. A razão entre os dois auto-valores de maior amplitude representa uma medida da razão entre a amplitude da fonte dominante (tweeter) e a amplitude da fonte secundária de maior importância, em cada frequência de análise. Mueller (2002) recomenda uma razão de pelo menos 10 para 1 entre os auto-valores dominantes, como um margem segura para se assegurar a dominância da fonte de referência em um procedimento de calibração de fase para uma antena de microfones.

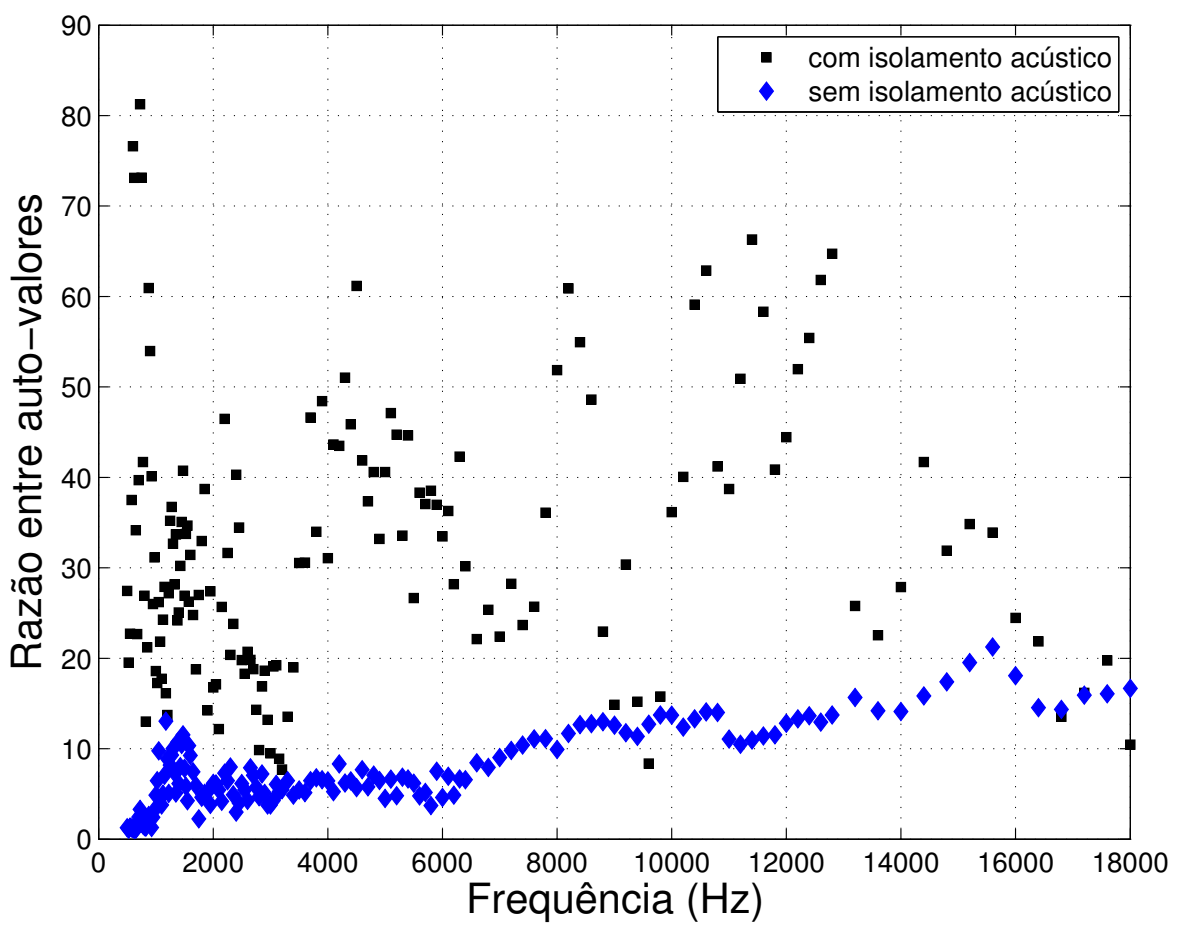

Figura 4.9: Razão entre auto-valores dominantes nas matrizes de espectros cruzados obtidas a partir de medições do ruído branco de um teweeter com e sem espumas para o isolamento acústico da fonte.

A Fig. 4.9 mostra claramente que o uso de espumas, com o objetivo de reduzir a influência de fontes secundárias com origem na reverberação do sinal emitido pelo tweeter, representa uma melhora significativa na qualidade da relação sinal/ruído obtida sem o uso de espumas.

A Fig. 4.10 mostra a comparação entre as fases $\left(\varphi_{m, n}\right)_{\text {exp }}$ e $\left(\varphi_{m, n}\right)_{c a l}$ que representam o resultado da correlação entre alguns pares de microfones na antena com 62 elementos.

Os resultados apresentados na Fig. 4.10 são representativos do padrão de correspon- 


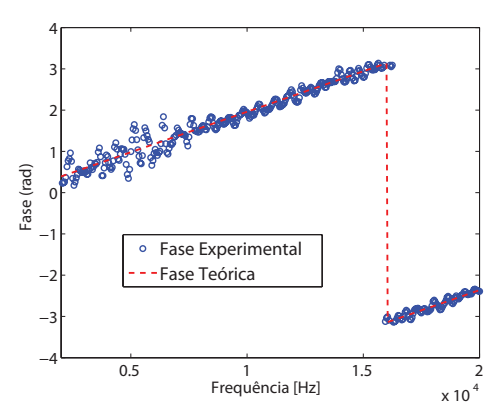

(a) $\left(\varphi_{1,2}\right)_{c a l} \times\left(\varphi_{1,2}\right)_{\exp }$

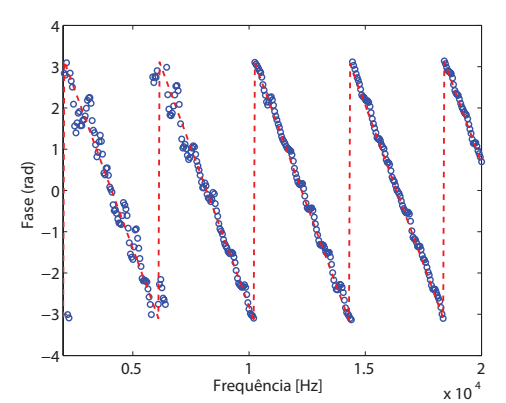

(d) $\left(\varphi_{1,17}\right)_{c a l} \times\left(\varphi_{1,17}\right)_{\text {exp }}$

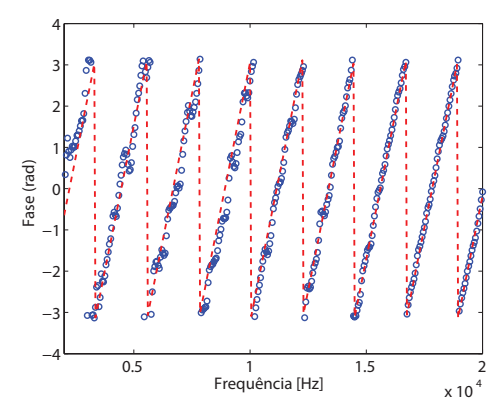

(g) $\left(\varphi_{30,41}\right)_{c a l} \times\left(\varphi_{30,41}\right)_{\exp }$

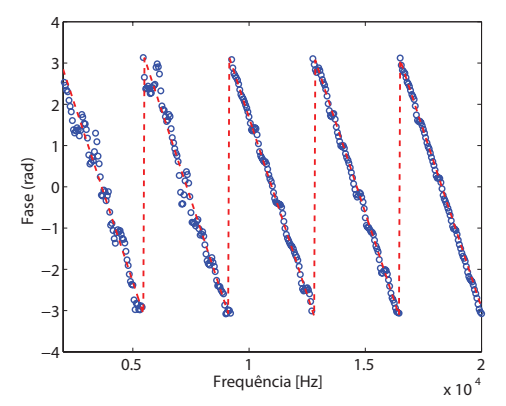

(j) $\left(\varphi_{13,28}\right)_{c a l} \times\left(\varphi_{13,28}\right)_{e x p}$

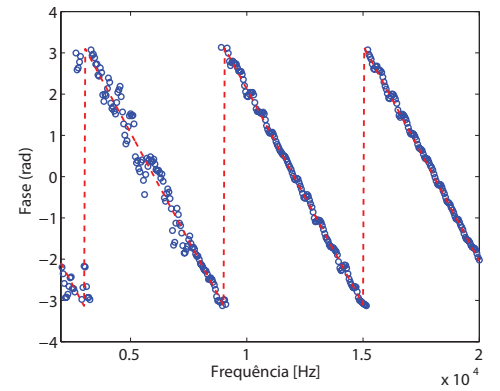

(b) $\left(\varphi_{4,7}\right)_{c a l} \times\left(\varphi_{4,7}\right)_{\exp }$

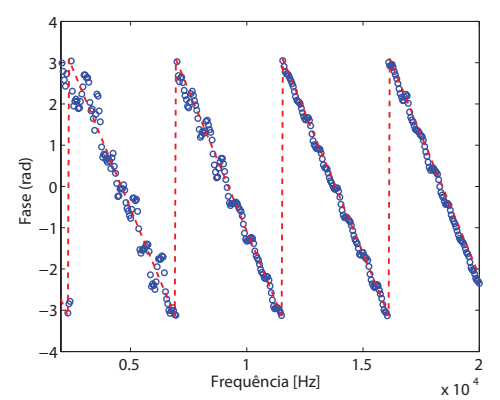

(e) $\left(\varphi_{1,16}\right)_{c a l} \times\left(\varphi_{1,16}\right)_{\exp }$

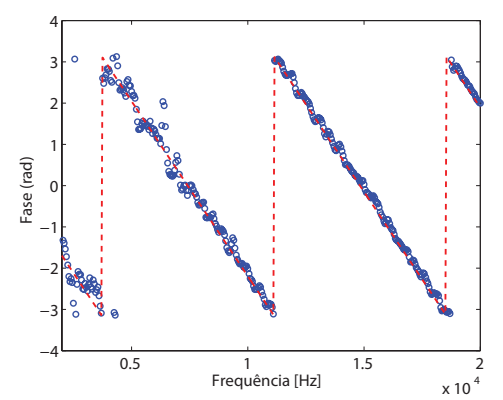

(h) $\left(\varphi_{1,8}\right)_{c a l} \times\left(\varphi_{1,8}\right)_{\text {exp }}$

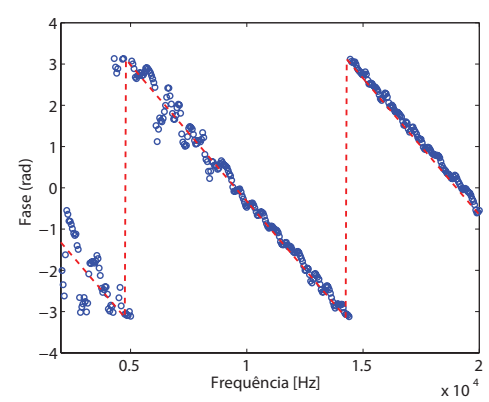

(k) $\left(\varphi_{59,60}\right)_{c a l} \times\left(\varphi_{59,60}\right)_{\exp }$

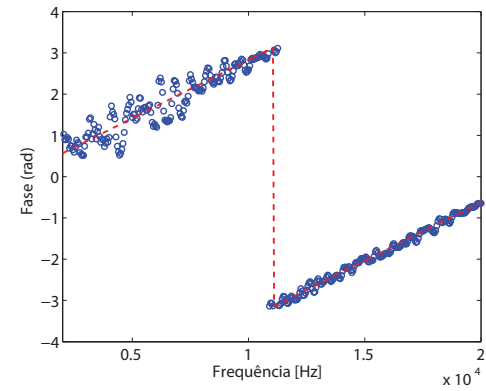

(c) $\left(\varphi_{2,11}\right)_{c a l} \times\left(\varphi_{2,11}\right)_{\exp }$

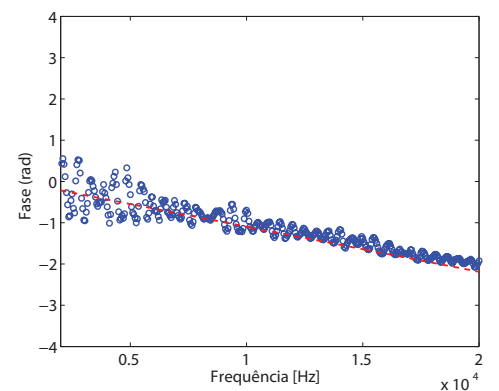

(f) $\left(\varphi_{7,8}\right)_{c a l} \times\left(\varphi_{7,8}\right)_{\exp }$

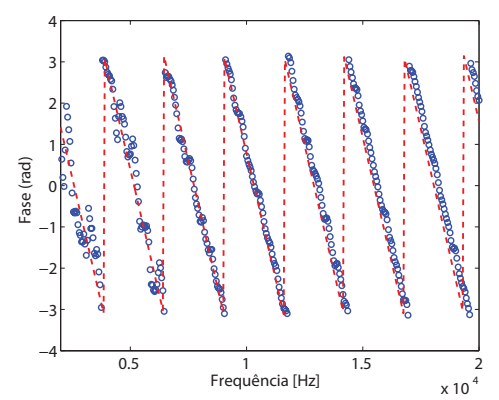

(i) $\left(\varphi_{1,60}\right)_{c a l} \times\left(\varphi_{1,60}\right)_{\exp }$

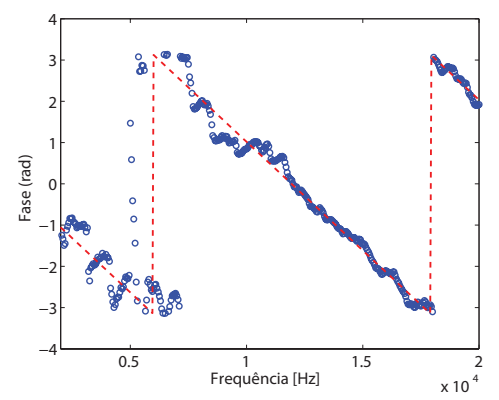

(l) $\left(\varphi_{20,21}\right)_{c a l} \times\left(\varphi_{20,21}\right)_{\exp }$

Figura 4.10: Comparação entre a fase teórica simulada, $(\varphi)_{c a l}$, e a fase experimental $(\varphi)_{\text {exp }}$, calculada a partir da correlação espectral entre pares microfones distintos.

dência entre fases experimental e teórica observado para uma amostra consideravelmente maior de casos analisados. Os resultados indicam que, para a presente antena, as fases medidas experimentalmente se comportam como aquelas previstas pelo modelo teórico, sem a indicação de qualquer fonte de erros sistemáticos. 
Estes resultados sugerem que os dados medidos, mesmo sem calibração, possuem qualidade suficiente para serem processados pelo método de beam-forming, que se baseia na hipótese de que as fases dos sinais medidos experimentalmente correspondem àquelas previstas pela função de transferência adotada na definição do pelo steering vector. Baseado nos resultados apresentados na Fig. 4.10, e principalmente nos resultados de diversos testes que mostram que é possível recuperar o nível de ruído no microfone de referência por integração dos mapas de beam-forming, com uma margem de erro aceitável, decidiu-se por não aplicar a calibração de fase ao processamento de dados. No entanto, a continuidade dos estudos para a calibração de fase em medições com a antena de microfones é altamente recomendado. 


\section{CAPÍTULO 5}

\section{Metodologias de Pós-Processamento Aplicadas ao Ruído do Eslate}

\subsection{Introdução}

Neste capítulo é apresentada uma visão geral sobre as metodologias adotadas para o processamento da base de dados acústicos do eslate e a definição de parâmetros computacionais utilizadas utilizados nos códigos. A estratégia adotada para a aplicação sistemática dos códigos de beam-forming implementados no contexto deste trabalho é apresentada em seus aspectos gerais. Este tópico representa uma importante parte dos desenvolvimentos realizados neste trabalho e descreve a forma como diferentes etapas do processamento são integrados em um fluxo contínuo de dados.

No decorrer dos estudos, vários testes foram realizados para verificar a independência dos resultados em relação aos parâmetros de processamento, tendo sido avaliados, por exemplo, efeitos do tempo de aquisição e da resolução em frequência sobre os espectros de ruído do eslate. A definição da malha é uma questão estratégica, por ser a malha um fator determinante para a convergência dos resultados e o custo computacional do processamento com o método de deconvolução DAMAS. A malha adotada neste trabalho possui tamanho e espaçamento entre pontos variáveis na frequência, o que permite flexibilizar a definição dos parâmetros de construção da malha ao longo da banda de frequência. Nesta seção, discutem-se com particular interesse os conceitos relevantes para a definição da malha e a independência das estimativas dos níveis de pressão sonora em relação aos parâmetros de processamento adotados. A definição de uma malha de pontos variável na frequência se mostrou uma solução adequada para a uma redução significativa no custo 
computacional inerente ao processamento com o algoritmo DAMAS.

Por fim, são apresentados os critérios adotados para escolha de uma região de interesse para a integração dos níveis de pressão sonora que determinam o espectro de ruído do eslate. O processo de integração representa a aplicação prática da malha e dos parâmetros de processamento discutidos e confere maior clareza às discussões subsequentes sobre o ruído do eslate.

\subsection{Metodologias de Processamento para a Base de Dados Acústicos}

O objetivo desta seção é descrever a estrutura dos códigos e as principais ações adotadas para o processamento da base de dados experimentais. Os resultados são obtidos a partir de duas etapas independentes e complementares de processamento dos dados, que são apresentadas e discutidas em seus aspectos gerais.

A elaboração de uma estratégia eficaz de processamento, de forma a transformar as várias etapas de processo em um código com fluxo de dados contínuo e automatizado, representou um desafio para a consolidação deste trabalho. O uso de um fluxograma pode contribuir para uma visão mais abrangente e unificada sobre a forma como diferentes etapas do processamento, discutidas em diferentes partes deste trabalho, encontram-se interligadas.

Na sequência, os dois conjuntos de ações que definem blocos de processamento com fluxo de dados contínuo, do ponto de vista operacional, são identificados e descritos como códigos (1) e (2).

\subsubsection{Descrição do Código (1)}

O código 1 tem como arquivos de entrada os sinais medidos pelos microfones no domínio do tempo, e como dados de saída matrizes que representam a distribuição de pressão sonora sobre um domínio espacial de interesse, obtidas pela aplicação das técnicas de beam-forming convencional ou DAMAS.

Esta etapa do processamento envolve o cálculo da matriz CSM com largura de banda e resolução em frequência definidas pelos critérios adotados para a análise dos dados. No entanto, para uma dada banda e resolução em frequência, a matriz CSM poderá ser calculada uma única vez a partir dos sinais dos microfones no domínio do tempo, podendo ser usada como arquivo de entrada para diferentes processamentos.

A partir do cálculo da matriz CSM, o processamento ocorre inteiramente no domínio 
da frequência. O código (1) opera em looping, calculando e salvando as matrizes de dados que correspondem às componentes de frequência definidas na banda selecionada para o processamento. O usuário deve escolher entre gerar resultados a partir da aplicação dos métodos de beam-forming convencional ou DAMAS, pois cada método possui particularidades no seu processamento. O método de beam-forming convencional requer que uma psf com ponto focal no centro da malha definida em cada frequência de análise seja calculada e salva para posterior normalização dos níveis integrados de pressão sonora. Embora o processamento DAMAS parta dos resultados obtidos com beam-forming convencional, o cálculo desta psf não é necessário ao método DAMAS, que é o foco deste trabalho.

O código (1) agrega as etapas do processamento que demandam alto custo computacional (CSM e deconvolução), representando a parte central do processamento de dados. A Fig. 5.1 é uma representação esquemática da sequência de ações e decisões que devem ser executadas para a aplicação do código (1).

\subsubsection{Descrição do Código (2)}

O código (2) toma como arquivos de entrada as matrizes de dados que representam os resultados de beam-forming convencional ou deconvolução DAMAS, obtidos pela aplicação do código (1). O objetivo da aplicação do código (2) é a obtenção de mapas representativos da distribuição espacial de fontes, ou simplesmente mapas de beam-forming, e espectros de ruído de decorrem da integração de níveis discretos de pressão sonora sobre um domínio de interesse, em uma dada banda de frequência. Os parâmetros que devem ser especificados são a região e a faixa dinâmica de integração. O código (2) basicamente reconstrói a malha de pontos em cada frequência, convertendo o domínio computacional no domínio espacial de origem, no qual determina-se a região de interesse, e realiza a integração. O processamento determinado pelo código (2) é bastante rápido, da ordem de poucos minutos. Os espectros de ruído (níveis de pressão sonora x frequência) representam o resultado de maior interesse decorrente da aplicação do código (2).

A Fig. 5.2 é uma representação esquemática da sequência de ações e decisões que devem ser executadas para a aplicação do código (2).

\subsection{Definição de uma Malha de Pontos para o Mape- amento de Fontes Acústicas}

Uma malha é um conjunto de pontos cujas coordenadas definem o domínio espacial discreto para a reconstrução numérica de uma distribuição de fontes acústicas. O processo de reconstrução de fontes consiste em estimar a distribuição de níveis de pressão sonora 


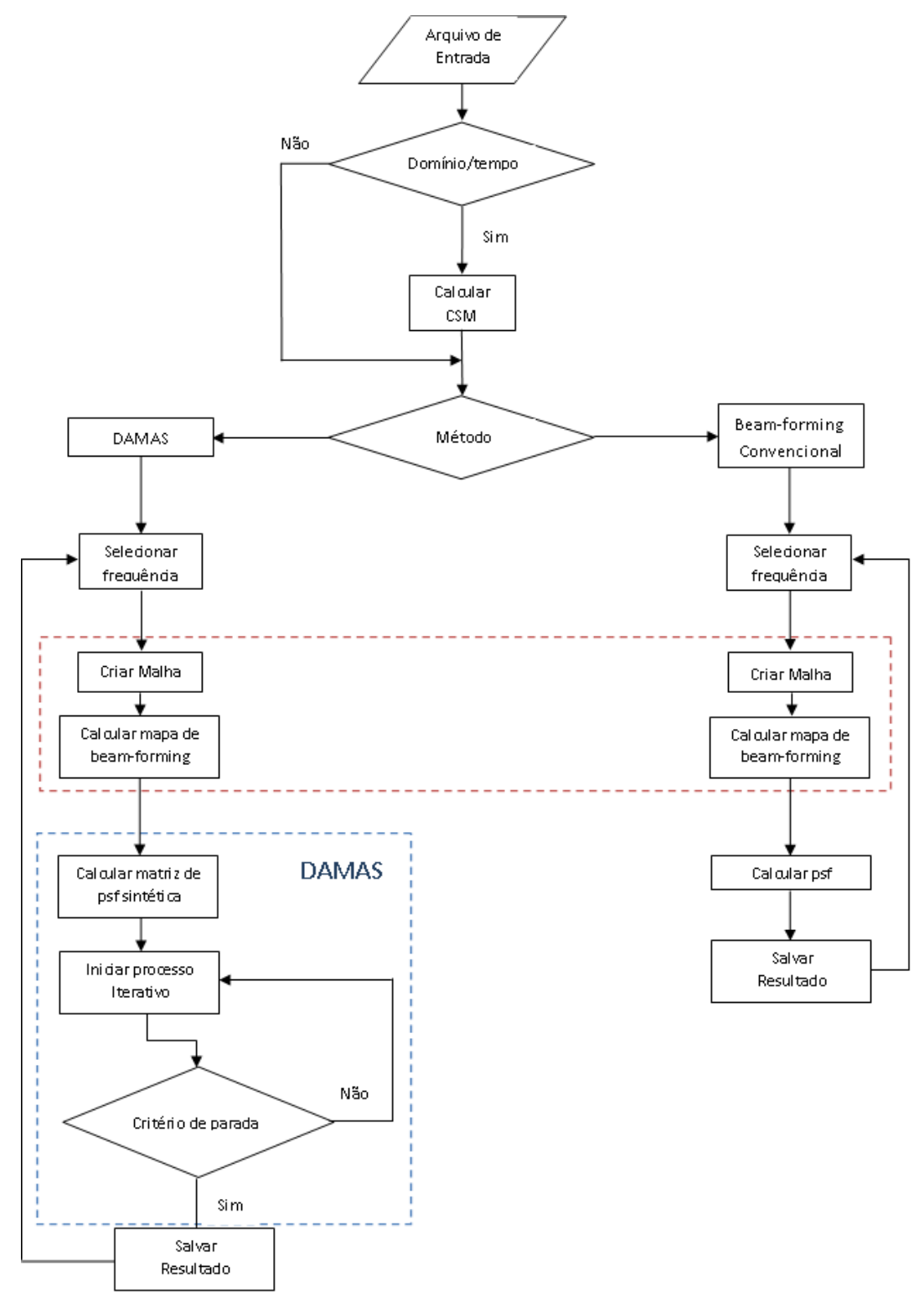

Figura 5.1: Representação esquemática das etapas de processamento definidas no código (1). 


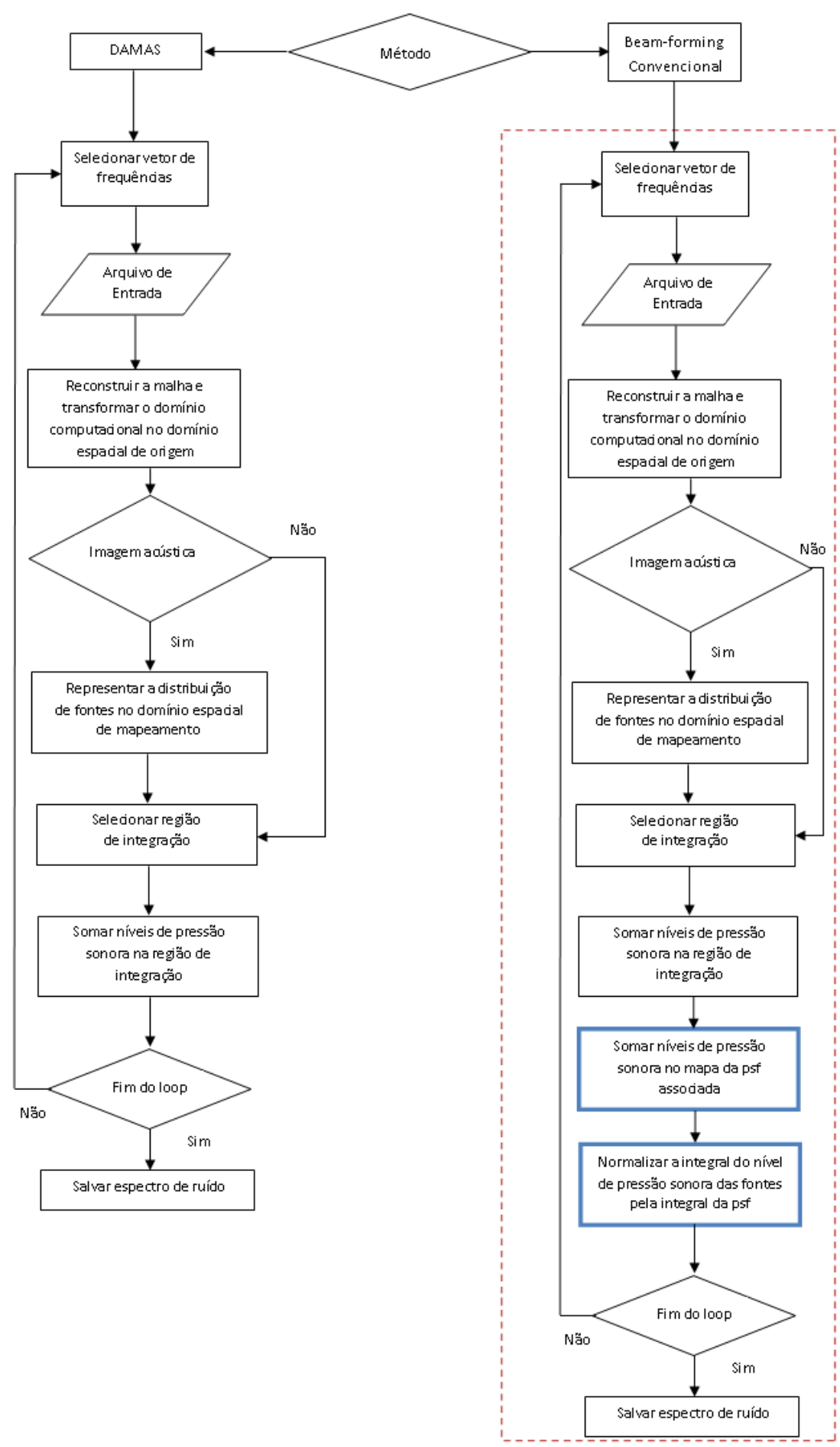

Figura 5.2: Representação esquemática das etapas de processamento definidas no código (2). O fluxograma à esquerda é utilizado para resultados obtidos com deconvolução DAMAS, equanto que o fluxograma à direita aplica-se ao caso de processamento com beam-forming convencional. 
que melhor representa a distribuição física de fontes no domínio de mapeamento. Através deste processo, torna-se possível representar a distribuição de fontes na forma de um mapa bidimensional (ou mesmo 3D) de imagens acústicas e integrar os níveis de pressão sonora em subdomínios deste mapa. Ou seja, somar os níveis discretos de pressão sonora nos pontos da malha que definem o subdomínio de interesse.

A definição da malha é um aspecto crítico no processo de mapeamento acústico com algoritmos de beam-forming, dado que a malha representa ambos os domínios físico e computacional do processamento. A malha deve mapear um subdomínio do espaço físico que contenha a distribuição de fontes de interesse. Entretanto, os resultados obtidos devem ser independentes dos parâmetros adotados para a definição da malha, e o processamento otimizado do ponto de vista computacional.

Brooks e Humphreys (2006) apresentam a razão $\Delta x / B$ como sendo um parâmetro de confiabilidade para a definição de uma malha dedicada ao mapeamento de fontes acústicas pelo método DAMAS, sendo $\Delta x$ a distância entre pontos adjacentes de uma malha cartesiana uniforme e $B$, a largura do lóbulo, ou beamwidth, do padrão de resposta da antena. A Fig. 5.3 representa a descrição de uma malha de pontos e os parâmetros chave para a sua caracterização.

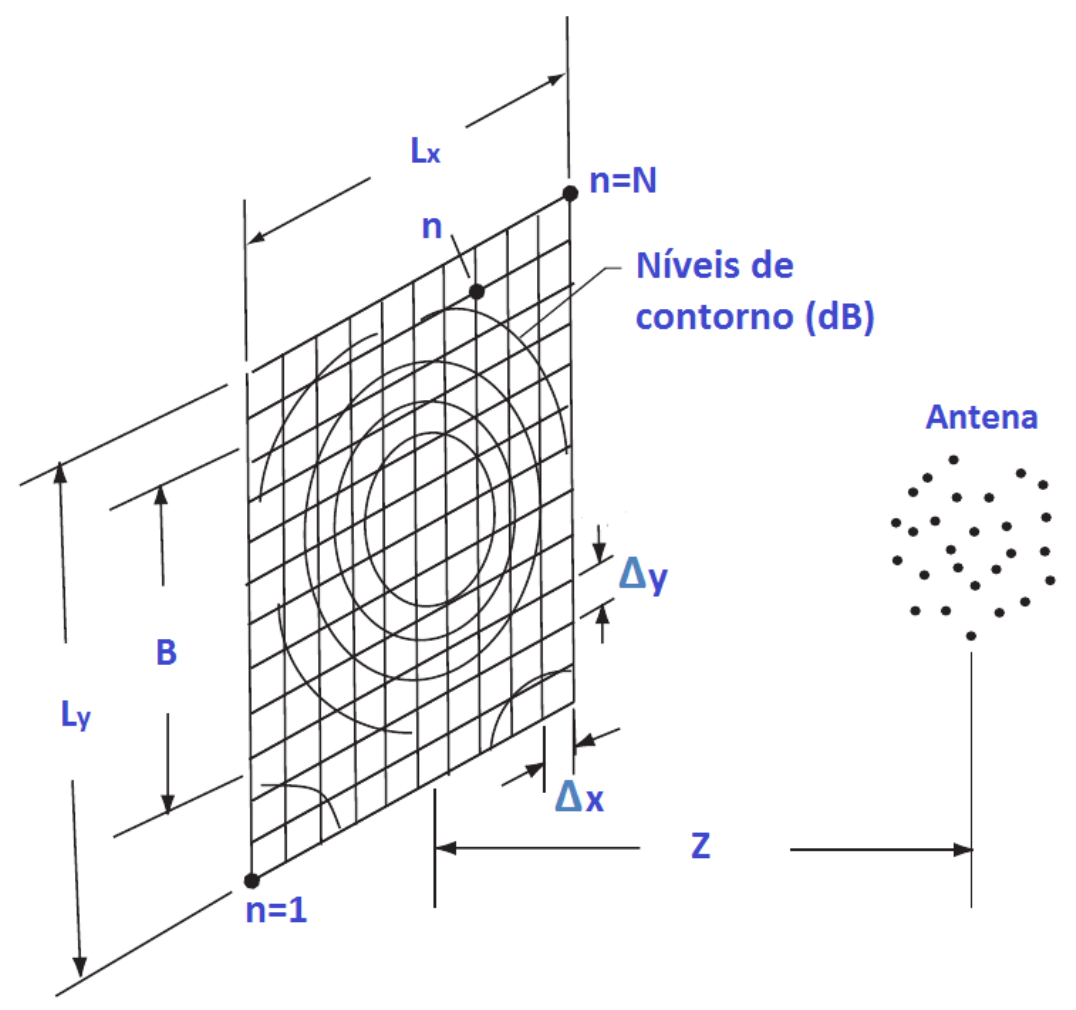

Figura 5.3: Representação de um malha cartesiana com número total de pontos $N$, extensão $L_{x}$, extensão vertical $L_{x}$ e espaçamentos regulares nas direções $x,(\Delta x)$, e $y,(\Delta y)$. O beamwidth do padrão de resposta da antena, $B$, acha-se projetado sobre a superfície da malha.

Brooks e Humphreys (2006) 
O parâmetro $\Delta x / B$ estabelece uma relação métrica simples entre o espaçamento dos pontos na malha e o beamwidth em cada frequência, sendo uma medida da capacidade do sistema de beam-forming em resolver fontes acústicas. Baseados em estudos com fontes sintéticas, e posteriores aplicações a dados experimentais, Brooks e Humphreys (2006) sugerem que o intervalo $0.05 \leq \Delta x / B \leq 0.2$ representa uma margem operacional segura para se evitar efeitos de aliasing espacial e assegurar uma reconstrução realista das fontes mapeadas. Com relação aos parâmetros $L_{x}$ e $L_{y}$, que representam a largura e o comprimento da malha, respectivamente, Brooks e Humphreys (2006) recomenda seus valores sejam múltiplos inteiros de $\boldsymbol{B}$.

Todavia, a construção de uma malha a partir de um critério baseado no parâmetro $\Delta x / B$ requer um compromisso entre o espaçamento da malha e a largura dó lóbulo do padrão de resposta do array. Dado que a largura de lóbulo varia com a frequência, o espaçamento da malha com a frequência deverá variar de forma subordinada. Humphreys et al. (1998) reporta uma técnica utilizada para manter invariante entre $10 \mathrm{kHz}$ e $40 \mathrm{kHz}$ o beamwdith de uma antena com 33 microfones, utilizando como referência a largura do lóbulo em uma frequência apropriada. Esta geometria de antena tem usada usado em vários testes acústicos sob o nome de SADA (small aperture array), (BROOKS; HUMPHREYS, 1999), (MENDOZA; BROOKS; HUMPHREYS, 2002). No entanto, a topologia particularmente simétrica do array SADA, que é composto por quatro círculos concêntricos com oito microfones cada e um microfone central, parece ser particularmente adequada à aplicação de uma função de ponderação sobre o sinal dos microfones, que permita manter o beamwidith do array constante em uma banda larga de frequências, conforme (HUMPHREYS et al., 1998).

Alguns testes preliminares indicaram um maior grau de dificuldade na determinação da função de ponderação para a geometria da antena de microfones utilizada neste trabalho. Diante da demanda de tempo necessária ao desenvolvimento de uma metodologia para determinar a função de ponderação adequada, e da urgência em avaliar outros aspectos funcionais do algoritmo DAMAS (in-house), optou-se pelo uso de uma malha com área superficial e espaçamento entre pontos variáveis na frequência.

\subsubsection{Descrição da Malha Adotada para o Mapeamento de Fon- tes com o Método DAMAS}

Neste trabalho, adota-se uma malha de pontos retangular e uniforme, com espaçamento entre pontos e área superficial variáveis com a frequência. A malha adotada representa uma estratégia para reduzir o custo computacional sem perdas na qualidade dos resultados.

O número total de pontos na malha adotada, N, depende de restrições geométricas im- 
postas sobre suas dimensões nas direções $x$ e $y$, representadas por $L_{x}$ e $L_{y}$, respectivamente, em unidades de metro, conforme as seguintes equações

$$
\begin{gathered}
N=\{[d /(\triangle x / B)]+1\}^{2} \text { se } L_{x}>0.30 \text { e } L_{y}>1.40 \\
N=\{[d /(\triangle x / B)]+1\}\left\{\left[L_{y} /(B \times(\triangle x / B))\right]+1\right\} \text { se } L_{x}>0.30 \text { e } L_{y}=1.40 \\
N=\left\{\left[L_{x} /(B \times(\triangle x / B))\right]+1\right\}\left\{\left[L_{y} /(B \times(\triangle x / B))\right]+1\right\} \text { se } L_{x}=0.30 e L_{y}=1.40
\end{gathered}
$$

O parâmetro $\triangle x / B$ é definido de forma a assumir valores discretos no intervalo $0.04 \leq$ $\triangle x / B \leq 0.36$. Os valores de $L_{x}$ e $L_{x}$ são definidos como

$$
\begin{aligned}
& L_{x}=d \times B \text { sed } \times B>0.30 \text { ou } L_{x}=0.30 \text { sed } \times B \leq 0.30 \\
& L_{y}=d \times B \text { sed } \times B>1.40 \text { ou } L_{y}=1.40 \text { sed } \times B \leq 1.40,
\end{aligned}
$$

onde $B=B(f)$ é o beamwidth do array e $d$ é um inteiro que determina as dimensões máximas da malha como um múltiplo de $B(f)$. Os valores $L_{x}=0.30$ e $L_{y}=1.40$ representam os valores mínimos que a malha deve assumir, de forma a mapear convenientemente uma distribuição típica de fontes sobre um eslate com 7,50 cm de corda e 1,30 m de envergadura.

A distribuição de pontos na malha, na direção $x$, é representada pelo vetor de coordenadas $p_{x}$, dado por

$$
p_{x}(i)=\left[x_{c}+\frac{(-1)\left(N_{x}-1\right) \triangle x}{2}\right]+(i-1) \triangle x,
$$

onde $x_{c}$ denota a posição do centro da malha em relação ao sistema de referência do array e $i=1,2, \ldots, N_{x}$, representa a indexação dos pontos no vetor $p_{x}$. De forma análoga, definese o vetor de pontos da malha na direção $y, p_{y}(j), j=1,2, \ldots, N_{y}$, porém considerando os parâmetros de entrada $y_{c}$, e $N_{y}$, dado que $\triangle x=\triangle y$ para uma malha $2 \mathrm{D}$ com espaçamento uniforme. A malha bidimensional é então criada como uma distribuição de pontos agrupados e linhas e colunas, $i=1,2, \ldots, N_{x}, j=1,2, \ldots, N_{y}$. Os valores de $N_{x}$ e $N_{y}$ encontram-se implicitamente representados nas Eqs. 5.1, 5.2 e 5.3, sendo $N_{x}=\{[d /(\triangle x / B)]+1\}$ e $N_{y}=\left\{\left[L_{y} /(B(\triangle x / B))\right]+1\right\}$ para as condições $L_{x}>0.30$ e $L_{y}=1.40$, por exemplo.

Uma condição adicional determina que $N_{x}$, e $N_{y}$ sejam sempre ímpares, com o ponto médio sobre a linha central da malha. Além disto, os valores entre colchetes nas Eqs. 5.1, 5.2 e 5.3 são truncados, ou seja, arredondados para o valor inteiro imediatamente inferior.

Para o processamento dos espectros de ruído do eslate adotou-se uma estratégia de bandas com resolução em frequência variável, conforme a tabela 5.1.

O processamento da base de dados com resolução variável em frequência, de forma a aumentar a largura da banda com o aumento da frequência, teve como principal motivação 
Tabela 5.1: Bandas e respectivas resoluções em frequência, em $\mathrm{Hz}$

\begin{tabular}{|c|c|c|c|c|}
\hline $500-1600$ & $1650-3200$ & $3300-6400$ & $6600-12800$ & $13200-18000$ \\
\hline 25 & 50 & 100 & 200 & 400 \\
\hline
\end{tabular}

reduzir o número de processos em alta frequência, onde se verifica um alto custo computacional. Não obstante, tal estratégia se mostrou conveniente para o espectro de ruído do eslate. Em baixas frequências, há uma relação sinal-ruído favorável, devido à grande amplitude dos picos tonais e, por conseguinte, a resolução estreita de $25 \mathrm{~Hz}$ propícia uma melhor definição dos picos tonais. Em frequências médias e altas, a maior largura da banda de frequência é obtida a partir da partição do sinal em blocos de dados menores, o que representa maior quantidade de blocos e maior número de médias no processamento. Como resultado, a variância dos espectros de ruído é reduzida.

O parâmetro $B(f)$ é, então, estimado em cada uma das 154 frequências contidas na tabela 5.1, para a determinação do espaçamento entre pontos e da área superficial da malha na respectiva frequência. A Fig. 5.4 mostra a distribuição de valores do parâmetro $\triangle x / B$ na banda de frequência entre $0.5 \mathrm{kHz}$ e $18 \mathrm{kHz}$, conforme resolução em frequência mostrada na tabela 5.1 .

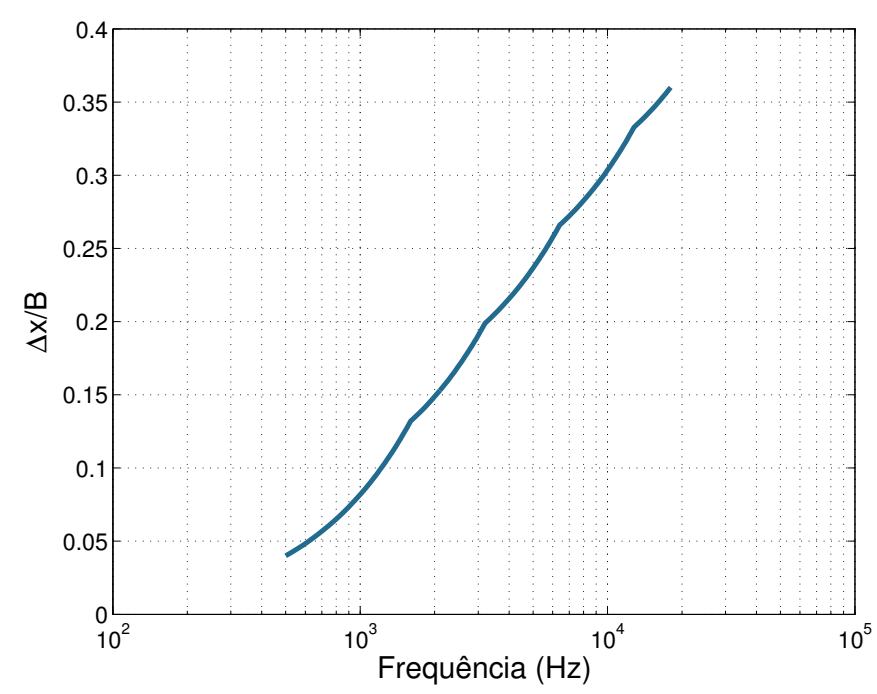

Figura 5.4: Distribuição de valores $\triangle x / B$ entre $500 \mathrm{~Hz}$ e $18 \mathrm{kHz}$, em escala logarítmica de frequência.

A Fig. 5.5 representa o comportamento pouco intuitivo dos parâmetros $\triangle x, N_{x}, N_{y}$, e $N$, que caracterizam os domínios físico e computacional da malha de pontos adotada.

A Fig. 5.5(a) mostra que o espaçamento entre os pontos da malha decresce em praticamente toda a banda de frequência, seguindo a tendência de redução do beamwidth com a frequência. A forma particular da curva decorre da ponderação dos valores de $B(f)$ pelos valores correspondentes do parâmetro $\triangle x / B(f)$. As Figs. 5.5(b) e 5.5(c) representam 


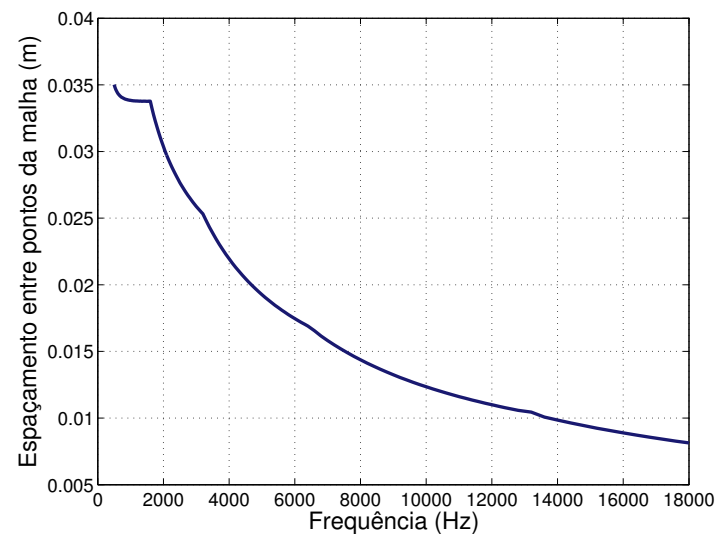

(a)

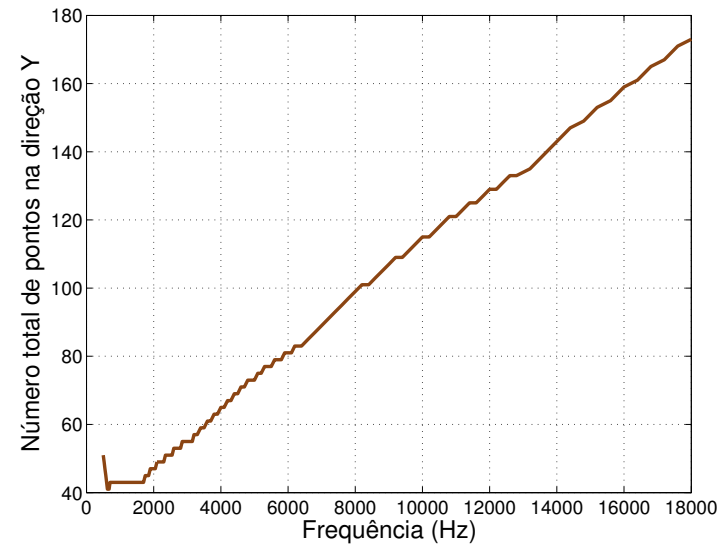

(c)

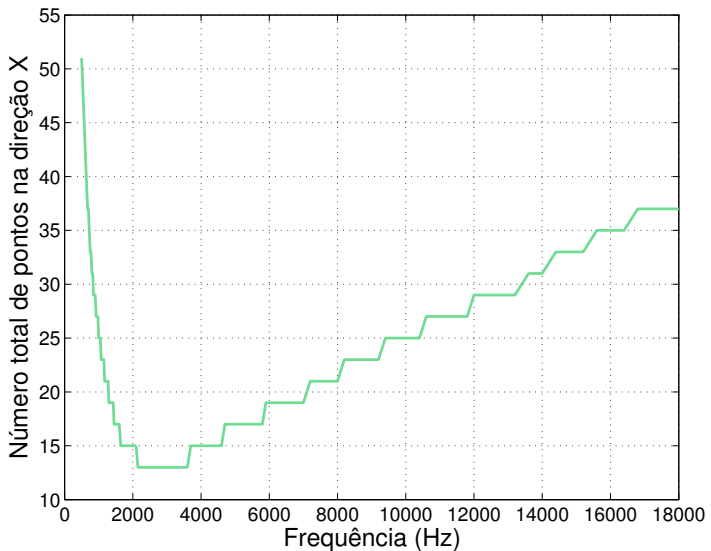

(b)

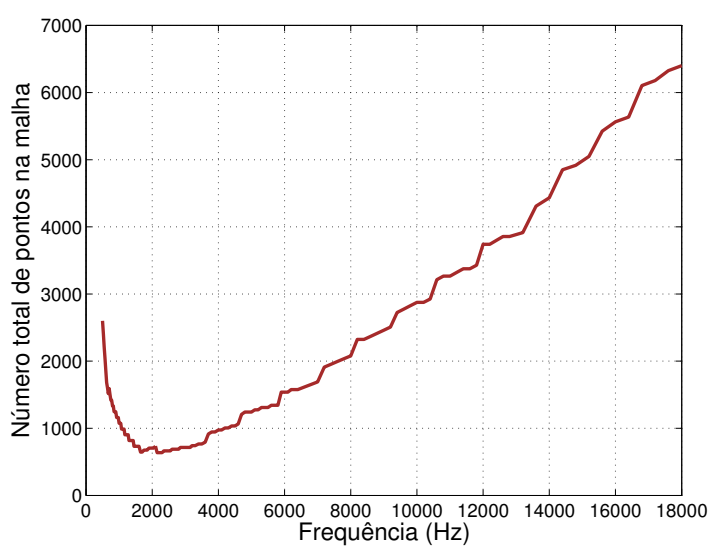

(d)

Figura 5.5: Representação do comportamento típico dos parâmetros chave para o projeto de malha; $\triangle x(\triangle y), N_{x}, N_{y}$, e $N$, em função da frequência.

graficamente o comportamento das variáveis $N_{x}$ e $N_{y}$, implícitas nas Eqs. 5.1, 5.2 e 5.3. Quando $L_{x}>0.30$ e $L_{y}>1.40$, a malha é quadrada com $N_{x}=N_{y}=\{[d /(\triangle x / B)]+1\}$. Nestas condições, $N_{x}$ e $N_{y}$ são decrescentes porquê $\triangle x / B$ cresce com a frequência, conforme a Fig. 5.4.

Na condição $L_{y}=1.40$, a malha tem tamanho fixo na direção y e espaçamento entre pontos decrescente com a frequência, o que leva o aumento no número de pontos da malha na direção $y$. A condição $L_{y}=1.40$ ocorre antes que a condição $L_{x}=0.30$, o que explica as diferentes tendências de crescimento entre as variáveis $N_{x}$ e $N_{y}$ em baixas frequências (Figs. 5.5(b) e 5.5(c)). A curva do número total de pontos com a frequência, $N(f)=N_{x}(f) \times N_{y}(f)$, dada na Fig. $5.5(\mathrm{~d})$, representa a interpretação gráfica das Eqs. 5.1, 5.2 e 5.3. A informação relevante na Fig. 5.5(d) é que malhas mais densas ocorrem em frequências mais altas, mostrando que o processamento em alta frequência demanda um maior custo computacional por iteração do código DAMAS. 


\subsubsection{Desempenho Computacional do Algoritmo DAMAS para a Malha de Pontos Adotada}

As primeiras aplicações do algoritmo DAMAS ao processamento do ruído do eslate consideraram malhas com área superficial e espaçamento entre pontos variáveis na frequência, satisfazendo à condição $\Delta x / B=0.2$. Esta escolha possibilitou uma avaliação geral dos resultados obtidos pela aplicação do método DAMAS, assumindo uma confiabilidade aceitável na definição da malha, de acordo com (BROOKS; HUMPHREYS, 2006), ao passo que o fator $\Delta x / B=0.2$ representava a melhor opção em termos de custo computacional no domínio $0.05 \leq \Delta x / B \leq 0.2$.

O uso deste critério para a definição da malha, embora tenha se mostrado eficaz para identificar as principais componentes do espectro de ruído do eslate, resultou em malhas muito grosseiras em baixas frequências e muito refinadas em altas frequências. A malha grosseira resulta em escassez de informação sobre as fontes, o que pode comprometer a qualidade dos resultados. Por outro lado, o refinamento excessivo em frequências mais altas gerou um custo computacional demasiadamente alto.

A demanda pelo processamento de uma base de dados extensa motivou estudos subsequentes para encontrar uma malha com uma melhor distribuição de pontos na banda de frequência de $500 \mathrm{~Hz}$ até $18 \mathrm{kHz}$, de forma a reduzir o custo computacional do processamento e garantir a independência dos resultados em relação à malha de pontos. Estes estudos culminaram na malha descrita na subseção 5.3.1, que atende aos requisitos acima mencionados.

Esta subseção analisa a questão do desempenho computacional do algoritmo DAMAS em relação à malha de pontos descrita na subseção 5.3.1, e compara-o com aquele obtido com a malha satisfazendo à condição $\Delta x / B=0.2$, na banda de frequência de $0.5 \mathrm{kHz}$ até $18 \mathrm{kHz}$. O número de iterações em cada frequência é determinado pelo critério de parada adotado, que estabelece o final do processo iterativo após 20 iterações consecutivas sem que haja uma variação superior a $0.10 \mathrm{~dB}$ no valor do nível de pressão sonora integrado no domínio da malha.

O tempo de processamento por iteração no algoritmo DAMAS pode ser calculado pela Eq. 5.6, segundo (BROOKS; HUMPHREYS, 2006)

$$
t(f)=4 C N^{2}
$$

sendo $C$ uma constante característica do sistema de hardware. Para o sistema operacional utilizado neste trabalho, o valor da constante $C$ calculado é $2,4910 \times 10^{-8}$. O tempo de iteração na Eq. 5.6 representa o tempo envolvido na solução iterativa do sistema de equações lineares pelo método de Gauss-Siedel, sendo dependente da frequência apenas porque 
neste estudo considera-se uma malha cujo número de pontos é variável na frequência.

A figura 5.6(a) compara o tempo por interação previsto a partir da Eq. 5.6 com o tempo médio por iteração aferido durante o processamento de uma medição de ruído do eslate com o algoritmo DAMAS. Para o caso experimental, o tempo médio por iteração é calculado pela razão entre o tempo requerido para a convergência do processo iterativo e o correspondente número de iterações, em uma dada frequência. A figura 5.6(b) mostra o erro absoluto entre os tempos de convergência teórico e experimental, bem como o erro absoluto médio na banda de frequência. A Fig 5.6(c) representa o número de iterações necessário para a convergência do algoritmo DAMAS em cada frequência de análise. Por fim, a Fig 5.6(d) representa o produto do número de iterações pelo respectivo tempo médio por iteração sendo, portanto, uma medida do tempo total de processamento em função da frequência. Os resultados experimentais apresentados na Fig. 5.6 são referentes ao eslate configurado para $\alpha=4^{\circ}$ e $U_{\infty}=34 \mathrm{~m} / \mathrm{s}$.

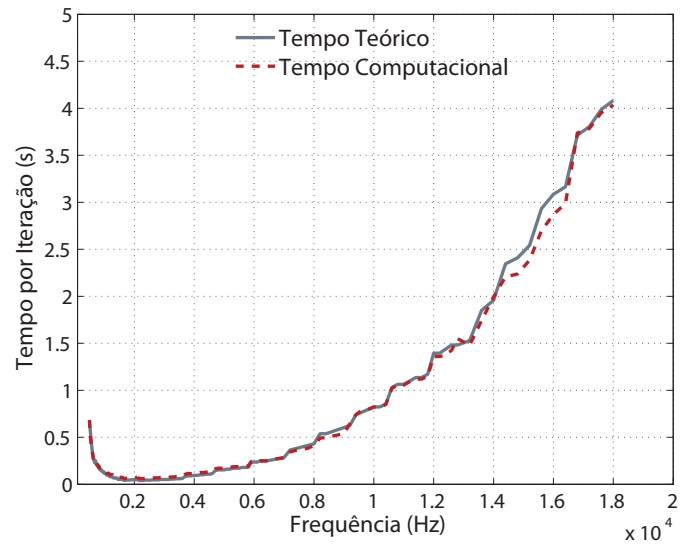

(a)

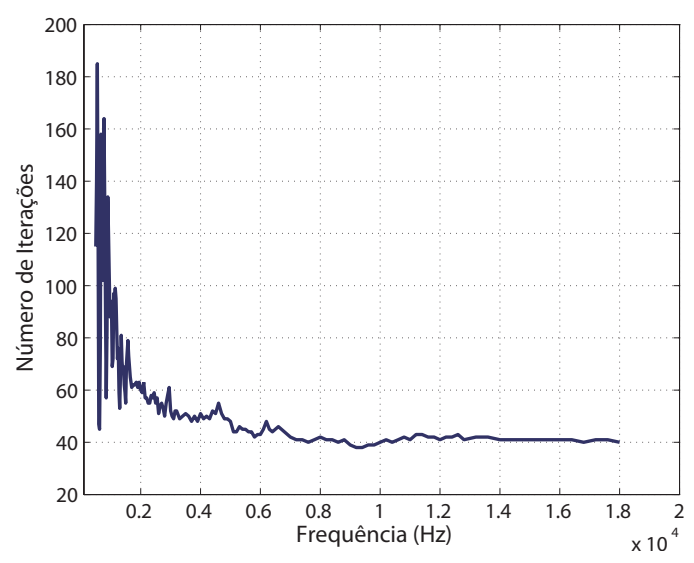

(c)

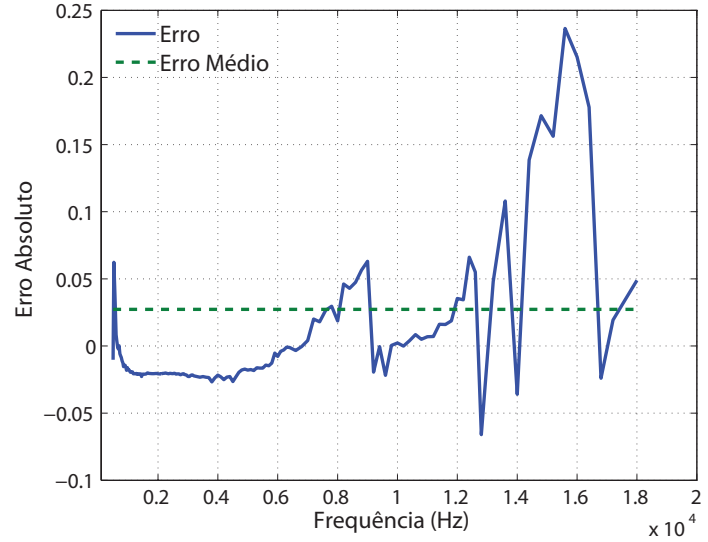

(b)

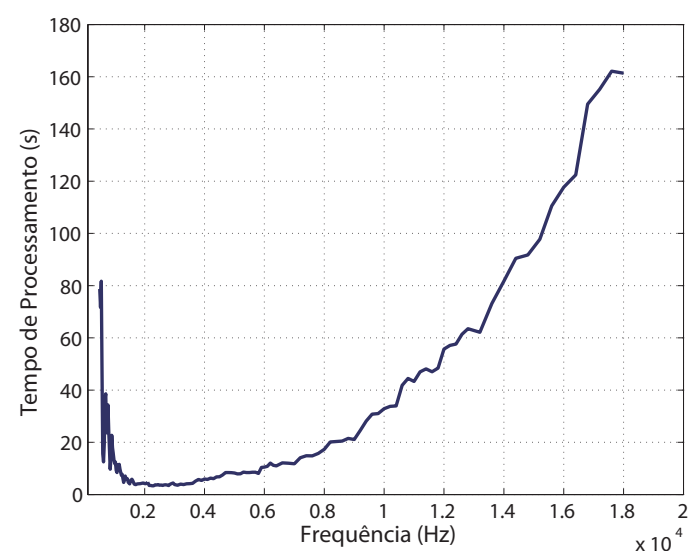

(d)

Figura 5.6: Resultados para avaliação de desempenho computacional do algoritmo DAMAS em termos dos parâmetros adotadas na construção da malha.

Os resultados apresentados nas Figs. 5.6(a) e 5.6(b) atestam uma boa concordância 
entre as curvas de tempo, por iteração, teórico e experimental, mostrando que o desempenho computacional do código corresponde aquele previsto pelo modelo teórico apresentado na Eq. 5.6.

A Fig. 5.6(c) mostra um padrão errático do número de iterações em baixas frequências e uma boa convergência para frequências a partir de $2 \mathrm{kHz}$. As variações abruptas no número de iterações em baixas frequências parecem estar relacionadas ao comportamento das fontes acústicas, dada a alternância entre picos tonais de alta amplitude. A boa convergência a partir de $8 \mathrm{kHz}$ mostra certa independência do número de iterações em relação ao tamanho do domínio computacional, dado que o número de pontos na malha cresça monotonicamente em bandas de média e alta frequência.

A Fig. 5.6(d) indica que o tempo médio por iteração é determinante para o custo computacional do processo iterativo, dada a sua forte taxa de crescimento com o número de pontos na malha, mostrando que o domínio computacional é ainda um ponto crítico para um melhor desempenho do código DAMAS.

A Fig. 5.7 mostra uma comparação de performance computacional do código DAMAS a partir do uso de malhas satisfazendo às condições $\Delta x / B=0.2$ (malha 1 ) e $0.04 \leq \Delta x / B \leq$ 0.36 (malha 2). Para ambas as malhas: a Fig. 5.7 (a) compara o número iterações necessário para a convergência do nível integrado de pressão sonora no domínio da malha, a Fig. 5.7 (b) compara a variação do espaçamento entre pontos da malha com a frequência e a Fig. 5.7 (c) compara o tempo total de processamento. Na Fig. 5.7 (c), o tempo de processamento obtido com o uso da malha (2) aparece multiplicado por um fator de 10. Estes resultados são representativos do comportamento observado em uma série de análises similares, com o eslate em diferentes configurações experimentais.

Os resultados apresentados na Fig. 5.7 são representativos do ganho em tempo de processamento decorrente do uso da malha (2). A Fig. 5.7 (a) mostra que o número de iterações em baixa frequência é maior para a malha (2), devido ao seu maior refinamento em relação à malha (1). A comparação entre as Figs. 5.7 (a) e 5.7 (b) mostra claramente o número de iterações é determinado pelo espaçamento entre os pontos da malha, na medida que, em aproximadamente $3 \mathrm{kHz}$, a tendência de crescimento do número de iterações para a malha (1), em relação à malha (2), é coincide com o maior refinamento da malha (1) em relação à malha (2). Para a malha (2), verifica-se que o número de iterações necessário para a convergência torna-se praticamente independente do espaçamento da malha nas regiões de média e alta frequência. A Fig. 5.7 (c) compara o tempo total de processamento decorrido a partir do uso das malhas (1) e (2). A pesar da curva de tempo para a malha (2) estar multiplicada por um fator de 10, é constatado que o uso da malha (2) demanda um maior custo computacional em baixa frequência, devido ao seu maior refinamento em relação à malha (1). No entanto, pode se ver que a região de alta frequência é um 


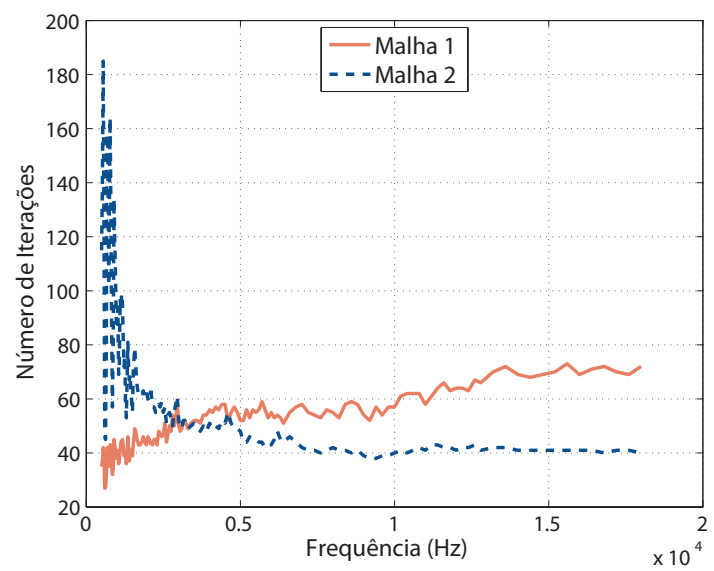

(a)

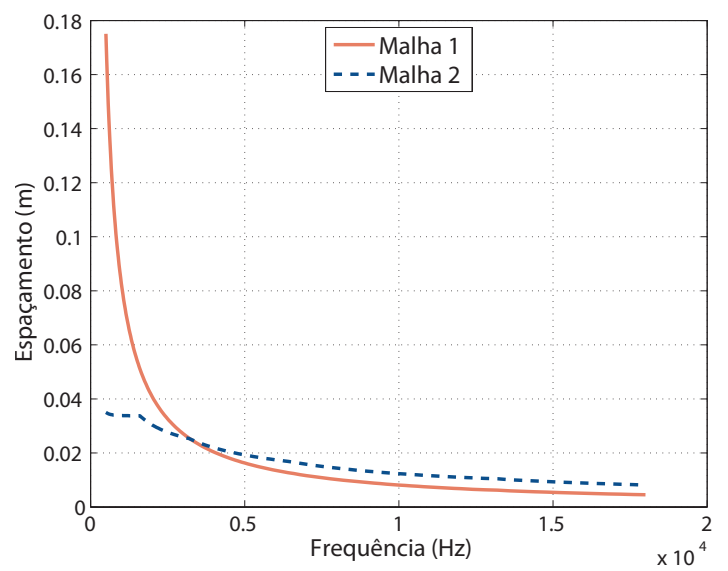

(b)

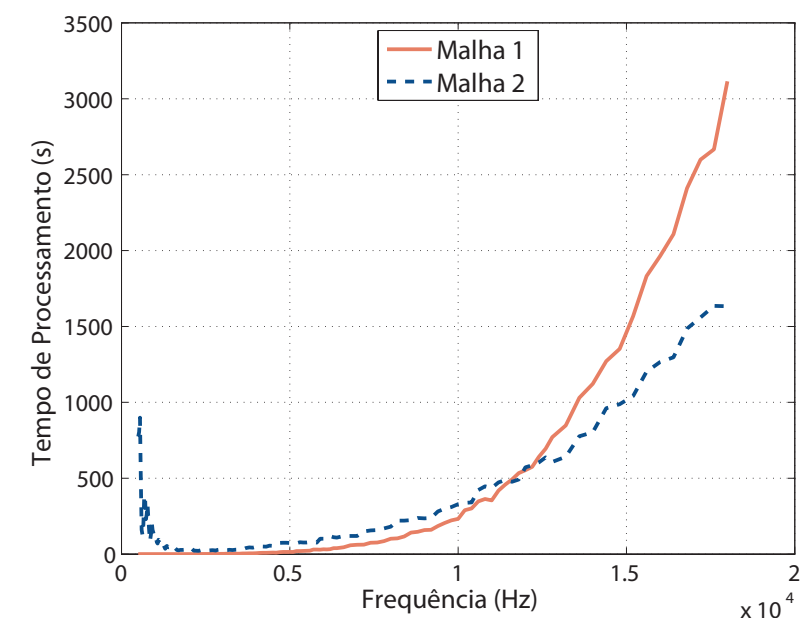

Figura 5.7: Comparação de desempenho computacional para o código DAMAS a partir do uso das malhas (1) e (2): (a) comparação entre o número de iterações necessário para a convergência dos resultados, (b) comparação entre o espaçamento entre os pontos na malha e comparação entre o tempo total de processamento, estando o tempo referente à malha (2) multiplicado por 10.

domínio crítico para o desempenho computacional do código DAMAS, particularmente para a malha (2), que se apresenta excessivamente refinada em alta frequência.

As simulações que embasam este estudo foram realizadas em sistema operacional Linux, com processamento sequencial (sem paralelização), utilizando um processador Intel I7 com $2.93 \mathrm{GHz}$, em ambiente Matlab. As funções internas do matlab cputime e tic-toc foram usadas para medir o tempo decorrido durante o processo iterativo. As medidas de tempo com a função cputime mostraram-se sistematicamente inconsistentes a partir de uma dada frequência. Matlab traz uma nota interna alertando para divergência nas medidas de tempo com cputime e tic-toc, embora para certas versões do Windows. Face ao caráter comparativo dos resultados, a função tic-toc foi aplicada considerando condições idênticas de processamento para os casos comparados. 


\subsection{Independência dos Resultados em Relação à Ma- lha e ao Critério de Parada}

A subseção 5.3.2 mostrou o ganho computacional decorrente da substituição da malha (1) pela malha (2). A redução no tempo de processamento ocorre devido à definição dos valores do parâmetro $\Delta x / B$ no intervalo $0.04 \leq \Delta x / B \leq 0.36$, ao invés do uso do limite superior no intervalo $0.05 \leq \Delta x / B \leq 0.2$, conforme sugerido por (BROOKS; HUMPHREYS, 2006). O uso do valor 0.36 como limite superior representa um maior espaçamento entre os pontos da malha em frequências mais altas e, consequentemente, um menor número de pontos na malha, reduzindo o custo do processo iterativo, conforme a Eq. 5.6. Não obstante, a adoção de um critério de parada para o processo iterativo tem por objetivo evitar que o algoritmo continue iterando após a convergência ser atingida, de forma a reduzir o custo computacional do processamento.

Nesta seção são apresentados alguns resultados que representam as margens de erro típicas dentro das quais a integral do nível de pressão sonora pode ser considerada independente da malha de pontos adotada. Os resultados são referentes ao caso experimental com $\alpha=4^{\circ}$ e $U_{\infty}=34 \mathrm{~m} / \mathrm{s}$. Estes resultados são representativos de uma amostragem de resultados obtidos a partir de medições de ruído do eslate com o aerofólio em diferentes configurações experimentais.

A Fig. 5.8 mostra a convergência dos níveis de ruído do eslate em frequências que representam componentes de ruído e distribuições de fontes bem caracterizadas. Neste estudo, o espectro de ruído do eslate resulta da integração de níveis discretos de pressão sonora no domínio da malha, conforme definida pelas Eqs. 5.1, 5.2 e 5.3. As curvas de convergência são representadas, em cada frequência, para um número fixo de 500 iterações. Como resultado de um processamento independente, os gráficos mostram linhas verticais que indicam o número de iterações necessário para a convergência dos espectros de ruído a partir do critério de parada adotado.

A tabela 5.2 mostra os parâmetros relevantes para a interpretação dos resultados apresentados na Fig. 5.8. Para as frequências nas quais avalia-se a independência dos resultados em relação à malha, estão indicados o espaçamento entre pontos da malha e o número de iterações necessário para a convergência, de acordo com o critério de parada. Ainda na tabela 5.2, o parâmetro $\Delta(d B)$ representa a diferença, em dB, entre o nível de ruído estimados após 500 iterações e o nível de ruído estimado após o número de iterações determinado pelo critério de parada adotado, que determina o final do processo iterativo após 20 iterações consecutivas com variação máxima no nível de ruído não superior à 0.10 dB. Resultados de simulações usando uma tolerância de 0.010 dB não mostraram diferenças significativas nos níveis de ruído após a convergência. 
Tabela 5.2: Parâmetros adotados no estudo de convergência na malha

\begin{tabular}{|c|c|c|c|}
\hline Frequência $(\mathrm{Hz})$ & $\triangle x(\mathrm{~cm})$ & Iterações & $\Delta(d B)$ \\
\hline 775 & 3,401 & 164 & 0,149 \\
\hline 1000 & 3,384 & 89 & 0,034 \\
\hline 1150 & 3,379 & 99 & 0.061 \\
\hline 1525 & 3,377 & 70 & $-0,002$ \\
\hline 4400 & 2,073 & 52 & 0,006 \\
\hline 8000 & 1,437 & 42 & 0,001 \\
\hline
\end{tabular}

Os resultados apresentados na Fig. 5.8 mostram uma convergência assintótica dos níveis de ruído. Os níveis de ruído obtidos a partir do número de iterações determinado pelo critério de parada são representativos dos valores obtidos após 500 iterações forçadas. Em $775 \mathrm{~Hz}$, a variação $\Delta(d B)$ entre os níveis de ruído obtidos após 500 e 164 iterações é de 0,149 dB. Em 775 Hz ocorre um ruído tonal de alta amplitude, cuja estimativa de nível se mostra particularmente dependente de variações na forma do processamento, tais como o método de deconvolução ou a antena de microfones usada. Todavia, a variação de 0,149 dB está bastante próxima da margem de tolerância assumida; 0.1 dB. Para frequências mais altas, os resultados mostram que os níveis de ruído são independentes da malha para uma tolerância da ordem de $0.01 \mathrm{~dB}$ e $0.001 \mathrm{~dB}$. Estes resultados são considerados satisfatórios para os objetivos deste estudo.

A Fig. 5.9 mostra a convergência dos espectros de ruído para malhas com diferentes espaçamentos. Para as frequências de $1525 \mathrm{~Hz}(\triangle x=3,377 \mathrm{~cm})$ e $4400 \mathrm{~Hz}(\triangle x=2,073$ $\mathrm{cm}$ ), as curva de convergência para a malha 2 são compradas às curvas de convergência para malhas com espaçamentos de 1 e $4.5 \mathrm{~cm}$, e 1 e $4 \mathrm{~cm}$, respectivamente. Estes resultados são representativos do comportamento geral das curvas de convergência dos níveis de ruído observado para outras frequências e casos experimentais.

Os resultados apresentados na Fig. 5.9 mostram que o espaçamento entre pontos da malha afeta a taxa de convergência dos espectros de ruído de forma significativa, notadamente em frequências mais baixas. No entanto, os níveis de ruído estimados a partir de malhas com diferentes espaçamentos convergem para valores bastante próximos, após um número adequado de iterações. Em 1525 Hz, o nível de ruído estimado com a malha $2(\triangle x=3,377 \mathrm{~cm})$ converge com diferenças de $0.0174 \mathrm{~dB}$ e $-0.0437 \mathrm{~dB}$ em relação aos níveis de ruído estimados com malhas espaçadas em $1 \mathrm{~cm}$ e $4,5 \mathrm{~cm}$, respectivamente. Em $4400 \mathrm{~Hz}$, o nível de ruído estimado com a malha $2(\triangle x=2,073 \mathrm{~cm})$ converge com diferenças de $0.0179 \mathrm{~dB}$ e $-0.0576 \mathrm{~dB}$ em relação às malhas espaçadas em $1 \mathrm{~cm}$ e $4 \mathrm{~cm}$, respectivamente. Estes resultados mostram que a convergência dos níveis de ruído obtida com o uso da malha 2 é estável para variações controladas no espaçamento da malha.

De forma geral, os espectros de ruído estimados com o uso do algoritmo DAMAS 


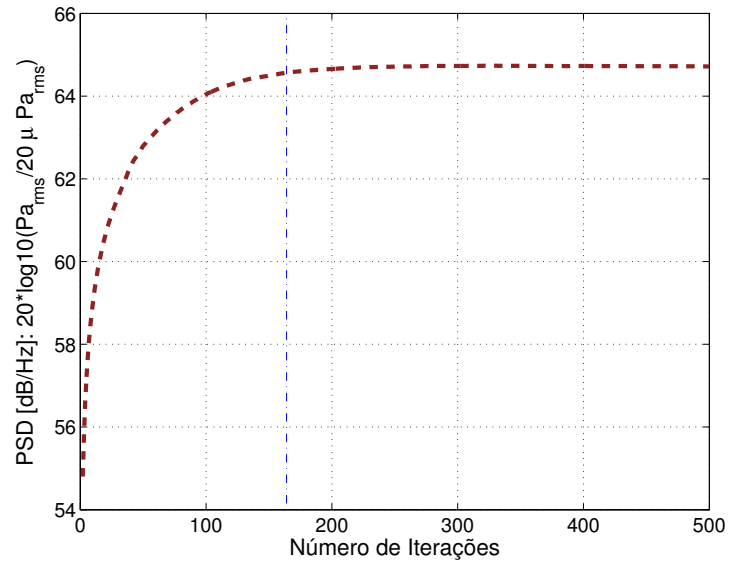

(a) $775 \mathrm{~Hz}, 164$ iterações

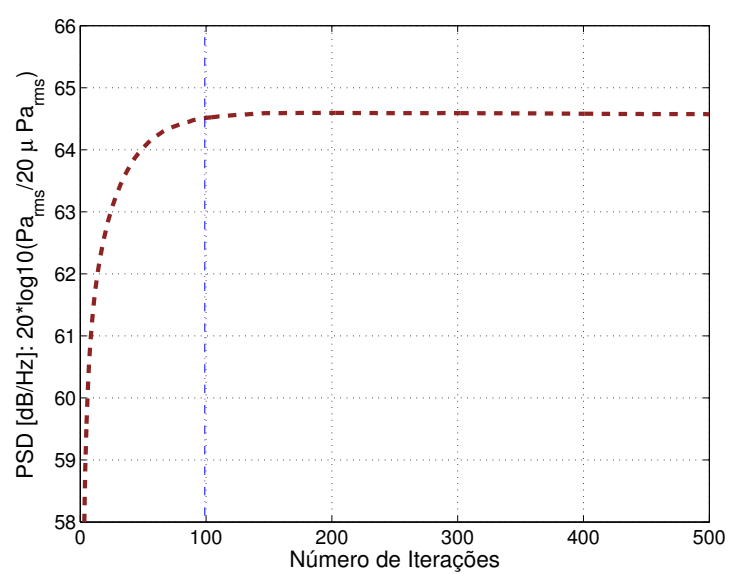

(c) $1150 \mathrm{~Hz}, 99$ iterações

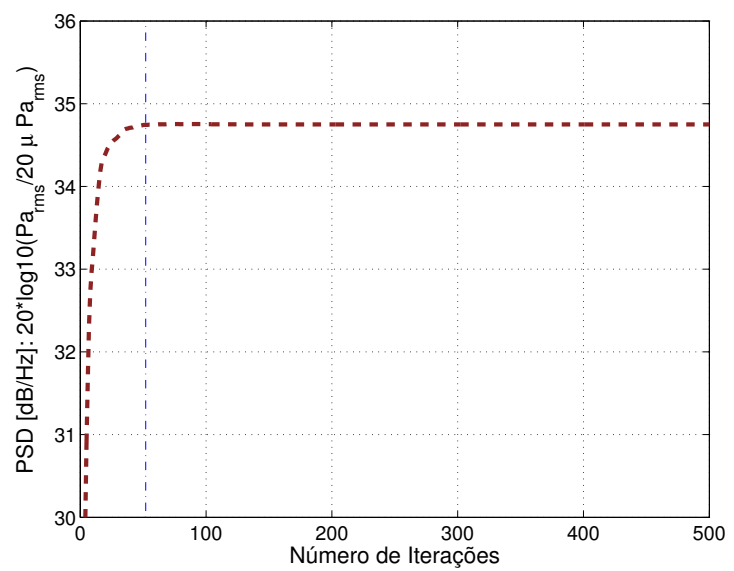

(e) $4400 \mathrm{~Hz}, 52$ iterações

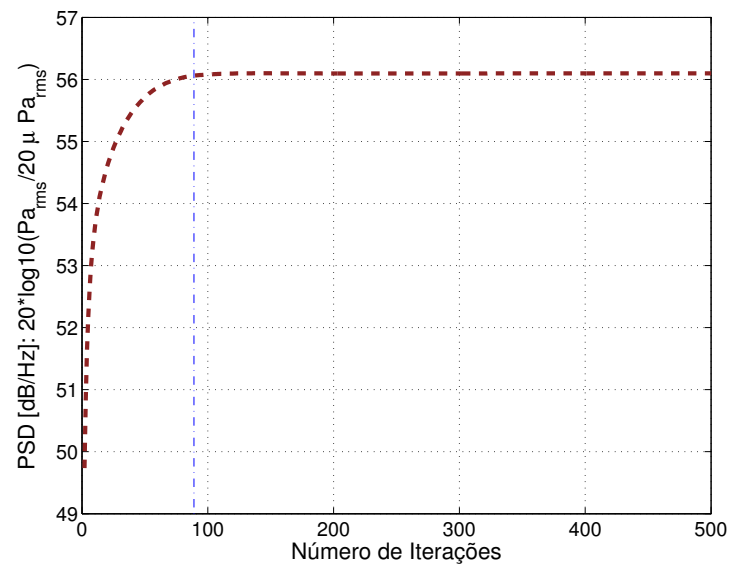

(b) $1000 \mathrm{~Hz}, 89$ iterações

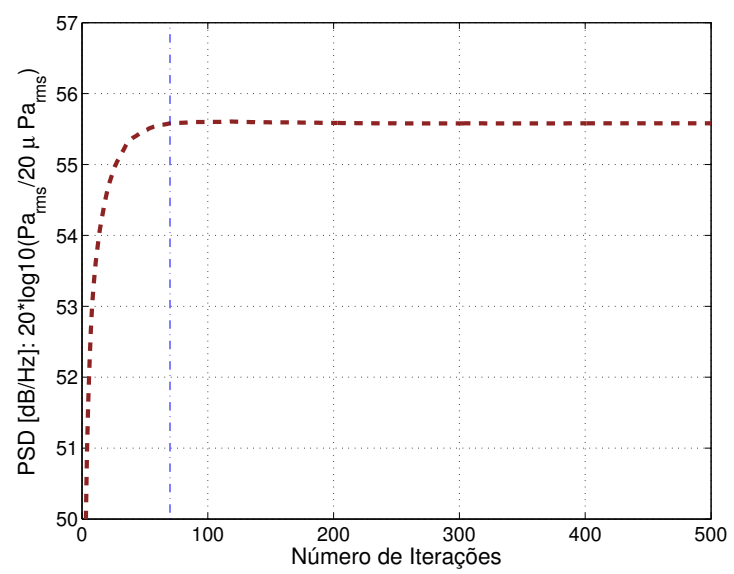

(d) $1525 \mathrm{~Hz}, 70$ iterações

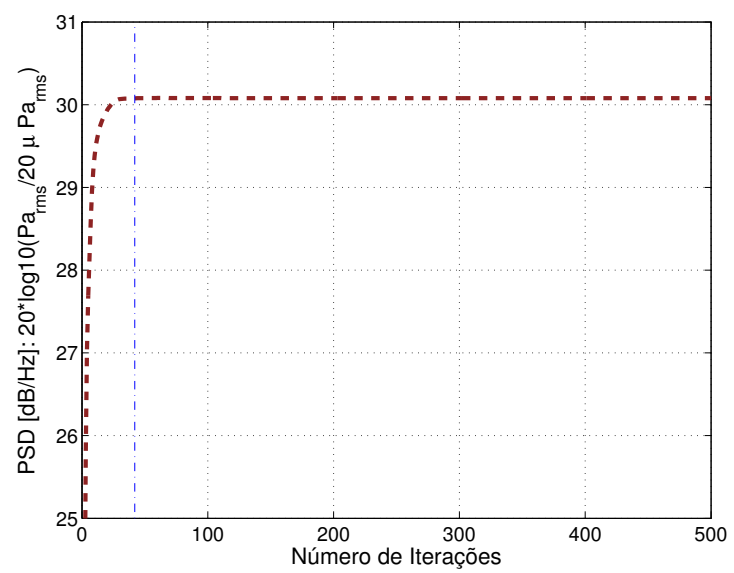

(f) $8000 \mathrm{~Hz}, 42$ iterações

Figura 5.8: Representação das curvas de convergência dos espectros de ruído, considerando um número máximo de 500 iterações. Para cada figura está indicada a frequência de processamento. A linha vertical indica o número de iterações, indicado ao lado da frequência, e o respectivo nível de ruído determinados pelo critério de parada do processo iterativo.

requerem um menor número de iterações para convergência em malhas mais grosseiras. Desta forma, malhas mais refinadas representam um fator de alto custo computacional 


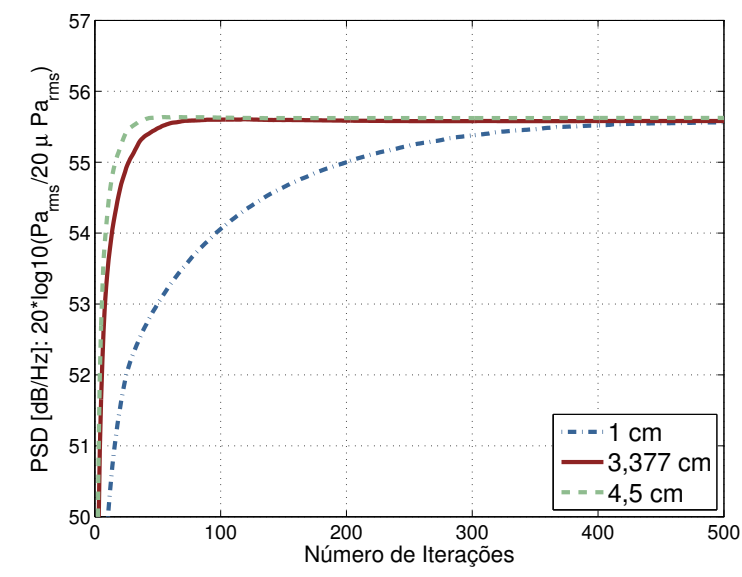

(a) $1525 \mathrm{~Hz}$

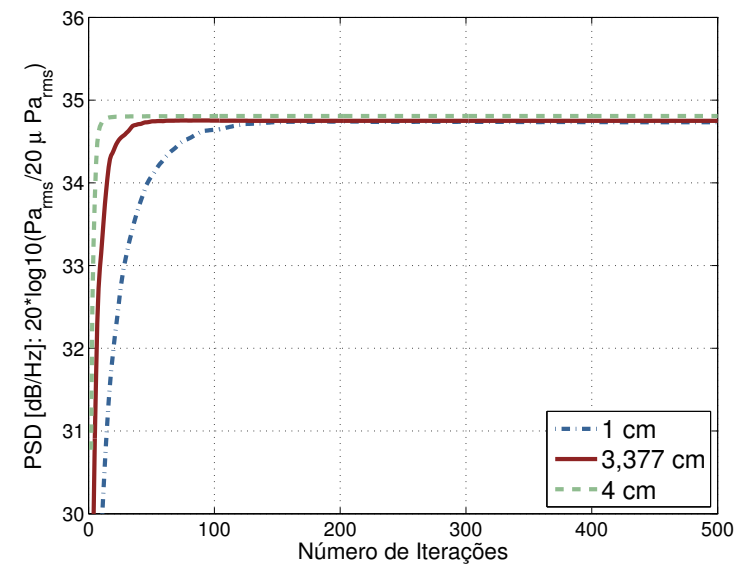

(b) $4400 \mathrm{~Hz}$

Figura 5.9: Comparação entre curvas de convergência para malhas uniformes com diferentes espaçamentos entre pontos.

devido ao maior número de pontos na malha e ao maior número de iterações necessário para a convergência. Apesar das vantagens computacionais decorrentes do uso de malhas grosseiras, estas devem ser refinadas o bastante para assegurar uma amostragem adequada das fontes na região de mapeamento e evitar fenômenos de aliasing espacial. A malha de pontos usada neste trabalho representa um compromisso entre a qualidade dos resultados, apresentados na forma de imagens acústicas e espectros de ruído, e desempenho computacional.

\subsection{Definição de uma Região para a Integração de Fontes Acústicas Sobre o Eslate}

Conforme discutido anteriormente, o eslate idealmente representa uma fonte de ruído distribuída ao longo de sua envergadura, para a qual o nível de pressão sonora medido por um array de microfones pode ser estimado por integração. Neste tópico, discutese a questão da escolha do domínio físico, ou região de interesse, para a integração de fontes sobre o eslate, o que consiste em somar níveis discretos de pressão sonora em um subdomínio da malha no qual se encontram as fontes de interesse.

Em geral, pode-se escolher a região de integração com base na localização das fontes presentes nos mapas de beam-forming, nas bandas de frequência de interesse. Neste sentido, o uso de métodos de deconvolução é de grande valia, pois permite uma melhor separação entre fontes concorrentes sobre um modelo de teste. Para o caso do eslate, as fontes em baixa frequência se mostram irregularmente distribuídas nos mapas de beamforming, gerando incertezas na determinação de uma região de integração adequada. Em 
médias e altas frequências, as fontes do eslate encontram-se bem distribuídas ao longo de sua envergadura. Neste caso, a região de integração deve ser definida de forma a representar uma boa amostragem da distribuição de fontes aerodinâmicas ao longo da envergadura e excluir eventuais fontes espúrias. Idealmente, a região do eslate sob integração deveria representar uma distribuição de fontes 2D, e excluir regiões com domínio de fontes 3D, tais como aquelas geradas por vórtices ferradura na junção entre o aerofólio e as mesas giratórias de suporte.

Estruturas vorticais discretas e estatisticamente independentes, porém com um comprimento de correlação finito, podem atuar como uma distribuição de fontes de ruído decorrelacionadas. Neste sentido, o ruído de eslate pode ser associado a uma distribuição de fontes descorrelacionadas ao longo de sua envergadura. A rigor, a extensão finita das fontes caracteriza uma distribuição espacialmente 3D, porém com aspecto de fonte contínua em forma de uma linha. Tal distribuição de fontes pode ser aproximada para uma distribuição $2 \mathrm{D}$, dado que o comprimento da envergadura do eslate é muito superior ao comprimento típico de correlação das fontes aerodinâmicas em média e altas frequências.

Sob este aspecto, a integração sobre uma região equivalente ao comprimento de correlação da fonte seria suficiente para uma estimativa realista do ruído de eslate. Neste caso, o nível de ruído irradiado por um extensão finita do eslate poderia ser facilmente determinada a partir de uma relação de escala entre o comprimento de correlação das fontes de ruído e o comprimento da envergadura. Esta abordagem é utilizada em simulações numéricas para estimar o ruído de um eslate com envergadura reduzida, dado o custo computacional proibitivo de simulações baseadas em dimensões reais. Na prática, efeitos de escoamento 3D, muitas vezes decorrentes de imperfeições do aerofólio, ou do uso de suportes de sustentação, desconfiguram o arranjo teoricamente $2 \mathrm{D}$ esperado para a distribuição de fontes no eslate. Neste caso, uma estimativa mais realista do nível de ruído envolve a integração sobre uma região de maiores dimensões, de forma que o resultado represente estatisticamente a distribuição de fontes de ruído aerodinâmico ao longo da envergadura.

Desta forma, o domínio de integração adequado seria aquele capaz de representar a maior extensão do eslate na qual o escoamento melhor se aproxima de um padrão 2D, excluindo fontes de ruído aerodinâmico com origem em escoamento 3D, fontes espúrias e lóbulos secundários das fontes principais. Não obstante, deseja-se um domínio de integração cujas dimensões permaneçam constantes ao longo de uma banda de frequência com a máxima largura possível, de forma a favorecer o processamento sistemático de uma base de dados.

Para este trabalho, a análise conjunta dos espectros de ruído e mapas de beam-forming determinou um domínio espacial de integração com dimensões constantes com 0.18 m 
(corda) e $0.80 \mathrm{~m}$ (envergadura), na banda de frequência de $0.5 \mathrm{kHz}$ até $18 \mathrm{kHz}$. Para validar a escolha da região de integração adotada, considere a superfície com dimensões de $0.18 \mathrm{~m}$ (corda) e 1.4 (envergadura), representada em azul sobre o eslate, que se encontra hachurado em cinza (Fig. 5.10). A região central na superfície de integração (linha contínua em azul) possui dimensões de 0.18 x $0.80 \mathrm{~m}$, está centrada sobre o eslate e apresenta-se dividida em sub-regiões de integração, designadas pelos números 2, 3, 4 e 5. As regiões 1 e 6 compreendem as partes complementares da malha ao longa da envergadura.

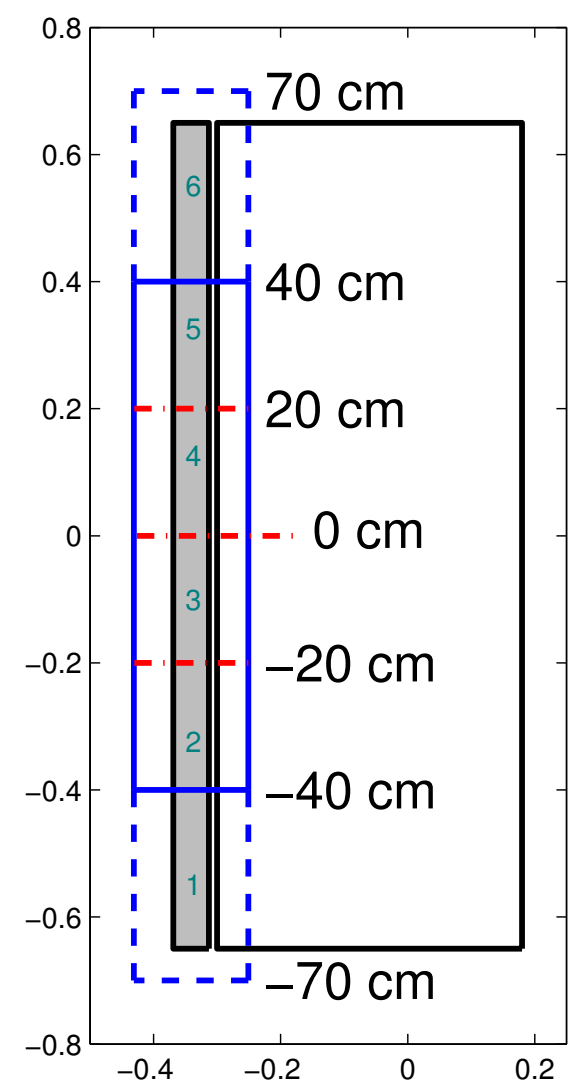

Figura 5.10: Representacão do perfil hiper-sustentador 30P30N com eslate (elemento hachurado à esquerda) e elemento principal, com destaque para a partição da envergadura do eslate em vários domínios de integração enumerados de 1 até 6 .

Do ponto de vista físico, as regiões 1 e 6 mapeiam as fontes na junção entre o eslate e a parede do túnel. Nesta região atua o sistema de sucção da camada limite da parede do túnel de vento. A figura 5.11 mostra os espectros de ruído do eslate resultantes da integração nas regiões de 1 até 6 , com o aerofólio nas condições $\alpha=4^{\circ}$ e $U_{\infty}=34 \mathrm{~m} / \mathrm{s}$.

A Figs. 5.11 mostra claramente que os espectros de ruído mapeados nas regiões 1 e 6 não reproduzem os componentes de ruído aerodinâmico mapeados na parte central da envergadura do eslate. Os resultados para as regiões 1 e 6 representam o ruído de fontes dominantes nas extremidades do aerofólio, que provavelmente decorrem da interação entre 

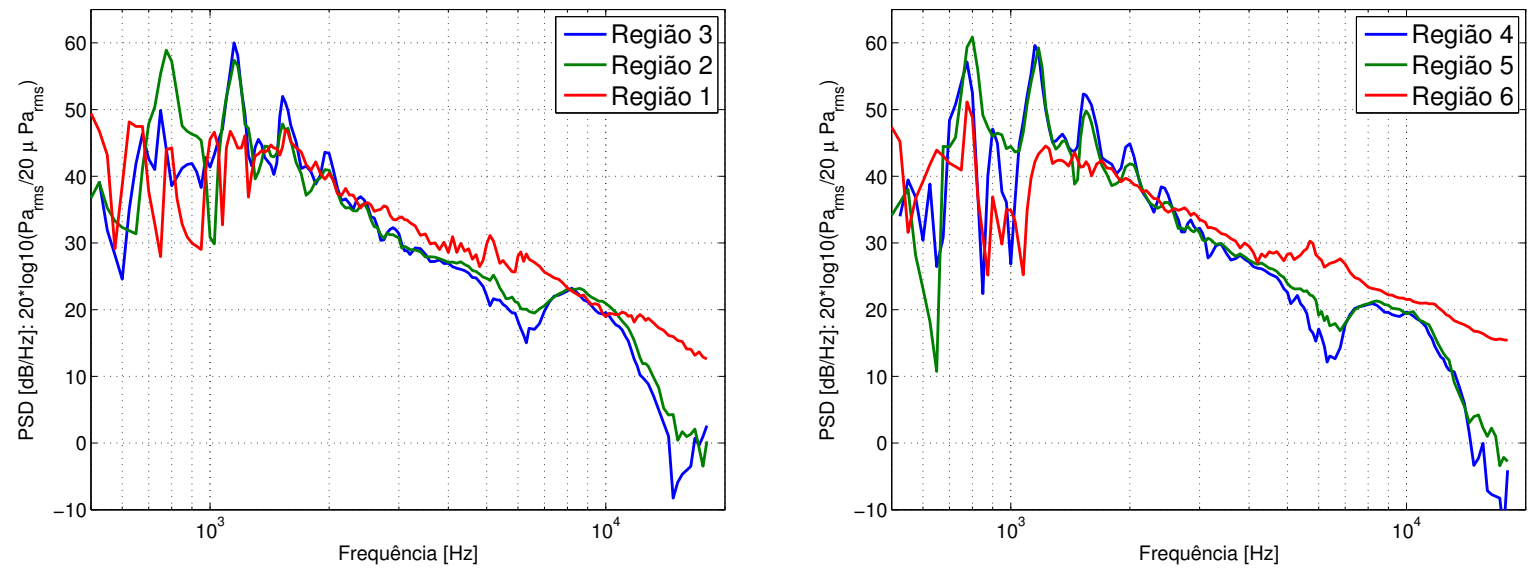

Figura 5.11: Espectros de ruído do eslate decorrentes da integração de fontes sobre as regiões enumeradas de 1 até 6 , conforme a Fig. 5.10. Uma faixa dinâmica de $12 \mathrm{~dB}$ foi adotada para integração.

a camada limite da parede do túnel e o aerofólio, de irregularidades na mesa giratória e do efeito local do próprio sistema de controle da camada limite. A presença de fontes espúrias na região da junção do aerofólio é evidente e de ocorrência sistemática nos mapas de beamforming voltados ao mapeamento destas regiões. Estas fontes mostram-se descontínuas às fontes de ruído aerodinâmico e sem correlação em frequência com estas últimas.

A comparação entre os espectros de ruído mapeados nas regiões de 2 até 5 sugere que o ruído de banda larga e o ruído tonal de alta frequência estão associadas à fontes com distribuições relativamente uniformes ao longo da envergadura do eslate, dado que o nível de ruído não varia de forma significativa entre estas regiões. O nível estimado para o primeiro pico tonal, por sua vez, mostra maior variância entre as regiões de integração, sugerindo uma distribuição de fonte mais concentrada em regiões específicas ao longo da envergadura do eslate. Estes resultados sugerem que o ruído tonal de baixa frequência está associado à uma fonte localizada. Tal conclusão é reforçada a partir da análise de mapas de beam-forming.

A partir dos resultados apresentados pode-se argumentar que as fontes mapeadas nas regiões 1 e 6 não representam o ruído aerodinâmico do eslate, devendo estas serem excluídas como regiões de integração. A integração sobre as regiões 2, 3, 4 e 5 é adequada para representar corretamente o ruído tonal e melhorar a amostragem estatística de fontes associadas aos componentes de ruído de média e alta frequência. Baseado nesta análise, adota-se uma região de integração com dimensões 0.18 m (corda) x 0.80 m (envergadura). Desta forma, os resultados quantitativos de ruído de eslate são representativos de uma distribuição de fontes perfazendo $0.8 \mathrm{~m}$ de envergadura. 
CAPÍTULO 6

\section{Validação das Metodologias Experimental e de Pós-processamento: Comparação entre Resultados Numéricos e Experimentais}

\subsection{Introdução}

Neste capítulo são apresentadas comparações de resultados aerodinâmicos e aeroacústicos obtidos a partir de medições experimentais e simulação computacional com o aerofólio hiper-sustentador 30P30N. Os resultados aerodinâmicos representam a distribuição de pressão ao longo da corda do perfil hiper-sustentador e os resultados aeroacústicos são comparados na forma de espectros de ruído do eslate. Os resultados mostram que as abordagens numérica e experimental são capazes de identificar os componentes de ruído do eslate, indicando que a física que determina os mecanismos de geração do ruído é bem representada a partir das duas metodologias. A concordância quantitativa entre os espectros de ruído é um aspecto a ser destacado na comparação entre os resultados, pois indica a viabilidade do uso de túneis de vento de seção fechada em experimentos aeroacústicos e a possibilidade de reprodução dos resultados experimentais a partir de uma modelagem numérica adequada do escoamento nas condições do experimento.

As simulações numéricas do escoamento foram realizadas com o uso do código comercial PowerFLOW 5.0a, baseado no método de Lattice-Boltzmann (LBM), cuja metodologia é brevemente descrita no apêndice A. Bonatto (2013) utilizou o código PowerFLOW para simular o ruído do eslate do aerofólio hiper-sustentador $30 \mathrm{P} 30 \mathrm{~N}$, idêntico àquele que é objeto de estudo nesta tese. Os resultados da simulação computacional foram comparados com resultados de medições experimentais com o modelo correspondente, também 
Capítulo 6. Validação das Metodologias Experimental e de Pós-processamento:

realizadas no túnel de vento LAE-1. Os resultados obtidos mostram uma boa correspondência entre o nível e a forma dos espectros de ruído, mostrando que as metodologias numérica e experimental foram capazes de revelar a ocorrência de ruído tonal de baixa frequência e ruído de banda larga em média frequência. Estes resultados mostraram que a formulação utilizada pelo código PowerFLOW é adequada para a investigação do ruído de eslate.

Para os resultados apresentados neste trabalho, as medições aerodinâmicas e aeroa-

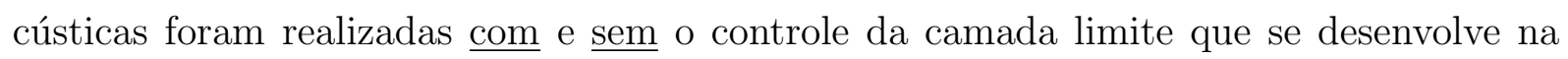
junção entre o aerofólio e as paredes horizontais do túnel de vento. A camada limite da parede foi succionada no extradorso do aerofólio, como forma de reduzir os efeitos do escoamento tridimensional sobre as medições aerodinâmicas, tornando as condições experimentais mais representativas das condições definidas para as simulações computacionais, que consideram a periodicidade do escoamento na direção da envergadura. Desta forma, é possível comparar e avaliar o efeito prático do controle da camada limite da parede a partir da comparação entre resultados numéricos e experimentais. Os resultados numéricos apresentados neste capítulo foram disponibilizados pelo aluno Daniel Sampaio, e obtidos no contexto do desenvolvimento de sua tese de doutorado.

\subsection{Sucção da Camada Limite da Parede do Túnel de Vento}

Experimentos com perfis aerodinâmicos em túneis de vento devem ser idealmente realizados sob a condição de um escoamento bidimensional. Para uma asa finita ensaiada em túnel de vento, o surgimento de efeitos de tridimensionalidade pode estar associado à interação o perfil aerodinâmico e a camada limite turbulenta sobre a parede do túnel. Nesta região ocorre a formação de vórtices tridimensionais que perturbam o regime de escoamento bidimensional sobre a asa, conforme ilustrado na Fig. 6.1.

A redução dos efeitos do escoamento tridimensional sobre a aerodinâmica de um aerofólio pode ser feita pela aplicação de técnicas de controle da camada limite turbulenta. Duas técnicas de uso comum são o sopro tangencial e a sucção da camada limite. O sopro tangencial injeta um fluxo de ar com objetivo de energizar o escoamento e impedir, ou retardar, a transição da camada limite do regime laminar para o regime turbulento. A sucção atua para remover a turbulência da camada limite. Ambas as técnicas buscam uniformizar a distribuição de pressão ao longo da envergadura do aerofólio, de forma que o carregamento aerodinâmico em qualquer ângulo de incidência seja representativo das condições aerodinâmicas verificadas sob escoamento bidimensional.

Paschal et al. (1991) mostram resultados de controle da camada limite para um perfil 


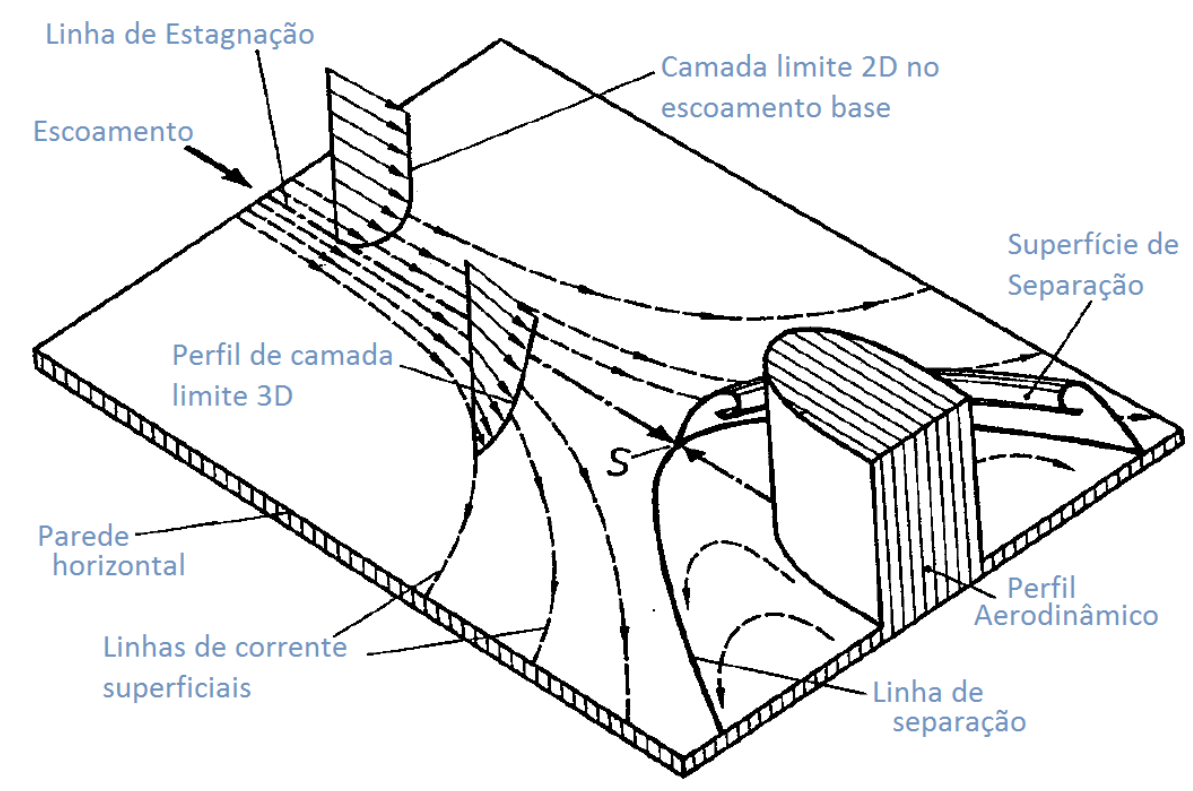

Figura 6.1: Representação do escoamento ao redor de um perfil aerodinâmico com formação de estruturas vorticais 3D.

Fonte: Adaptado de. Schlichting (1979)

hiper-sustentador utilizando as técnicas de sucção e sopro tangencial, a partir de experimentos realizados no Langley low turbulence pressure tunnel (LTPT). A bidimensionalidade do escoamento foi avaliada como uma medida da uniformidade da distribuição de pressão ao longo da envergadura do aerofólio. Testes com sucção distribuída sobre diferentes superfícies no entorno da base do perfil aerodinâmico sugerem que a sucção da camada limite seja feita ao longo do extradorso, na região adjacente à junção entre o aerofólio e as paredes do túnel. A Fig. 6.2 ilustra arranjos experimentais utilizados para a aplicação das técnicas de sopro tangencial e sucção da camada limite.

Em experimentos aerodinâmicos com um modelo hiper-sustentador genérico 30P30N realizados no NASA Langley low turbulence pressure tunnel (LTPT), Rumsey, Lee-Rausch e Watson (2003) succionam a camada limite como forma de obter um escoamento nominalmente bidimensional. Os resultados experimentais foram comparados com resultados de simulações numéricas (CFD) que consideravam uma malha 3D e incluíam no modelo computacional efeitos de sucção da camada limite, mostrando que os resultados numéricos previam carregamento aerodinâmico máximo e ângulo de stall superiores àqueles observados experimentalmente.

Para os resultados apresentados neste trabalho, as medições aeroacústicas com o perfil hiper-sustentador 30P30N foram realizadas com aplicação de sucção para o controle da camada limite da parede. A sucção foi aplicada através de placas porosas instaladas sobre as mesas de suporte giratórias, ao longo de uma faixa irregular com poucos centímetros de largura, na região do extradorso do elemento principal (suction side) e à frente do 


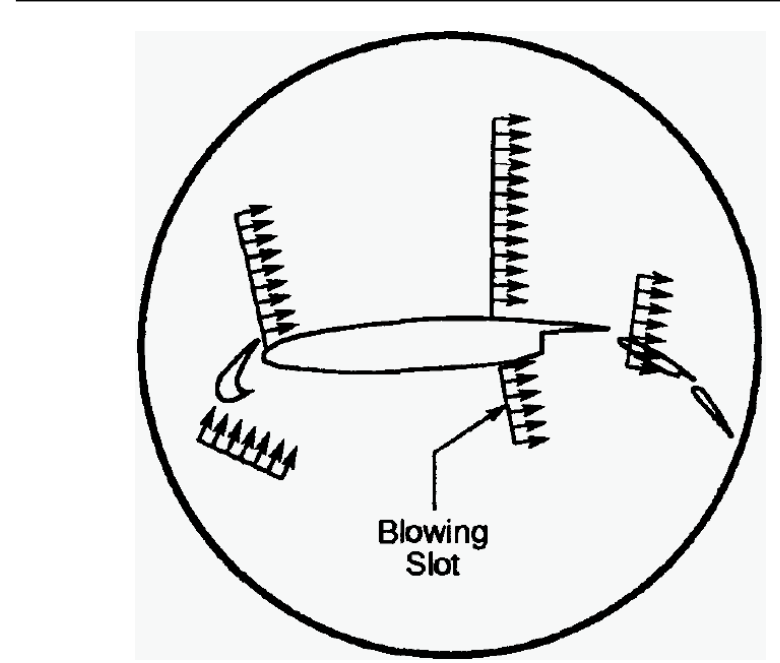

(a) Sopro tangencial

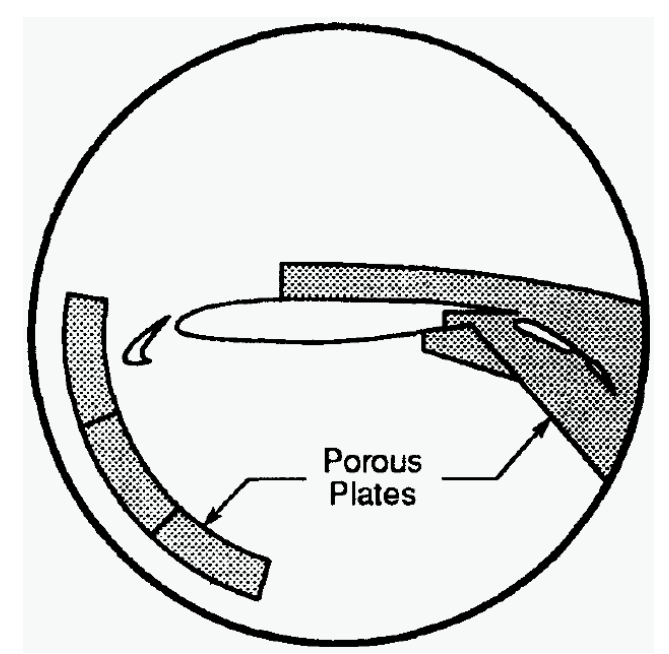

(b) Sucção da camda limite

Figura 6.2: (a) sopro tangencial e (b) representação de superfície porosa utilizada para a sucção da camada limite. A região efetiva para aplicação da sucção pode ser otimizada pela utilização parcial da superfície porosa total.

Fonte: Paschal et al. (1991).

bordo de ataque do eslate. O nível de sucção considerado ideal foi ajustado a partir da análise da distribuição de pressão ao longo da envergadura do elemento principal do aerofólio. De forma a adequar o nível de sucção ao carregamento aerodinâmico, ajustou-se a vazão volumétrica do mecanismo de sucção de forma independente para cada ângulo de incidência do aerofólio e velocidade de escoamento livre. O equipamento utilizado e a estratégia adotada para a sucção da camada limite no túnel de vento LAE-1 encontram-se documentados em maiores detalhes em (CATALANO; VANUCCI; CORREA, 2012).

Em suma, o objetivo do controle da camada limite via sucção é mitigar efeitos de tridimensionalidade sobre o escoamento na superfície da asa e garantir medições aerodinâmicas/aeroacústicas em condição de escoamento tão bidimensional quanto possível.

A Fig. 6.3 mostra distribuições do coeficiente de pressão (cp) ao longo da envergadura do elemento principal do aerofólio, para a configuração experimental $\alpha=8^{\circ}$ e $U_{\infty}=34 \mathrm{~m} / \mathrm{s}$. As medições foram realizadas no extradorso do elemento principal, em regiões próximas ao bordo de ataque e ao bordo de fuga. As medições de Cp foram realizadas com e sem a aplicação de sucção para o controle da camada limite da parede.

Conforme pode ser observado a partir da Fig. 6.3, o controle da camada limite via sucção tem o efeito de uniformizar a distribuição de pressão ao longo da envergadura do aerofólio. O efeito do controle da camada limite é mais significativo nas regiões próximas às extremidades do aerofólio, onde ocorre maior influência da camada limite turbulenta sobre o escoamento na superfície do aerofólio. Todavia, o efeito de uniformização na distribuição de pressão pode ser observado nas regiões do bordo de ataque e do bordo de 


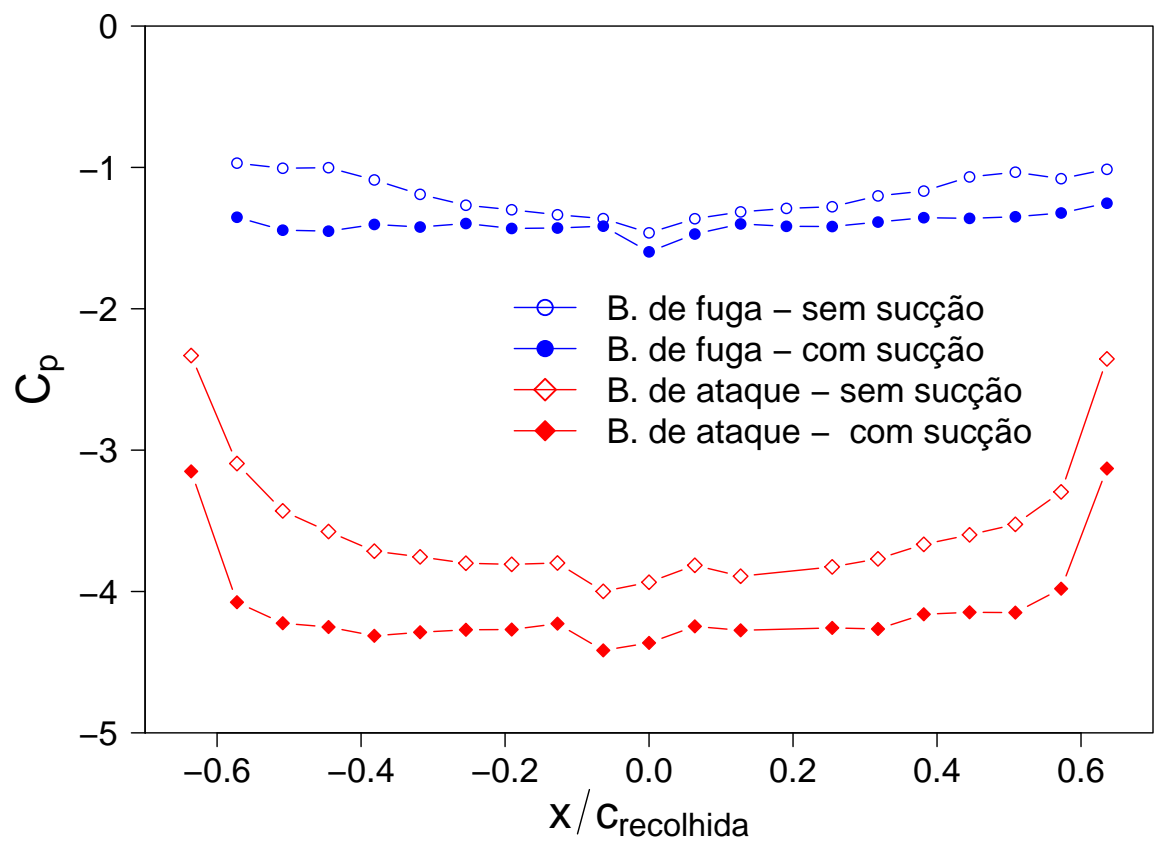

Figura 6.3: Distribuições do coeficiente de pressão $(\mathrm{Cp})$ ao longo da envergadura do elemento principal; próximo ao bordo de ataque (linhas azuis superiores) e ao bordo de fuga (linhas vermelhas inferiores), com sucção (linhas com símbolos hachurados) e sem sucção para o controle da camada limite da parede.

fuga do elemento principal do aerofólio. Nossos resultados experimentais também mostram que o controle da camada limite torna-se mais necessário para ângulos de ataque mais altos.

\subsection{Breve Descrição da Metodologia Numérica}

As simulações numéricas do escoamento foram realizadas com o uso do código comercial PowerFLOW 5.0a, baseado no método de Lattice-Boltzmann (LBM), cuja metodologia é brevemente descrita no apêndice B. O desenvolvimento da metodologia numérica ocorre no contexto do trabalho de doutorado (em desenvolvimento) do aluno Daniel Sampaio, tendo sido os resultados disponibilizados para apresentação nesta tese.

$\mathrm{Na}$ abordagem numérica, as flutuações de pressão acústica obtidas pela aplicação do método de Lattice-Boltzmann são propagadas para a posição correspondente ao centro da antena de microfones, pelo o uso da analogia de Ffowcs Williams-Hawkings (FW-H). O algoritmo FW-H implementado no PowerFLOW segue a formulação 1A de Farassat para modelos em túneis de vento (FARASSAT; SUCCI, 1980; BRÈS; PÉROT; FREED, 2010). A integração da superfície FW-H considerada nas simulações compreende a superfície do eslate e metade da superfície do elemento principal adjacente ao eslate. Os dados simulados usados no cálculo FW-H representam 0.144s (após o descarte do transiente 
inicial), com um incremento de $1,26 \times 10^{-5} \mathrm{~s}$.

Análises estatísticas realizadas por Choudhari e Khorrami (2007) mostram que uma envergadura correspondente à $\sim 40 \%$ da corda do eslate é suficiente para levar em conta a decorrelação das estruturas vorticais na cova do eslate. O modelo simulado numericamente possui envergadura correspondente à $68 \%$ da corda do eslate, que mede $7,5 \mathrm{~cm}$. A tabela 6.1 compara as dimensões da corda e da envergadura dos modelos real e simulado computacionalmente.

Tabela 6.1: Dimensões dos modelos experimental e numérico

\begin{tabular}{|c|c|c|}
\cline { 2 - 3 } \multicolumn{1}{c|}{} & \multicolumn{2}{c|}{ modelo } \\
\hline parâmetros & experimental & numérico \\
\hline corda recolhida $(\mathrm{m})$ & 0,50 & 0,50 \\
\hline corda do eslate $(\mathrm{m})$ & 0,075 & 0,075 \\
\hline envergadura $(\mathrm{m})$ & 1,30 & 0.051 \\
\hline
\end{tabular}

\subsection{Comparação entre Resultados Numéricos e Ex- perimentais}

\subsubsection{Distribuição de Pressão ao Longo da Corda do Aerofólio}

A distribuição experimental de pressão ao longo da corda do aerofólio, adimensionalizada na forma de coeficiente de pressão (Cp), é comparada com a distribuição de pressão obtida por simulação numérica, considerando velocidade de escoamento livre de $34 \mathrm{~m} / \mathrm{e}$ o aerofólio em ângulos de ataque de $4^{\circ}$ e $8^{\circ}$. Os resultados para $4^{\circ}$ e $8^{\circ}$ são apresentados nas Figs. 6.4 e 6.5, respectivamente. Os resultados numéricos foram obtidos utilizando um modelo computacional com malhas refinadas em $\delta x_{\min }=0.14 \mathrm{~mm}$ e $\delta x_{\min }=0.20 \mathrm{~mm}$.

As medições experimentais foram realizadas na linha central da envergadura do aerofólio, conforme instrumentação descrita na secção 3.2, para os casos com e sem o controle da camada limite de parede via sucção. De forma similar, os resultados numéricos para a distribuição de pressão, obtidos pelo método de Laticce-Bolzmann, decorrem de medições no plano central da envergadura do modelo simulado.

O resultado para $\alpha=4^{\circ}$ mostra uma boa correspondência entre distribuições de Cp obtidas por medições e simulação computacional. Para o elemento principal, a melhor correspondência ocorre na região do extradorso, próximo ao pico de sucção, para resultados numérico com pontos da malha espaçados de $\delta x_{\text {min }}=0.20 \mathrm{~mm}$, e experimental com o controle da camada limite da parede. Também há uma boa correspondência entre os valores do pico de sucção obtidos por experimento e simulação. Na superfície de sucção do flape ocorre uma melhor correspondência entre as curvas de Cp quando os resultados 


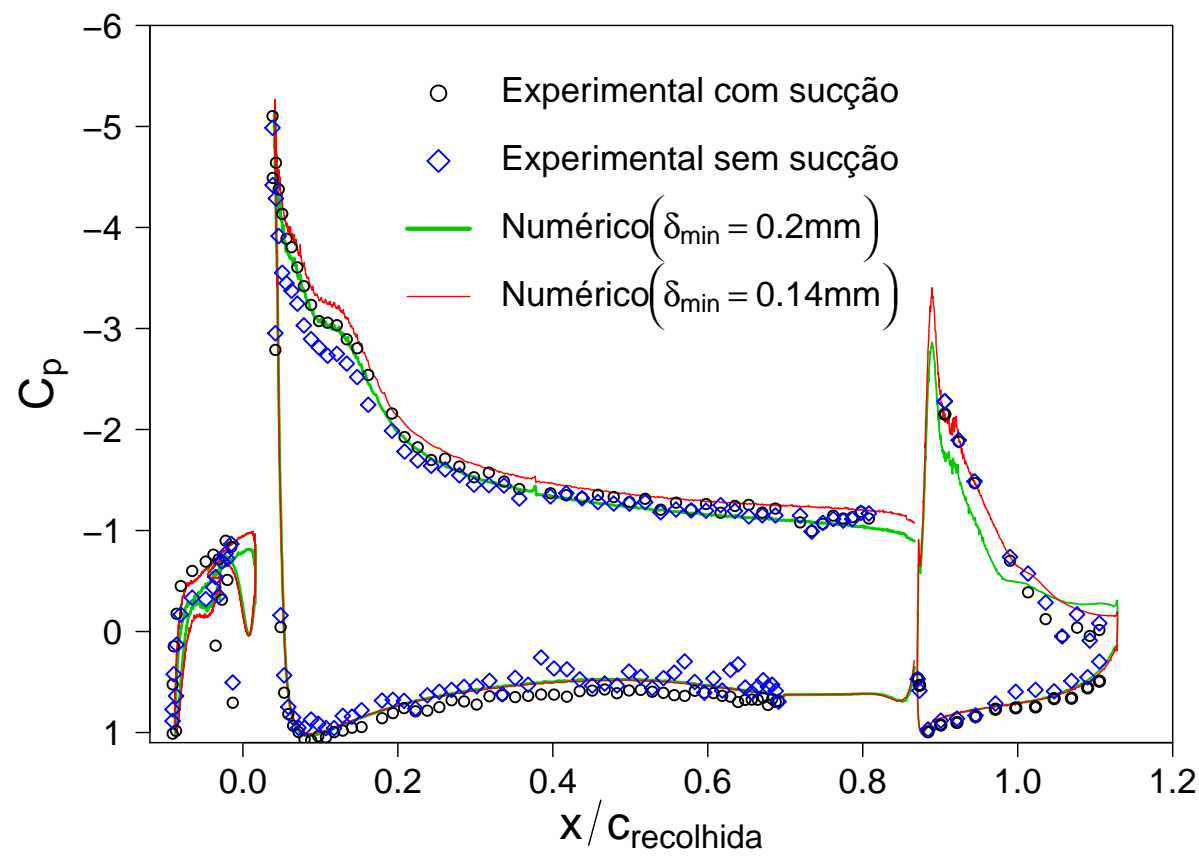

Figura 6.4: Distribuições de pressão $(\mathrm{Cp})$ ao longo do ponto médio da envergadura do perfil hiper-sustentador 30P30N, obtidas por simulação computacional e medições experimentais (com e sem suç̧ão da camada limite da parede). Os resultados correspondem ao aerofólio em ângulo de ataque de $4^{\circ}$ e velocidade de escoamento livre de $34 \mathrm{~m} / \mathrm{s}$.

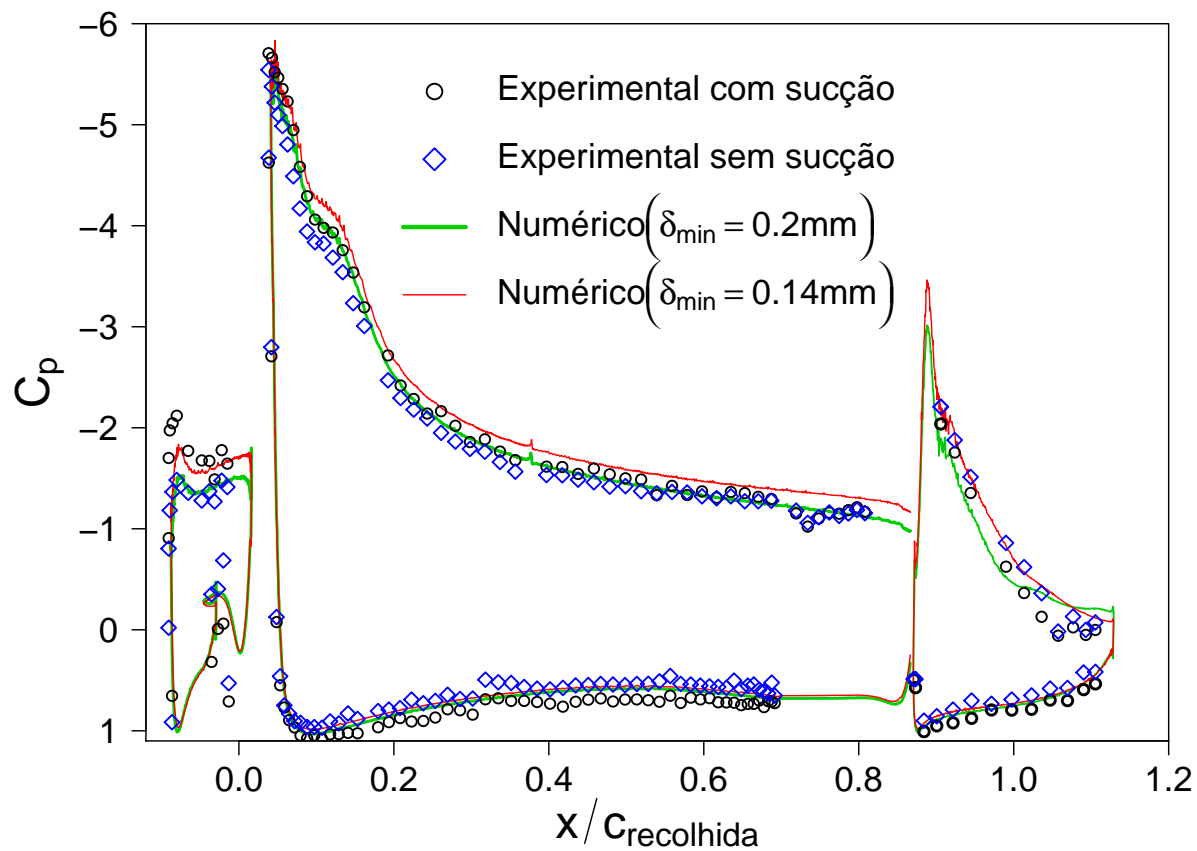

Figura 6.5: Distribuições de pressão $(\mathrm{Cp})$ ao longo do ponto médio da envergadura do perfil hiper-sustentador 30P30N, obtidas por simulação computacional e medições experimentais (com e sem sucção da camada limite da parede). Os resultados correspondem ao aerofólio em ângulo de ataque de $8^{\circ}$ e velocidade de escoamento livre de $34 \mathrm{~m} / \mathrm{s}$. 
experimentais são comparados com o resultado numérico obtido com a malha $\delta x_{\min }=$ $0.14 \mathrm{~mm}$. Nesta condição, o resultado numérico mostra uma boa correspondência com o experimento, inclusive na região de provável separação da camada limite.

Para $\alpha=8^{\circ}$, também destaca-se a boa correspondência entre distribuições de Cp para resultados numérico e experimental. Para a superfície de sucção do eslate, verifica-se que o resultado numérico obtido com a malha $\delta x_{\text {min }}=0.14 \mathrm{~mm}$ apresenta melhor concordância com o resultado experimental obtido com sucção da camada limite, enquanto que o resultado numérico obtido com a malha $\delta x_{\min }=0.12 \mathrm{~mm}$ corresponde melhor ao caso experimental sem sucção da camada limite da parede. Para $\alpha=4^{\circ}$ e $\alpha=8^{\circ}$, as simulações com a malha $\delta x_{\min }=0.14 \mathrm{~mm}$ mostram um aumento na circulação e na sustentação aerodinâmica do aerofólio, efeito que também é observado nas medições experimentais com aplicação de sucção para o controle da camada limite.

\subsubsection{Espectros de Ruído do Eslate}

A comparação entre espectros de ruído do eslate obtidos a partir de medições experimentais e simulação computacional é feita com o aerofólio em ângulos de incidência de $4^{\circ} \mathrm{e}$ $8^{\circ}$, com $U_{\infty}=34 \mathrm{~m} / \mathrm{s}$. Para o sinal numérico que representa flutuações de pressão acústica no microfone de referência, o espectro de ruído é obtido a partir da mesma metodologia de processamento de sinais aplicada às medições feitas pela antena de microfone instalada no túnel de vento LAE-1, que é descrita em maiores detalhes na seção 4.10. A tabela 6.2 representa a partição do intervalo de frequência entre $500 \mathrm{~Hz}$ e $18 \mathrm{kHz}$ em quatro bandas com diferentes resoluções em frequência para o espectro de ruído, bem como os números de blocos de dados usados nos processamentos numérico e experimental.

Tabela 6.2: Parâmetros utilizados nos processamentos numérico e experimental. Nas duas últimas linhas encontram-se representados os números de blocos de dados usados nos processamentos experimental e numérico.

\begin{tabular}{|l|c|c|c|c|}
\hline & $0.5-3.2 \mathrm{kHz}$ & $3.3-6.4 \mathrm{kHz}$ & $6.6-12.8 \mathrm{kHz}$ & $12.8-18 \mathrm{kHz}$ \\
\hline Experimental & $50 \mathrm{~Hz}$ & $100 \mathrm{~Hz}$ & $200 \mathrm{~Hz}$ & $400 \mathrm{~Hz}$ \\
\hline Numérico & $50 \mathrm{~Hz}$ & $100 \mathrm{~Hz}$ & $200 \mathrm{~Hz}$ & $400 \mathrm{~Hz}$ \\
\hline Experimental & 3895 & 7791 & 15584 & 31170 \\
\hline Numérico & 13 & 27 & 55 & 113 \\
\hline
\end{tabular}

Os espectros de ruído numérico e experimental são apresentados como densidade de potência espectral $(\mathrm{dB} / \mathrm{Hz})$. Os níveis espectrais $(\mathrm{dB} / \mathrm{Hz})$ para o sinal numérico no microfone de referência, utilizados na comparação com os níveis de ruído experimentais, são obtidos a partir da seguinte relação

$$
P S D(d B / H z)=P S D(d B / H z)-10 \log \left(\frac{L_{z}[m]}{0.8[m]}\right),
$$


sendo $L_{z}=0,051 \mathrm{~m}$ o comprimento da envergadura do modelo simulado, correspondente à $68 \%$ da corda medindo $0,075 \mathrm{~m}$, e $0.8 \mathrm{~m}$ o comprimento da envergadura do eslate na qual integra-se os valores discretos de pressão sonora obtidos experimentalmente.

A definição da Eq. 6.1 baseia-se na hipótese de que ambos os espectros de ruído do eslate, obtidos por simulação computacional e medições experimentais, decorrem de distribuições de fontes uniformes e periódicas ao longo da envergadura do eslate, e que apresentam as mesmas propriedades estatísticas. A Eq. 6.1 assume que a envergadura é a dimensão relevante para a normalização dos níveis de ruído do eslate. Desta forma, embora a dimensão da região simulada numericamente, na direção da corda do aerofólio, seja distinta daquela utilizada para a integração de fontes no caso experimental, considera-se que em ambos os casos, numérico e experimental, as dimensões das regiões de mapeamento são adequadas para representar a distribuição de fontes que efetivamente contribuem para o ruído do eslate em campo distante. Para os espectros de ruído experimentais apresentados neste trabalho, adota-se a subtração de $6 \mathrm{~dB}$ para compensar efeitos decorrentes de medição com microfones posicionados em uma parede rígida.

A Figs. 6.6 e 6.7 mostram comparações entre espectros de ruído experimentais e numéricos para as configurações experimentais com $\alpha=4^{\circ}$ e $8^{\circ}$, e $U_{\infty}=34 \mathrm{~m} / \mathrm{s}$. Os espectros experimentais foram obtidos para os casos com e sem o controle da camada limite de parede, e os resultados numéricos foram obtidos com as malhas $\delta x_{\text {min }}=14$ e $\delta x_{\text {min }}=$ $20 \mathrm{~mm}$.

De forma geral, os resultados mostram uma boa correspondência quantitativa entre espectros de ruído do eslate obtidos a partir de medições em túnel de vento e simulação computacional, nas faixas de Strouhal onde ocorrem os picos tonais de alta amplitude e o ruído de banda larga. Também é observada uma boa correspondência entre as frequências de ocorrência dos picos tonais, que são melhor definidas para $\alpha=4^{\circ}$. A forma do espectro do ruído de banda larga é bem representada pelo modelo numérico, que apresenta um decaimento em amplitude típico de resultados experimentais na faixa de Strouhal aproximadamente entre 5 e 12. A melhor correspondência quantitativa entre resultados numéricos e experimentais para o ruído de banda larga ocorre para $\alpha=4^{\circ}$. A partir de $\mathrm{St} \approx 12$, ocorre uma notória discordância entre resultados numéricos e experimentais. No entanto, as malhas adotadas na simulação numérica não são suficientemente refinadas para garantir a convergência dos espectros de ruído (BANDLE et al., 2012). Para tornar os resultados obtidos nesta faixa de Strouhal independentes dos parâmetros do processamento, uma malha ao menos 5 vezes mais refinada deveria ser usada para os casos em estudo neste trabalho.

Para $\alpha=4^{\circ}$, a aplicação de sucção para o controle da camada limite da parede e o refinamento da malha na simulação numérica têm o efeito em comum de reduzir a 
Capítulo 6. Validação das Metodologias Experimental e de Pós-processamento:

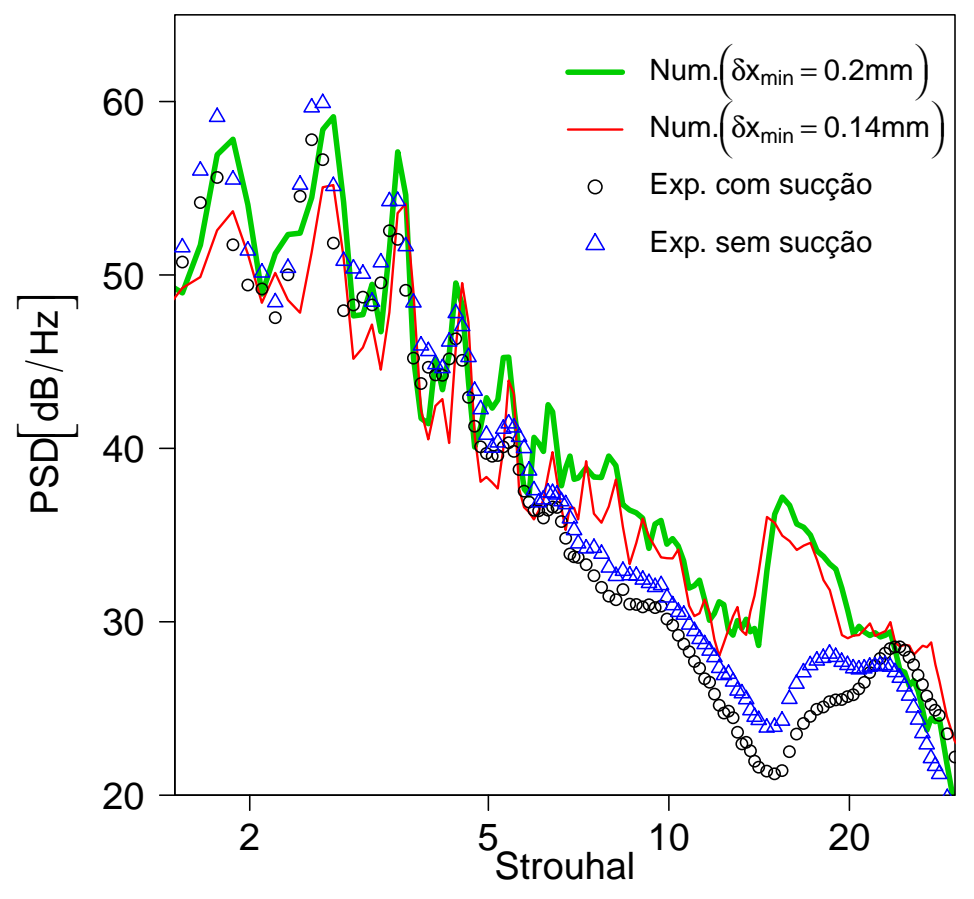

Figura 6.6: Espectros de ruído do eslate obtidos via simulação computacional e processamento de dados experimentais (com e sem o controle da camada limite da parede), para $\alpha=4^{\circ}$ e $U_{\infty}=34 m / s$.

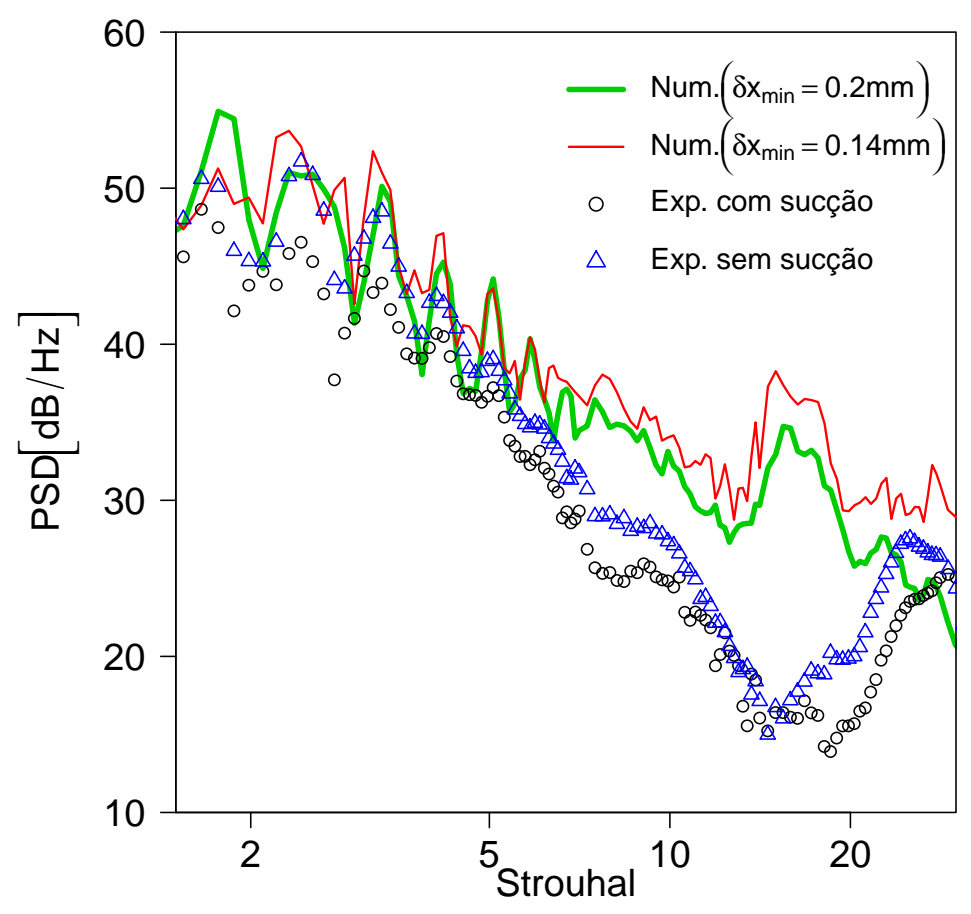

Figura 6.7: Espectros de ruído do eslate obtidos via simulação computacional e processamento de dados experimentais (com e sem o controle da camada limite da parede), para $\alpha=8^{\circ}$ e $U_{\infty}=34 \mathrm{~m} / \mathrm{s}$. 
amplitude dos picos tonais que ocorrem até St $\approx 5$. Para $\alpha=8^{\circ}$, ocorre uma redução mais significativa no nível de ruído por conta da sucção da camada limite, enquanto que o refinamento da malha aumenta a amplitude dos principais picos tonais, exceto o primeiro. Para $\alpha=8^{\circ}$, ocorre uma melhor correspondência quantitativa entre os espectros de ruído numéricos e o espectro de ruído experimental obtido na ausência de sucção da camada limite. Todavia, o resultado numérico obtido com a malha refinada em $\delta x_{\text {min }}=$ $0.14 \mathrm{~mm}$ potencialmente representa uma melhor aproximação para a solução exata com o modelo simulado. Por sua vez, o resultado experimental com o controle da camada limite estabelece uma melhor correspondência entre as condições aerodinâmicas verificadas no experimento e na simulação computacional. De forma geral, há uma correspondência quantitativa bastante satisfatória entre os espectros de ruído numérico e experimental, notadamente até $\mathrm{St} \approx 5$, onde ocorrem os componentes de ruído dominantes no espectro acústico do eslate para o aerofólio 30P30N.

Os resultados apresentados nesta seção indicam que as metodologias numérica e experimental são capazes de representar a física dos mecanismos de geração de ruído do eslate. Os resultados também advogam pela viabilidade do uso de túneis de vento de seção fechada para a realização de experimentos aeroacústicos, bem como qualificam os resultados experimentais para análises mais abrangentes sobre a dependência do ruído do eslate em relação aos parâmetros do escoamento e a configuração geométrica do aerofólio. 
Capítulo 6. Validação das Metodologias Experimental e de Pós-processamento: 
CAPÍTULO 7

\section{Ruído Aerodinâmico do Eslate}

\subsection{Introdução}

Este capítulo tem por objetivo apresentar um estudo descritivo do ruído aerodinâmico do elemento eslate do perfil hiper-sustentador 30P30N. Os resultados são apresentados na forma de espectros de ruído e mapas de beam-forming, obtidos pelo processamento de dados experimentais com o método de deconvolução DAMAS. Os espectros de ruído representam níveis de pressão sonora integrada no domínio de uma malha de pontos com $0.80 \mathrm{~m}$ de extensão sobre a envergadura e $0.18 \mathrm{~m}$ sobre a corda do eslate. Os mapas de beam-forming representam a distribuição espacial de fontes associada ao elemento eslate.

Neste capítulo são avaliados resultados de medições com o aerofólio em diferentes configurações experimentais, com variações no ângulo de ataque, $\alpha$, e na velocidade de escoamento livre, $U_{\infty}$. Os casos experimentais avaliados correspondem à configuração geométrica de referência para o perfil hiper-sustentador 30P30N. A tabela 7.1 representa os parâmetros geométricos que definem a configuração de referência $30 \mathrm{P} 30 \mathrm{~N}$, e os valores adotados para os parâmetros $\alpha$ e $U_{\infty}$. Ao todo, são processados 24 casos experimentais.

Tabela 7.1: Parâmetros de configuração do aerofólio

\begin{tabular}{|c|c|c|c|c|c|c|c|}
\hline \multicolumn{5}{|c|}{ Geometria do Aerofólio } & \multirow{2}{*}{ Configuração Experimental } \\
\hline \multicolumn{3}{|c|}{ Eslate } & \multicolumn{3}{c|}{ Flape } & \multirow{2}{*}{$\alpha(\mathrm{o})$} & $\mathrm{U}(\mathrm{m} / \mathrm{s})$ \\
\hline $\boldsymbol{\delta}_{\boldsymbol{s}}$ & gap & overlap & $\boldsymbol{\delta}_{f}$ & gap & overlap & & \\
\hline $30^{\circ}$ & $2,95 \%$ & $-2,50 \%$ & $30^{\circ}$ & $1,27 \%$ & $0,25 \%$ & $0 ; 2 ; 4 ; 6 ; 8 ; 10$ & $24 ; 27 ; 31 ; 34$ \\
\hline
\end{tabular}


A Fig. 7.1 mostra o espectro de ruído do eslate para $\alpha=2^{\circ}$ e $U_{\infty}=34 \mathrm{~m} / \mathrm{s}$, com destaque para os componentes do ruído que ocorrem em bandas de frequência bem definidas. Em baixa frequência pode-se observar a ocorrência de múltiplos picos tonais de grande amplitude, relativamente aos demais componentes do ruído. Na frequência média ocorre ruído de banda larga que apresenta um decaimento em amplitude com o aumento da frequência que é típico de ruído de eslate. Em frequências mais altas ocorre um ruído tonal de banda larga e amplitude moderada. Estes três componentes caracterizam os espectros de ruído do eslate nas condições experimentais e geométricas avaliadas neste trabalho, e mostram-se dependentes do ângulo de ataque do aerofólio, da velocidade de escoamento e dos parâmetros de configuração geométrica do eslate.

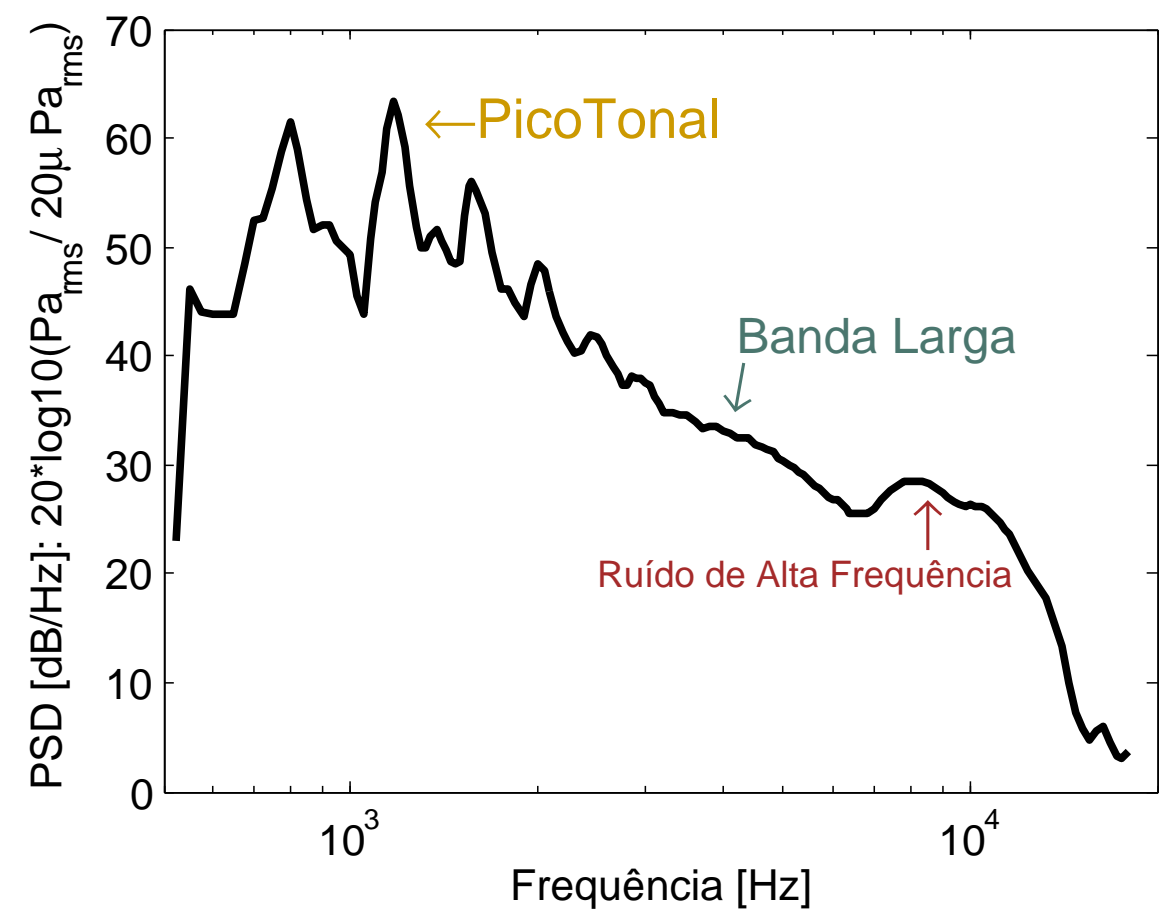

Figura 7.1: Espectro de ruído típico do elemento eslate do aerofólio 30P30N, apresentando componentes de ruído bem definidos em baixa, média e alta frequência.

Na seção 7.4, a distribuição espacial de fontes correspondente a cada componente de ruído identificado na Fig. 7.1 é representada na forma de mapas de beam-forming. A localização das fontes em um mapa de beam-forming permite identificar as regiões do escoamento onde potencialmente ocorrem mecanismos de geração do ruído aerodinâmico. Em particular, as medições experimentais utilizadas no estudo dos mapas de beam-forming foram realizadas após a instalação de espumas para absorção acústica na câmara de ensaios, no entorno do modelo de testes. Comparações entre medições acústicas antes e após a instalação de espumas mostram que o arranjo experimental com espumas melhora significativamente a representação de fontes 2D ao longo da envergadura do eslate, sem causar alterações significativas nos respectivos espectros de ruído. 
A dependência dos espectros de ruído em relação à velocidade de escoamento é uma característica de ruídos gerados por fontes aerodinâmicas. Certos mecanismos de emissão de ruído aerodinâmico produzem energia acústica $\left(\sim p^{2}\right)$ de forma proporcional ao número de Mach $(M a)$ do escoamento livre, elevado a um expoente $n$, conforme

$$
p^{2} \sim M a^{n}
$$

O número de Mach do escoamento livre é definido pela relação $M a=U_{\infty} / c$, onde $c$ é a velocidade do som medida nas condições do experimento. Seja $p_{0}$ o nível de pressão sonora associado ao ruído aerodinâmico de um aerofólio sob escoamento livre com velocidade $U_{0}$ e número de Mach dado por $U_{0} / c$. Sob a relação de escalas $p^{2} \sim M a^{n}$, pode-se deduzir a relação entre níveis de pressão sonora medidos em campo distante sob diferentes velocidades de escoamento livre na forma

$$
10 \log _{10}\left(p / p_{r}\right)^{2}-10 \log _{10}\left(p_{0} / p_{r}\right)^{2} \approx 10 \log _{10}\left(U_{\infty} / U_{0}\right)^{n}
$$

sendo $p_{r}=2 \times 10^{-5}(\mathrm{~Pa})$ a pressão de referência. A Eq. 7.2 pode ser reescrita na seguinte forma

$$
S P L\left(U_{\infty}\right) \approx n\left[10 \log _{10}\left(U_{\infty} / U_{0}\right)\right]+S P L\left(U_{0}\right)
$$

A Eq. 7.3 mostra que, em vista da hipótese 7.1, a quantidade $\operatorname{SPL}\left(U_{\infty}\right)^{1}$, usada para representar o nível de pressão sonora sob a velocidade $U_{\infty}$, varia linearmente com o termo $10 \log _{10}\left(U_{\infty} / U_{0}\right)$, sendo o expoente $n$ uma constante de proporcionalidade. Os níveis de ruído estimados para diferentes velocidades de escoamento podem, então, serem reduzidos a um nível de referência $S P L\left(U_{0}\right)$, representativo da velocidade de escoamento $U_{0}$, conforme

$$
\operatorname{SPL}\left(U_{0}\right) \approx S P L\left(U_{\infty}\right)-n\left[10 \log _{10}\left(U_{\infty} / U_{0}\right)\right]
$$

Neste caso, dizemos que as curvas colapsam pela normalização dada pela Eq. 7.4. Naturalmente, a qualidade dos resultados depende do uso de um expoente $n$ que seja representativo da relação $p^{2} \sim\left(U_{\infty} / c\right)^{n}$, considerando $U_{\infty}$ o único parâmetro experimental variável ao longo de diferentes medições.

Vários estudos têm focado na determinação do expoente que melhor representa a dependência quantitativa do ruído de eslate em relação ao Mach de escoamento livre. Os valores de referência são $M a^{4}$ Choudhari et al. (2002), $M a^{4,5}$ Dobrzynski e Pott-Pollenske (2001) e $M a^{5}$ Guo, Yamamoto e Stoker (2003), Guo e Joshi (2003), ou mesmo variações entre $M a^{4}$ e $M a^{5}$ ao longo da frequência, (MENDOZA; BROOKS; HUMPHREYS, 2002).

\footnotetext{
${ }^{1}$ SPL, do Inglês Sound Pressure Level designa Nível de Pressão Sonora (NPS).
} 
O colapso dos espectros de ruído com $M a^{5}$ é típico de emissão de som a partir da incidência de escoamento turbulento sobre uma superfície com borda delgada (DOWLING; WILLIAMS, 1983). No contexto da teoria que prevê a geração de ruído no bordo de fuga do eslate, com o colapso do espectros determinado pelo fator $M a^{5}$, o colapso das curvas de ruído verificado para $M a^{4,5}$, ou $M a^{4}$, pode estar associado à ação de mecanismos concorrentes de geração de ruído ou mesmo à dominância de um mecanismo de natureza distinta. Os espectros de ruído de eslate apresentados neste estudo foram testados com base em várias normalizações, sendo $\mathrm{Ma}^{4}$ o fator de normalização que apresentou os melhores resultados.

O número de Strouhal é definido como

$$
S t=\frac{f \times c_{s}}{U_{\infty}}
$$

sendo $c_{s}$ a corda do eslate e $f$ a frequência, em unidades de $H z$. A adimensionalização da frequência, de acordo com a Eq. 7.5, assume que a dimensão da corda do eslate é representativa da dimensão das fontes aerodinâmicas que geram o ruído do eslate. Conforme Dobrzynski e Pott-Pollenske (2001), a definição de Strouhal dada pela Eq. 7.5 é consistente com o fato de que o escoamento turbulento que é convectado através do gap do eslate, e incide sobre a região do bordo de fuga, tem origem na região de recirculação que é gerada na cova do eslate. O escoamento vortical ocupa uma região substancial da cova, notadamente para o aerofólio em baixos ângulos de incidência, condição na qual o ponto de recolamento da camada de mistura se aproxima do bordo de fuga e expande o vórtice central (JENKINS; KHORRAMI; CHOUDHARI, 2004).

\subsection{Espectros de Ruído do Eslate e Dependência Com o Mach do Escoamento}

As Figs. de 7.2 até 7.7 mostram os espectros de ruído do eslate para os ângulos de incidência de $0^{\circ}, 2^{\circ}, 4^{\circ}, 6^{\circ}, 8^{\circ}$ e $10^{\circ}$, respectivamente. Para cada ângulo de incidência do aerofólio, apresentam-se os espectros de ruído referentes às medições com velocidades de escoamento de $24 \mathrm{~m} / \mathrm{s}, 27 \mathrm{~m} / \mathrm{s}, 31 \mathrm{~m} / \mathrm{s}$ e $34 \mathrm{~m} / \mathrm{s}$. Os espectros de ruído são apresentados: a) como densidade espectral de potência contra a frequência e b) como densidade espectral de potência normalizada, ou reescalada pelo fator $10 n \log _{10}\left(M a / M a_{0}\right)$, contra Strouhal baseado no comprimento da corda do eslate e na velocidade de escoamento livre (Eq. 7.5). Os espectros adimensionais (em frequência) para $\alpha=0^{\circ}, 4^{\circ}$ e $8^{\circ}$ e $10^{\circ}$ são normalizados com base no expoente $n=4.5$. Para $\alpha=2^{\circ}$ e $6^{\circ}$, os espectros de ruído são normalizados com base nos expoentes $n=4,4.5$ e 5 . O Mach de referência, $M a_{0}$, corresponde à velocidade de $34 \mathrm{~m} / \mathrm{s}$, considerando variações decimais medidas em cada caso. 
Estes resultados têm por objetivo evidenciar a natureza aerodinâmica do ruído do eslate e indicar a dependência quantitativa dos espectros de ruído em relação ao parâmetro $M a$.

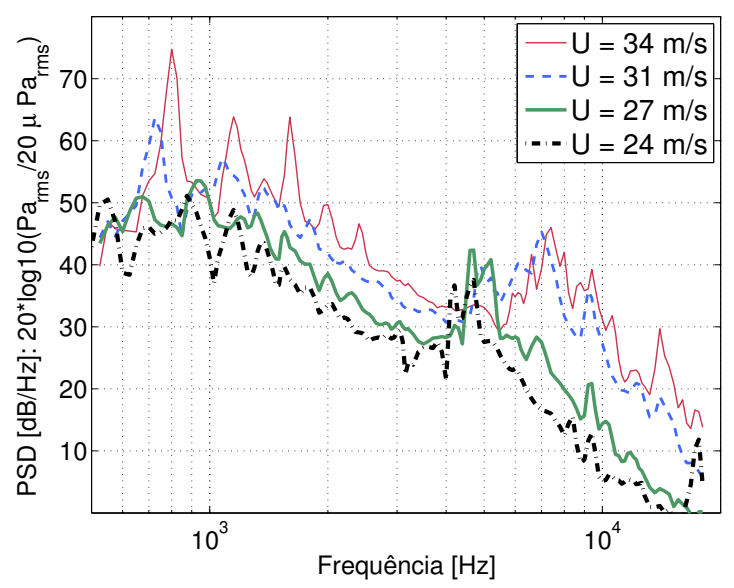

(a) PSD x Frequência

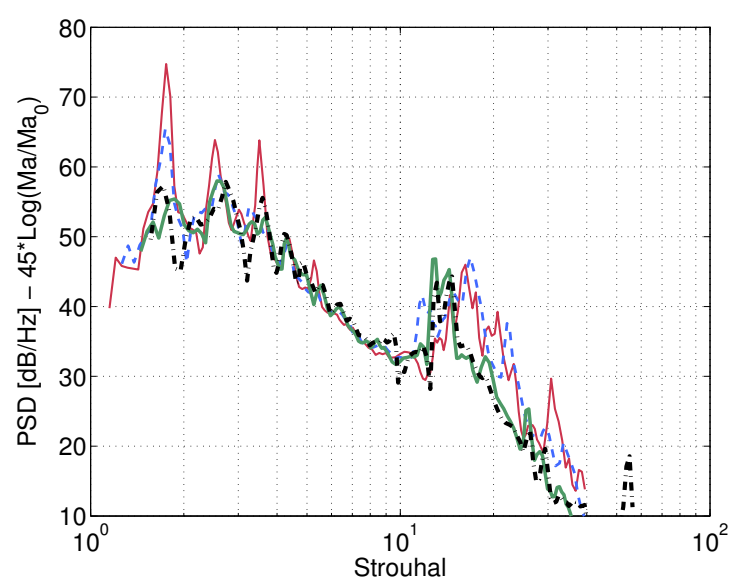

(b) PSD reescalada $\left(p^{2} \sim M a^{(4,5)}\right) \times$ Strouhal

Figura 7.2: Espectros de ruído do eslate para $\alpha=0^{\circ}$ e $U_{\infty}=24,27,31$ e $34 \mathrm{~m} / \mathrm{s}$.

Os espectros de ruído do eslate apresentados nas Figs. de 7.2 até 7.7, para vários ângulos de ataque e velocidades de escoamento livre, mostram a dominância de picos tonais para Strouhal aproximadamente entre 1 e 5 . Os picos tonais estão aparentemente sobrepostos a um ruído de banda-larga de grande amplitude, com pico em torno de St = 2,5. Também é evidente que as amplitudes do ruído de baixa frequência e dos picos tonais aumentam com a velocidade de escoamento livre e com a redução do ângulo de incidência do aerofólio na faixa de valores considerada, $0^{\circ} \leq \alpha \leq 10^{\circ}$. Não obstante, o ruído tonal de baixa frequência foi observado para todos os ângulos de ataque e velocidades de escoamento avaliados, sugerindo ser este um fenômeno robusto para o perfil hiper-sustentador 30P30N em sua configuração geométrica de referência, dentro das condições experimentais avaliadas. O ruído de banda larga, sem a sobreposição de picos tonais de grande amplitude, ocorre na região de média frequência, aproximadamente para $5<\mathrm{St}<10$, e também mostra uma tendência de crescimento com o aumento na velocidade de escoamento livre. O ruído tonal de mais alta frequência domina o espectro acústico na região $11<$ St $<12$.

Os melhores colapsos verticais são observados para o ruído de banda larga, quando são usados $n=4$ ou 4.5, particularmente com o aerofólio em baixo ângulo de incidência. Conforme sugerido por Dobrzynski e Pott-Pollenske (2001), Pott-Pollenske, Alvarez e Dobrzynski (2003), a dependência do colapso vertical com o ângulo de incidência do aerofólio pode estar relacionada ao escoamento na região de recirculação da cova do eslate e à velocidade de escoamento através do gap do eslate. Notadamente, a região $10<$ St $<11$ representa a pior qualidade de colapso das curvas devido à ausência de fontes aerodinâmicas, o que tem sido constatado pela análise de mapas de beam-forming. 


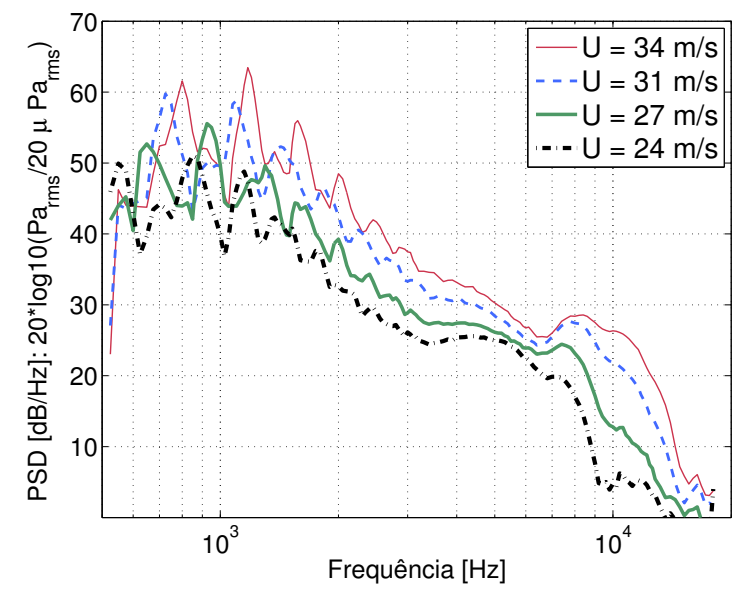

(a) PSD x Frequência

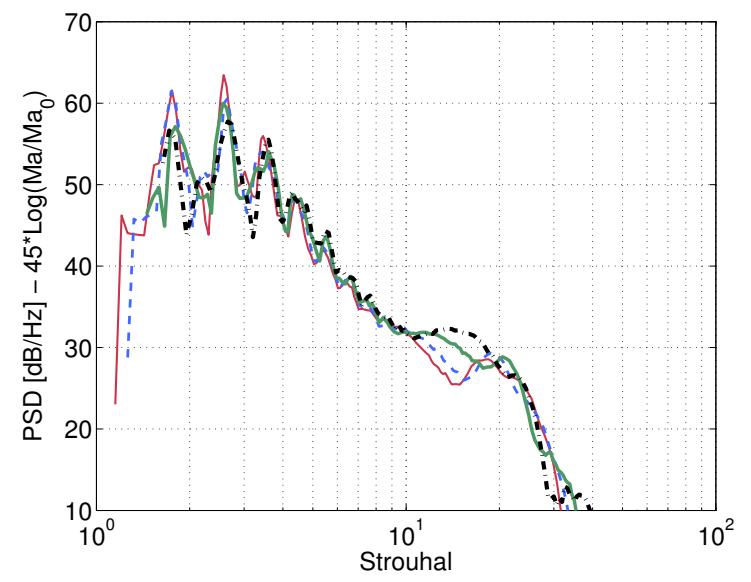

(c) PSD reescalada $\left(p^{2} \sim M a^{(4,5)}\right)$ x Strouhal

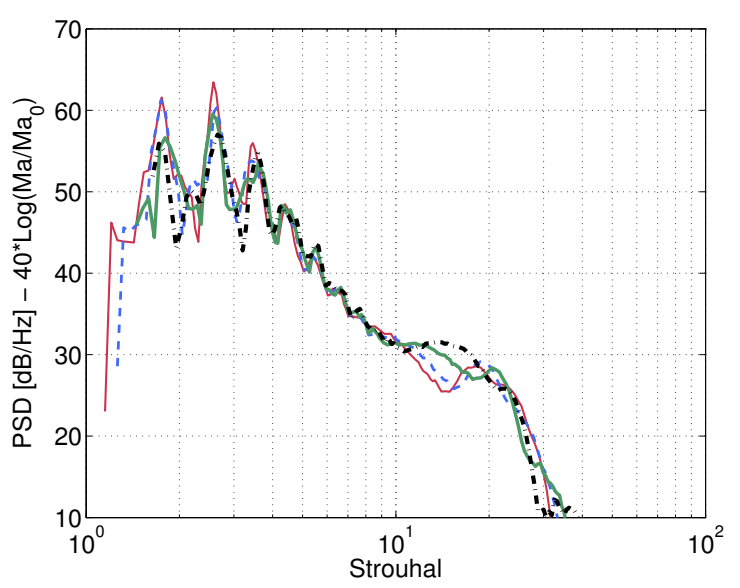

(b) PSD reescalada $\left(p^{2} \sim M a^{(4)}\right) \times$ Strouhal

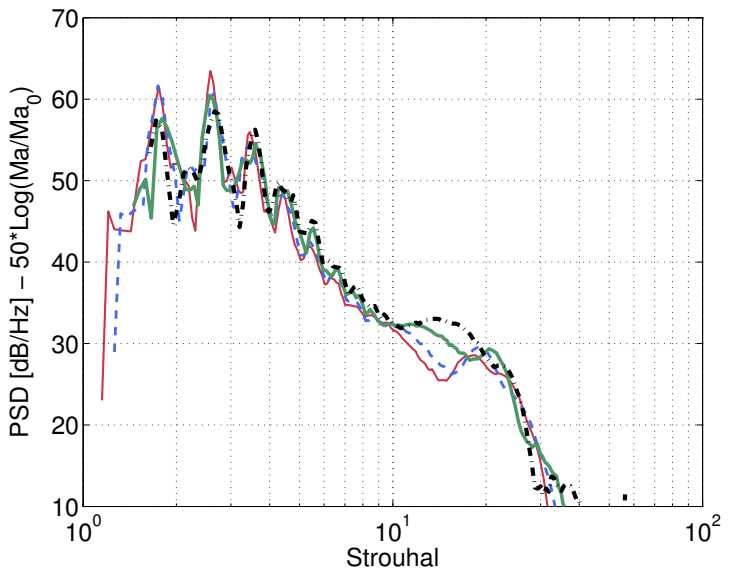

(d) PSD reescalada $\left(p^{2} \sim M a^{(5)}\right) \times$ Strouhal

Figura 7.3: Espectros de ruído do eslate para $\alpha=2^{\circ}$ e $U_{\infty}=24,27,31$ e $34 \mathrm{~m} / \mathrm{s}$.

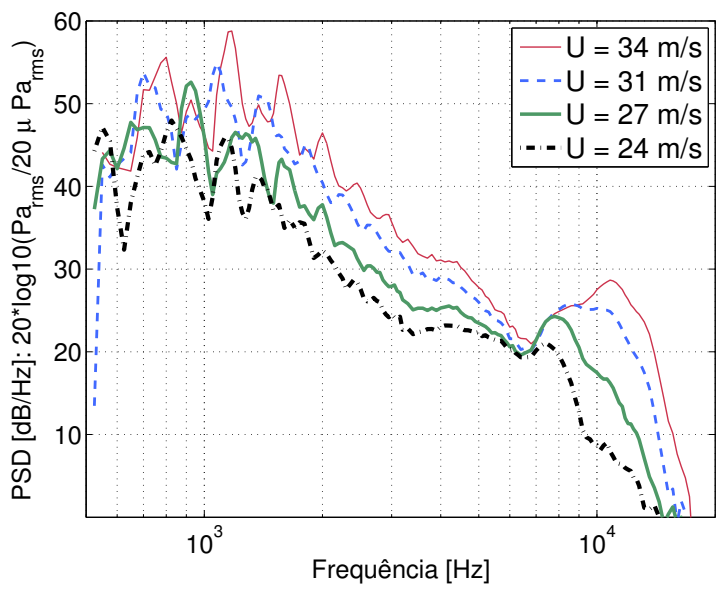

(a) PSD x Frequência

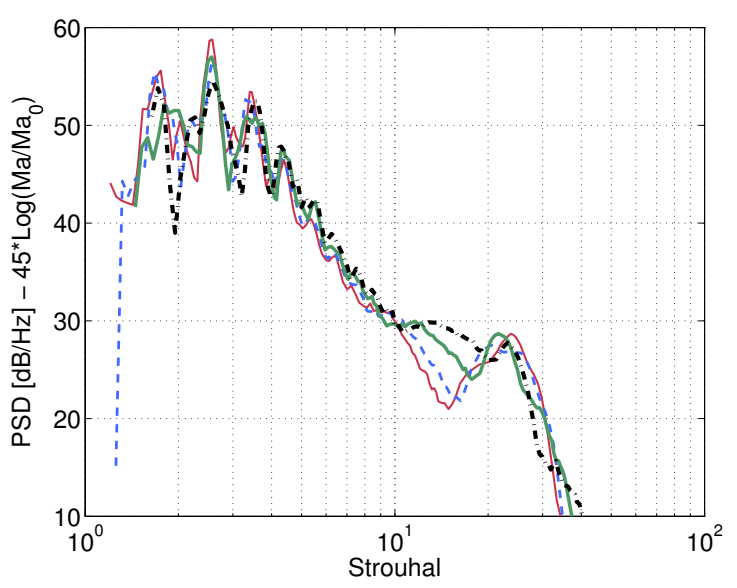

(b) PSD reescalada $\left(p^{2} \sim M a^{(4,5)}\right) \times$ Strouhal

Figura 7.4: Espectros de ruído do eslate para $\alpha=4^{\circ}$ e $U_{\infty}=24,27,31$ e $34 \mathrm{~m} / \mathrm{s}$.

Verifica-se um bom colapso dos picos tonais de baixa frequência e do ruído de alta 


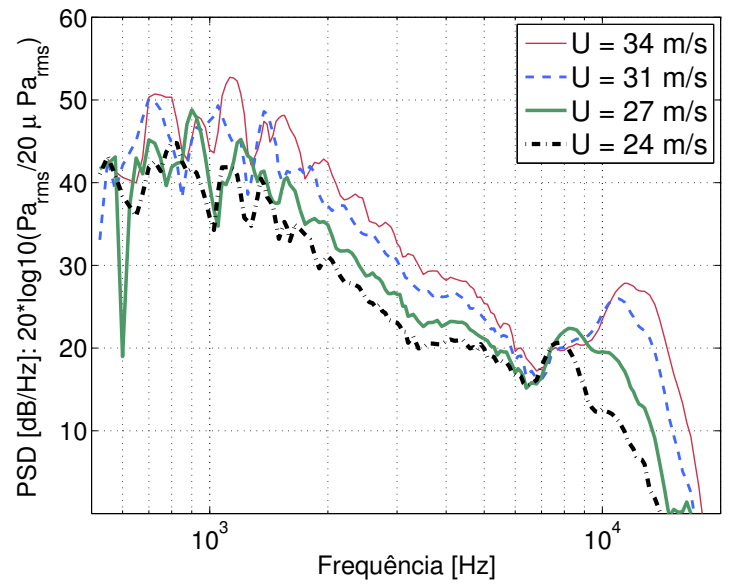

(a) PSD x Frequência

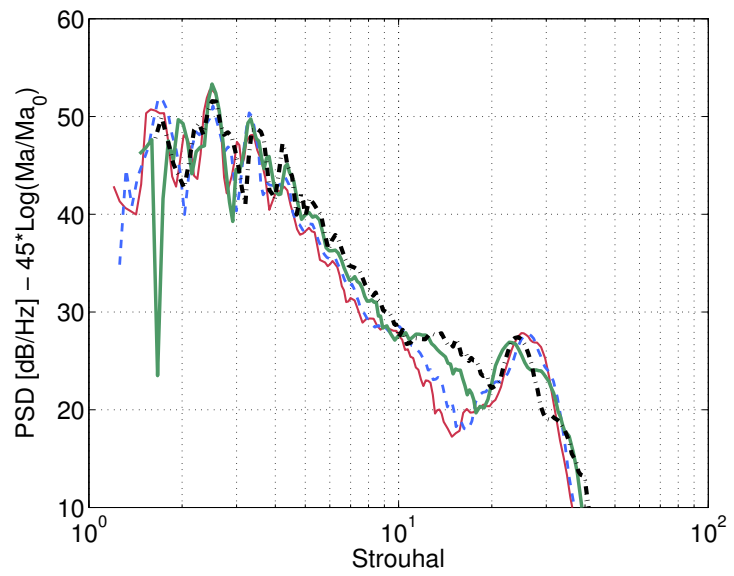

(c) PSD reescalada $\left(p^{2} \sim M a^{(4,5)}\right)$ x Strouhal

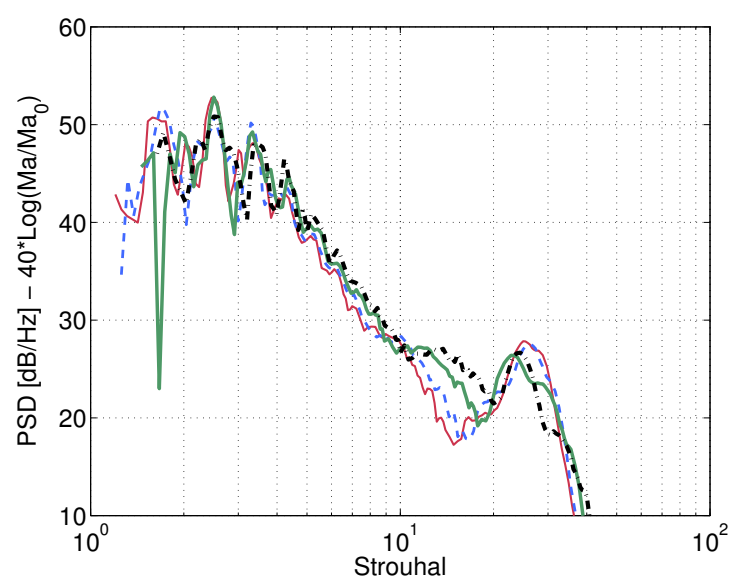

(b) PSD reescalada $\left(p^{2} \sim M a^{(4)}\right) \times$ Strouhal

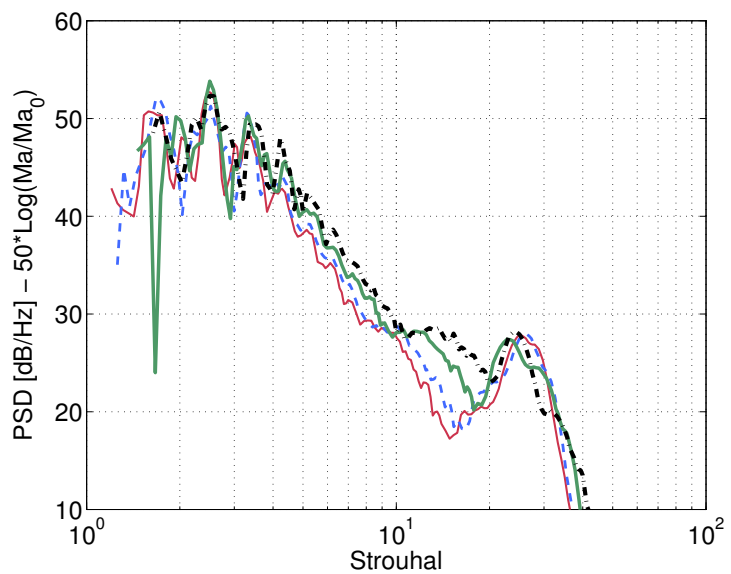

(d) PSD reescalada $\left(p^{2} \sim M a^{(5)}\right) \times$ Strouhal

Figura 7.5: Espectros de ruído do eslate para $\alpha=6^{\circ}$ e $U_{\infty}=24,27,31$ e $34 \mathrm{~m} / \mathrm{s}$.

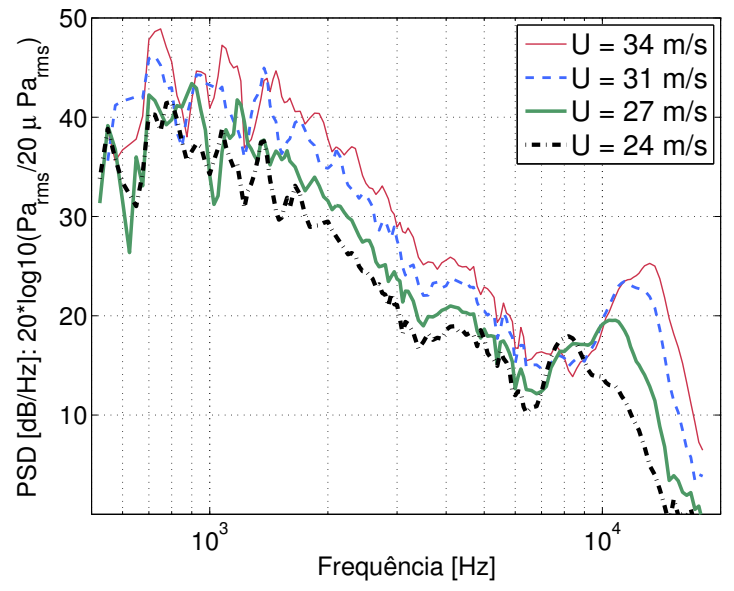

(a) PSD x Frequência

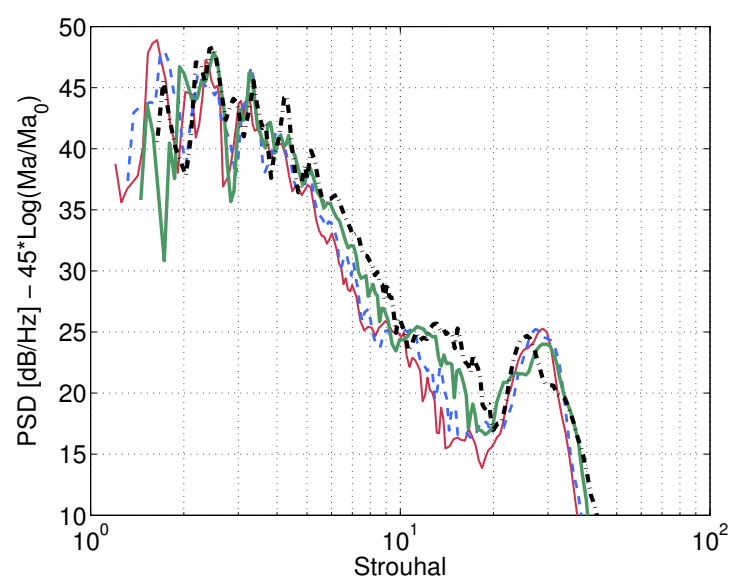

(b) PSD reescalada $\left(p^{2} \sim M a^{(4,5)}\right) \times$ Strouhal

Figura 7.6: Espectros de ruído do eslate para $\alpha=8^{\circ}$ e $U_{\infty}=24,27,31$ e $34 \mathrm{~m} / \mathrm{s}$.

frequência quando a frequência é adimensionalizada pelo número de Strouhal baseado no 


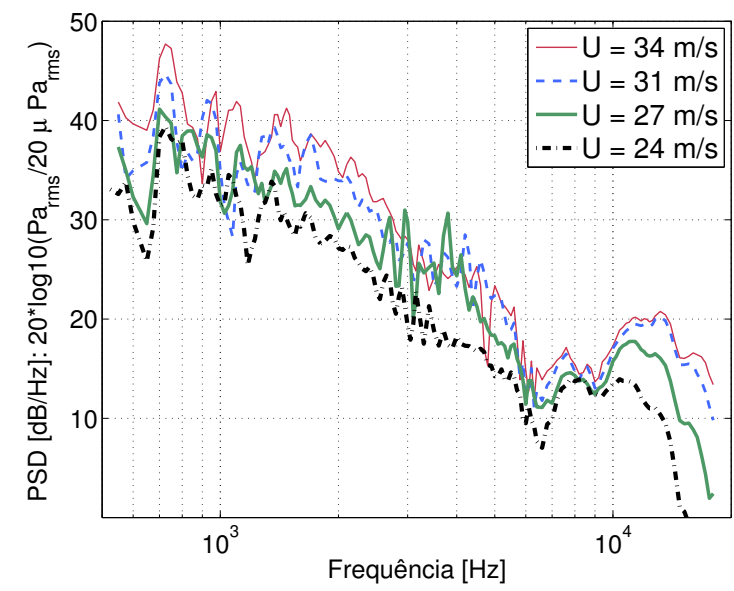

(a) PSD x Frequência

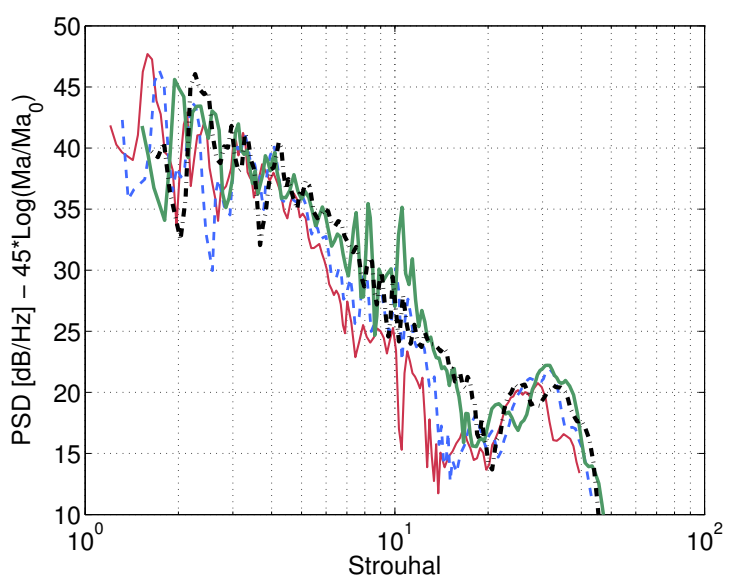

(b) PSD reescalada $\left(p^{2} \sim M a^{(4,5)}\right)$ x Strouhal

Figura 7.7: Espectros de ruído do eslate para $\alpha=10^{\circ}$ e $U_{\infty}=24,27,31$ e $34 \mathrm{~m} / \mathrm{s}$.

corda do eslate. Este resultado representa um indicativo de que a geração do ruído tonal é influenciada pelo escoamento na cova do eslate. De forma geral, o colapso das curvas em Strouhal parece ser menos dependente de variações no ângulo de incidência do aerofólio, quando comparado ao colapso vertical.

Para o caso $\alpha=0^{\circ}$, observa-se a ocorrência de picos tonais de maior amplitude em baixas frequências, particularmente para a velocidade de escoamento de $34 \mathrm{~m} / \mathrm{s}$. Também observa-se a ocorrência de ruído tonal para $10<\mathrm{St}<13$. Este fenômeno é particular para o caso $\alpha=0^{\circ}$ e aparentemente não corresponde a nenhum dos componentes de ruído documentos neste trabalho. Sua origem e natureza exigem investigações mais detalhadas.

\subsection{Variação do Ruído de Eslate Com o Ângulo de Ataque do Aerofólio}

As Figs. 7.8 e 7.9 mostram resultados que permitem avaliar a dependência do ruído do eslate em relação ao ângulo de ataque do aerofólio. Os resultados correspondem às velocidades de escoamento de 27 e $34 \mathrm{~m} / \mathrm{s}$, considerando o aerofólio em ângulos de incidência de $2^{\circ}, 4^{\circ}, 6^{\circ}, 8^{\circ}$ e $10^{\circ}$. A Fig. 7.10 mostra o perfil hiper-sustentador $30 \mathrm{P} 30 \mathrm{~N}$ posicionado para medições aeroacústicas na câmara de ensaios do túnel de vento LAE-1, em ângulos de ataque de $2^{\circ}$ e $10^{\circ}$.

Os resultados apresentados nas Figs. 7.8 e 7.9 mostram que as amplitudes do ruído de baixa frequência e dos picos tonais decrescem com o aumento do ângulo de ataque do aerofólio. Em baixos ângulos de incidência, os picos tonais são mais "agudos", com melhor definição da frequência de pico. A tendência de redução do nível de ruído com o aumento do ângulo de incidência do aerofólio também é observada para o ruído de 


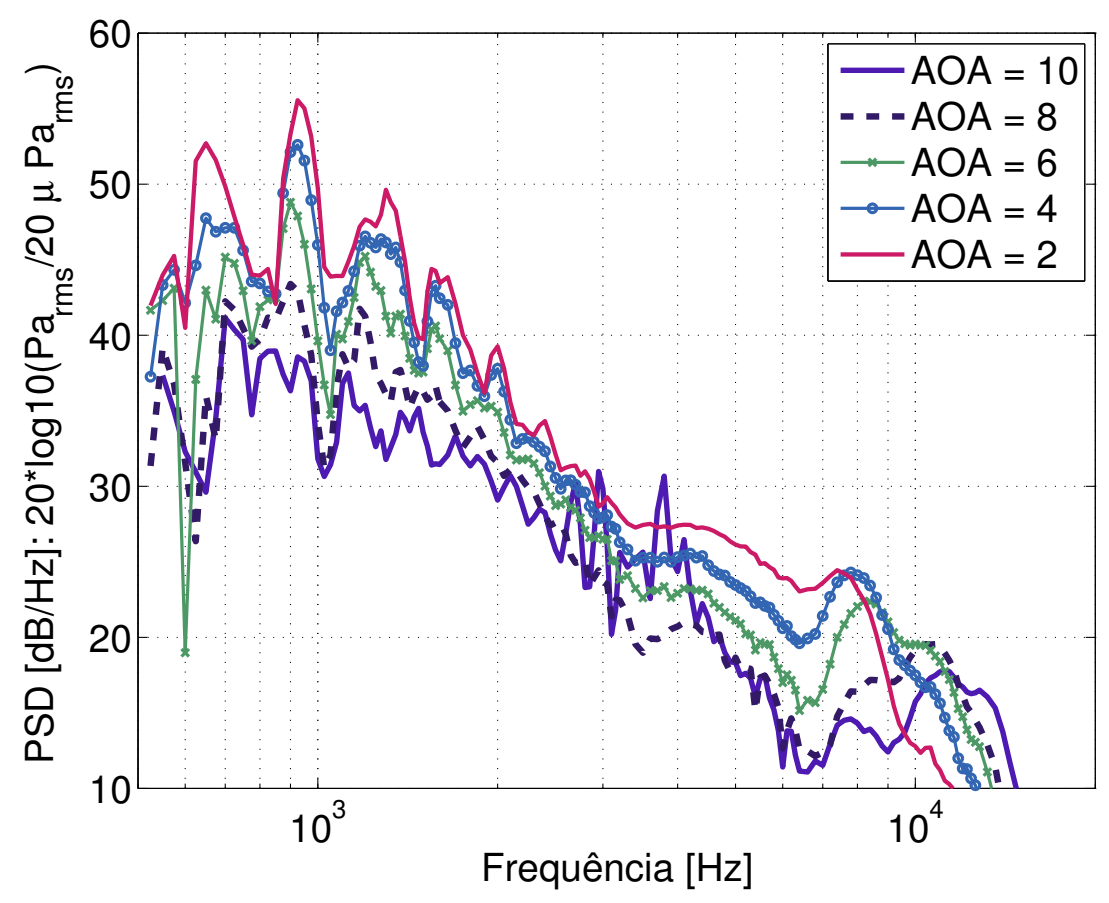

Figura 7.8: Espectros de ruído do eslate para $\alpha=2^{\circ}, \alpha=4^{\circ}, \alpha=6^{\circ}, \alpha=8^{\circ}$, e $\alpha=10^{\circ}$ e $U_{\infty}=27 \mathrm{~m} / \mathrm{s}$.

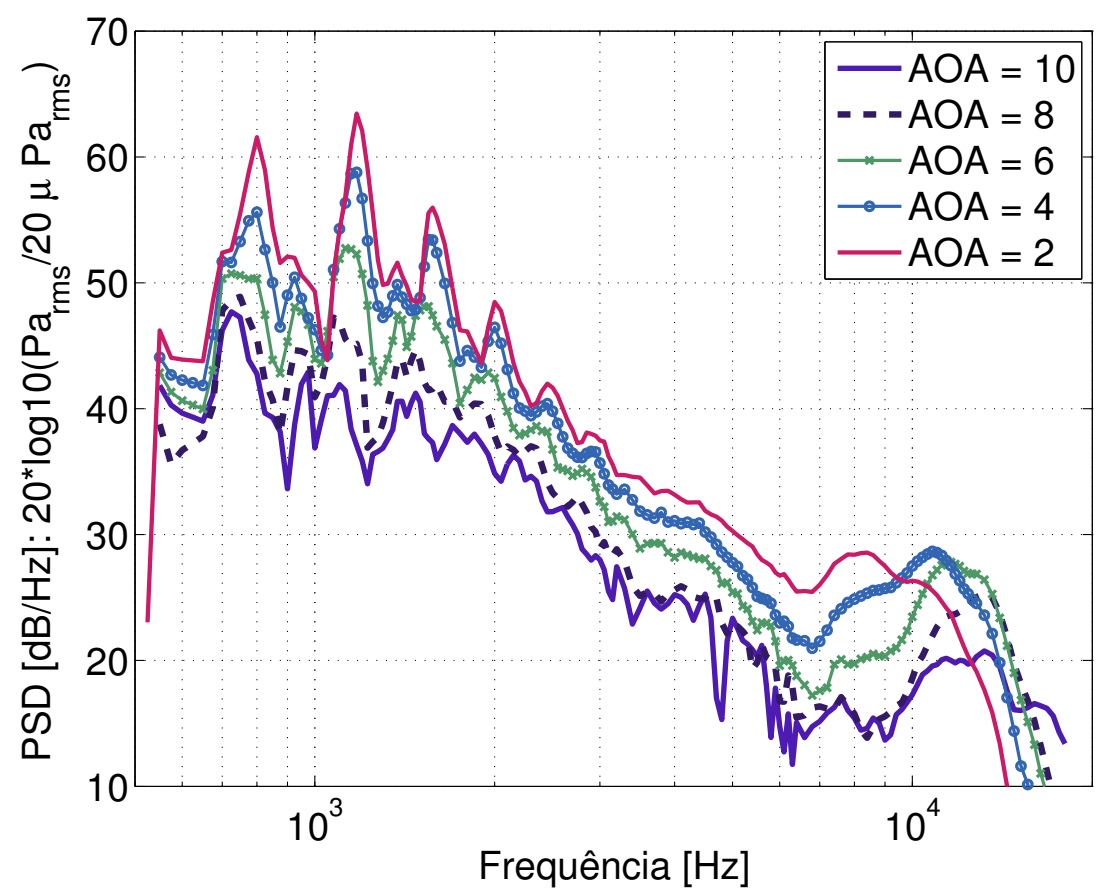

Figura 7.9: Espectros de ruído do eslate para $\alpha=2^{\circ}, \alpha=4^{\circ}, \alpha=6^{\circ}, \alpha=8^{\circ}$, e $\alpha=10^{\circ}$ e $U_{\infty}=34 \mathrm{~m} / \mathrm{s}$.

banda larga em frequências intermediárias. As frequências de ocorrência dos picos tonais de grande amplitude apresentam uma tendência discreta de redução com o aumento do ângulo de ataque do aerofólio. Por outro lado, o pico do ruído tonal de alta frequência 


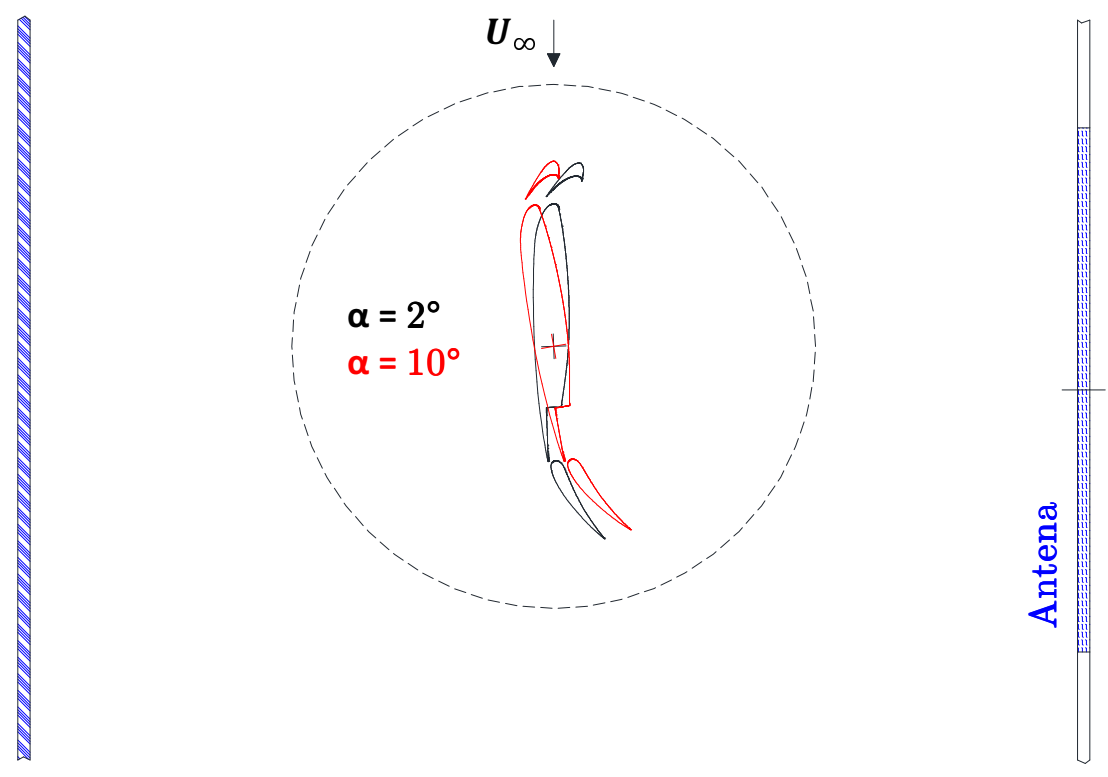

Figura 7.10: Representação da posição do aerofólio, com elemento principal, flape e eslate, em relação à antena de microfones para ângulos de ataque de $2^{\circ}$ e $10^{\circ}$.

desloca-se para frequências mais altas com o aumento no ângulo de ataque do aerofólio. Este resultado será discutido em maiores detalhes no apêndice A.

\subsection{Imagem Acústica das Fontes de Ruído do Eslate - Mapas de Beam-forming}

Esta seção tem por objetivo apresentar o padrão de distribuição de fontes associadas ao ruído típico do eslate em diferentes bandas de frequência. Os mapas de beam-forming são obtidos pela aplicação do algoritmo de deconvolução DAMAS. Todos os resultados apresentados decorrem do processamento do ruído do eslate com o aerofólio em sua configuração de referência.

As medições aeroacústicas, cujos resultados são apresentados nesta seção, foram realizadas após a instalação parcial de placas de espuma, com 2,5 cm de espessura, nas paredes da câmara de ensaios. O procedimento para instalação das espumas na câmara de ensaios foi feito na etapa final da campanha de medições realizada em 2013, como proposta para um experimento exploratório para avaliar o efeito do tratamento acústico de paredes rígidas sobre as medições do ruído do eslate.

A instalação de espumas na câmara de ensaios de um túnel de vento de seção fechada tem por objetivo reduzir efeitos de reverberação, ou seja, eliminar parcialmente a reflexão de ondas acústicas que atingem a antena de microfones. Ondas de pressão refletidas em paredes rígidas atingem a antena de microfones e são representadas em mapas de 
beam-forming na forma de fontes imagem correlacionadas com a fonte física de origem (OERLEMANS; SIJTSMA, 2002). O efeito de reverberação sobre medições acústicas é particularmente significativo quando o método de processamento utilizado não apresenta resolução de fontes suficiente para separar as fontes físicas de suas fontes imagem. No pior cenário, a distribuição de fontes no mapa de beam-forming resulta da superposição entre os lóbulos de fontes reais e fontes imagens, o que distorce a representação das fontes e torna imprecisa a quantificação das fontes por integração. Em baixa frequência as fontes apresentam lóbulos principais mais largos, o que torna a questão da reverberação particularmente crítica na região das extremidades do aerofólio, devido à reflexão das superfícies rígidas de apoio.

Esta seção não tem por objetivo se aprofundar na discussão acerca dos efeitos de reverberação acústica sobre medição e processamento do ruído. Maiores detalhes sobre o assunto podem ser encontrados em (SIJTSMA; HOLTHUSEN, 2003; FLEURY; DAVY, 2012). Não obstante, a comparação entre casos experimentais que se diferenciam apenas pela instalação de espumas na câmara de ensaios mostrou o benefício inegável do tratamento acústico para obtenção de uma distribuição de fontes mais uniforme ao longo do eslate.

A Fig. 7.11 mostra o arranjo das placas de espuma instaladas no entorno do modelo de testes posicionado na câmara de ensaios do túnel de vento LAE-1. Foram instaladas placas de espuma sobre as paredes horizontais e a parede vertical oposta ao plano da antena. A montagem permite variações no ângulo de ataque do modelo e a aplicação do mecanismo de sucção da camada limite da parede. As velocidades de escoamento livre medidas com o tubo de Pitot estático foram corrigidas de forma a levar em consideração a redução da área efetiva de escoamento após a instalação das placas de espuma.

As Figs. 7.12(a) e 7.12(b) comparam mapas de beam-forming para a condição $\alpha=2^{\circ}$ e $U_{\infty}=34 \mathrm{~m} / \mathrm{s}$, antes e após a instalação de espumas na câmara de ensaios. A Fig. 7.12(c) compara espectros de ruído medidos antes e após a instalação das espumas. As medições foram realizadas com controle da camada limite por meio de sucção, em conformidade com as demais medições de ruído de eslate analisadas nesta tese. Os resultados apresentados na Fig. 7.12 são representativos da comparação de mapas de beam-forming e espectros de ruído do eslate, obtidos antes e após a instalação de espumas, para vários ângulos de incidência e velocidades de escoamento.

A comparação entre as Fig. 7.12(a) e 7.12(b) mostra que a instalação das espumas de absorção acústica resultou na redução do pico de ruído (de $34 \mathrm{~dB}$ para $33 \mathrm{~dB}$ ), bem como em uma distribuição de fontes mais uniforme ao longo da envergadura do eslate. A Fig. 7.12(c) mostra que a instalação da espuma não alterou o espectro de ruído do eslate. Desta forma, os resultados obtidos após a instalação de espumas representam, 

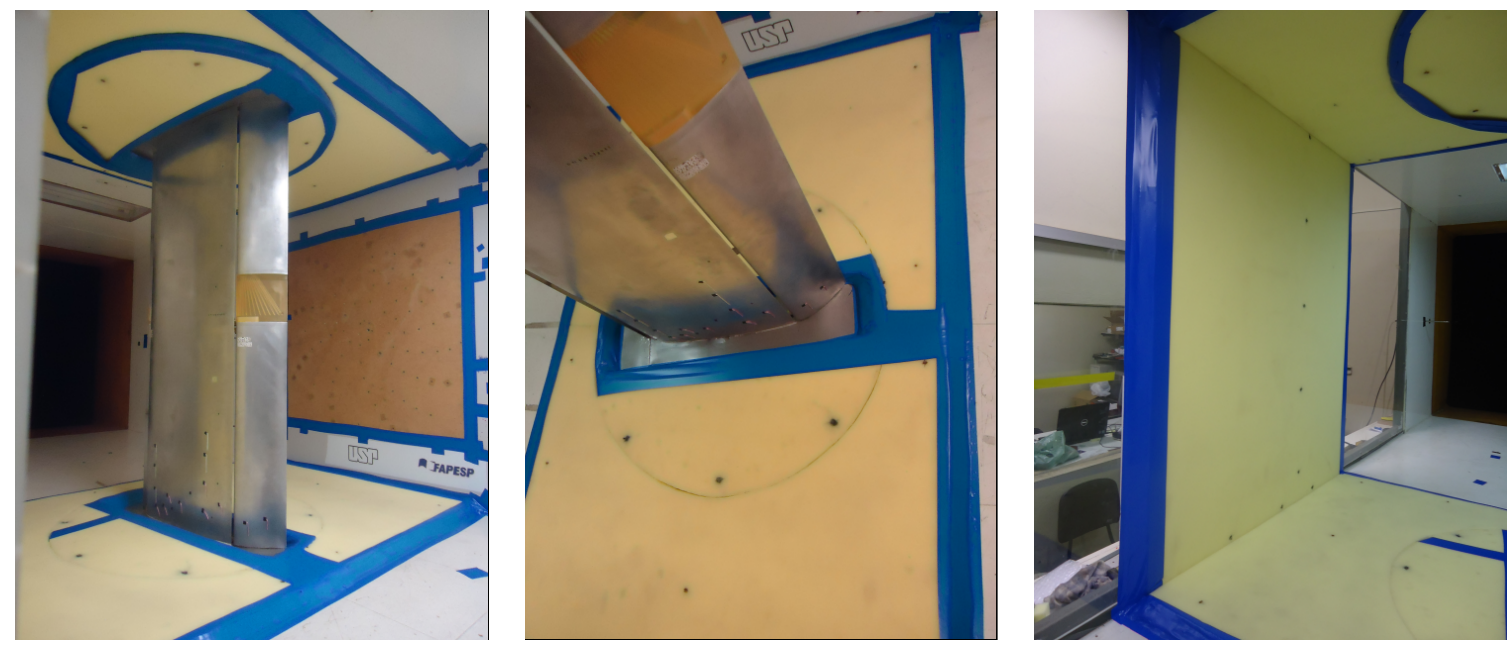

Figura 7.11: Representação da câmara de ensaios após a instalação de placas de espuma no entorno do perfil hiper-sustentador 30P30N. Da esquerda para a direita, as paredes horizontais inferior e superior, a região exposta para a sucção da camada limite e a parede oposta ao plano da antena de microfones.

quantitativamente, os resultados obtidos sem a instalação de espumas, porém associados a uma melhor representação de fontes em linha.

As Figs. 7.13 e 7.14 apresentam mapas de beam-forming representando distribuições de fontes associadas com o ruído do eslate em diferentes bandas de frequência. Os resultados representam medições acústicas para $\alpha=2^{\circ}$ e $\alpha=6^{\circ}, \operatorname{com} U_{\infty}=34 \mathrm{~m} / \mathrm{s}$.

Os mapas de fontes para as frequências de $775 \mathrm{~Hz}, 1000 \mathrm{~Hz}$ e $1150 \mathrm{~Hz}$ mostram-se irregularmente distribuídos ao longo da envergadura do eslate, sugerindo um padrão de distribuição de fontes 3D. Nas frequências de $775 \mathrm{~Hz}$ e $1150 \mathrm{~Hz}$ ocorrem fontes associadas com picos de ruído tonal, enquanto que para a frequência de $1000 \mathrm{~Hz}$ ocorre um vale entre os dois picos de maior amplitude. Neste domínio, torna-se difícil identificar um padrão para a distribuição de fontes em função da frequência, ou do ângulo de incidência do aerofólio. A incerteza na determinação das fontes torna difícil a identificação de regiões nas quais atuam os mecanismos de geração do ruído tonal de baixa frequência. Não obstante, mais estudos são necessários para avaliar as limitações das técnicas de processamento ora utilizadas para o mapeamento de fontes do eslate em baixas frequências.

Os mapas de fontes para as frequências de $1525 \mathrm{~Hz}, 2000 \mathrm{~Hz}$ e $3400 \mathrm{~Hz}$ representam regiões de transição entre o ruído de baixa frequência e o ruído puro de banda larga, que já está bem caracterizado em $3400 \mathrm{~Hz}$. Para estas frequências, é possível observar que as distribuições de fontes sobre o eslate apresentam tendência para um padrão de fontes em linha. Nas frequências de $4400 \mathrm{~Hz}$ e $4700 \mathrm{~Hz}$, o ruído de banda larga é bem caracterizado por um distribuição de fontes em linha, praticamente contínua ao longo da envergadura do eslate. Esta distribuição de fontes $2 \mathrm{D}$ é melhor caracterizada para a configuração $\alpha=2^{\circ}$. 


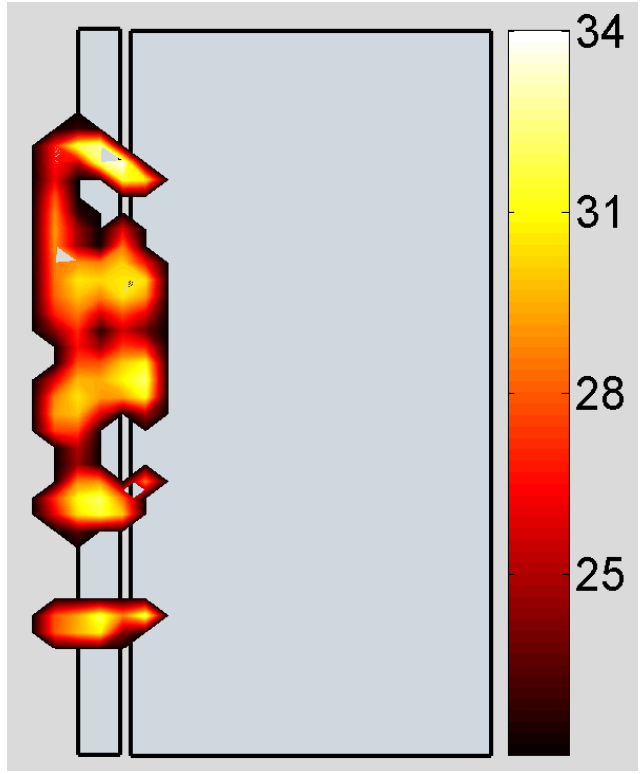

(a) Mapa de fontes sem espuma $(2050 \mathrm{~Hz})$

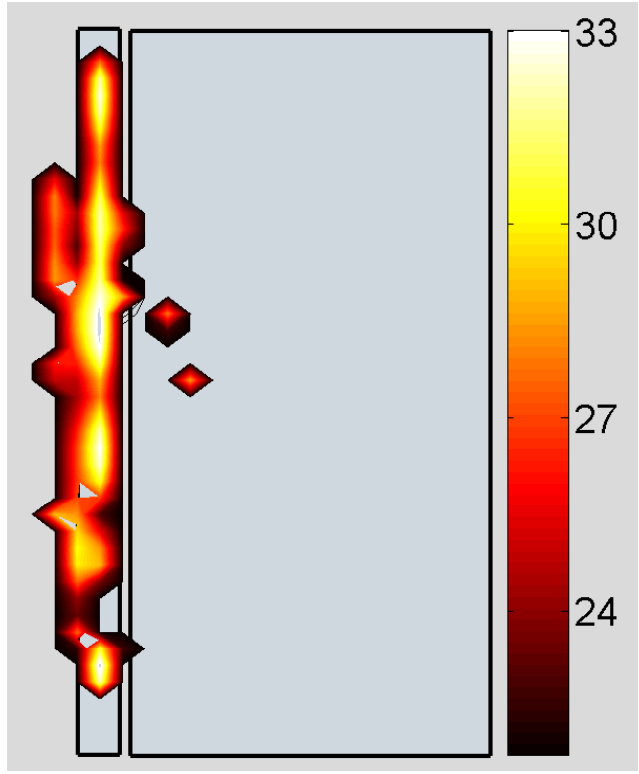

(b) Mapa de fontes com espuma $(2050 \mathrm{~Hz})$

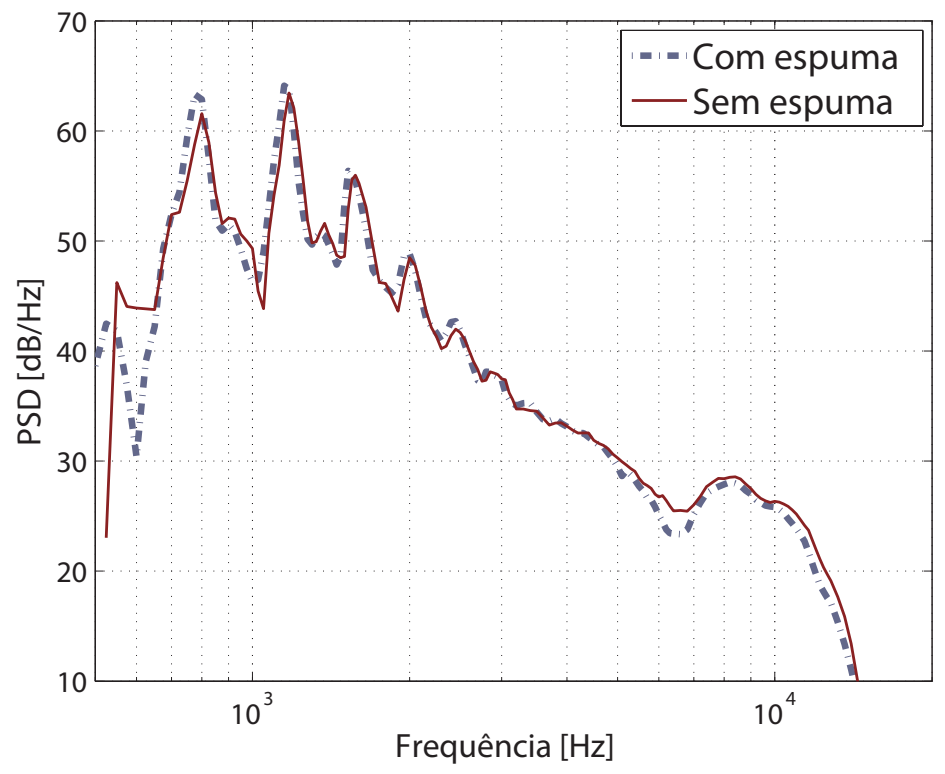

(c)

Figura 7.12: Representação do efeito da instalação de espumas para absorção acústica na câmara de ensaios do túnel de vento LAE-1, sobre a caracterização da distribuição de fontes e espectros de ruído do eslate.

Nas frequências de $8.4 \mathrm{kHz}\left(\alpha=2^{\circ}\right)$ e $11.6 \mathrm{kHz}\left(\alpha=6^{\circ}\right)$ também ocorrem distribuições de fontes bem definidas ao longo da envergadura do eslate. Estas frequências representam aproximadamente o pico de amplitude do ruído de alta frequência. No entanto, nota-se que estas distribuições de fontes encontram-se melhor alinhadas com o bordo de fuga do aerofólio.

De forma geral, pode-se concluir que o algoritmo DAMAS consegue representar corretamente as distribuições de fontes associadas ao ruído aerodinâmico do eslate em médias 


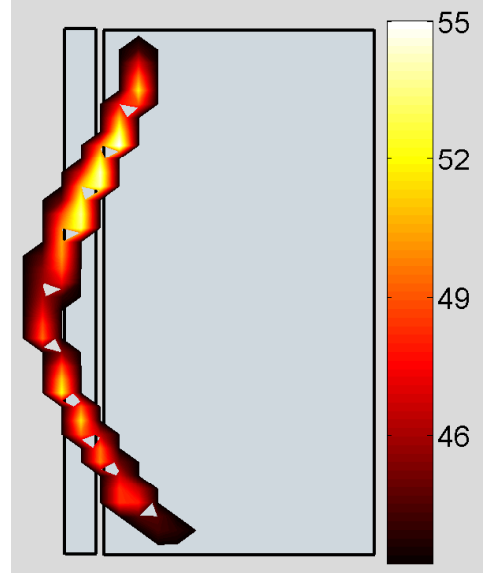

(a) $775 \mathrm{~Hz}$

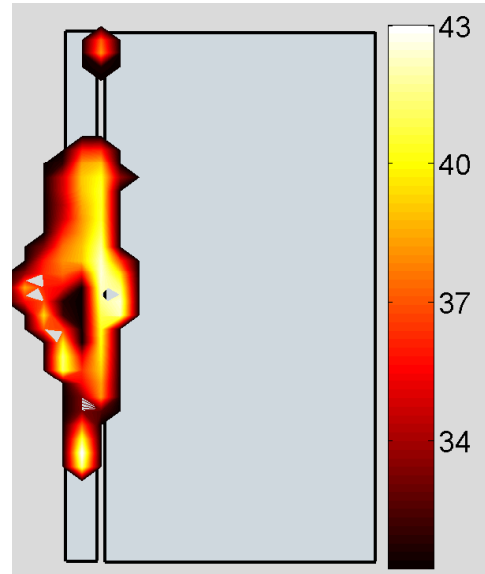

(d) $1525 \mathrm{~Hz}$

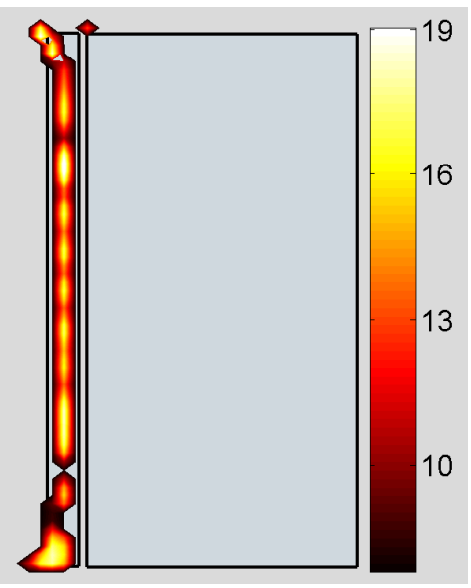

(g) $4400 \mathrm{~Hz}$

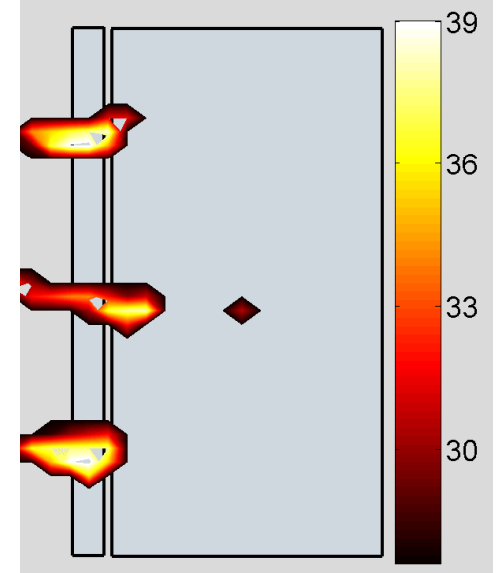

(b) $1000 \mathrm{~Hz}$

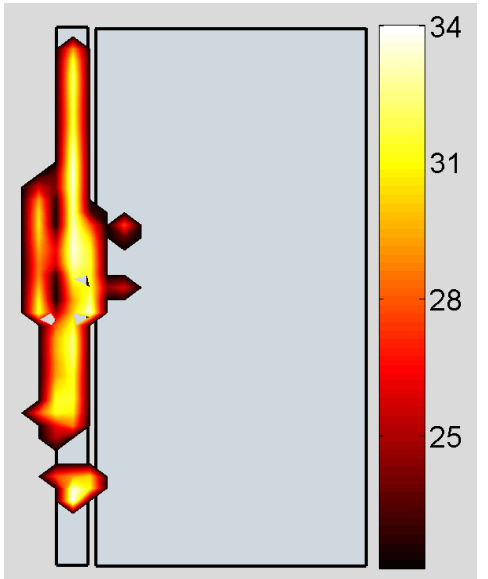

(e) $2000 \mathrm{~Hz}$

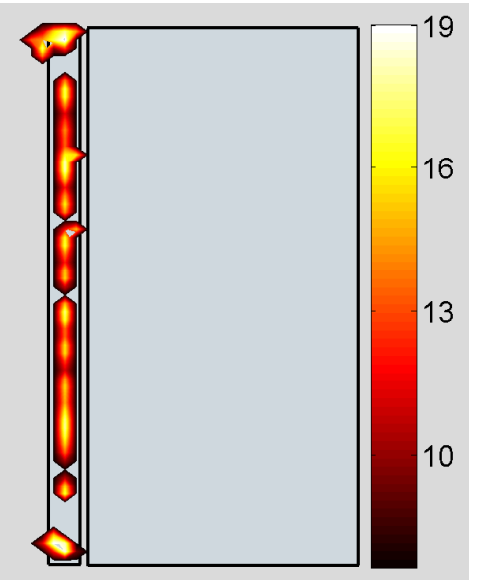

(h) $4700 \mathrm{~Hz}$

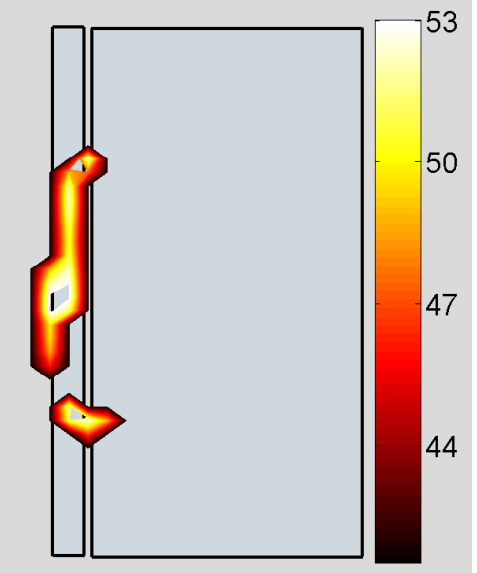

(c) $1150 \mathrm{~Hz}$

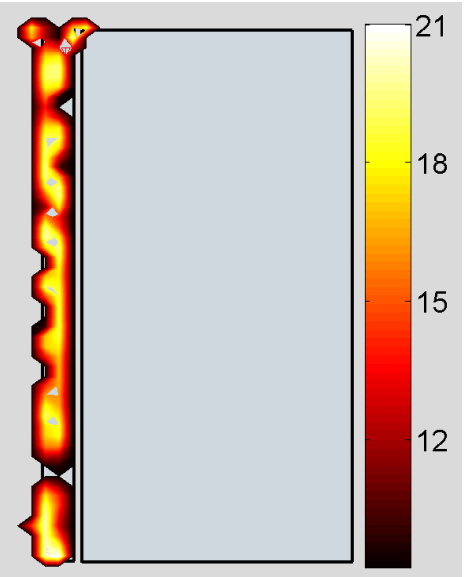

(f) $3400 \mathrm{~Hz}$

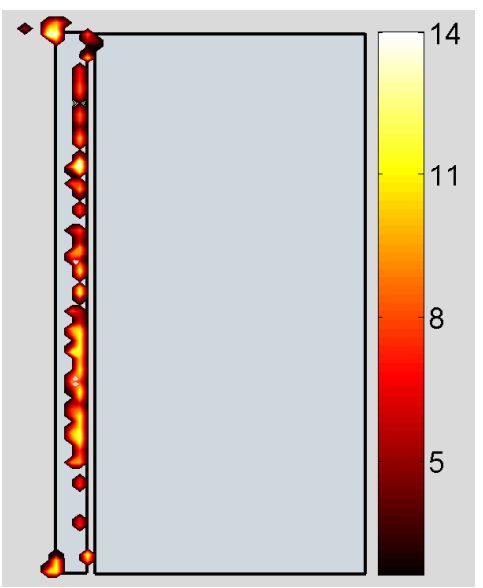

(i) $8400 \mathrm{~Hz}$

Figura 7.13: Mapas acústicos representando distribuições de fontes sobre o eslate com o aerofólio em ângulo de ataque de $2^{\circ}$ e velocidade de escoamento de $34 \mathrm{~m} / \mathrm{s}$.

de altas frequências. Estas fontes, quando mapeadas a partir de medições acústicas em condições de escoamento nominalmente bidimensionais (2D), mostram um padrão esperado, com distribuição relativamente uniforme e contínua ao longo da envergadura do 


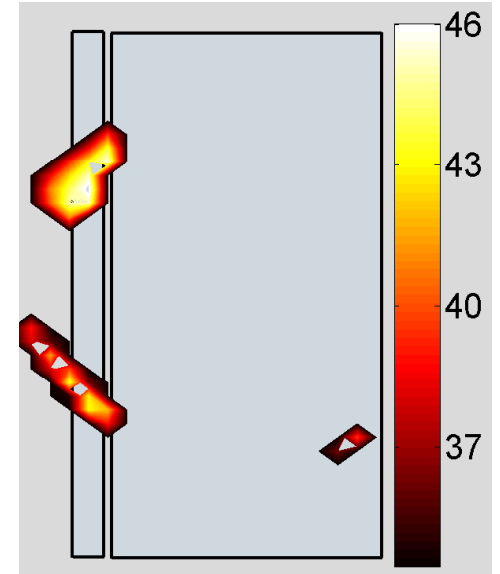

(a) $775 \mathrm{~Hz}$

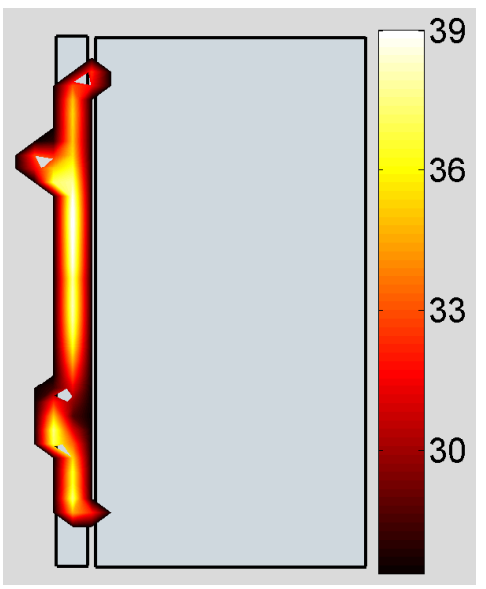

(d) $1525 \mathrm{~Hz}$

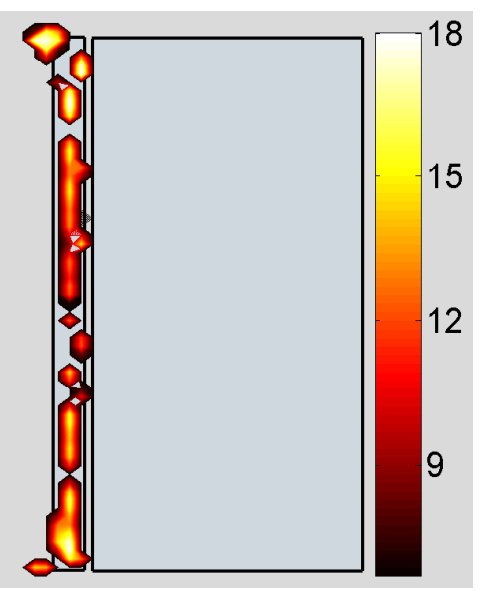

(g) $4400 \mathrm{~Hz}$

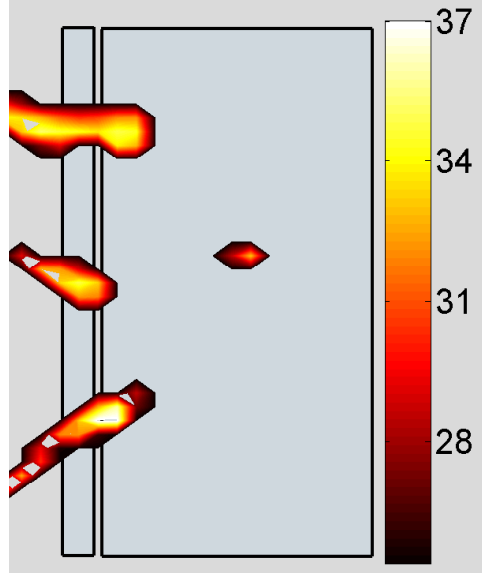

(b) $1000 \mathrm{~Hz}$

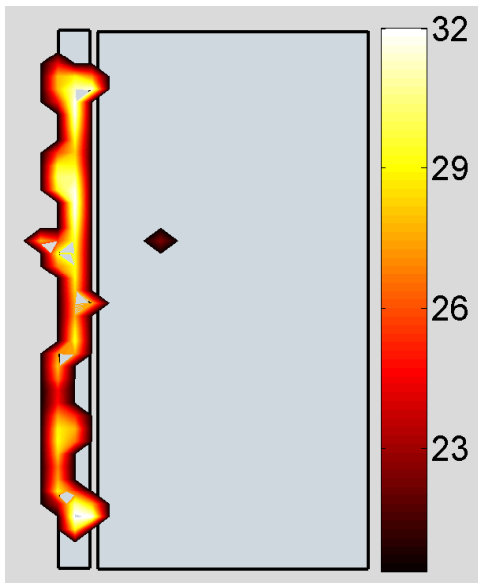

(e) $2000 \mathrm{~Hz}$

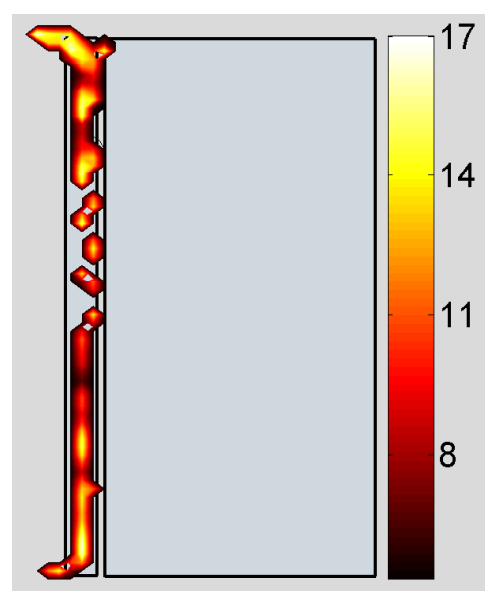

(h) $4700 \mathrm{~Hz}$

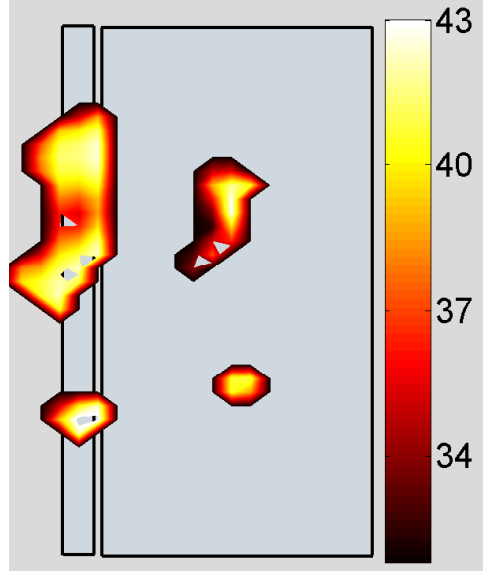

(c) $1150 \mathrm{~Hz}$

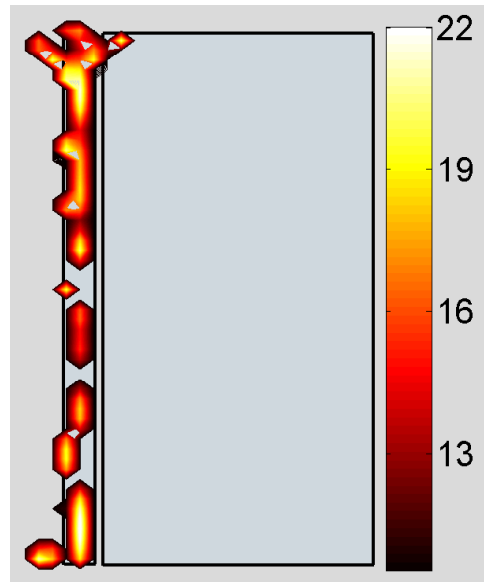

(f) $3400 \mathrm{~Hz}$

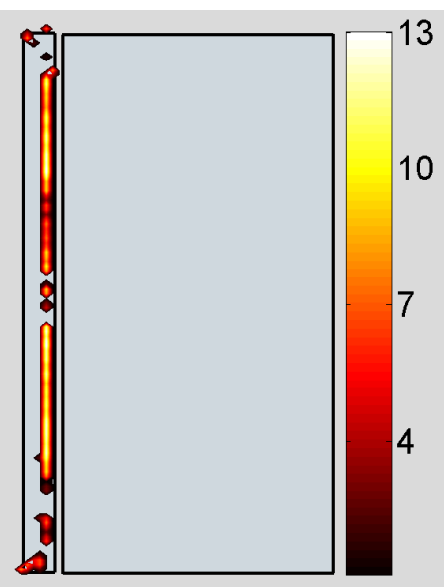

(i) $11600 \mathrm{~Hz}$

Figura 7.14: Mapas acústicos representando distribuições de fontes sobre o eslate com o aerofólio em ângulo de ataque de $6^{\circ}$ e velocidade de escoamento de $34 \mathrm{~m} / \mathrm{s}$.

eslate. Em baixas frequências, há uma boa confiabilidade no nível de pressão sonora estimado a partir da integração sobre o domínio das fontes mapeadas, na medida em que os resultados mostram-se convergentes na malha e independentes dos parâmetros de pro- 
cessamento. No entanto, há incertezas sobre a utilização do mapa de fontes como um indicativo sobre a localização dos potenciais mecanismos de geração do ruído em baixa frequência.

\subsection{Considerações Gerais sobre o Ruído Aerodinâ- mico do Eslate do Aerofólio 30P30N}

Os resultados apresentados neste capítulo evidenciam que o espectro acústico do eslate, determinado a partir de medições experimentais com o perfil hiper-sustentador 30P30N em escala, é determinado pelas seguintes características:

(1) Múltiplos picos tonais, que ocorrem para Strouhal variando aproximadamente entre 1 e 5, e aparentemente concorrem com ruído de banda larga com máximo de amplitude em aproximadamente $\mathrm{St}=2.5$. Este ruído tonal cresce em amplitude com o aumento da velocidade de escoamento livre e decresce com o aumento do ângulo de incidência do aerofólio no intervalo de $2^{\circ}$ até $10^{\circ}$. Os picos tonais para diferentes velocidades de escoamento livre colapsam em frequência adimensional, dada pelo número de Strouhal baseado na corda do eslate e na velocidade do escoamento, e mostram uma tendência de colapso vertical pela normalização dos níveis de ruído com o número de Mach elevado a uma potência entre 4 e 5 . As distribuições de fontes acústicas associadas aos picos tonais foram investigadas com o uso de mapas de beam-forming, que sugerem a ocorrência de fontes localizadas em regiões limitadas ao longo da envergadura do eslate, para as quais não se identificou um padrão evidente ao longo da frequência. No entanto, estudos adicionais são necessários, uma vez que estes resultados podem estar sendo influenciados por limitações inerentes à metodologia utilizada para o mapeamento de fontes em baixa frequência.

(2) Ruído de banda larga, que pôde ser estudado, sem sobreposição do ruído tonal, na faixa de Strouhal entre 5 e 10, aproximadamente. Nesta região, o ruído de banda larga apresenta um decaimento com o aumento da frequência que é típico de ruído de eslate Imamura et al. (2009), cresce em amplitude com o aumento da velocidade de escoamento livre e decresce com o aumento do ângulo de incidência do aerofólio. O ruído de banda larga mostra um excelente colapso em amplitude mediante a normalização dos espectros pelo número de Mach elevado a uma potência entre 4 e 5, particularmente para o valor 4 . No entanto, os melhores colapsos verticais ocorrem para configurações com o aerofólio em baixos ângulos de ataque. Para as frequências nas quais o espectro acústico do eslate é dominado por ruído de banda larga, os mapas de beam-forming mostram distribuições de fontes em linha ao longo da envergadura do eslate. 
(3) Ruído tonal de alta frequência, caracterizado pela ocorrência de um único tonal de banda larga e amplitude moderada, em Strouhal variando entre 11 e 13, aproximadamente. O ruído tonal de alta frequência cresce em amplitude com o aumento da velocidade de escoamento livre e desloca-se para frequências ligeiramente mais altas com o aumento no ângulo de incidência do aerofólio. Este componente de ruído apresenta um bom colapso vertical quando os espectros obtidos para diferentes velocidades de escoamento são normalizados pelo Mach do escoamento base elevado a uma potência entre 4 e 5 , bem como um colapso em frequência adimensional dada pelo número de Strouhal baseado na corda do eslate e na velocidade do escoamento. Para frequências em torno do valor de pico do ruído tonal, os mapas de beam-forming mostram uma distribuição de fontes em linha ocupando parte significativa da envergadura do eslate. No entanto, os mapas de beam-forming sugerem que as fontes estão deslocada em direção ao bordo de fuga do eslate, sugerindo uma provável emissão de ruído a partir do bordo de fuga.

De forma geral, os resultados apresentados indicam a natureza aerodinâmica do ruído do eslate e estabelecem uma dependência quantitativa do ruído em relação aos parâmetros experimentais $\alpha$ e $U_{\infty}$. De um ponto de vista descritivo, os componentes de ruído do eslate identificados neste estudo encontram-se documentados na literatura para modelos 2D e 3D em escala, veja por exemplo (IMAMURA et al., 2009; DOBRZYNSKI, 2010). As relações utilizadas para avaliar a dependência dos espectros de ruído em relação aos números de Mach e Strouhal mostram bons resultados e sugerem que os componentes de ruído aerodinâmico seguem o comportamento esperado para o ruído de eslate (DOBRZYNSKI; POTT-POLLENSKE, 2001; GUO; JOSHI, 2003). 


\section{CAPÍTULO 8}

\section{Efeitos de Configuração Geométrica Sobre o Ruído do Eslate}

\subsection{Introdução}

A configuração geométrica de um aerofólio hiper-sustentador, definida pelos parâmetros de gap, overlap e deflexão dos elementos flape e eslate, é uma condição determinante para o desempenho aerodinâmico de uma aeronave (DAM, 2002). A dependência do ruído gerado em relação à configuração geométrica do aerofólio é atualmente um tema de grande interesse em aeroacústica, mas muito pouco abordado.

Neste capítulo, apresentam-se resultados de comparações entre espectros de ruído para diferentes configurações geométricas do eslate no perfil hiper-sustentador 30P30N. A amplitude do ruído e as bandas de frequência nas quais ocorrem cada componente de ruído representam uma informação importante em projetos voltados à redução do ruído gerado por um perfil hiper-sustentador. A configuração geométrica ideal é aquela que concilia baixos níveis de emissão de ruído com alto desempenho aerodinâmico (sustentação/arrasto).

A tabela 8.1 mostra os casos experimentais testados neste estudo, que representam 10 configurações geométricas distintas. Para cada configuração, são consideradas medições para diferentes ângulos de incidência do aerofólio e velocidades de escoamento livre, totalizando 160 medições experimentais. Tal base de dados permite a comparação entre espectros de ruído com o aerofólio em diferentes configurações geométricas, bem como uma investigação sobre a dependência do ruído do eslate em relação à condição operacional do aerofólio ( $\alpha$ e Mach), para cada geometria em particular. 
Tabela 8.1: Representação das configurações experimentais consideradas neste estudo, com variações dos parâmetros de configuração geométrica do eslate; gap, $\left(g_{s}\right)$, overlap, $\left(o_{s}\right)$ e deflexão, $\left(\delta_{s}\right)$, mantendo-se o flape em configuração de referência.

\begin{tabular}{|c|c|c|c|c|c|c|c|}
\hline \multicolumn{6}{|c|}{ Geometria do Aerofólio } & \multicolumn{2}{|c|}{ Configuração Experimental } \\
\hline \multicolumn{3}{|c|}{ Eslate } & \multicolumn{3}{|c|}{ Flape (baseline) } & \multirow{2}{*}{$\alpha(\circ)$} & \multirow{2}{*}{$U_{\infty}(m / s)$} \\
\hline$\delta_{s}(\circ)$ & $g_{s}(\%)$ & $o_{S}(\%)$ & $\delta_{f}(\circ)$ & $g_{f}(\%)$ & $o_{f}(\%)$ & & \\
\hline 30 & 2,95 & $-2,50$ & 30 & 1,27 & 0,25 & $2 ; 4 ; 6 ; 8$ & $24,27,31,34$ \\
\hline 30 & 2,95 & 1,00 & 30 & 1,27 & 0,25 & $2 ; 4 ; 6 ; 8$ & 24,$27 ; 31,34$ \\
\hline 30 & 2,95 & $-1,60$ & 30 & 1,27 & 0,25 & $2 ; 4 ; 6 ; 8$ & $24,27,31,34$ \\
\hline 30 & 2,06 & $-1,60$ & 30 & 1,27 & 0,25 & $2 ; 4 ; 6 ; 8$ & $24,27,31,34$ \\
\hline 30 & 2,95 & $-2,95$ & 30 & 1,27 & 0,25 & $2 ; 4 ; 6 ; 8$ & $24,27,31,34$ \\
\hline 30 & 3,50 & $-1,60$ & 30 & 1,27 & 0,25 & $2 ; 4 ; 6 ; 8$ & $24,27,31,34$ \\
\hline 30 & 1,20 & 1,00 & 30 & 1,27 & 0,25 & $2 ; 4 ; 6 ; 8$ & $24,27,31,34$ \\
\hline 20 & 2,95 & $-1,60$ & 30 & 1,27 & 0,25 & $2 ; 4 ; 6 ; 8$ & $24,27,31,34$ \\
\hline 25 & 2,95 & $-1,60$ & 30 & 1,27 & 0,25 & $2 ; 4 ; 6 ; 8$ & $24,27,31,34$ \\
\hline 35 & 2,95 & $-1,60$ & 30 & 1,27 & 0,25 & $2 ; 4 ; 6 ; 8$ & $24,27,31,34$ \\
\hline
\end{tabular}

Na tabela 8.2 estão representadas as posições do eslate em relação ao bordo de ataque do elemento principal, para as diferentes configurações de gap e overlap apresentadas na tabela 8.1, com o eslate defletido em $30^{\circ}$. As posições do eslate para diferentes configurações de gap e overlap são representadas em relação à configuração de referência do eslate, $\operatorname{com} g_{s}=2,95 \%$ e $o_{s}=-2,50 \%$.

O conjunto de orientações do eslate em relação ao elemento principal representa as condições geométricas que determinam os regimes de escoamento no entorno do eslate. Um ponto a ser destacado é que a região sobre a superfície do eslate que emite som diretamente sobre a antena de microfones depende da configuração geométrica adotada. Conforme representado na Fig. 3.8, o centro da antena se encontra à jusante do bordo de fuga do eslate, recebendo energia acústica preferencialmente emitida a partir do intradorso do aerofólio. A maior variação na superfície de sobreposição do eslate ao elemento principal ocorre para os diferentes valores de overlap avaliados. Na configuração dada por $g_{s}=$ $2,95 \%$ e $o_{s}=-2,95 \%$, o eslate encontra-se em uma posição relativamente favorável para emissão acústica sobre a superfície da antena de microfones. No outro extremo, para $g_{s}=2,95 \%$ e $o_{s}=1 \%$, a parte superior do intradorso e o bordo de fuga do eslate encontramse sobrepostos ao bordo de ataque do elemento principal, condição que potencialmente influencia na propagação do ruído gerado pelo eslate e, consequentemente, na recepção do ruído pela antena. Desta forma, os resultados apresentados devem ser avaliados no contexto da posição do aerofólio em relação à antena de microfones. Dada a ausência de estudos prévios que indicassem a influência do elemento principal do aerofólio sobre a diretividade do ruído do eslate para diferentes configurações experimentais, nenhum fator de correções foi aplicado aos resultados apresentados neste capítulo. 
Tabela 8.2: Representação da posição física do eslate para cada configuração dos parâmetros de gap e overlap avaliada, com o eslate defletido em $30^{\circ}$.

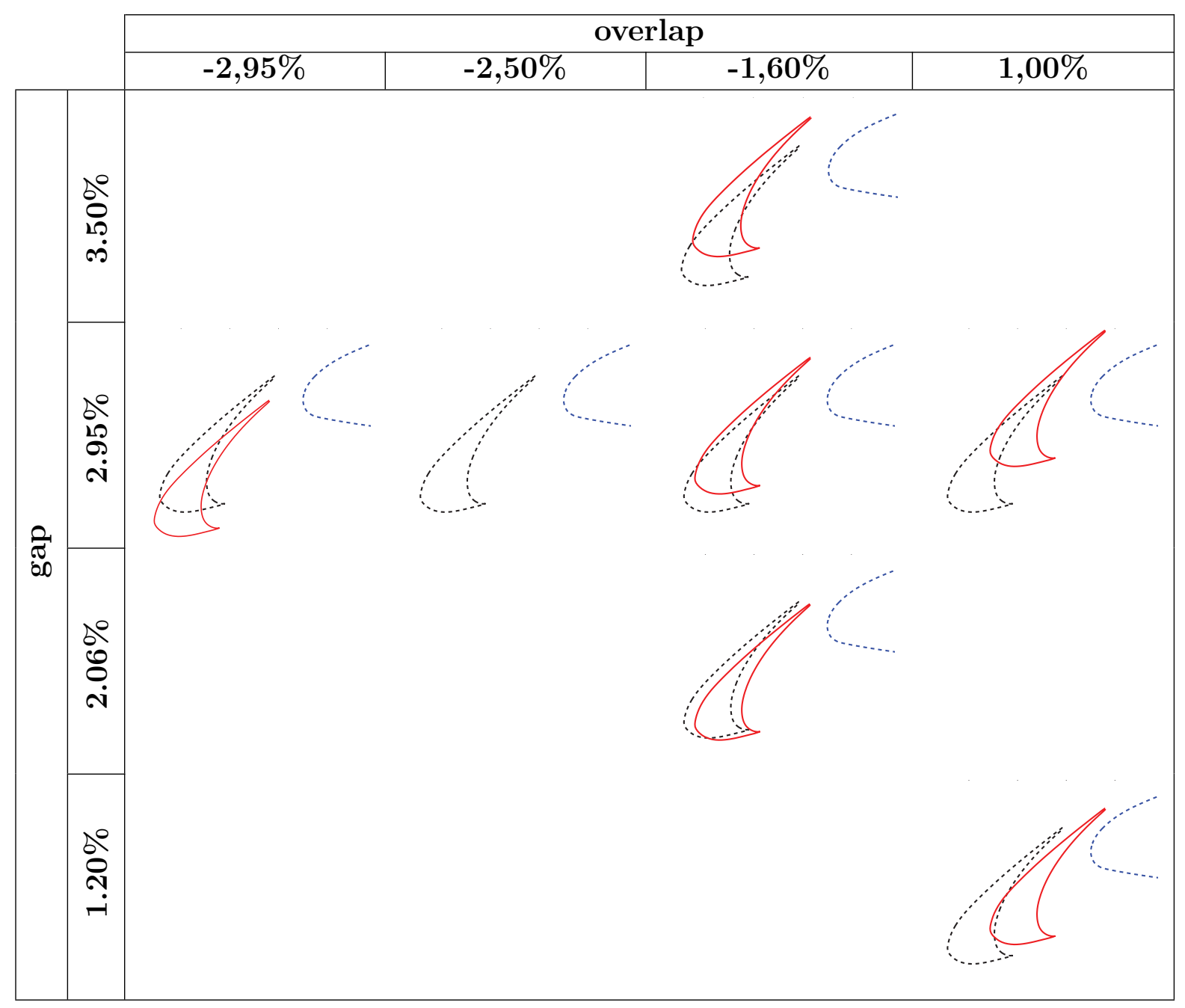

Cada configuração geométrica apresentada na tabela 8.2 é obtida pelo uso de um conjunto de quatro suportes especialmente projetados para o ajuste dos valores de gap, overlap e deflexão do eslate em relação ao elemento principal do aerofólio.

\subsection{Dependência do Ruído do Eslate em Relação ao Gap e ao Overlap}

Em uma primeira abordagem são estudados os efeitos de variações de gap e overlap sobre os espectros de ruído do eslate, considerando-se o mesmo em deflexão de $30^{\circ}$. A posição do flape corresponde à configuração de referência $\left(\boldsymbol{\delta}_{f}=30^{\circ}, g_{f}=1,27 \%\right.$ e $o_{f}=$ $0,25 \%)$ para todos os casos experimentais avaliados.

Na Fig. 8.1, os níveis globais de ruído (overall) do eslate, estimados em cada uma das configurações geométricas apresentadas na tabela 8.2, são interpolados para avaliar 
as tendências de variação em relação aos parâmetros de gap e overlap. Os resultados representam casos experimentais com o aerofólio em ângulos de incidência de $2^{\circ}, 4^{\circ}, 6^{\circ}$ e $8^{\circ}$ e velocidade de escoamento livre de $34 \mathrm{~m} / \mathrm{s}$.

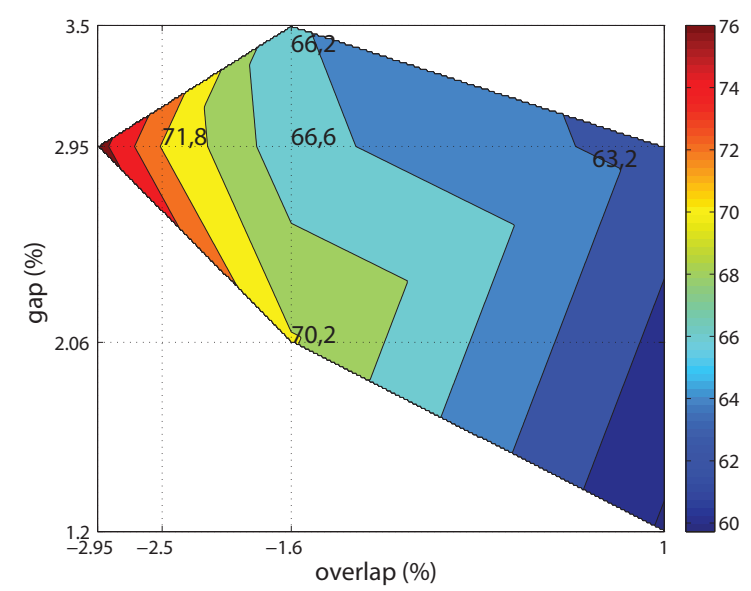

(a) $\alpha=2^{\circ}$

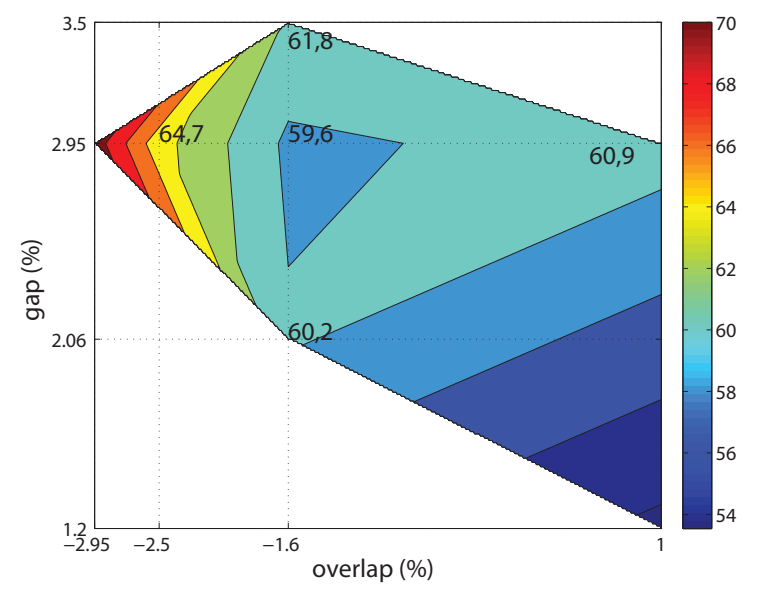

(c) $\alpha=6^{\circ}$

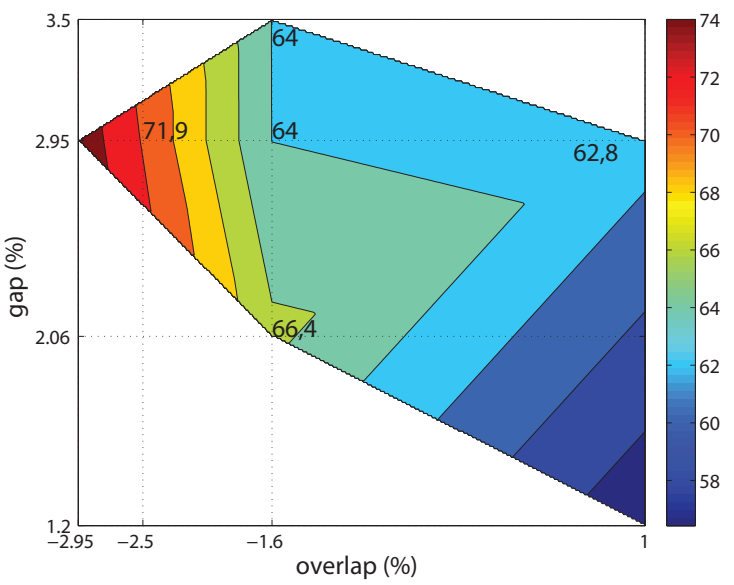

(b) $\alpha=4^{\circ}$

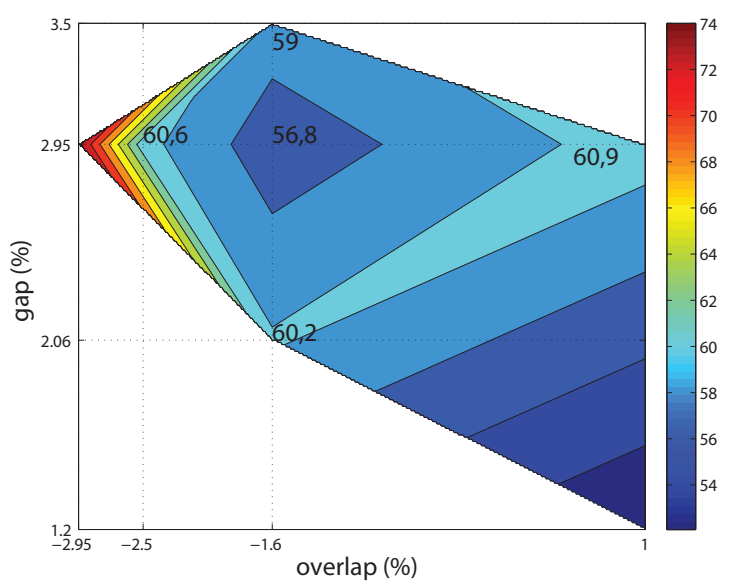

(d) $\alpha=8^{\circ}$

Figura 8.1: Superfícies de contorno representando tendências de variação do ruído global do eslate em relação ao gap e ao overlap, com o eslate defletido em $30^{\circ}$. O ruído global é dado pela soma dos componentes de ruído, em unidades de $P \mathrm{~Pa}^{2} / \mathrm{Hz}$, para cada frequência na banda entre $500 \mathrm{~Hz}$ e $22 \mathrm{kHz}$. Os resultados são apresentados em escala $d B / H z$.

Os resultados apresentados na Fig. 8.1 mostram que o nível máximo de ruído global do eslate é obtido para a configuração definida por $g_{s}=2,95 \%$ e $o_{s}=-2,95 \%$, para variações no ângulo de incidência do aerofólio entre $2^{\circ}$ e $8^{\circ}$. Para estes ângulos, verificase uma maior dependência do ruído em relação aos valores de gap, quando o overlap é configurado em $-1,6 \%$. De forma geral, há uma tendência de redução no nível de ruído global com valores crescentes de overlap ${ }^{1}$.

\footnotetext{
${ }^{1}$ Nesta trabalho, considera-se que valores crescentes de overlap representam uma maior sobreposição do eslate em relação ao elemento principal (aumento dos valores positivos), ou um menor afastamento (redução dos valores negativos)
} 
Os resultados mostrados na Fig. 8.1 apresentam uma perspectiva geral sobre a dependência do ruído do eslate em relação às configurações geométricas adotadas para o conjunto aerofólio/eslate. Os resultados apresentados nas tabelas 8.3 e 8.4 comparam espectros de ruído do eslate para diferentes configurações geométricas, considerando todas as possíveis combinações de gap e overlap avaliadas neste trabalho, com o eslate defletido em $30^{\circ}$. Esta abordagem permite avaliar em maiores detalhes o efeito da configuração geométrica do aerofólio sobre o ruído do eslate e determinar tendências de variação de cada componente do ruído em relação a um dado parâmetro (gap ou overlap), mantendo-se fixo os demais. Os resultados apresentados correspondem aos casos experimentais com o aerofólio em ângulos de ataque de $2^{\circ}$ e $8^{\circ}$, para medições com velocidades de escoamento livre de $27 \mathrm{~m} / \mathrm{s}$ e $34 \mathrm{~m} / \mathrm{s}$. Os resultados apresentados nas tabelas 8.3 e 8.4 permitem aprofundar e justificar algumas conclusões sobre a dependência do ruído do eslate em relação aos parâmetros de configuração geométrica $g_{s}$ e $o_{s}$, obtidas a partir da análise do ruído global.

Para ângulo de ataque de $2^{\circ}$, ocorre uma redução substancial na amplitude dos picos tonais de baixa frequência com o aumento do overlap de $-2,95 \%$ para de $1 \%$, com o gap fixo em 2,95\%. Redução menos significativa na amplitude do ruído tonal ocorre variandose o gap de 2,06\% para 3,50\%, com o overlap fixo em -1,60\%. A redução na amplitude dos picos tonais que ocorre com o aumento nos valores de gap e overlap são acompanhadas por um certo crescimento na amplitude do ruído tonal de banda larga em alta frequência. O comportamento dos picos tonais de baixa frequência com variações no gap e overlap mostra-se consistente para as velocidades de $27 \mathrm{~m} / \mathrm{s}$ e $34 \mathrm{~m} / \mathrm{s}$.

Conforme será evidenciado na Fig. 8.2, a tendência de redução na amplitude dos picos tonais com variações positivas de gap e overlap é consistente para ângulos de ataque entre $2^{\circ}$ e $6^{\circ}$. Os resultados apresentados nas tabelas 8.3 e 8.4 mostram que para $\alpha=8^{\circ}$, ocorre uma forte redução na amplitude dos picos tonais de baixa frequência, mesmo para a configuração $g_{s}=2,95 \%$ e $o_{s}=-2,95 \%$, com o surgimento de múltiplos picos tonais de alta amplitude na região de média frequência. Diferentemente do comportamento observado para o ruído tonal de baixa frequência, que invariavelmente decresce com a redução da velocidade de escoamento, o ruído tonal de média frequência observado em $8^{\circ}$ mostra uma redução no valor de pico, quando a velocidade de escoamento é aumentada de $27 \mathrm{~m} / \mathrm{s}$ para $34 \mathrm{~m} / \mathrm{s}$. Para altos ângulos de ataque, a redução substancial do ruído de baixa frequência que ocorre para a configuração $g_{s}=2,95 \%$ e $o_{s}=1 \%$, é acompanhada por uma maior elevação nos níveis do ruído de média e alta frequências. 
Tabela 8.3: Espectros de ruído de eslate para $\alpha=2^{\circ}$ e $\alpha=8^{\circ}, \operatorname{com} U_{\infty}=27 \mathrm{~m} / \mathrm{s}$.

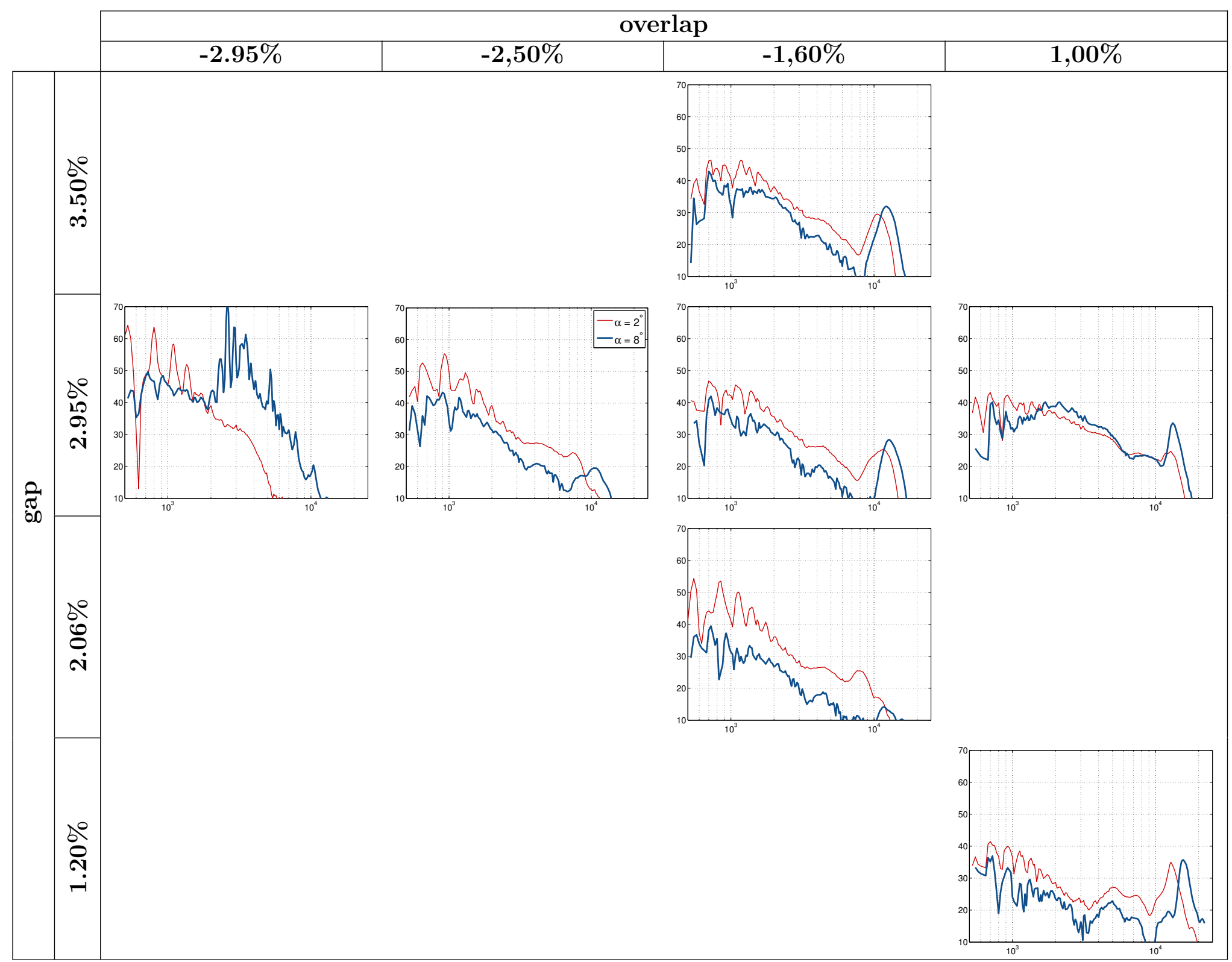

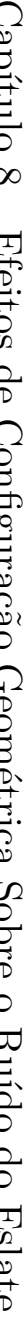


Tabela 8.4: Espectros de ruído de eslate para $\alpha=2^{\circ}$ e $\alpha=8^{\circ}$, com $U_{\infty}=34 \mathrm{~m} / \mathrm{s}$.

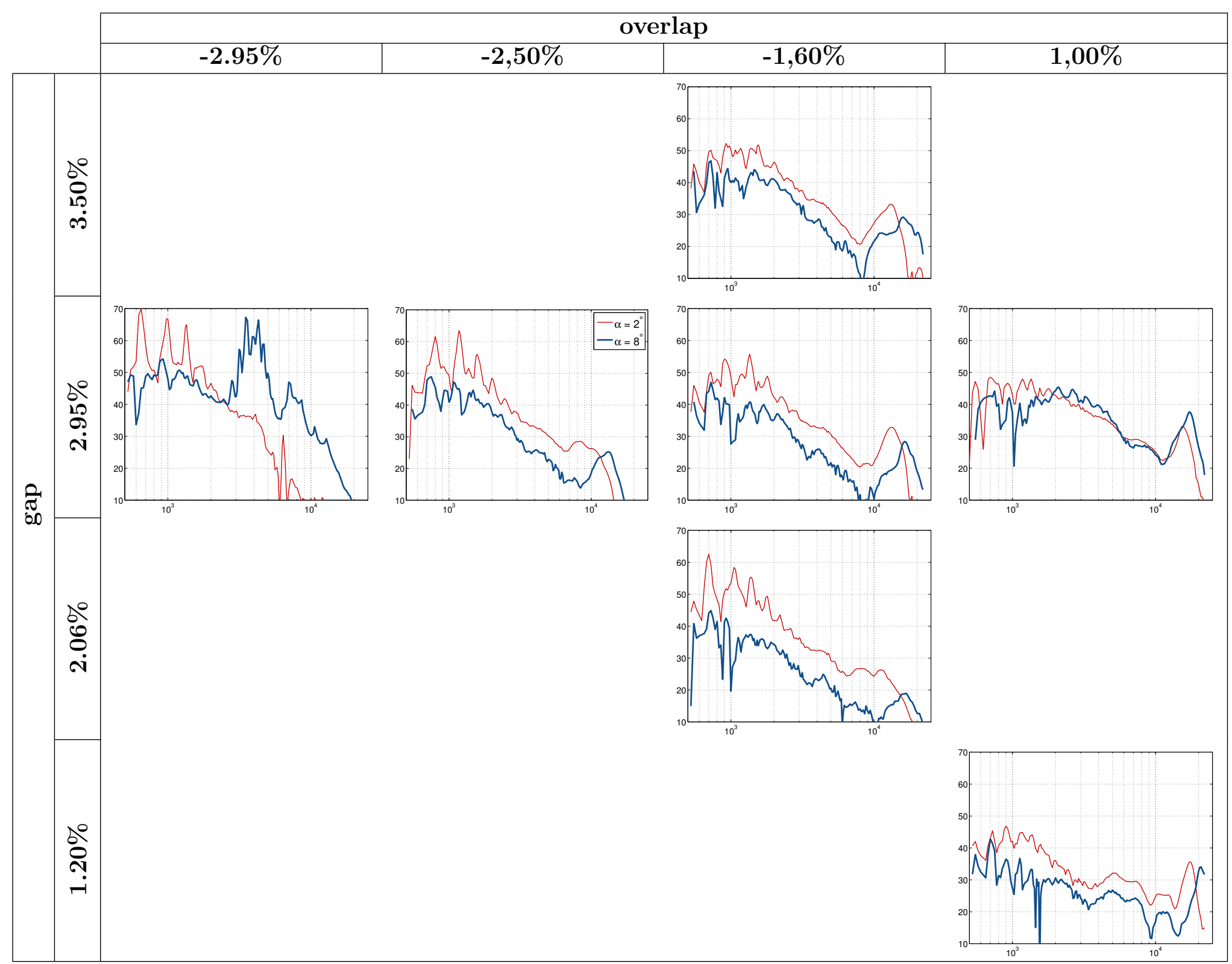


De forma geral, com exceção das configurações dadas por $g_{s}=2,95 \%$ e $o_{s}=-2,95 \%$, e $g_{s}=2,95 \%$ e $o_{s}=1 \%$, todas as demais configurações estudadas mostram uma clara tendência de redução do ruído de baixa e média frequência, com o aumento no ângulo de ataque do aerofólio.

A Fig. 8.2 mostra uma comparação entre espectros de ruído do eslate referentes às configurações com gap fixo em $2,95 \%$ e overlap em $-2,95 \%,-2,50 \%,-1,60 \%$ e $1 \%$, bem como para overlap fixo em $-1,60 \%$ e gap em $2,06 \%, 2,95 \%$ e $3,50 \%$. Os resultados são apresentados para as configurações $\alpha=2^{\circ}$ e $6^{\circ}$, com $U_{\infty}=34 \mathrm{~m} / \mathrm{s}$. O objetivo desta análise é mostrar com maiores detalhes o efeito de variações no gap e overlap sobre o ruído tonal de baixa frequência, que é o componente de ruído dominante no espectro e fortemente influenciado por variações destes parâmetros.

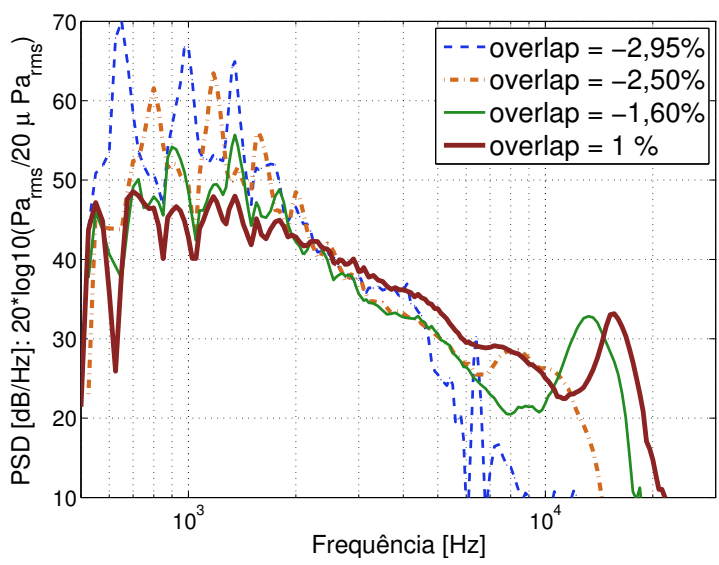

(a) $\alpha=2^{\circ}, g_{s}=2,95 \%, U_{\infty}=34 m / s$

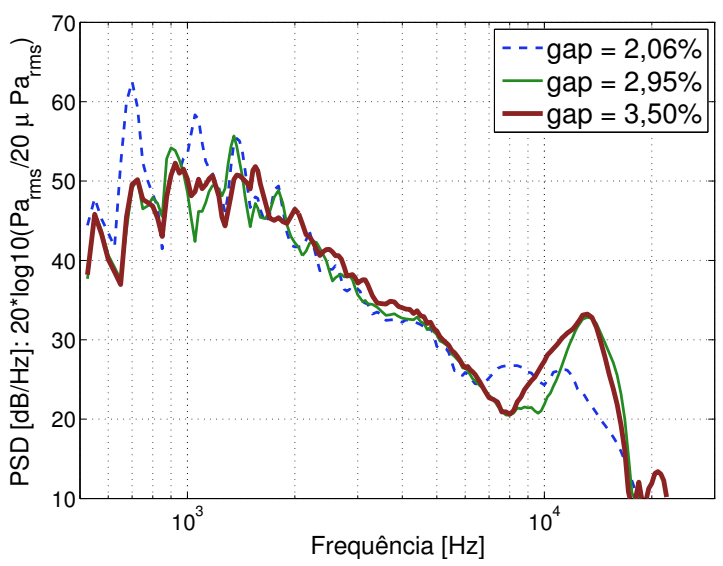

(c) $\alpha=2^{\circ}, o_{s}=-1,60 \%, U_{\infty}=34 m / s$

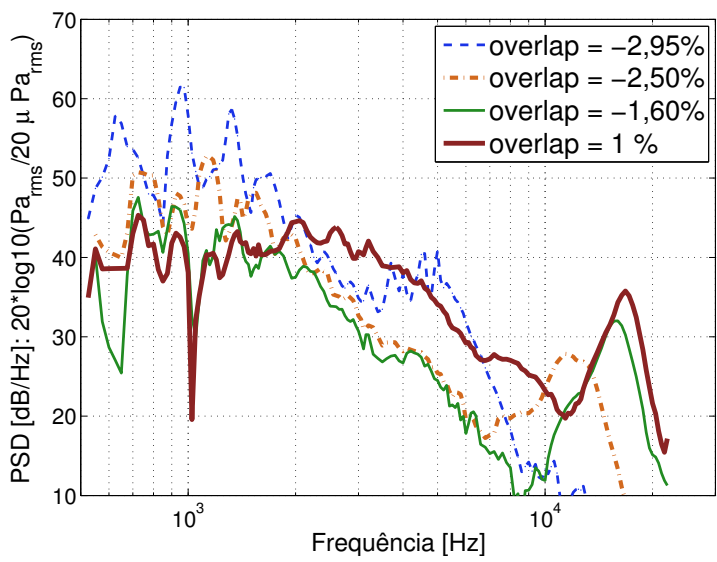

(b) $\alpha=6^{\circ}, g_{s}=2,95 \%, U_{\infty}=34 m / s$

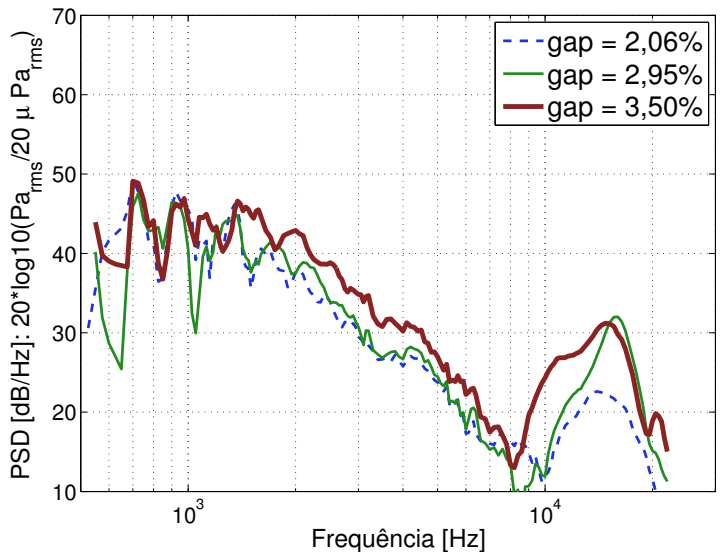

(d) $\alpha=6^{\circ}, o_{s}=-1,60 \%, U_{\infty}=34 m / s$

Figura 8.2: Comparação entre espectros de ruído do eslate para as configurações geométricas obtidas com 1) gap fixo em $2,95 \%$ e 2) overlap fixo $-1,60 \%$. Os resultados são apresentados para $\alpha=2^{\circ}$, e $6^{\circ}$, com $U_{\infty}=34 \mathrm{~m} / \mathrm{s}$.

Os resultados apresentados nas Figs. 8.2(a) e 8.2(b) evidenciam a tendência de redução na amplitude do ruído tonal de baixa frequência com o crescimento do overlap, ou sobreposição ente o eslate e o aerofólio. Comparativamente, a redução na amplitude dos 
picos tonais que ocorre pela variação do overlap de $-2,95 \%$ para $1 \%$ é bastante significativa, alcançando $20 \mathrm{~dB} / \mathrm{Hz}$ para $\alpha=2^{\circ}$. A maior amplitude dos picos tonais ocorre na configuração em que a emissão de ruído pelo eslate sobre a antena de microfones parece ser menos influenciada pelo elemento principal do aerofólio. Entretanto, há uma tendência de crescimento nas frequências de ocorrência dos picos tonais com o aumento do overlap. Tal efeito pode ser um indicativo de dependência dos mecanismos de geração do ruído tonal em relação aos valores deste parâmetro. Para $\alpha=6^{\circ}$, a forte redução na amplitude dos picos tonais verificada para $o_{s}=1 \%$ é acompanhada por um crescimento em amplitude do ruído de banda larga e do ruído de alta frequência. É interessante notar que, para $\alpha=6^{\circ}$, a tendência de crescimento do ruídos em média e alta frequência ocorre em uma configuração na qual a parte superior do intradorso do eslate encontra-se parcialmente sobreposta ao elemento principal do aerofólio. Por outro lado, o ruído tonal de alta frequência não ocorre para a configuração com $o_{s}=-2,95 \%$, na qual emissão do ruído a partir do bordo de fuga do eslate é favorecida pela menor sobreposição entre o eslate e ao elemento principal.

A Fig. 8.2(c) mostra que a configuração dada por $g_{s}=2,06 \%$ e $o_{s}=-1,60 \%$ favorece o surgimento de picos tonais de baixa frequência com maior amplitude, em relação às demais configurações de gap, com overlap fixo em $-1,60 \%$. No entanto, este resultado está restrito ao caso $\alpha=2^{\circ}$. De forma geral, os resultados apresentados nas Figs. 8.2(c) e 8.2(d) mostram uma menor de dependentes do ruído em relação ao ângulo de ataque do aerofólio.

A partir dos resultados apresentados na Fig. 8.2, pode-se aferir que entre $2^{\circ}$ e $6^{\circ}$ o ruído do eslate mostra maior dependência às variações de overlap, considerando as configurações geométricas sob estudo, com destaque para as variações em amplitude e frequência do ruído tonal de baixa frequência.

\subsubsection{Dependência em Relação ao Mach do Escoamento}

Nesta subseção são avaliadas a dependência do ruído do eslate em relação ao número de Mach do escoamento e a qualidade do colapso dos espectros com o número de Strouhal. A metodologia usada é análoga àquela descrita na seção 7.2, sendo utilizado o valor $n=4.5$ para o expoente do número de Mach. Os espectros de ruído avaliados correspondem às configurações definidas por $o_{s}=-2,95 \%$ e $o_{s}=1 \%$, com $g_{s}$ fixo em 2,95\%. Para estas configurações, ocorrem espectros acústicos com características distintas. Os resultados são mostrados para os ângulos de ataque de $2^{\circ}$ e $8^{\circ}$, intervalo no qual também ocorre uma variação significativa nos espectros de ruído, para estas duas configurações geométricas. Conforme as Figs. 8.3 e 8.4, para $o_{s}=-2,95 \%$ e ângulo de ataque de $2^{\circ}$, o espectro de ruído do eslate é fortemente dominado por picos tonais de baixa frequência. Em $8^{\circ}$, 
ocorrem múltiplos picos tonais em média frequência, com ruído de amplitude moderada em baixa frequência. Para $o_{s}=1 \%$ e $\alpha=2^{\circ}$, ocorrem ruído da bixa frequência, no qual não se destacam picos tonais de grande amplitude, ruído de banda larga e um pico tonal de alta frequência. Para $o_{s}=1 \%$ e $\alpha=8^{\circ}$, ocorre redução no nível do ruído de baixa frequência, com o surgimento de picos de amplitude moderada sobre o ruído de banda larga de média frequência e uma majoração no nível do ruído de alta frequência.

As Figs. 8.3 e 8.4 mostram os espectros de ruído para velocidades de escoamento de 24, 27, 31 e $34 \mathrm{~m} / \mathrm{s}$, bem como o colapso vertical das curvas de ruído, utilizando $n=$ 4.5 como expoente para o número de Mach, e o colapso horizontal do ruído tonal pela adimensionalização da frequência pelo número de Strouhal.

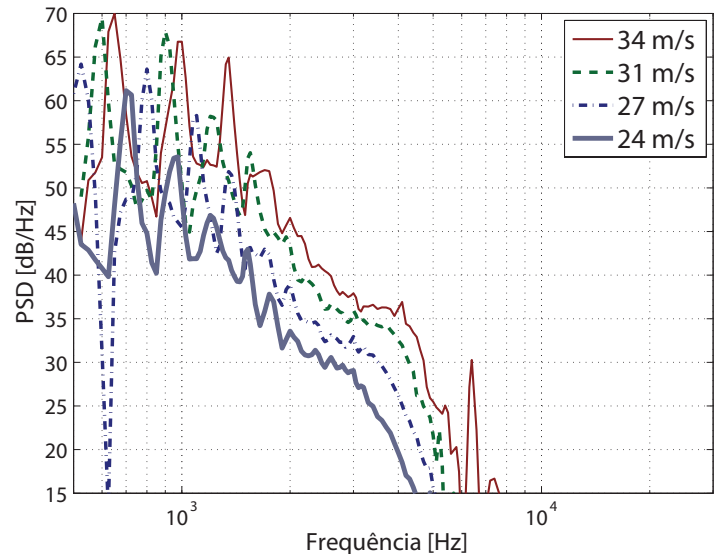

(a) PSD x Frequência $\left(\alpha=2^{\circ}\right)$

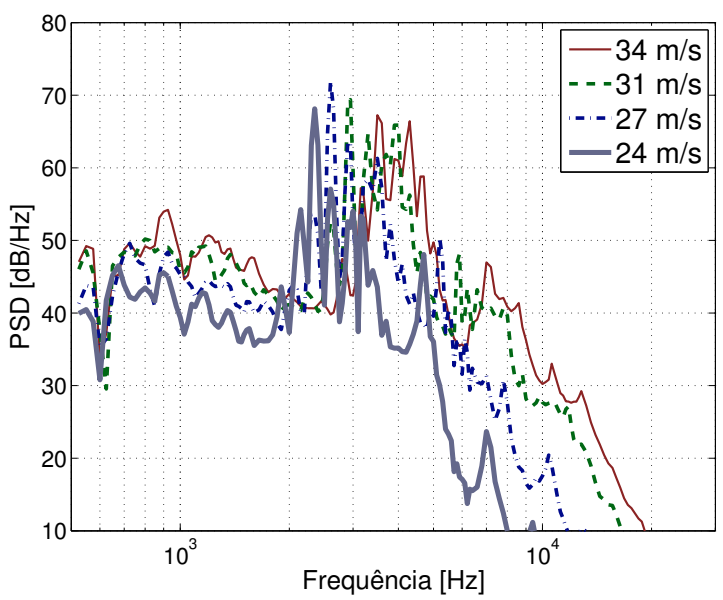

(c) PSD x Frequência $\left(\alpha=8^{\circ}\right)$

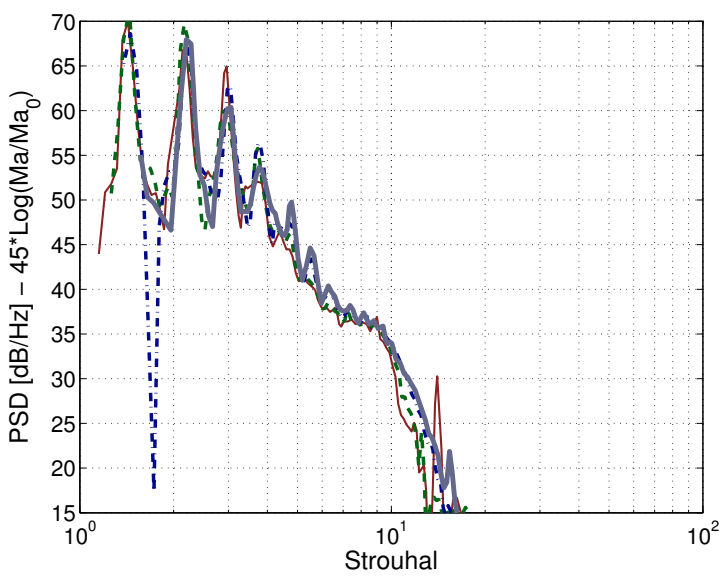

(b) PSD reescalada $\left(p^{2} \sim M a^{(4,5)}\right) \times$ Strouhal

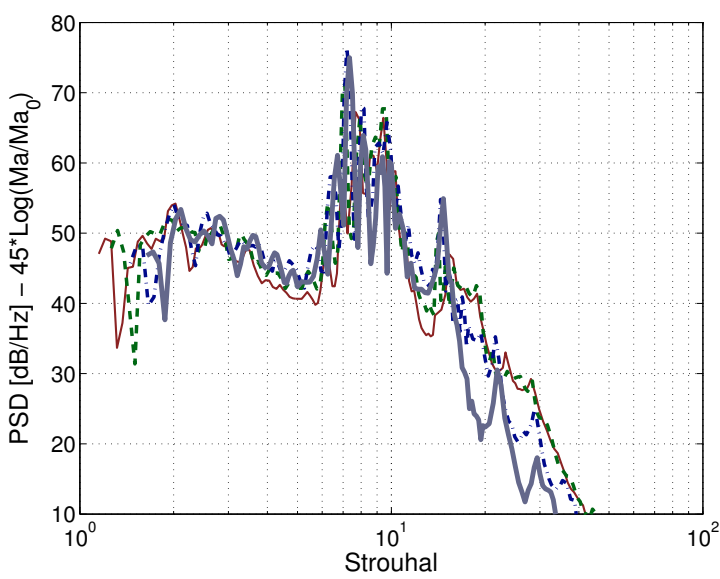

(d) PSD reescalada $\left(p^{2} \sim M a^{(4,5)}\right) \times$ Strouhal

Figura 8.3: Configuração com $o_{s}=-2,95 \%$ e $g_{s}=2,95 \%$ : comparação dos espectros de ruído para diferentes velocidades de escoamento e avaliação do colapso das curvas em amplitude e Strouhal para $2^{\circ}$ e $8^{\circ}$.

Pela Fig. 8.3(a), não há variação significativa na amplitude dos dois primeiros picos tonais quando a velocidade do escoamento é reduzida e $34 \mathrm{~m} / \mathrm{s}$ para $31 \mathrm{~m} / \mathrm{s}$. O primeiro pico tonal que ocorre para a velocidade de $24 \mathrm{~m} / \mathrm{s}$, correspondente aos primeiros picos 


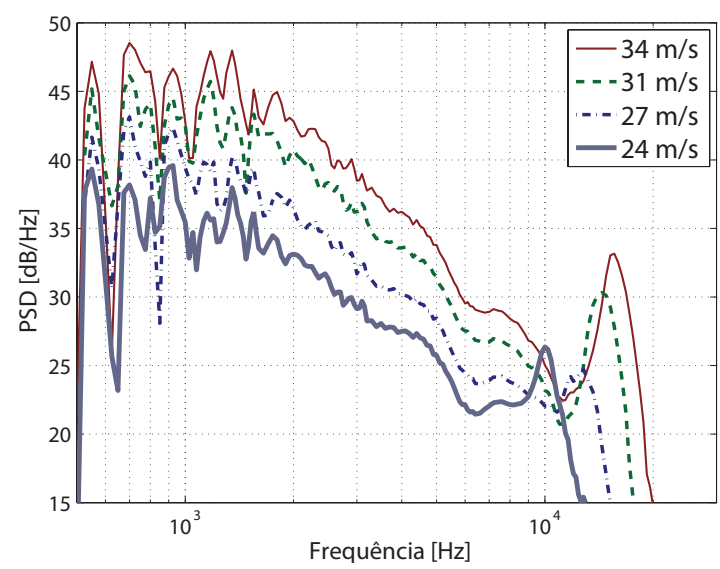

(a) PSD x Frequência $\left(\alpha=2^{\circ}\right)$

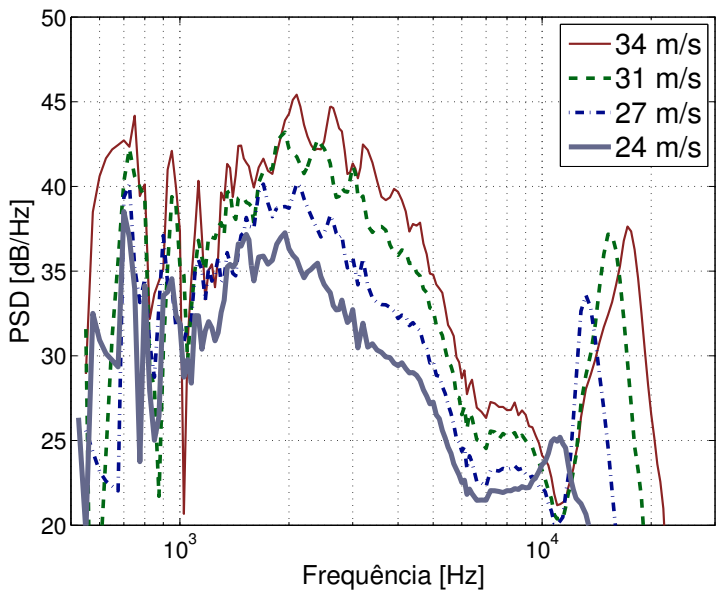

(c) PSD x Frequência $\left(\alpha=8^{\circ}\right)$

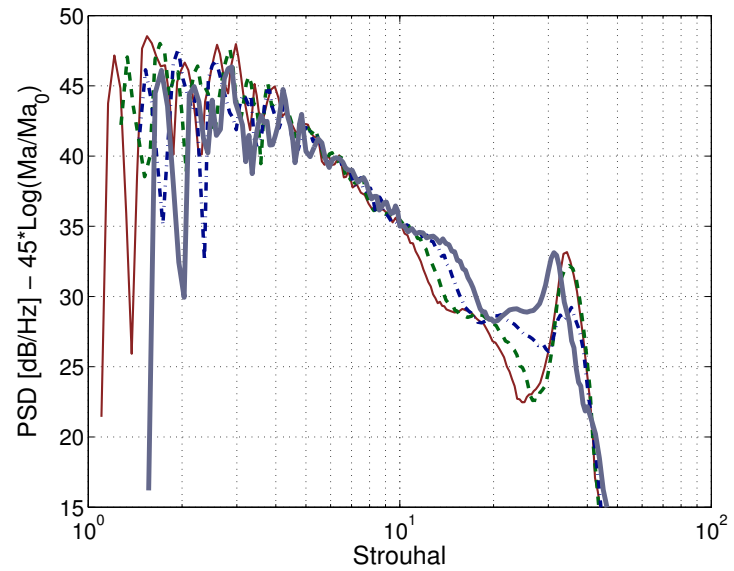

(b) PSD reescalada $\left(p^{2} \sim M a^{(4,5)}\right) \times$ Strouhal

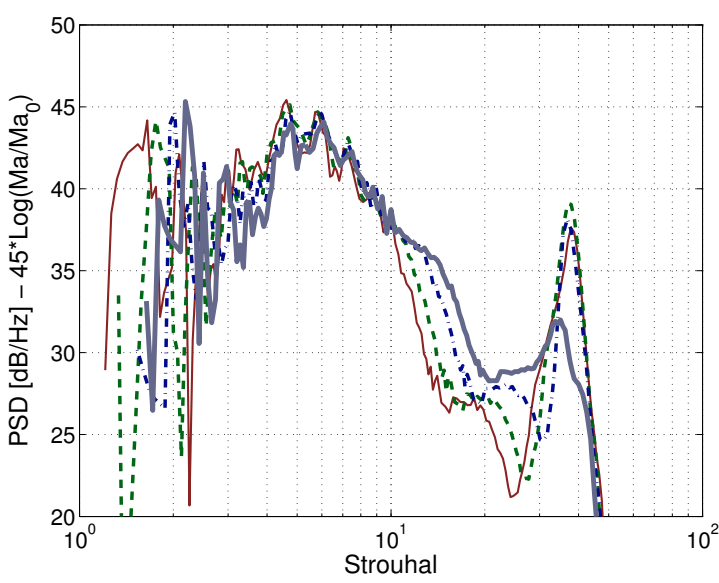

(d) PSD reescalada $\left(p^{2} \sim M a^{(4,5)}\right) \times$ Strouhal

Figura 8.4: Configuração com $o_{s}=1 \%$ e $g_{s}=2,95 \%$ : comparação dos espectros de ruído para diferentes velocidades de escoamento e avaliação do colapso das curvas em amplitude e Strouhal para $2^{\circ}$ e $8^{\circ}$.

para as velocidades de $27 \mathrm{~m} / \mathrm{s}, 31 \mathrm{~m} / \mathrm{s}$ e $34 \mathrm{~m} / \mathrm{s}$, parece ocorrer abaixo de $500 \mathrm{~Hz}$.

Conforme a Fig. 8.3(b), ocorre um colapso substancial dos picos tonais em amplitude e Strouhal. A Fig. 8.3(d) mostra um bom colapso em amplitude e Strouhal para o ruído de baixa frequência, e um bom colapso em Strouhal para os picos tonais de média frequência.

A Fig. 8.4(a) mostra que os picos tonais de amplitude moderada, que ocorrem em baixa frequência para $\alpha=2^{\circ}$, praticamente não se deslocam com o aumento da velocidade de escoamento. No entanto, os picos que ocorrem sobrepostos ao ruído de banda larga para $\alpha=8^{\circ}$, deslocam-se na frequência com o aumento na velocidade de escoamento livre. Para ambos os ângulos de ataque, os picos tonais de alta frequência deslocam-se com o aumento da velocidade de escoamento livre. Por outro lado, para $2^{\circ}$ e $8^{\circ}$, verifica-se um crescimento significativo no ruído de média frequência com o aumento da velocidade do escoamento. As Figs. 8.4(b) e (d) mostram um excelente colapso em amplitude para 
o ruído de média frequência até $\mathrm{St}=10$, quando os espectros são normalizadas pelo número de Mach com expoente $\mathrm{n}=4.5$. O ruído tonal de alta frequência apresenta um bom colapso em Strouhal.

\subsection{Dependência do Ruído do Eslate em Relação ao Parâmetro de Deflexão $\left(\delta_{s}\right)$}

Nesta secção estuda-se a influência da deflexão do eslate sobre a geração de ruído aerodinâmico. Os casos em estudo correspondem às configurações com $\delta_{s}=20^{\circ}, 25^{\circ}, 30^{\circ}$ e $35^{\circ}$, para $g_{s}=2,95 \%$ e $o_{s}=-1,60 \%$ da corda do aerofólio recolhido. A Fig. 8.5 mostra a posição do eslate em relação ao elemento principal do aerofólio, para cada ângulo de deflexão adotado. O ângulo de deflexão corresponde ao ângulo do eslate em relação à direção definida pela corda do aerofólio, sendo este ângulo determinado pela rotação do eslate em torno da linha que define o bordo de fuga.

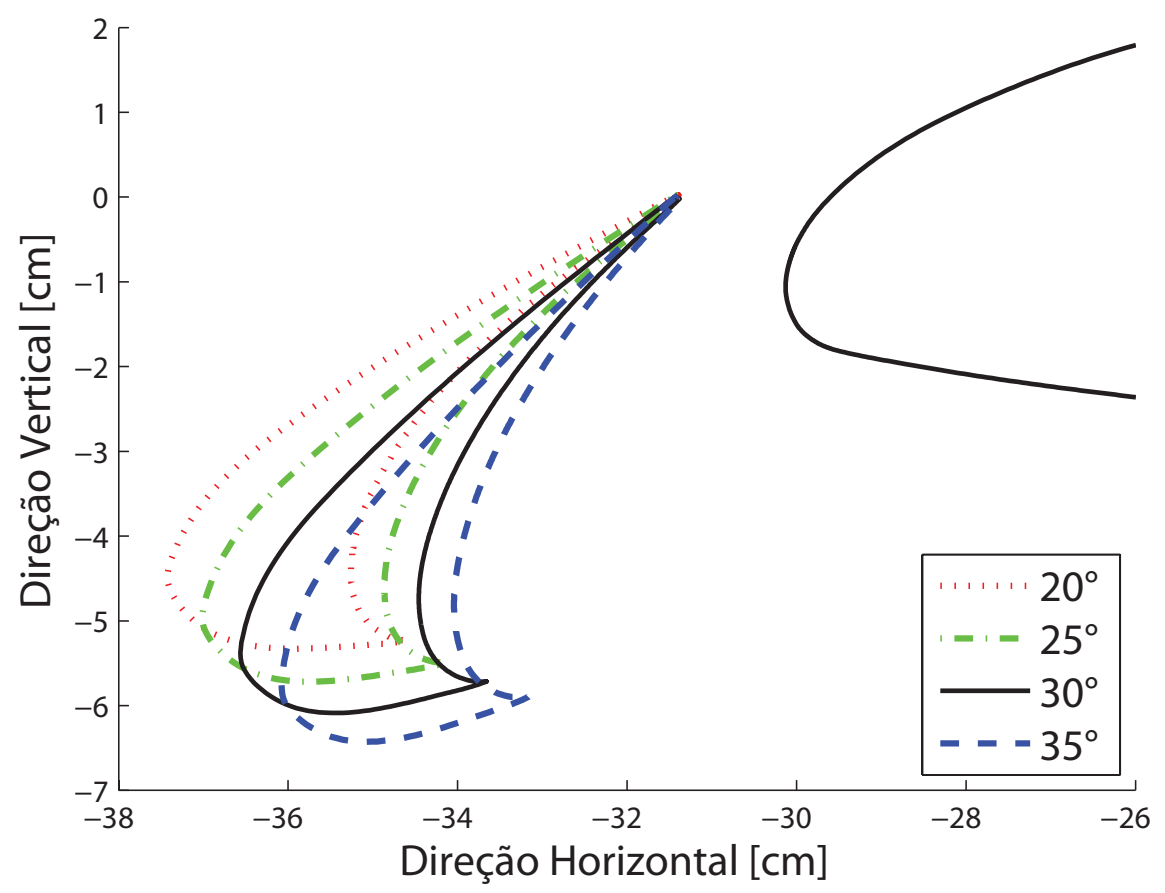

Figura 8.5: Representação das posições do eslate em relação ao elemento principal do aerofólio, correspondentes aos ângulos de deflexão de $20^{\circ}, 25^{\circ}, 30^{\circ}$ e $35^{\circ}$.

Na Fig. 8.6 comparam-se espectros acústicos do eslate para diferentes valores do parâmetro $\delta_{s}$, com o aerofólio em ângulos de ataque de $2^{\circ}, 6^{\circ}$ e $8^{\circ}$, e velocidades de escoamento livre de $27 \mathrm{~m} / \mathrm{s}$ e $34 \mathrm{~m} / \mathrm{s}$. Os resultados apresentados mostram que o aumento no ângulo de deflexão do eslate está associado a um aumento no nível do ruído tonal em alta frequência, acompanhado por um ligeiro crescimento da frequência de pico. O ruído em baixa e média frequência é pouco afetado pela variação do ângulo de deflexão entre 
$20^{\circ}$ e $35^{\circ}$. Os resultados sugerem que um aumento no ângulo de incidência do aerofólio produz um ligeiro aumento do ruído para a configuração $\delta_{s}=35^{\circ}$, em relação aos ângulos de deflexão inferiores.

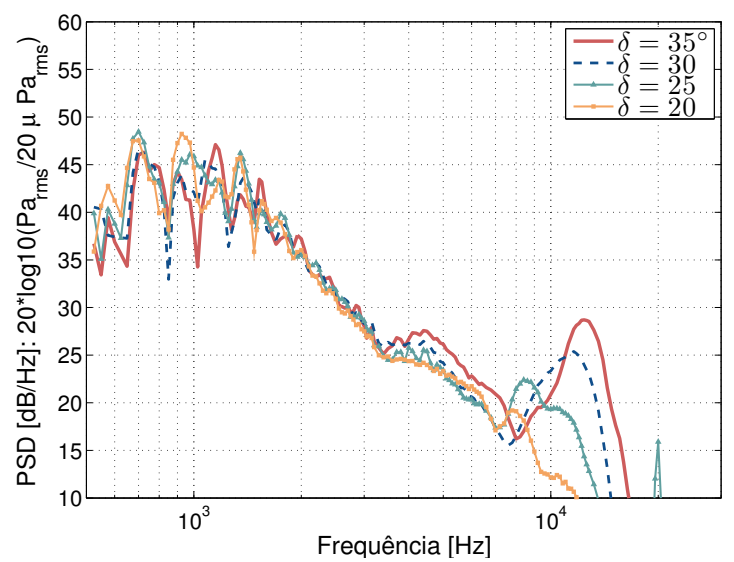

(a) $\alpha=2^{\circ}, U_{\infty}=27 \mathrm{~m} / \mathrm{s}$

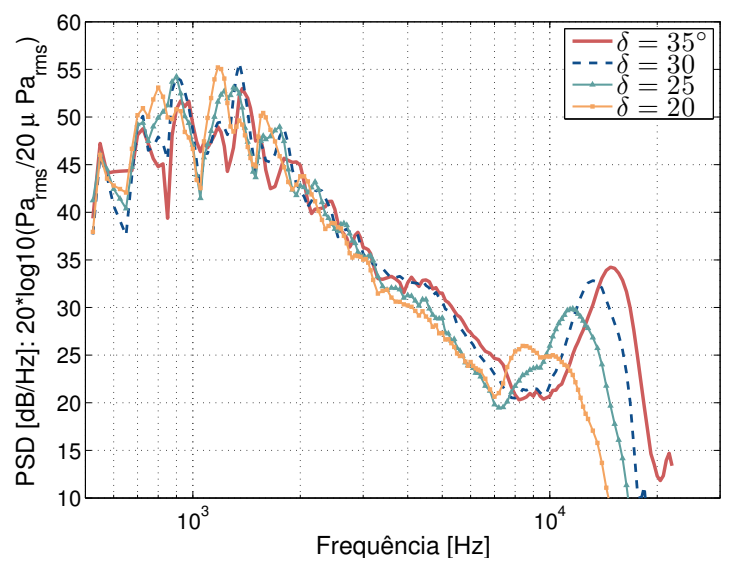

(c) $\alpha=2^{\circ}, U_{\infty}=34 \mathrm{~m} / \mathrm{s}$

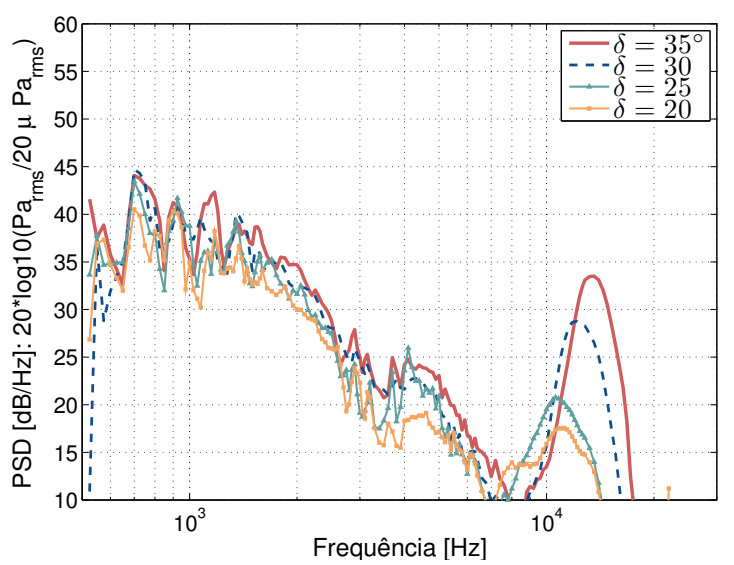

(b) $\alpha=6^{\circ}, U_{\infty}=27 \mathrm{~m} / \mathrm{s}$

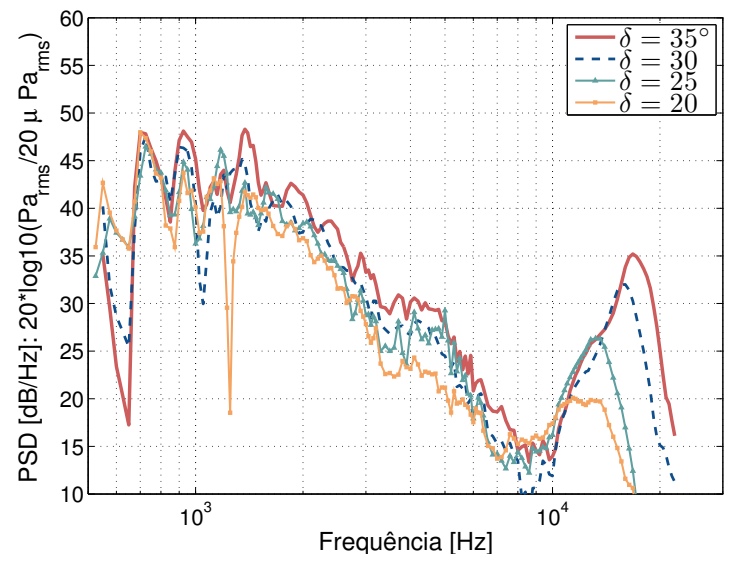

(d) $\alpha=6^{\circ}, U_{\infty}=34 \mathrm{~m} / \mathrm{s}$

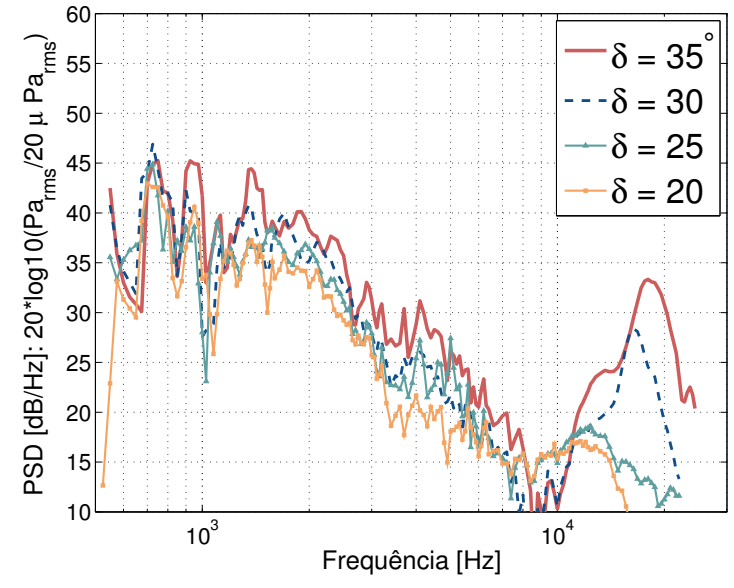

(e) $\alpha=8^{\circ}, U_{\infty}=34 \mathrm{~m} / \mathrm{s}$

Figura 8.6: Comparação entre espectros acústicos do eslate para vários ângulos de deflexão do eslate, na configuração $g_{s}=2,95 \%$ e $o_{s}=-1,60 \%$. 


\subsubsection{Dependência em Relação ao Mach do Escoamento}

A dependência do ruído do eslate em relação ao Mach do escoamento e à corda do eslate foi avaliada para ângulos de ataque de $2^{\circ}$ e $8^{\circ}$, com o eslate defletido em $35^{\circ}$. As Figs. 8.7 (a) e (c) mostram espectros de ruído do eslate para as velocidades de 24, 27, 31 e $34 \mathrm{~m} / \mathrm{s}$, em ângulos de ataque de $2^{\circ}$ e $8^{\circ}$, respectivamente. As Figs. 8.7 (b) e (d) mostram os colapsos das curvas de ruído.

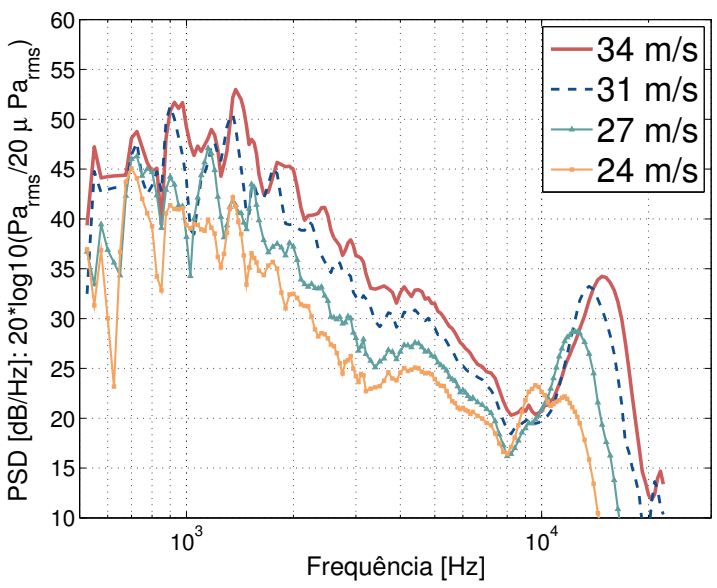

(a) PSD x Frequência $\left(\alpha=2^{\circ}\right)$

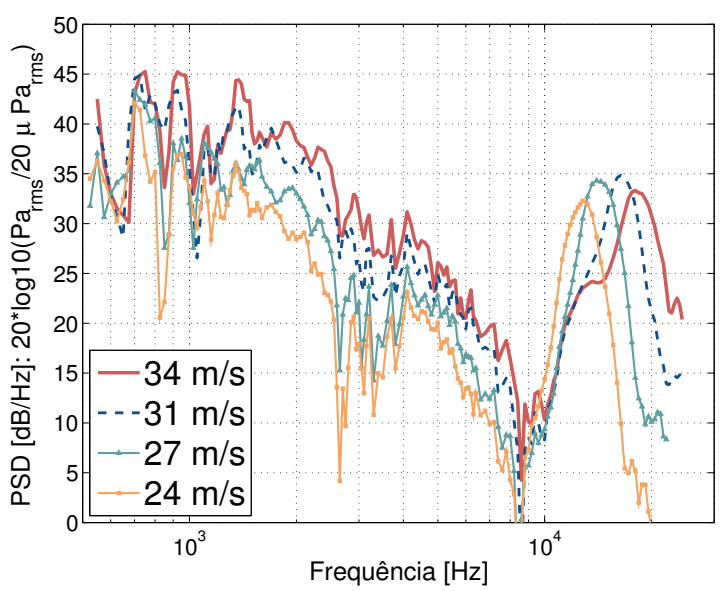

(c) PSD x Frequência $\left(\alpha=8^{\circ}\right)$

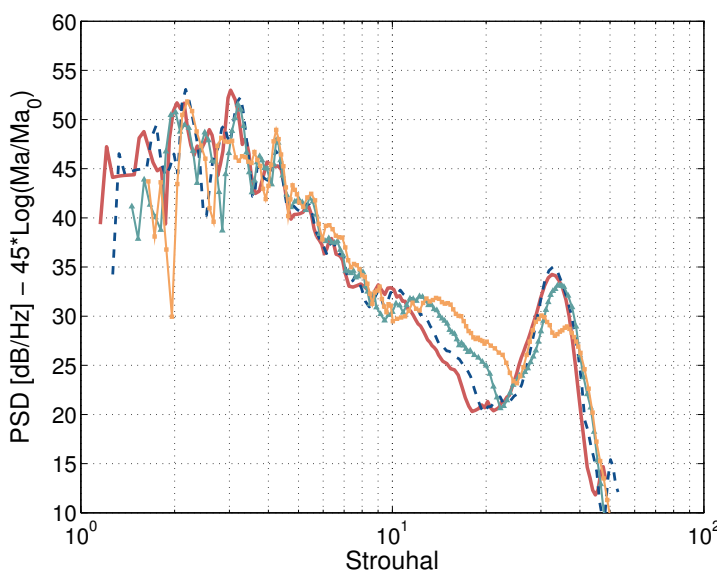

(b) PSD reescalada $\left(p^{2} \sim M a^{(4,5)}\right) \times$ Strouhal

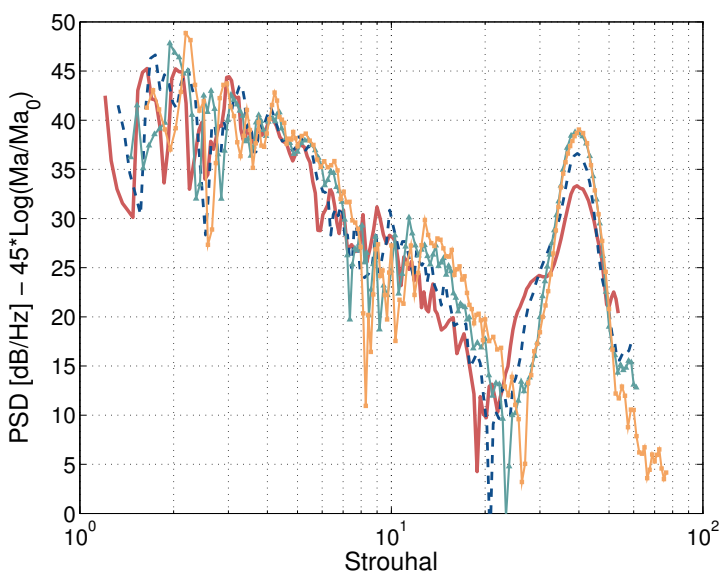

(d) PSD reescalada $\left(p^{2} \sim M a^{(4,5)}\right) \times$ Strouhal

Figura 8.7: Espectros de ruído do eslate em diferentes velocidades de escoamento e o colapso das curvas normalizadas pelo Mach do escoamento livre com expoente 4.5 e adimensionalizadas pelo número de Strouhal.

Os resultados apresentados na Fig. 8.7 mostram que o ruído de eslate cresce com a velocidade de escoamento livre. Os espectros apresentam um bom colapso em amplitude até St $=10$, particularmente para $\alpha=2^{\circ}$. O colapso dos picos tonais de alta frequência em Strouhal é notável, particularmente para $\alpha=8^{\circ}$. 
CAPÍTULO 9

Conclusões

\subsection{Descrição do Ruído do Eslate}

Este trabalho apresenta resultados de mapeamento de ruído do eslate de um aerofólio hiper-sustentador McDonnell Douglas (MDA - 30P30N), obtidos a partir de medições experimentais em túnel de vento de seção fechada. Os resultados mostram a ocorrência de componentes de ruído tonal e de banda larga no espectro acústico do eslate, em bandas de frequência bem definidas. Em baixa frequência ocorrem múltiplos picos tonais de grande amplitude. Os picos tonais estão aparentemente sobrepostos ao ruído de banda larga, que atinge sua máxima amplitude em torno de $\mathrm{St}=2.5$. Os picos tonais não ocorrem na banda média de frequência, e o espectro é dominado por ruído de banda larga, que decresce com o aumento da frequência. Após o ruído de banda larga, ocorre um único tonal de amplitude moderada, distribuído em uma banda de frequência mais larga que aquela ocupada por um tonal de baixa frequência.

\subsection{Dependência do Ruído do Eslate em Relação aos Parâmetros do Experimento}

Os espectros de ruído obtidos para o eslate do aerofólio 30P30N são característicos de um modelo em escala testado em condições de baixo Reynolds. De forma geral, os componentes de ruído tonal colapsam em Strouhal baseado na corda do eslate e na velocidade de escoamento livre. O colapso vertical dos espectros de ruído ocorre para uma 
lei de escala que determina a normalização dos níveis de ruído pelo número de Mach com expoente entre 4 e 5. Este colapso é parcial para o ruído tonal e bastante satisfatório para o ruído de banda larga em média frequência, particularmente para o aerofólio em baixo ângulo de incidência. Estes resultados indicam a natureza aerodinâmica do ruído do eslate e corroboram os resultados de referência que se encontram documentados na literatura. O efeito do ângulo de incidência do aerofólio sobre o ruído do eslate tem sido investigado majoritariamente a partir de medições acústicas em túneis de vento de seção aberta, onde há grande incerteza na determinação do ângulo de ataque aerodinâmico. Os resultados obtidos neste trabalho baseiam-se na boa correspondência entre ângulos de ataque geométrico e aerodinâmico, que pode ser obtida em túneis de vento de seção fechada, e representam a dependência do ruído do eslate em relação ao ângulo de incidência do aerofólio com menor grau de incerteza. Para a configuração geométrica de referência do aerofólio, é observado que o ruído tonal de baixa frequência e o ruído de banda larga têm suas amplitudes reduzidas com o aumento do ângulo de incidência do aerofólio de 2 para 10 graus. Em linhas gerais, esta tendência é verificada para as demais configurações geométricas avaliadas neste trabalho.

\subsection{Representação de Fontes Acústicas: Mapas de Beam-forming}

O mapa de beam-forming, obtido com o método de deconvolução DAMAS, foi o recurso utilizado para representar a distribuição espacial das fontes acústicas associadas ao ruído do eslate. Os resultados indicam uma distribuição de fontes em linha, ao longo da envergadura do eslate, nas frequências de ocorrência do ruído de banda larga e do tonal de alta frequência.

\subsection{Resultados Experimentais e Numéricos para o Ruído do Eslate}

Os resultados experimentais são comparados com resultados de simulação computacional utilizando um modelo numérico baseado no método de Lattice-Boltzmann (LBM), que reproduz a geometria do aerofólio e as dimensões e condições de contorno do túnel de vento utilizado nos experimentos. A comparação entre resultados numéricos e experimentais mostra uma boa correspondência quantitativa, do ponto de vista aerodinâmico e aeroacústico. Para os resultados acústicos, destaca-se a boa correspondência para as frequências de ocorrência e as amplitudes dos picos tonais de baixa frequência. Para o ruído de banda larga, os resultados numérico e experimental mostram boa correspondên- 
cia para a amplitude e a forma dos espectros. A melhor correspondência entre resultados numérico e experimental ocorre para ângulo de incidência de $4^{\circ}$, comparativamente ao resultado para $8^{\circ}$. Estes resultados indicam a viabilidade do uso de túneis de vento de seção fechada para a realização de experimentos aeroacústicos de boa qualidade. A viabilidade da utilização de túneis de vento de secção fechada, particularmente para experimentos nos quais se deseja obter uma estimativa confiável do nível de ruído emitido pelas fontes, ainda é um tema bastante controverso. Neste sentido, os resultados apresentados contribuem para a qualificação desta categoria de túnel de vento para a realização de experimentos aeroacústicos.

\subsection{Efeitos da Geometria Sobre o Ruído do Eslate}

A comparação entre espectros acústicos do eslate para diferentes configurações geométricas do aerofólio evidencia a dependência dos componentes do ruído em relação aos parâmetros de gap, overlap e deflexão do eslate em relação ao elemento principal. Considerando a faixa para a variação de parâmetros adotada neste trabalho, foi verificada uma maior dependência do ruído do eslate em relação ao overlap. Para ângulos de ataque de até $6^{\circ}$, os picos tonais de maior amplitude ocorrem para a configuração ( $g a p=2,95 \%$ e overlap $=-2,95 \%$ ). Porém, verifica-se que o aumento no overlap para $1 \%$ causa uma redução da ordem de $20 \mathrm{~dB} / \mathrm{Hz}$ na amplitude dos picos tonais de baixa frequência. Este efeito é acompanhado por um deslocamento dos picos tonais para frequências mais altas, bem como de um aumento moderado nas amplitudes do ruído de banda larga e do tonal de alta frequência para ângulo de incidência de $6^{\circ}$. Variações no gap exercem menor influência sobre o ruído do eslate. O efeito do aumento do ângulo de deflexão do eslate pôde ser avaliado apenas para uma configuração de gap e overlap, e parece restrito ao aumento do ruído tonal de alta frequência. Para as configurações com overlap em -2,95\% e $1 \%$, ocorrem variações significativas no espectro de ruído do eslate quando o ângulo de incidência do aerofólio é aumentado de $6^{\circ}$ para $8^{\circ}$. Este fenômeno não é observado com o aerofólio em configuração geométrica de referência. Em linhas gerais, este estudo permitiu uma visão mais abrangente sobre as características do ruído do eslate para o aerofólio 30P30N.

\subsection{Avaliação das Metodologias Adotadas}

\subsubsection{Metodologia Experimental}

Vários aspectos experimentais foram considerados para viabilizar a medição do ruído do eslate em túnel de vento de seção fechada. Em particular, o controle da camada limite 
de parede foi aplicado para reduzir efeitos de escoamento tridimensional nas extremidades do aerofólio, e tornar as condições aerodinâmicas representativas de um escoamento uniforme sobre o modelo de testes. Os resultados mostram que a aplicação de sucção para o controle da camada limite uniformiza a distribuição de pressão ao longo da envergadura do aerofólio. A comparação entre resultados numérico e experimental mostra uma melhor correspondência quando a sucção para o controle da camada limite é aplicada, indicando que as condições aerodinâmicas no experimentos tornaram-se mais representativas daquelas definidas para o modelo numérico, que assume uma asa com envergadura infinita. Do ponto de vista acústico, a aplicação de sucção reduziu o nível do ruído aerodinâmico em baixa e média frequência. O controle da camada limite de parede tem sido pouco investigado no contexto dos experimentos aeroacústicos. Não obstante, os resultados apresentados neste trabalho contribuem como uma investigação sobre os potenciais efeitos do controle da camada limite, via sucção, sobre os resultados aerodinâmicos e acústicos para um perfil hiper-sustentador.

\subsubsection{Metodologia de Processamento de Dados}

Os resultados apresentados neste trabalho referentes ao ruído do eslate foram obtidos, em última instância, pela aplicação do método de deconvolução DAMAS. Este método tem o potencial de melhorar substancialmente a representação de fontes obtida pelo método de beam-forming convencional, porém, às custas de um aumento considerável na complexidade e demanda computacional. Os estudos realizados para a otimização da malha resultaram em uma redução significativa no tempo de processamento dos dados acústicos, o que tornou possível a avaliação de um grande número de casos experimentais. Não obstante, inúmeros testes foram realizados para avaliar a independência dos resultados em relação aos parâmetros do processamento e ao critério de convergência adotado, bem como para a escolha de uma região de integração adequada para mapear o ruído aerodinâmico do eslate. Vale ressaltar que há poucos relatos sobre a aplicação do método DAMAS ao processamento de dados medidos em túnel de vento de seção fechada, e a capacidade deste método em mapear fontes na presença de altos níveis de ruído é por vezes dada como incerta. De forma geral, os resultados apresentados validam a metodologia de processamento de sinais aplicada às medições realizadas em túnel de vento de seção fechada. Em particular, o método DAMAS permitiu a representação dos espectros de ruído com nível de detalhes suficiente para avaliar a dependência do ruído em relação a todos os parâmetros experimentais e geométricos considerados, bem como proveu a resolução de fontes necessária para identificar um perfil de fontes em linha, permitindo identificar fontes potencialmente associadas ao bordo de fuga do eslate. 


\subsection{Considerações Finais}

O aerofólio hiper-sustentador 30P30N tem sido estudado do ponto de vista aerodinâmico. Recentemente, estudos baseados em modelos numéricos têm sido realizados com o objetivo de investigar os mecanismos de geração de ruído e caracterizar o espectro acústico do eslate de um aerofólio 30P30N. No entanto, resultados para o ruído do eslate baseado em medições experimentais são reconhecidamente escassos na literatura. Este trabalho apresenta um conjunto amplo de resultados baseados em medições experimentais, que potencialmente contribuem para a caracterização acústica do elemento eslate do aerofólio hiper-sustentador 30P30N. 


\section{APÊNDICE A}

\section{Investigação Sobre Mecanismos de Geração do Ruído Tonal do \\ Eslate}

Neste apêndice são apresentados alguns resultados que indicam a ocorrência de possíveis mecanismos de geração do ruído tonal do eslate, para o modelo 30P30N avaliado neste trabalho. Estes resultados representam linhas de pesquisa atualmente em desenvolvimento pelo grupo do Prof. Marcello Faraco de Medeiros.

\section{A.0.1 Múltiplos Picos Tonais}

A Fig. A.1 mostra resultados de um estudo disponibilizado pelo aluno Daniel Sampaio, obtido no contexto de colaboração entre trabalhos numéricos e experimentais. O estudo tem por objetivo avaliar as frequências de ocorrência dos múltiplos picos tonais no ruído do eslate do aerofólio 30P30N, com base no modelo teórico proposto por Terracol, Manoha e Lemoine (2011), introduzido na seção 2.3.

No presente estudo, o ruído do eslate para o aerofólio 30P30N é obtido por medições experimentais, que correspondem aos resultados apresentados nesta tese, e simulação numérica. A partir do campo de escoamento no eslate, simulado com o código PowerFLOW, são obtidos os parâmetros numéricos necessários para o cálculo das frequências dos picos tonais, conforme a Eq. 2.1. Os resultados experimentais são apresentados para Mach entre 0.07 e 0.1 , e os resultados numéricos para Mach de 0.1, ambos com o aerofólio em ângulo de incidência de $4^{\circ}$. 


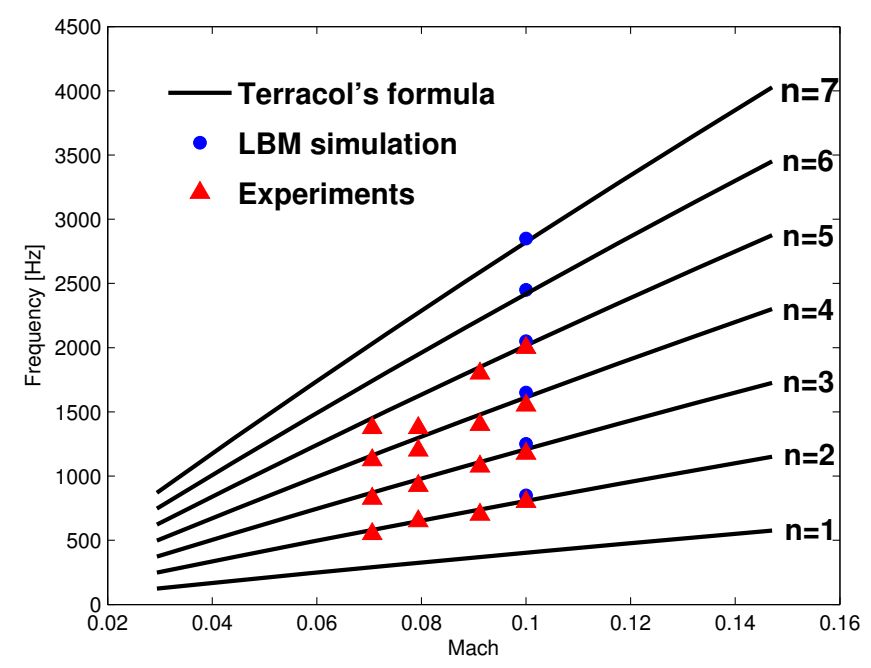

Figura A.1: Resultados indicando as frequências de ocorrência dos picos tonais de baixa frequência do ruído do eslate para o aerofólio 30P30N, obtidas a partir de medições experimentais, resultados numéricos (LBM Simulation) e previsão com o modelo proposto por Terracol, Manoha e Lemoine (2011), que se baseia nos modos de Rossiter para o ruído de cavidade, adaptado para a geometria e condições do escoamento na cova do eslate.

Os resultados apresentados na Fig. A.1 confirmam a boa correspondência entre as frequências dos picos tonais nos espectros de ruído numérico e experimental, conforme discutido anteriormente na subseção 6.4.2. Os resultados também mostram que, a partir do segundo modo de ressonância acústica, os picos tonais ocorrem em frequências que apresentam boa concordância com aquelas previstas pelo modelo proposto por (TERRACOL; MANOHA; LEMOINE, 2011). Estes resultados indicam que o surgimento dos picos tonais está relacionado com mecanismos de retro-alimentação acústica, que ocorrem na região do cova do eslate.

\section{A.0.2 Tonal de Alta Frequência}

A Fig. A.2 mostra o perfil de velocidades na esteira do bordo de fuga do eslate do aerofólio 30P30N, para ângulos de ataque de $4^{\circ}$ e $8^{\circ}$. Este resultado numérico foi obtido com o uso do código PowerFLOW 5.0, e disponibilizado para apresentação pelo aluno Daniel Sampaio.

Em geral, associa-se a frequência de pico do ruído tonal ao fenômeno de desprendimento de vórtices no bordo de fuga do eslate (KHORRAMI; BERKMAN; CHOUDHARI, 2000; HUTCHESON; BROOKS, 2004). As frequências para as quais ocorrem o desprendimento de vórtices depende da espessura da esteira; quanto maior a espessura da esteira, menor a frequência, e vice-versa. Em aerofólios simples, o aumento do ângulo de ataque provoca o aumento da espessura da esteira e, portanto, uma redução na frequência de 


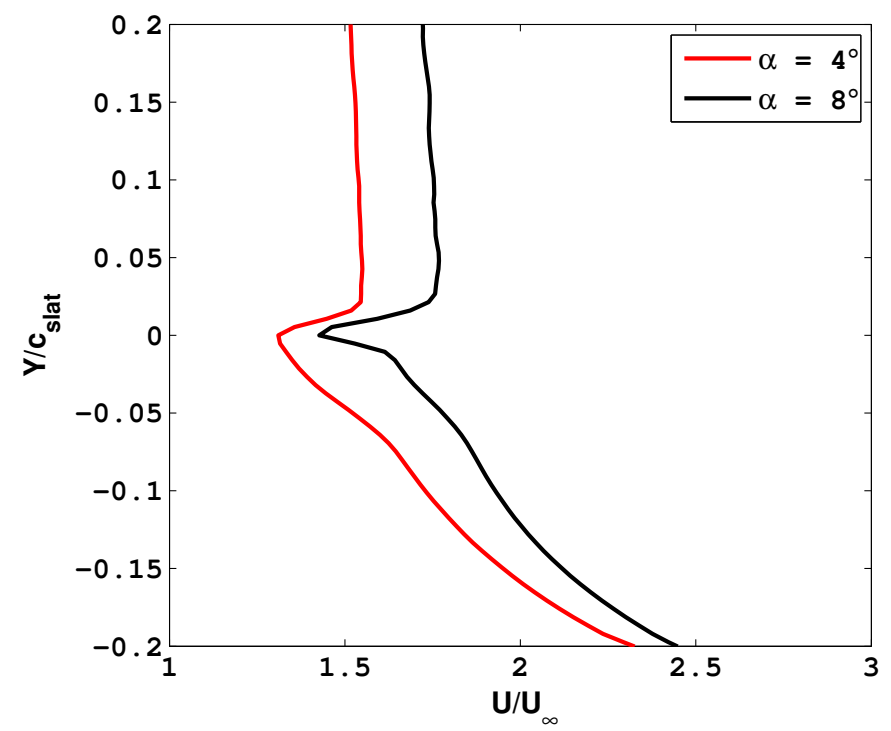

Figura A.2: Perfil de velocidades na esteira do bordo de fuga do eslate do aerofólio 30P30N, para ângulos de ataque do $4^{\circ}$ e $8^{\circ}$, e velocidade de escoamento livre de $34 \mathrm{~m} / \mathrm{s}$.

desprendimento de vórtices (HUTCHESON; BROOKS, 2004). No caso do eslate, a Fig. A.2 mostra que o aumento do ângulo de ataque reduz a espessura da esteira, o que leva ao aumento da frequência de desprendimento de vórtices que determina a frequência de pico do ruído tonal. Este argumento, baseado em um resultado obtido por simulação computacional, corrobora o deslocamento do ruído tonal para frequências mais altas, que é observado com o aumento do ângulo de ataque do aerofólio, a partir de nossos resultados experimentais. 


\section{APÊNDICE B}

\section{Descrição da Metodologia Lattice-Boltzmann}

As simulações numéricas do escoamento foram realizadas com o uso do código comercial PowerFLOW 5.0a, que utiliza o método de Lattice-Boltzmann (LBM) para resolver a equação discreta de Boltzmann com termo de colisão definido pela aproximação de Bhatnagar-Gross-Krook (BGK), Bhatnagar, Gross e Krook (1954), conforme

$$
f_{i}\left(\vec{x}+\vec{c}_{i} \Delta t, t+\Delta t\right)=f_{i}(\vec{x}, t)+\frac{\Delta t}{\tau}\left[f_{i}^{e q}(\vec{x}, t)-f_{i}(\vec{x}, t)\right]
$$

A aproximação para a distribuição de equilíbrio, $f_{i}^{e q}$, leva em conta termos de ordem de até a terceira potência da velocidade do escoamento base (FARES, 2006). O espaço de fase é discretizado em 19 vetores de velocidade $\left(\vec{c}_{i}, i=0,1,2, \ldots, 18\right)$, na forma de uma rede cúbica alinhada com as coordenadas cartesianas. As propriedades macroscópicas do escoamento são calculadas através seguintes momentos hidrodinâmicos

$$
\begin{gathered}
\rho(\vec{x}, t)=\sum_{i} f_{i}(\vec{x}, t) \\
\rho \vec{u}(\vec{x}, t)=\sum_{i} \vec{c}_{i} f_{i}(\vec{x}, t) .
\end{gathered}
$$

A temperatura do escoamento é considerada constante, condição na qual a expansão de Chapman-Enskog da equação de Lattice-Boltzmann leva à equação de Navier-Stokes baseada na hipótese de gas ideal Chen e Doolen (1998),

$$
p=\rho T
$$


Com uma malha cartesiana, tal modelagem exigiria uma resolução extremamente fina para a solução do perfil de camada limite que se desenvolve na superfície do aerofólio. Portanto, a lei-da-parede é considerada no cálculo da velocidade no volume mais próximo de parede sem deslizamento (no-slip). Para representar o efeito da turbulência de menor escala, uma versão modificada do modelo de turbulência k- $\varepsilon$, na forma Renormalization Group (RNG), é implementada no código.

As equações de conservação para a energia cinética turbulenta (k) e a dissipação turbulenta $(\varepsilon)$ são resolvidas na mesma malha cartesiana que a função distribuição, por meio de um método de Lax-Wendroff, e a viscosidade cinemática turbulenta $\left(v_{T}\right)$ é considerada em conexão com a viscosidade molecular $(v)$ na a definição do tempo de relaxação (TEIXEIRA, 1998; FARES, 2006),

$$
\tau=\frac{v_{T}+v}{T}+\frac{\Delta t}{2}
$$

Os parâmetros das simulações foram escolhidos para corresponder aos experimentos realizados no túnel de vento LAE-1, com a aplicação da condição de deslizamento livre free-slip para as paredes horizontais inferior e superior do túnel de vento. No entanto, seria inviável simular numericamente toda a envergadura do eslate perfazendo $1.30 \mathrm{~m}$. Desta forma, a análise considera periodicidade do escoamento na direção da envergadura, o que corresponde a simular uma asa infinita, contanto que o período seja longo o suficiente. Análises estatísticas realizadas por Choudhari e Khorrami (2007) mostram que um domínio da envergadura correspondente à $\sim 40 \%$ da corda do eslate é suficiente para levar em conta a de-correlação das estruturas vorticais na cova do eslate. As simulações apresentadas neste trabalho consideram um domínio na envergadura de $68 \%$ da corda do eslate. Na condição de entrada (inflow), um vetor de velocidade uniforme de $34 \mathrm{~m} / \mathrm{s}$ na direção do escoamento é usado com uma intensidade de turbulência de 0.0009, e escala de comprimento de turbulência de $1 \mathrm{~mm}$, enquanto que para a condição de saída (outflow) a pressão estática é de 1 atm.

Para reduzir o efeito do transiente inicial nas simulações, a parte externa do domínio é modelada como um fluído com viscosidade 100 vezes superior ao valor da viscosidade real. O domínio do escoamento com alta viscosidade atua como uma camada anecoica, que amortece as ondas acústicas que se aproximam das fronteiras do domínio simulado. Embora esta camada não esteja necessariamente presente nos experimentos em túnel de vento, ela é necessária no contexto da simulação, para reduzir a duração do transiente inicial. Mesmo com esta diferença entre experimento e simulação, a comparação entre os resultados ainda é válida sob a condição de que as ondas refletidas não afetam significativamente o escoamento turbulento no interior da cova do eslate. 


\section{Referências Bibliográficas}

AGARWAL, A.; MORRIS, P. J. Broadband noise from the unsteady flow in a slat cove. AIAA Paper, v. 854, 2004.

AMIET, R. K. Correction of open jet wind tunnel measurements for shear layer refraction. In: AIAA Conference on the Exploration of the Outer Planets, Hampton, 1975 Proceedings... Reston: AIAA: [s.n.], 1975. (AIAA Paper 75-532).

BAHR, C. et al. Measurement of phased array point spread functions for use with beamforming. In: 17th AIAA/CEAS Aeroacoustics Conference, 5-8 June 2011, Portland, Oregon. [S.l.: s.n.], 2011.

BANDLE, L. et al. On detrimental effects of excrescences on the slat noise. In: Proceedings of the 18th AIAA/CEAS Aeroacoustics Conference. Colorado Springs, USA: [s.n.], 2012.

BENDAT, J.; PIERSOL, A. Engineering applications of correlation and spectral analysis. New York: Wiley, 1980.

BHATNAGAR, P. L.; GROSS, E. P.; KROOK, M. A model for collision processes in gases. i. small amplitude processes in charged and neutral one-component systems. Physical Review, v. 94, n. 3, p. 511-525, 1954.

BONATTO, S. A. Caracterização e simulação do ruído aerodinâmico gerado por "slats". Dissertação (Mestrado) - Escola Politécnica, Universidade de São Paulo, São Paulo, 2013.

BRÈS, G. A.; PÉROT, F.; FREED, D. A Ffowcs Williams-Hawkings solver for Lattice-Boltzmann based computational aeroacoustics. In: Proceedings of the 16th AIAA/CEAS Aeroacoustics Conference. Stockholm,Sweden: [s.n.], 2010.

BROOKS, T.; HUMPHREYS JR, W. M.; PLASSMAN, G. E. Damas processing for a phased array study in the nasa langley jet noise laboratory. In: 16th AIAA/CEAS Aeroacoustics Conference, Stockholm, Sweden, June 7-9, 2010. [S.l.: s.n.], 2010. 
BROOKS, T. F.; HUMPHREYS JR, W. M. Extension of damas phased array processing for spatial coherence determination (damas-c). In: 12th AIAA/CEAS Aeroacoustics Conference, Cambridge, Massachusetts, May 8-10, 2006. [S.1.: s.n.], 2006.

BROOKS, T. F.; HUMPHREYS, W. M. Effect of directional array size on the measurement of airframe noise components. In: 15th Aerodynamic Decelerator Systems Technology Conference, Bellevue, Washington, May 10-12, 1999. [S.l.: s.n.], 1999.

BROOKS, T. F.; HUMPHREYS, W. M. A Deconvolution approach for the mapping of acoustic sources (damas) determined from phased microphone arrays. Journal of Sound and Vibration, v. 294, n. 4-5, p. $856-879,2006$.

CATALANO, F. M.; VANUCCI, P.; CORREA, G. Wind tunnel testing devices for the reduction of flap side-edge noise. In: 28th International Congress of the Aeronautical Science, Brisbane, Australia, September 23-28, 2012. [S.l.: s.n.], 2012.

CHEN, S.; DOOLEN, G. D. Lattice Boltzmann method for fluid flows. Annual Review of Fluid Mechanics, v. 30, p. 329-364, 1998.

CHIN, V. D. et al. Flowfield measurements about a multi-element airfoil at high Reynolds numbers. AIAA paper 93-313\%, jul. 1993.

CHOUDHARI, M.; KHORRAMI. Slat cove unsteadiness: Effect of 3d flow structures. In: 44th AIAA Aerospace Sciences Meeting and Exhibit, AIAA-Paper 2006-0211, Reno, Nevada, January 9-12, 2006. [S.l.: s.n.], 2006.

CHOUDHARI, M. et al. Slat cove noise modeling: A posteriori analysis of unsteady rans simulations. AIAA paper, v. 2468, p. 2002, 2002.

CHOUDHARI, M. M.; KHORRAMI, M. R. Effect of three-dimensional shear-layer on slat cove unsteadiness. AIAA Journal, v. 45, n. 9, p. 2174-2186, 2007.

CHOUDHARI, M. M. et al. Aeroacoustic experiments in the langley low-turbulence pressure tunnel. NASA TM, v. 211432, 2002.

DAM, C. V. The aerodynamic design of multi-element high-lift systems for transport airplanes. Progress in Aerospace Sciences, Elsevier, v. 38, n. 2, p. 101-144, 2002.

DANTAS, L. A Capacitação do Túnel de Vento de Circuito Fechado da Escola de Engenharia de São Carlos a Realização de Ensaios Aeroacústicos, Levantamento de suas Características e Potencialidades. Dissertação (Mestrado) - Escola de Engenharia de São Carlos, 2010.

DOBRZYNSKI, W. Almost 40 years of airframe noise reserach: what did we achieved. Journal of Aircraft, v. 47, n. 2, p. 353-367, 2010.

DOBRZYNSKI, W. et al. Airframe noise studies on wings with deployed high-lift devices. Reston: American Institute of Aeronautics and Astronautics, 1998.

DOBRZYNSKI, W.; POTT-POLLENSKE, M. Slat noise source studies for farfield noise prediction. Reston: American Institute of Aeronautics and Astronautics, 2001. 
DOUGHERTY, R. P. Deconvolution approach for the mapping of acoustic sources (DAMAS) applied to enhance turbofan engine duct mode measurements. Acoustical Society of America Journal, v. 118, p. 1864-1864, 2005.

DOUGHERTY, R. P. Extensions of damas and benefits and limitations of deconvolution in beamforming. In: 11th AIAA/CEAS Aeroacoustics Conference, Monterey, California, May 23-25, 2005. [S.1.: s.n.], 2005.

DOWLING, A.; WILLIAMS, J. Sound and sources of sound. [S.l.]: E. Horwood, 1983. (Ellis Horwood Series in Engineering Science).

EHRENFRIED, K.; KOOP, L. Comparison of iterative deconvolution algorithms for the mapping of acoustic sources. AIAA Journal, v. 45, n. 7, p. 1584-1595, 2007.

FARASSAT, F.; SUCCI, G. P. A review of propeller discrete frequency noise prediction technology with emphasis on two current methods for time doamin calculations. Journal of Sound and Vibration, v. 71, n. 3, p. 399-419, 1980.

FARES, E. Unsteady flow simulation of the Ahmed reference body using a lattice Boltzmann approach. Computers and Fluids, v. 35, p. 940-950, 2006.

FLEURY, V.; DAVY, R. Beamforming-based noise level measurements in hard-wall closed-section wind tunnels. In: Proceedings of the 18th AIAA/CEAS Aeroacoustic Conference (33rd AIAA Aeroacoustics Conference). Colorado Springs, Colorado: [s.n.], 2012.

FONSECA, W. D. et al. A Different Approach to Archimedean Spiral Equation in the Development of a High Frequency Array. In: II SAE Brasil International Noise And Vibration Congress. Florianópolis, Brazil: [s.n.], 2010.

GUO, Y. A Discrete vortex model for slat noise prediction. AIAA Paper, v. 2157, p. 2001, 2001.

GUO, Y. Aircraft slat noise modeling and prediction. AIAA paper, v. 3837, p. 2010, 2010 .

GUO, Y. P.; JOSHI, M. C. Noise characteristics of aircraft high lift systems. Journal of Aircraft, v. 41, n. 7, p. 1247 - 1256, 2003.

GUO, Y. P.; YAMAMOTO, K. J.; STOKER, R. W. Component-based empirical model for high-lift system noise prediction. Journal of Aircraft, v. 40, n. 5, p. $914-922,2003$.

HAYES, J. et al. Measurement of reynolds number effect on airframe noise in the 12-foot pressure wind tunnel. In: 5th AIAA/CEAS Aeroacoustics Conference and Exhibit, Seattle, WA. [S.l.: s.n.], 1999.

HAYES, J. A. et al. Airframe noise characteristics of a 4.7 percent scale dc-10 model. AIAA Paper, n. 1954, 1997.

HOGBOM, J. Aperture synthesis with a non-regular distribution of interferometer baselines. Astronomy and Astrophysics Supplement Series, v. 15, p. 417-426, 1974. 
HORNE, C. et al. Effects of distributed source coherence on the response of phased acoustic arrays. In: AIAA/CEAS, Aeroacoustics Conference and Exhibit, 6th (21st AIAA Aeroacoustics Conference), Lahaina, HI, June 12-14, 2000. [S.l.: s.n.], 2000.

HUMPHREYS, W. M. et al. Design and use of microphone directional arrays for aeroacoustic measurements. In: AIAA Paper 98-0471, 36 st Aerospace Sciences Meeting and Exhibit, Reno, NV. [S.l.: s.n.], 1998.

HUTCHESON, F.; BROOKS, T. Effects of angle of attack and velocity on trailing edge noise. In: 42nd AIAA Aerospace Sciences Meeting and Exhibit, Reno, Nevada, 2004 Proceedings... Reston: AIAA: [s.n.], 2004. (AIAA Paper 2004-1031).

IMAMURA, T. et al. A Far-field noise and near-field unsteadiness of a simplified high-lift-configuration model (slat). 47th AIAA Aerospace Sciences Meeting including The New Horizons Forum and Aerospace Exposition, v. 1239, 2009.

JAEGER, S. M.; HORNE, W. C.; ALLEN, C. S. Effect of surface treatment on array microphone self-noise. AIAA, v. 1937, p. 2000, 2000.

JENKINS, L. N.; KHORRAMI, M. R.; CHOUDHARI, M. Characterization of unsteady flow structures near leading-edge slat: Part 1. piv measurements. In: 10th AIAA/CEAS Aeroacoustics Conferenc. United Kingdom: [s.n.], 2004.

JOHNSON, D.; DUDGEON, D. Array signal processing: concepts and techniques. [S.1.]: P T R Prentice Hall, 1993.

KHORRAMI, M. R.; BERKMAN, M. E.; CHOUDHARI, M. Unsteady flow computations of a slat with a blunt trailing edge. AIAA Journal, v. 38, p. $2050-2058,2000$.

KHORRAMI, M. R.; SINGER, B. A.; BERKMAN, M. E. Time-accurate simulations and acoustic analysis of slat free shear layer. AIAA journal, v. 40, n. 7, p. 1284-1291, 2002 .

KHORRAMI, M. R.; SINGER, B. A.; LOCKARD, D. P. Time-accurate simulations and acoustic analysis of slat free shear layer: Part ii. In: AIAA Paper. Breckenridge, CO: [s.n.], 2002.

KLAUSMEYER, S. M.; LIN, J. C. Comparative results from a cfd challenge over a 2d threeelement high-lift airfoil. NASA TM, v. 112858, 1997.

KOLB, A. et al. Aeroacoustic wind tunnel measurements on a $2 \mathrm{~d}$ high-lift configuration. American Institute of Aeronautics and Astronautics, 2007.

KROBER; STEFAN. Comparability of Microphone Array Measurements in Open and Closed Wind Tunnels. Tese (Doutorado) - Fakultat V- Verkehrs- und Maschinensyteme der Technishen Universitat Berlin, 2013.

LOCKARD, D.; CHOUDHARI, M. The influence of realistic reynolds numbers on slat noise simulations. In: 18th AIAA/CEAS Aeroacoustics Conference; 4-6 Jun. 2012; Colorado Springs, CO; United States. [S.l.: s.n.], 2012.

MANOHA, E. et al. Slat noise measurement and numerical prediction in the valiant programme. In: 18th AIAA/CEAS Aeroacoustics Conference; 4-6 Jun. 2012; Colorado Springs, CO; United States. [S.l.: s.n.], 2012. 
MENDOZA, J.; BROOKS, T.; HUMPHREYS, W. Aeroacoustic measurements of a wing/slat model. In: 8th AIAA/CEAS Aeroacoustics Conference and Exhibit, Breckenridge, Colorado, June 17-19, 2002. [S.l.: s.n.], 2002.

MICHEL, U. History of acoustic beamforming. In: Proceedings on CD of the 1st Berlin Beamforming Conference, 22-23 November, 2006. [S.1.]: GFaI, Gesellschaft zu Förderung angewandter Informatik e.V., Berlin, 2006.

MUELLER, T. Aeroacoustic Measurements. [S.1.]: Springer, 2002.

OERLEMANS, S. Detection of aeroacoustic sound sources on aircraft and wind turbines. Tese (Doutorado) - University of Twente, Enschede, 2009.

OERLEMANS, S.; SIJTSMA, P. Determination of absolute levels from phased array measurements using spatial source coherence. In: 8th AIAA/CEAS Aeroacoustics Conference and Exhibit, Breckenridge, Colorado, June 17-19, 2002. [S.l.: s.n.], 2002.

OLSON, S.; THOMAS, F. O.; NELSON, R. C. A Preliminary investigation into slat noise production mechanisms in a high-lift configuration. AIAA Paper, v. 4508, 2000.

PASCHAL, K. et al. Evaluation of tunnel sidewall boundary-layer-control systems for high-lift airfoil testing. AIAA Paper, n. 91-3243, 1991.

POTT-POLLENSKE, M.; ALVAREZ, G. J.; DOBRZYNSKI, W. Effect of slat gap on farfield radiated noise and correlation with local flow characteristics. In: 9th AIAA/CEAS Aeroacoustic Conference. Hilton Head, South Caroline/USA: [s.n.], 2003.

POTT-POLLENSKE, M.; DELFS, J.; REICHENBERGER, J. A testbed for large scale and high reynolds number airframe noise research. In: 19th AIAA/CEAS Aeroacoustics Conference. [S.l.: s.n.], 2013.

PRIME, Z.; DOOLAN, C. A comparison of popular beamforming arrays. In: ACOUSTIC 2013 VICTOR HARBOR: science technology and amenity, Australia, 2013. Proceedings... Australia: Australian Acoustical Society: [s.n.], 2013.

PUMPHREY, H. C. Design of sparse arrays in one, two, and three dimensions. The Journal of the Acoustical Society of America, v. 93, n. 3, p. 1620-1628, 1993. Disponível em: <http://scitation.aip.org/content/asa/journal/jasa/93/3/10.1121/1.406821>.

ROGERS, S. E. et al. A comparison of turbulence models in computing multi-element airfoil flows. AIAA paper, v. 94, p. 0291, 1994.

ROSSITER, J. E. Wind-tunnel experiments on the flow Over rectangular cavities at subsonic and transonic speeds. London: Ministry of Aviation, 1964.

RUIJGROK, G. Elements of aviation acoustics. [S.l.]: Delft University Press, 2004.

RUMSEY, C.; LEE-RAUSCH, E.; WATSON, R. Three-dimensional effects in multi-element high lift computations. Computers and Fluids, v. 32, n. 5, p. 631-657, 2003.

SARRADJ, E. Three-dimensional acoustic source mapping with different beamforming steering vector formulations. Advances in Acoustics and Vibration, v. 2012, n. 292695, p. $1-12,2012$. 
SCHLICHTING, H. Boundary layer theory. [S.l.]: McGraw Hill, 1979.

SHIN, H.-C. et al. Implementation of a phased microphone array in a closed-section wind tunnel. AIAA journal, v. 45, n. 12, p. 2897-2909, 2007.

SIJTSMA, P. Clean based on spatial source coherence. International Journal of Aeroacoustics, v. 6, n. 4, p. 357-374, 2007.

SIJTSMA, P. Acoustic array corrections for coherence loss due to the wind tunnel shear layer. In: Second Berlin Beamforming Conference (BeBeC), Berlin, Germany. [S.l.: s.n.], 2008.

SIJTSMA, P.; HOLTHUSEN, H. Corrections for mirror sources in phased array processing techniques. In: 9th AIAA/CEAS Aeroacoustics Conference and Exhibit, Hilton Head, South Carolline, May, 12-14. [S.l.: s.n.], 2003.

SIMOES, L. G. C. Estudo da geração de som em um eslate utilizando código comercial. Dissertação (Mestrado) — Escola de Engenharia de São Carlos, Universidade de São Paulo, 2011.

SMITH, A. M. O. High-lift aerodynamics. Journal of Aircraft, v. 12, n. 6, p. 501-530, 1975.

STEINBERG, B. Principles of aperture and array system design: including random and adaptive arrays. New York: John Wiley, 1976.

STORMS, B.; HAYES, J.; ROSS, J. Aeroacoustic measurements of slat noise on a three-dimensional high-lift system. AIAA Paper, 1957, 1994.

SUZUKI, T. A review of diagnostic studies on jet-noise sources and generation mechanisms of subsonically convecting jets. Fluid Dyn. Res., v. 42, n. 1, p. 014001, 2010.

TAKEDA, K. et al. Unsteady aerodynamics of flap cove flow in a high-lift device configuration. In: 39th Aerospace Sciences Meeting and Exhibition. Honolulu, Havaii: [s.n.], 2001.

TEIXEIRA, C. M. Incorporating turbulence model into the lattice-Boltzmann method. Iternational Journal of Modern Physics C, v. 9, n. 8, p. 1159-1175, 1998.

TERRACOL, M.; MANOHA, E. .; LEMOINE, B. Investigation of the unsteady flow and noise sources generation in a slat cove: hybrid zonal rans/les simulation and dedicated experiment. In: 20th AIAA Computational Fluid Dynamics Conference. Honolulu, Havaii: [s.n.], 2011.

UNDERBRINK, R. J. Practical considerations in focused array design for passive broad-band source mapping applications. Tese (Doutorado) — Pennsylvania State University, Pennsylvania, USA, May, 1995.

WELCH, P. D. The use of fast fourier transform for the estimation of power spectra: a method based on time averaging over short, modified periodograms. IEEE Transactions on Audio and Electroacoustics, v. 15, n. 2, p. 70-73, June 1967. 
WILLIAMS, J. F.; HAWKINGS, D. L. Sound generation by turbulence and surfaces in arbitrary motion. Philosophical Transactions of the Royal Society of London. Series A, Mathematical and Physical Sciences, The Royal Society, v. 264, n. 1151, p. 321-342, 1969.

YARDIBI, T. et al. Uncertainty analysis of the standard delay-and-sum beamformer and array calibration. In: 15th AIAA/CEAS Aeroacoustics Conference (30th AIAA Aeroacoustics Conference), Miami, Florida, May 11-13, 2009. [S.1.: s.n.], 2009. 